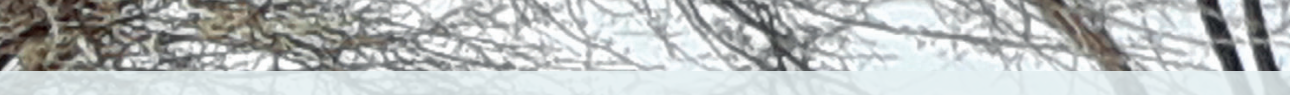

\title{
The impacts of large-scale land investments on agropastoral livelihoods in Ethiopia
}

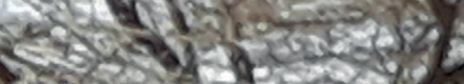

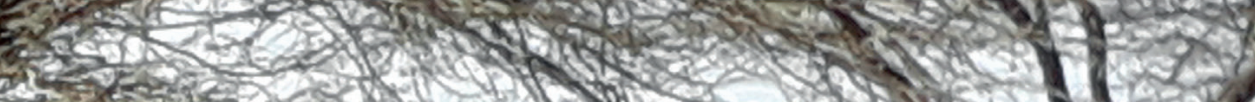

(4)

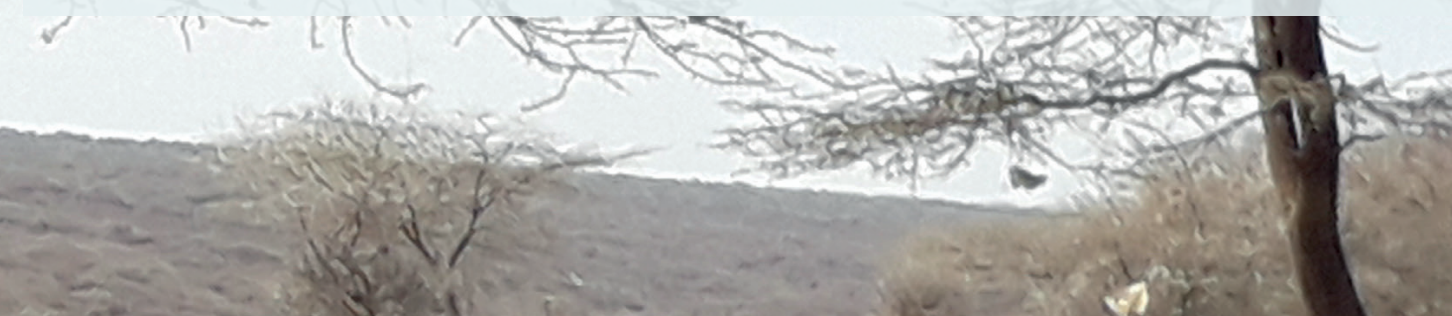

and





Propositions

1. Large-scale land investments reduce the resilience capacity of agropastoral households. (this thesis)

2. Communal land tenure security receives insufficient attention in Ethiopia's land reform. (this thesis)

3. An insignificant variable in a regression output is also insignificant in real life.

4. In social sciences, quantitative research provides more rigorous findings than qualitative research.

5. Diversity is the beauty of life, and it does not impede prosperity.

6. Knowing what to do is more important than doing what you know.

Propositions belonging to the thesis, entitled

The impacts of large-scale land investments on agropastoral livelihoods in Ethiopia

Adugna Eneyew Bekele

Wageningen, February 22, 2022. 

The impacts of large-scale land investments on agropastoral livelihoods in Ethiopia 


\section{Thesis committee}

\section{Promoters}

Dr. Liesbeth Dries

Associate Professor, Agricultural Economics \& Rural Policy Group

Wageningen University \& Research

Prof. Dr W.J.M. Heijman

Special Professor, Regional Economics

Wageningen University \& Research

Professor of Economics

Czech University of Life Sciences, Prague, Czech Republic

\section{Co-promoter}

Dr. Dušan Drabik

Associate Professor, Agricultural Economics \& Rural Policy Group

Wageningen University \& Research

\section{Other members}

Prof. Dr E. H Bulte, Wageningen University \& Research

Prof. Dr Marijke D'Haese, Ghent University, Belgium

Prof. Dr Taye Tole Mariam, Jimma University, Ethiopia

Dr Xueqin Zhu, Wageningen University \& Research

This research was conducted under the auspices of the Wageningen School of Social Sciences (WASS) 
The impacts of large-scale land investments on agropastoral livelihoods in Ethiopia

Adugna Eneyew Bekele

\section{Thesis}

submitted in fulfilment of the requirements for the degree of doctor at Wageningen University

by the authority of the Rector Magnificus,

Prof. Dr A.P.J. Mol,

in the presence of the

Thesis Committee appointed by the Academic Board

to be defended in public

on Tuesday 22 February 2022

at 1:30 p.m. in the Aula. 
Adugna Eneyew Bekele

The impacts of large-scale land investments on agropastoral livelihoods in Ethiopia 209 pages.

PhD thesis, Wageningen University, Wageningen, the Netherlands (2022) With references, with summary in English \& Dutch

ISBN: 978-94-6447-052-9

DOI: https://doi.org/10.18174/559406 


\section{Acknowledgment}

In the last four years, it would not be possible to finish this thesis without the generous support of many people and I would like to gratefully acknowledge them.

First and foremost, I thank my supervisors prof. Wim Heijman, Dr. Liesbeth Dries, and Dr. Dusan Drabik for their guidance and unlimited support throughout the whole research process. It has been a great pleasure and honor to have them as my supervisors.

I am highly grateful to prof. Wim Heijman for accepting me as a student to pursue my Ph.D. at Wageningen University and Research. Wim thank you for your confidence in me, introducing me to such a diligent supervisory team, guidance, support, and inspiration throughout my study. Your constructive comments on my papers have shaped and broadened my perspectives. You have taught me the importance of paying attention to the big picture in scientific discourse. Thanks also for allowing me to go home in the first year when I needed to be with my family and for visiting me in Ethiopia.

I am highly thankful to my supervisor Dr. Liesbeth Dries for her invaluable supervision and guidance during my Ph.D. study. Thank you, Lisbeth, for re-reading several versions of my papers, for your in-depth comments, and for responding to my questions instantly, even late at night or on weekends, being always supportive. During our meetings and discussions, your critical comments helped me improve my understanding. I have gained a lot from your rich scientific knowledge about how to think critically and link my arguments to the standard theoretical perspectives.

I am highly indebted to my co-supervisor Dr. Dusan Drabik for re-reading and critically reviewing my papers many times even during the evening and weekends, giving valuable comments, and proofreading which contributed to the quality of this final version. Dusan thank you for your quick responses to my emails, encouragement, innovative solutions, and unlimited supports including covering the costs of language editions. You have taught me the importance of paying attention to details, formatting, and quality in academic writing and being purposeful which is also helpful for my future career.

Besides my promotors, I would like to thank the rest of my thesis committee: Prof. dr.ir. E. H Bulte, prof. dr.ir. Marijke D'Haese, prof. Taye Tole Mariam and Dr. Xueqin Zhu for their time, their insightful comments, and the evaluation of my thesis but also for the challenging questions which inspired me for future research work.

I would also express my sincere gratitude to Jimma University College of Agriculture \& Veterinary Medicine (JUCAVM) for providing me with logistics, Agricultural Economics and 
Rural Policy Group (AEP), and Wageningen School of Social Sciences (WASS) for providing me facilities and support during my study.

My gratitude also goes to AEP members for the warm hospitality and assistance during my study. Thank you, Justus, Koos, Jack, Rico, Esther, and everyone in the AEP group for being always helpful. The morning coffee breaks and special dinner events are unforgettable. My special thanks go to Mrs. Karen Heide, for her support in processing my travel, finance, and quick reply to my emails. I thank the groups' secretariat staff: Betty, Dineke, Frank, Gre, and Neon for their support during my stay. Dr. Mohammed Beshir and his family deserve my deepest gratitude for their hospitality, his comments on my proposal, and his guidance about regulations at Wageningen University. Melodi thank you for translating my thesis summary to Dutch. I thank my office mates Eko, Muinat, and Mohammed for the good time we had together. I also thank my Ethiopian colleagues in Wageningen, Abebe, Betelhem, Dessalegn, Mohammedamin, Shimelis, Solomon, Tesfahun and Yeshimebet for the social events spent together.

I am grateful to prof. Fikre Lemessa, prof. Gezahegn Berecha, Dr Solomon Tullu, Dr. Fikadu Mitiku, Dr. Duguma Debele, Mrs. Umi Abdulkadir, Mr. Belay Duguma, prof. Weyesa Garedew and the late prof. Debela Hunde for their support and encouragement. I especially thank Fikre for keeping me professionally networked, Gezahegn and Fikadu for providing me vehicles for data collection, Solomon for his valuable advice about handling my Ph.D. I also appreciate Mr. Dereje Bekele, Dr. Fikremariam Geda, Dr. Melkamu Dumesa and Mr. Zerihun Kibebew for the fun times we shared. Melkamu thank you for proofreading my second paper. I acknowledge Mr. Jima Nago for supporting me in the translation of the survey questionnaire. I thank my office mates Prof. Deribew Belew and Dr. Daniel Teshome for their positive energy, as well as prof. Solomon (Ababa), Dr. Sirawdink Fikreyesus, and Dr. Yetnayet Bekele, for their collaborations on various projects and supportive ideas. Thanks to Dr. Huub Mudde, Dr. Kenenisa Lemi, and Dr. Wondaferaw Mulugeta for collaboration in the agribusiness project.

I thank the World Bank and Ethiopian statistical agency for the living standards measurement survey data. I thank my respondents and enumerators for their time and opinions. I appreciate drivers Shimelis, Kassahun, and Solomon for traveling with me in a less secure environment.

Finally, I express my sincere gratitude to all my extended families whose prayers and thoughts have been always with me. My special dedication goes to my wife Amelework Kebede for nurturing our children, Kena, Yanet and Yeron in my absence, and I am indebted to them from whom I have taken away precious family times. I am grateful to my brother Sisay Sima for his moral support and for visiting my family during my absence. 


\section{Table of Contents}

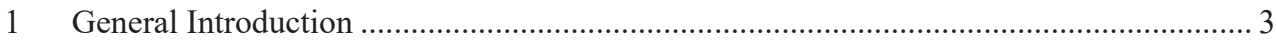

1.1 Pastoralism in Brief ............................................................................... 3

1.2 Large-scale Land Investments in Agropastoral Areas............................................... 7

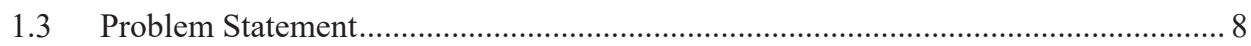

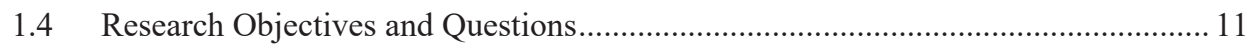

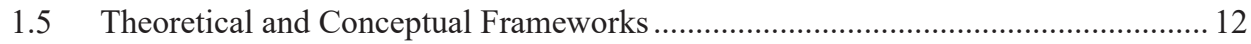

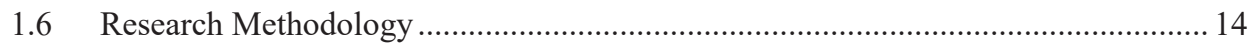

2 Large-scale Land Investments and Food Security in Agropastoral Areas of Ethiopia .... 19

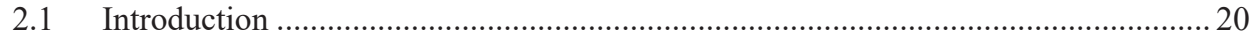

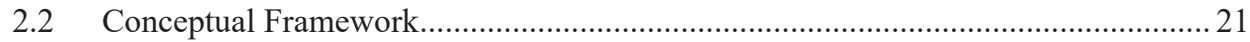

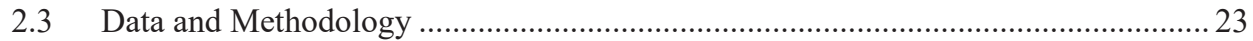



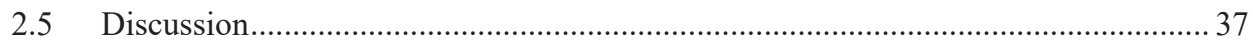

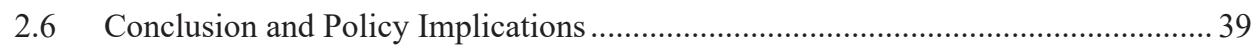



3 Large-scale Land Investments, Household Displacement and the Effect on Land Degradation



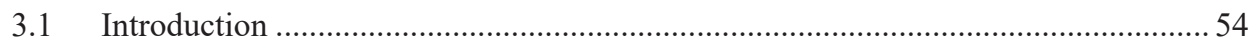



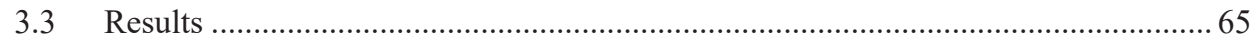

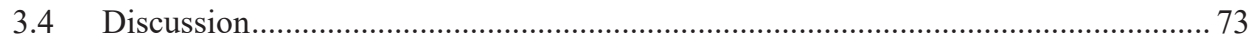

3.5 Conclusion and Policy Recommendations ............................................................. 75

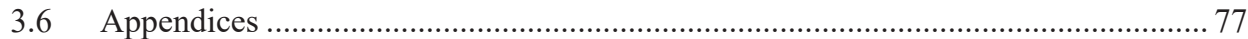

4 Large-scale Land Investments and Land Use Conflicts in the Agropastoral Areas of



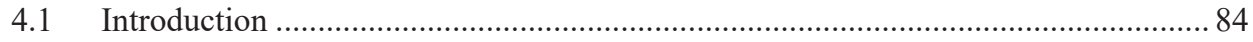

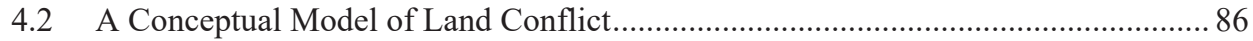




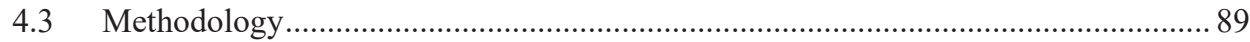

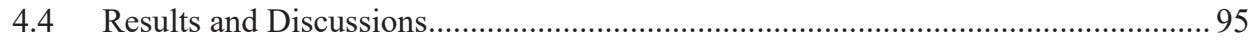

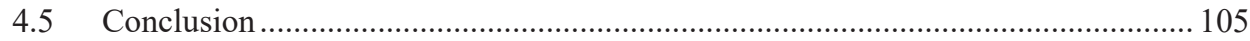

5 The Resilience of Ethiopian Agropastoral Households in the Presence of Large-Scale Land

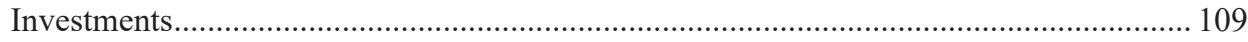

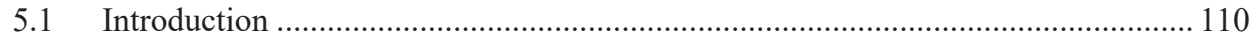

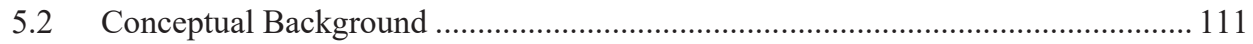

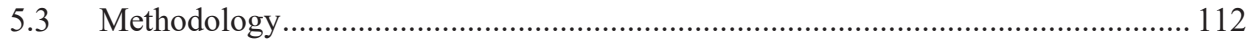

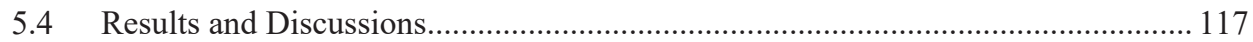



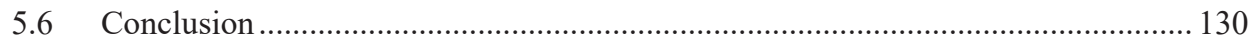

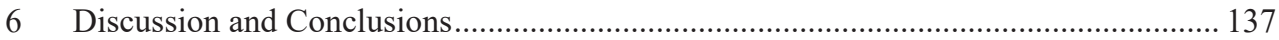

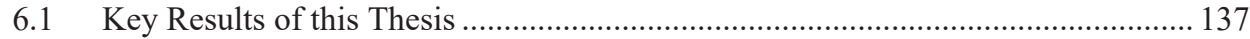

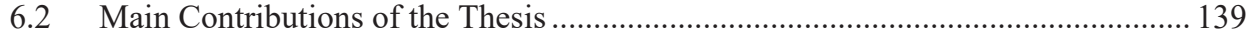



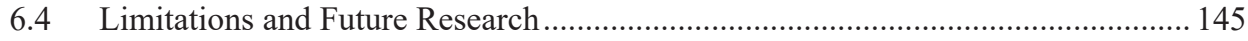

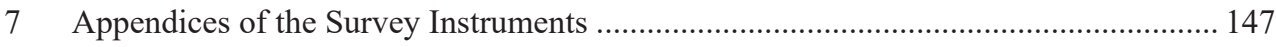



7.2 Key Informant Interview Checklist for Agricultural Experts............................... 159

7.3 Key Informant Interview Checklists for Sugar Plantations ..................................... 161

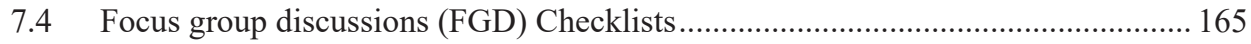

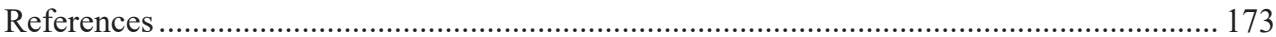


Chapter 1

General introduction 
Chapter 1 


\section{General Introduction}

\subsection{Pastoralism in Brief}

Pastoralism is the subsistence livelihood in many parts of the drylands of the world and has existed for 9,000 years in Northeast Africa. Globally, about 500 million pastoralists herd about one billion animals, manage a third of the rangelands of the Earth and contribute over $65 \%$ of meat and $70 \%$ of milk sold on local markets in the western and north-central African region (Davies et al., 2016; FAO, 2021). Extensive pastoralism exists in more than 100 countries (Dong, 2016) (Figure 1.1).

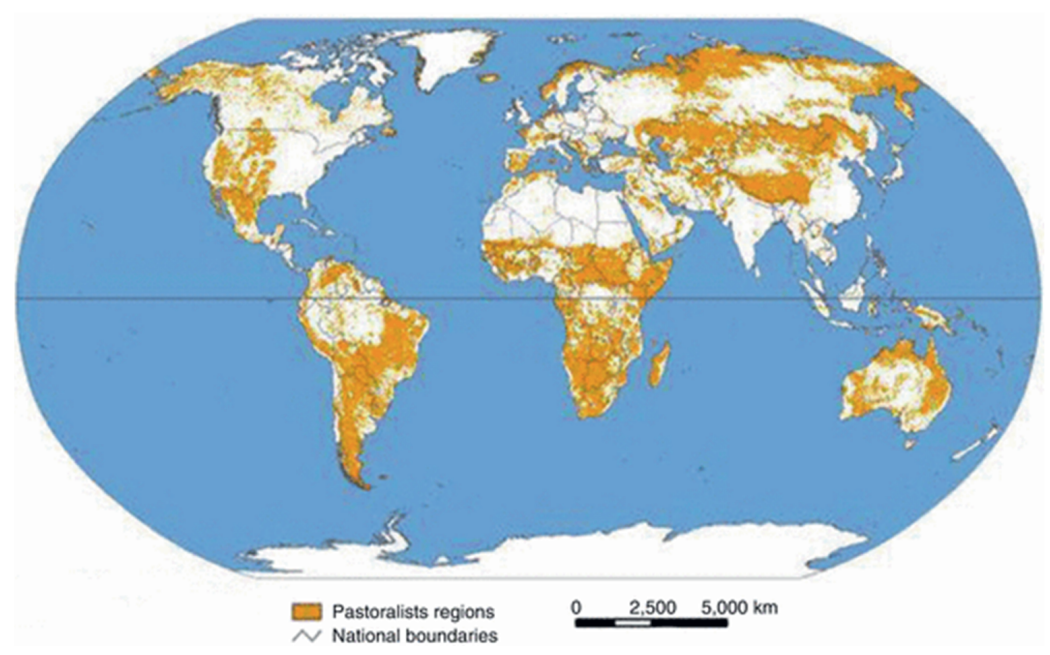

Figure 1-1. Global distribution of pastoralism [Adapted from Dong (2016)]

Pastoralism is a complex interaction between people, livestock, and rangelands (Figure 1.2). Pastoralism ${ }^{1}$ is extensive livestock production in rangelands (Amel and Stefano, 2017) for economic benefit and ecological sustainability in fragile areas (Davies et al., 2016; Dong, 2016). From a production perspective, pastoralism is the art of keeping livestock, which involves the care, tending, and grazing of livestock in dry or cold rangeland areas (Dong, 2016). From a livelihood perspective, pastoralism is a subsistence strategy based on herding animals.

\footnotetext{
${ }^{1}$ In this thesis, I use pastoral and agropastoral interchangeably. Nonetheless, I used pure pastoral to exclusively indicate those people who do not cultivate crops. Most of the people in the study population pursues agropastoralism.
} 
Pastoralists depend on livestock for more than $50 \%$ of their income, while agropastoralists derive $25-50 \%$ of their income from livestock while cultivating crops (Swift, 1988).

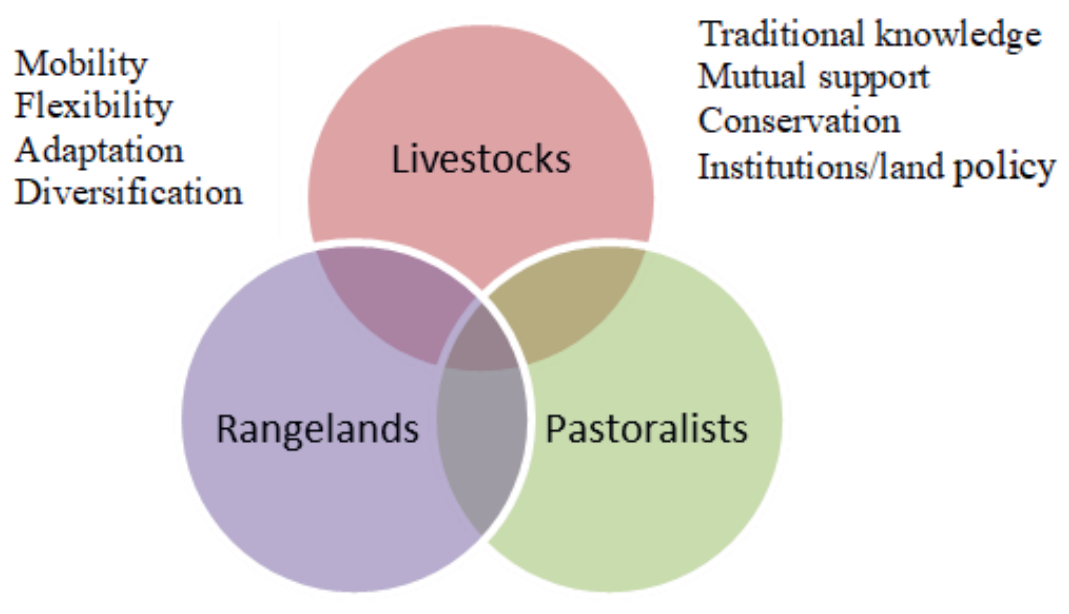

Figure 1.2. Pastoralism: A sustainable natural resource management system [adapted from Dong (2016)].

The pastoral production system is adapted to arid and semi-arid lands that are highly fragile, harsh, and unsuitable for farming (Adnew et al., 2019; Botterli, 2015). Pastoral societies are well adapted to these challenges and have developed customs and rules for governing the management and use of pastoral land (Davies et al., 2016). Communal land use systems and herd mobility are critical land management systems for environmental sustainability (Nori and Scoones, 2019; UNDP, 2003). With livestock mobility, the use of natural resources is optimized, pastoral production systems are enhanced, and risks are managed (Bollig and Lesorogol, 2016; FAO, 2018b; Osman et al., 2018; Scoones, 2020).

In Africa, over 43\% of the land host 268 million pastoralists (FAO, 2018b; SNV, 2012), and $75 \%$ of the land in the Horn of Africa are home to the largest pastoral population in the world (Abbink et al., 2014; De Haan et al., 2016). A total of 36 African countries are covered by pastoralism. Pastoralism occurs from the Sahelian West to the rangelands of Eastern Africa, the Horn of Africa, and the south of the continent (FAO, 2018b). Pastoralism exists in all African regions and is the dominant means of livelihood in some countries (African Union, 2013). Most human populations in the drylands in eastern Africa are agropastoralists, who predominantly practice diverse livelihoods (Abbink et al., 2014; Dinku, 2018; Scoones, 2020). 
The contribution of pastoral livestock production reaches up to $44 \%$ of the gross domestic product (GDP) (Osman et al., 2018) and 80\% of the animal product supply in Africa (Grandval, 2012). Pastoralism contributes 57\% to the agricultural GDPs in the east and the Horn of Africa (AFSA, 2017). In Africa, 50\% of the total value of marketed livestock and livestock activities is provided by pastoral areas (African Union, 2013). However, the importance of pastoralism in most African countries has been significantly underestimated (Davies et al., 2016).

Despite the contribution of pastoral production systems to national economies, pastoral societies across the globe and Africa are marginalized and have little voice in policy formulation and implementation (FAO, 2012, 2021; Rass, 2006). Policy failures are led by the misunderstanding of pastoralism or even the deliberate portrayal of pastoralism as backward (Davies et al., 2016). Although pastoralists cope with social and natural pressures, most pastoral societies are marginalized by governmental policies and development strategies (Dong, 2016). Government leaders often neglect to invest in and provide public services and tenure security for pastoralists. Consequently, less than $1 \%$ of African national budgets are allocated to pastoralists (Osman et al., 2018). Such a situation results in a high poverty level in many pastoral areas (FAO, 2021).

With over 112 million (CSA, 2013a), Ethiopia is the second-most populous African country after Nigeria. Agriculture is the backbone of the Ethiopian economy, contributing 37\% to the national GDP and $73 \%$ of total employment (UNDP, 2018). The Ethiopian economy grew by more than 9.4\% annually from 2011-2018. Nevertheless, Ethiopia is still one of the lowest-income and highest food-deficit countries, with $24 \%, 30.8 \%$, and $73.5 \%$ of its citizens respectively living below the national poverty line, international poverty line, and multidimensional poverty (World Bank, 2019). Poverty is widespread in pastoral regions of Ethiopia. In the Ethiopian highlands, rainfed-based farming is practiced, whereas the lowlands depend heavily on agropastoralism. More than 15 million pastoralists reside in $60 \%$ of Ethiopian drylands, and their number is still growing (Gebremeskel et al., 2019; PFE, 2010).

The main regions hosting pastoralism are Afar, Somalia, Oromia, Gambella, and the Southern Nations, Nationalities, and Peoples' Region (SNNPR). There are also a few pastoral people in Dire Dawa, Tigray, and Benishangul regional states. Ethiopia is highly ranked in Africa by its livestock population, with over 88 million headcounts of livestock (FDRE, 2014; Rass, 2006). The contribution of pastoral livestock production to the Ethiopian GDP ranges from $6-12 \%$ and from $30-35 \%$ if only the agricultural GDP is considered (Gebremeskel et al., 2019). As the Ethiopian population has grown fast, the demand for livestock products has also 
risen. However, the contribution of pastoral areas to the Ethiopian economy has been underestimated.

In Ethiopian agropastoral regions, like elsewhere in Africa, development and political marginalization are experienced (Devereux, 2006; FDRE, 2013; Little, 2001). Ethiopian pastoralists live in dryland areas with low productivity and unpredictable weather (PFE, 2010). The livestock production system is based on extensive free grazing and communally shared resources (Beyene, 2010). However, access to free grazing is diminishing due to land use shifts for commercial agriculture and urbanization.

Across Africa, particularly Ethiopia, policies in pastoral areas are contested (FAO, 2018c; McPeak and Little, 2003). Since the 1960s, pastoral policies in Ethiopia have been focused on modernizing, settling, and commercializing livestock from pastoralists (Devereux, 2006; McPeak and Little, 2018). Since then, the attention of development models has been paid to transforming or modernizing Ethiopian pastoralism, and similar policies have been replicated by one after the other Ethiopian regimes.

Over the last 50 or so years, Ethiopian pastoralism has changed dramatically. The primary change source was associated with land use changes (Beyene, 2016; Said, 1994). Since the 1970s, the conversion of rangelands into large-scale land investments (LSLIs), mainly industrial plantations, such as sugarcane and cotton (Said, 1994), has been the focus of the development policy in pastoral areas of the country. With the expansion of sugarcane and cotton plantations, rangelands are becoming fragmented, reducing the accessibility and availability of pasture land, and limiting livestock mobility (World Bank, 2019). These LSLIs also could increase environmental degradation by clearing vegetation for plantation cultivation and conflict by restricting pastoral peoples' access to land. Environmental degradation further aggravates drought. Drought has had a profound impact on the livelihood of the agropastoral community (Biazin and Sterk, 2013). One of the key environmental challenges in pastoral areas of Ethiopia is the replacement of rangelands by invasive weeds, such as Prosopis. Invasive Prosopis juliflora L. (Leguminosae) rapidly degrades rangelands by displacing native plants used for grazing and forage. 


\subsection{Large-scale Land Investments ${ }^{2}$ in Agropastoral Areas}

Pastoral systems are among the most efficient forms of land management in semi-arid areas (African Union, 2013; FAO, 2012; Osman et al., 2018; The Oakland Institute, 2016; WISP, 2007). However, competition over land has been increasing in pastoral areas, and mobility is no longer possible in many African agropastoral areas (Scoones, 2020). Remarkably, mobility is prevented by allocating rangelands for LSLIs in many African drylands (Zaehringer et al., 2018). The ecological mitigation strategies used by pastoralists are further jeopardized by LSLIs (Bollig and Lesorogol, 2016), increasing food insecurity (FAO, 2021), and land degradation. Hence, land rights remain the primary concern for the future of pastoralism.

The impact of LSLIs has received more attention in recent years, as LSLIs are on the rise in developing countries and regions occupied by smallholders and pastoralists (Cotula, 2009; Hak et al., 2018). However, the main focus so far has been on land grabs (Cochrane and Legault, 2020; Cotula, 2009; De Schutter, 2011), environmental impacts (Kareem, 2019; Zaehringer et al., 2018), and foreign investment (Hufe and Heuermann, 2017; Keeley, 2014). In Africa, interest in LSLIs has risen following the triple crisis of food, energy, and finance during the 2007-2008 global economic crisis (Cochrane and Legault, 2020). Consequently, more than 10 million ha of African land has been leased for LSLIs (Lay, 2017). However, the impact of LSLIs on local social-ecological systems in Africa is less known (Zaehringer et al., 2018).

Three kinds of LSLIs exist based on ownership type in Ethiopia: those owned by the state, those owned by domestic investors, and those owned by foreign investors. The livelihoods of poor peasants and pastoralists have been affected by all LSLI forms over the past five decades (Keeley, 2014; Moreda, 2017; Rahmato, 2014). However, LSLIs run by the state have received little attention in past studies. In most previous studies, more attention has been paid to LSLIs run by foreign investors (Baumgartner et al., 2015; Cochrane and Legault, 2020; Debela et al., 2020).

Development in Ethiopia is dominated by government-run investments (IFAD, 2020). LSLIs are one of the development strategies of the Ethiopian government, which are aimed at enhancing the export earnings of the country (Keeley, 2014; Rahmato, 2014). LSLIs would not be problematic if the access of pastoralists to rangelands was not jeopardized or if the host community was integrated into development by them. However, the best rangelands have been taken by LSLIs while denying access to pastoralists, compromising their livelihoods (Belay et al., 2013; Beyene, 2006).

\footnotetext{
${ }^{2}$ In this thesis, LSLIs are referred to state run sugar plantations in Ethiopia.
} 
All land in Ethiopia is the property of the state, and people have only use rights; the selling of rural land is prohibited (Rahmato, 2011). This is the reason why pastoral rangelands could be taken by LSLIs without the consent of pastoralists (Behnke and Kerven, 2011; PFE, 2010). The right of pastoralists to land is indicated in the Ethiopian Constitution, but its legal implementation is not addressed by any specific policy (PFE, 2010). All grazing lands in Ethiopian pastoral regions are managed communally, except for agropastoral areas, where people grow crops (PFE, 2010). However, there is no land policy regarding the governance of communal land in Ethiopia. Moreover, there are no formal or informal obligations on the part of LSLIs to care for host communities and contribute to the food security needs of the population (Rahmato, 2011).

Since the 1990s, about 3.5 million ha of land in Ethiopia, mainly in lowland areas, have been transferred to LSLIs (Keeley, 2014; Rahmato, 2011, 2014). Most state-run LSLIs in the country are sugarcane plantations. A well-known example is the Awash Valley development, which has failed to incorporate the Afar and Karrayyu pastoralists. In the last decade, significant sugarcane plantation expansions have been seen. About 10 sugarcane plantations were under construction, of which more than six were located in pastoral areas. Over 335,000 ha of land are allocated for state-run sugar plantations (Keeley, 2014). Therefore, it is pertinent to understand the impact of LSLI sugarcane plantations on pastoral livelihoods in Ethiopia. Such an analysis could be the basis for better policy interventions in agropastoral areas.

The scarcity of grazing land caused by LSLIs results in overgrazing, as herds concentrate on fewer rangelands (Bekele et al., 2020; Garedew et al., 2009; Hundie, 2006; Sonneveld et al., 2010). Land degradation is linked to food insecurity and poverty, leading to a cycle of livelihood deterioration (Mussa et al., 2016). Land conflicts have been further intensified by the scarcity of land (Beyene, 2009). In Ethiopia, competition over land and conflicts have intensified over the last few decades, mainly due to LSLIs, for example, in the Ethiopian Awash rift valley area (PFE, 2010). Therefore, understanding the effect of LSLIs on the livelihoods of agropastoral households is necessary to design appropriate policies governing rangelands and LSLIs.

\subsection{Problem Statement}

The future of pastoralism has been intensively debated by academics, practitioners, and policymakers in Africa and elsewhere in the world (Abbink et al., 2014; Basupi et al., 2019; Little. et al., 2010). This situation is because pastoralists have been facing multiple challenges, 
including food insecurity, conflict, climatic shocks, and inappropriate land policies (Abbink et al., 2014; Ayantunde et al., 2011; Basupi et al., 2019). Unfavorable land policies are the key challenge faced by agropastoral systems (Halderman, 1985; Kameri-Mbote, 2013).

Access to natural resources, such as pastures and water, is necessary for agropastoral adaptation to risks (Scoones, 2020). Increased vulnerability is led by a lack of secure access to vital resources for pastoralists (Ayantunde et al., 2011; Basupi et al., 2019). The lands lost to LSLIs are mainly dry season grazing areas without which pastoral subsistence systems cannot operate effectively (Halderman, 1985). The mobility of many pastoral societies has been considerably reduced by these changes (Homewood et al., 2012; Osman et al., 2018), triggering land degradation and conflicts (Senda et al., 2020).

The effect of LSLIs on the livelihoods of local communities has been widely debated in recent years, and this debate is ongoing (Ali et al., 2019; Baumgartner et al., 2015; Hufe and Heuermann, 2017). Three arguments exist regarding the likely effects of LSLIs on the livelihood of local people. The first is about a potentially positive impact through employment opportunities, technology transfers, and rural infrastructure development. Advocates of this view, such as the World Bank, argue that LSLIs can bring a win-win solution to investors and host communities (Deininger and Byerlee, 2011; Deininger and Xia, 2016). The importance of LSLIs for economic growth and poverty reduction in developing countries is also advocated by these groups (Ali et al., 2019; Hilhorst and Zomers, 2011). The Ethiopian government is in line with this idea.

The second argument is focused on the adverse effects caused by LSLIs. With LSLIs, local land use rights are hindered and natural resources are exploited, impoverishing farmers (Aabø and Kring, 2012; Rahmato, 2011, 2014). Hence, the livelihoods of host communities are compromised by the allocation of rangelands to LSLIs (Little et al., 2008; Little and McPeak, 2014). In line with this, the risks caused by LSLIs to the livelihoods of rural poor African people are highlighted in many studies (Dye, 2015; Gyapong, 2020; Keeley, 2014; Wayessa, 2020). The main concerns are that the forceful dispossession and displacement of local communities have resulted from the establishment of LSLIs. The loss of agricultural land to LSLI is a cause of food insecurity in Ethiopia (Debela et al., 2020; Lavers, 2012; Shete and Rutten, 2015; Wayessa, 2020). Moreover, meager employment opportunities (Fitawek and Hendriks, 2021) and technology transfers (Baumgartner et al., 2015; Gyapong, 2020; Shete and Rutten, 2015) are generated by LSLIs. Thus, the expansion of LSLIs into rangelands is a paradox in developing countries with prominent levels of poverty and hunger (Cotula, 2009; Dinku, 2018; Scoones, 2020). Since Ethiopian leaders mainly aim to achieve poverty reduction and food 
security, these objectives may not be directly addressed by the expansion of LSLIs (Rahmato, 2014).

In the third argument, the above two arguments are combined. In such an argument, LSLIs are viewed as having mixed effects, with some positive and some negative ones, on the livelihoods of local communities. Perhaps, the advantages of LSLIs may not outweigh their opportunity costs (Aabø and Kring, 2012). The expected positive spillover effects may not have been brought about by LSLIs (Aabø and Kring, 2012). In these cases, local inequalities are potentially increased by LSLIs (Bottazzi et al., 2018).

In this dissertation, I assess which argument holds in the case of LSLIs in Ethiopian agropastoral areas. Specifically, I investigate the impacts of LSLIs on the livelihood outcomes of pastoralists, such as household food security, land degradation, land use conflict, and resilience.

The scarcity of grazing land and feed shortages are the critical drivers of poverty and food insecurity in Ethiopian agropastoral areas. For instance, multidimensional headcount poverty in the Afar and Somali pastoral regions was $88.73 \%$ and $91.86 \%$ of the total population (Alkire et al., 2020), respectively, and 87.3\% in Borena (Dika et al., 2021). These areas have the highest poverty indices compared to other regional states in the country. Thus, the key question to be answered is to what extent are LSLIs a risk for local food security? LSLIs are advocated by the Ethiopian government under the narratives of improving local food security. Thus, it was necessary to evaluate this narrative empirically to influence government policy.

Land degradation is one of the most pressing environmental problems worldwide. Globally, about $30 \%$ of land is degraded, affecting about 3.2 billion people (GEF, 2019). Land degradation is already a severe problem in Ethiopia (Wassie, 2020), as more than $23 \%$ of the land is degraded (Gebreselassie et al., 2016). Land degradation is more severe in drylands where pastoralists reside. As good rangeland areas are withdrawn from common-pool resources for LSLIs, the overall productivity of the land may decline (Abbink et al., 2014). As livestock intensively grazes in the same land, rangeland degradation is likely. Therefore, the grazing land used by pastoralists could be fragmented and degraded by expanding cultivation to rangelands (Dika et al., 2021). Rangeland degradation is increased by LSLIs, which further harms the food security and resilience of pastoralists (Basupi et al., 2019; Hak et al., 2018; Haller et al., 2020; Osman et al., 2018; Shete and Rutten, 2015).

Land use conflicts are common in all societies across the globe. In developing countries, access to water and land for grazing or crop production are key conflict sources. For instance, in sub-Saharan Africa, half of all land disputes between sugar companies and local communities 
last for more than ten years (Bowie and Feyertag, 2019). Ethiopia is a conflict-prone African country, and in one way or another, the conflicts are related to land. For instance, the wave of protests that has swept across the country since 2014 is directly linked to land policy (e.g., expansion of the Addis Ababa land use plan). Notably, Ethiopian pastoralists have always resisted the allocation of pasture land for LSLIs, which has involved armed confrontation (Hundie, 2006) Endless land conflicts among various land users are entailed by this confrontation, damaging lives and livelihoods in an already fragile environment (Beyene, 2009; Hundie, 2006; Lind et al., 2016; Zaehringer et al., 2018). Land use conflict is perilous in dryland areas with harsh climates, where livestock routinely search for water and grass.

Building resilience is one of the sustainable development goals (Bahadur et al., 2015) and has become one of the development goals in many developing countries in recent years (Alfani et al., 2015; FAO, 2018b). The food security and resilience of pastoralists are harmed by the influence of LSLIs on land access, land conflicts, and degradation (Basupi et al., 2019; Hak et al., 2018; Haller et al., 2020; Osman et al., 2018; Shete and Rutten, 2015). Therefore, the resilience of pastoral production systems is questionable in the face of intense land use competition.

\subsection{Research Objectives and Questions}

This dissertation aimed to analyze the impact of LSLIs on the livelihoods of Ethiopian agropastoral households. Specifically, the effects of LSLIs on household food security, land degradation, land conflict, and household resilience were considered. The four specific research questions listed below were comprised in this research.

The general research question: What are the impacts of LSLIs on the livelihoods of (agro) pastoral households?

Specific Research Questions

1. What is the impact of large-scale land investments on the food security of agropastoral households? [chapter two]

2. What is the impact of large-scale land investments on pasture land degradation in agropastoral drylands? [chapter three] 
3. What are the drivers of land use conflicts between agropastoral households and large-scale land investments? [chapter four]

4. What is the impact of large-scale land investment on agropastoral household resilience? [chapter five]

The objectives of this thesis were chosen based on Ethiopian development priorities and the sustainable development goals (SDGs) (Bahadur et al., 2015; Davies et al., 2016; FDRE, 2014). The research problem explained above, which is in line with SDGs, is addressed by the research objectives of this dissertation. Chapter two is in line with SDG 2 - End hunger, achieve food security, improve nutrition and promote sustainable agriculture. Chapter three fits with SDG 15 - Life on land: Protect, restore and promote sustainable use of terrestrial ecosystems, sustainably manage forests, combat desertification, and halt and reverse land degradation and halt biodiversity loss (Davies et al., 2016). Chapter four is associated with SDG 16 - Promote just, peaceful and inclusive societies. Chapter five is part of the SDG 1 - Target 1.5 end poverty in all its forms everywhere by building the resilience of the poor and reducing their exposure to climate-related extreme events, and SDG 13 - Target 13.1 strengthen resilience and adaptive capacity to climate-related hazards and natural disasters in all countries Climate Action (Bahadur et al., 2015).

\subsection{Theoretical and Conceptual Frameworks}

The overall theoretical framework guiding this dissertation is the sustainable livelihoods framework (SLF). The SLF is a holistic, people-centered approach to understanding livelihoods based on vulnerability context, five core assets (e.g., human, social, natural, physical, and economic), policies and institutions, livelihood strategies, and livelihood outcomes (DFID, 1999; Ellis, 2000). A livelihood comprises the capabilities, assets, and activities required for a means of living (Chambers and Conway, 1992). The SLF emphasized how the assets of a household are used to undertake a range of livelihood activities to achieve the intended livelihood outcomes. The choice of households to participate in pure pastoralism, agropastoralism, and diversified livelihoods to achieve livelihood goals (e.g., more income, food security, and sustainable land use) is determined by the asset endowments (e.g., labor, land, livestock) and vulnerability (e.g., climate, displacement, and conflict) of the pastoral 
households (Figure 1.3). In SLF, access to land as a core natural resource is crucial to obtaining a positive livelihood outcome for food security and income.

The dissertation benefits from multiple concepts and theories in line with SLF, including rangeland degradation, household displacement, property rights, environmental scarcity, political ecology, and resilience. Property rights are the rules specifying a bundle of rights of property, such as user rights, control rights, and authoritative rights (Schlager and Ostrom, 1992). Access to secure land is critical to the livelihoods of pastoralists. Understanding land conflicts from a scarcity point of view can be explained by environmental scarcity (Martin et al., 2006). How land use policy is shaped by power relations and how land use conflict is caused by them can be illustrated by political ecology. Various insights about the drivers of land use conflict are provided by each of the theories.

In Figure 1.3, the focus points of each of the chapters are shown, starting from the SLF (DFID, 1999; Ellis, 2000). In chapter two, the different aspects of SLF are drawn, and it is concluded that access to land is crucial to obtain a positive livelihood outcome of food security. In chapter three, the concepts of land degradation and displacement within SLF are applied. Chapter four is based on property rights, environmental scarcity, and political ecology theories to unpack the drivers of land conflict in the presence of LSLIs. Resilience as a livelihood outcome is focused on in chapter five. Resilience is the persistence of systems and their ability to absorb changes and disturbances and maintain the same relationships between populations or state variables (Holling, 1973).



Figure 1.3. The theoretical framework of this study [adapted from DFID (1999)]. 


\subsection{Research Methodology}

\subsubsection{Data Sources and Study Areas}

This thesis is based on two primary datasets and secondary literature on land use policy in Ethiopia. The first primary data source is high-quality panel data from the living standard measurement survey (LSMS) for Ethiopia in 2012, 2014, and 2016. I extracted data from the LSMS panel dataset for the most significant agropastoral societies (Figure 2.1). The sample was adequate for the explanatory power of the intended econometric operations. However, the sample is not nationally representative of the whole Ethiopian pastoral population. In the study, several pastoralist populations were included, such as (1) Somali pastoralists from three zones of Somalia regional state (Jigjiga, Liben, and Shinile), (2) Afar pastoralists from two zones of Afar regional state (Afar zone one and zone three), (3) Borana, Guji, Karrayyu, and Itu pastoralists from five zones of Oromia regional states (e.g., Borana, Guji, Bale, and east and west Hararghe), (4) Omo pastoralists from south Omo zone of SNNPR, and (5) Nuer pastoralists from Gambella regional state. Chapters two and five are based on the LSMS data, and 2,106 pastoral households were included in the data analysis. I included five sugar plantations established in the aforementioned pastoral regions or border regions (Figure 2.1) (ESC, 2017). These are the Metehara, Kesem, and Tendaho in the central rift valley, the Omokuraz in the southern rift valley, and Arjo-Didessa in western Ethiopia.

The second primary data source for chapters three and four was cross-sectional data collected from 870 households in the Awash Central Rift Valley (Figure 3.1). First, I conducted a community survey of 43 male and 16 female elders to understand land conflict and land degradation drivers. Second, using the preliminary results from the community survey, I developed a structured questionnaire and trained enumerators to conduct face-to-face interviews with households. The Metehara and Tendaho sugarcane plantations were considered for an in-depth investigation of land use conflict and land degradation.

The Awash Rift Valley of Ethiopia is mainly home to Karrayyu and Afar pastoralists. However, access to critical rangelands in the Awash Rift Valley has been declining with the expansion of sugarcane plantations (Little. et al., 2010). Since the 1970s, lands with good pasture and water have been taken for state-run sugar plantations (Lavers, 2012). It is where the state and pastoralists compete over strategic interests (Müller-Mahn et al., 2010). Since 2010, pastoral areas have seen further expansion of sugar plantations into the rangelands. The problem was intensified by the expansion of sugar plantations into grazing lands, further raising the urgent need to investigate the livelihood impacts of plantations by improving the limitations of 
previous studies. Hence, a good example for investigating the effect of LSLIs in sugar plantations on pastoral livelihoods was provided by the Awash Valley Area. Moreover, the area is of geopolitical importance because the main road and train transport linking Ethiopia to international trade via Djibouti Port were built through it. There have been road blockage incidents by pastoralists to express their grievances and resistance to the conversion of rangelands to sugar plantations. As a result, it is a place where stability and peace are essential for the safe movement of import and export items. Thus, chapters two and three were mainly focused on pastoralists residing in the Awash Valley of Central Rift Valley in Ethiopia.

\subsubsection{Data Analysis}

Evaluating the impact of LSLIs on the livelihood of the people is not straightforward due to endogeneity problems and a lack of baseline information. Thus, I applied a quasi-experimental research design on the cross-sectional and panel data described above, using household proximity to LSLI ( 1 if $<150 \mathrm{~km}, 0$ otherwise) as a treatment variable in chapters two and five. This procedure was employed considering the importance of the herd mobility strategy (up to $450 \mathrm{~km}$ ), as pastoralists were forced to move increasingly long distances in search of pasture and water (Deininger and Xia, 2016). Household global positioning systems (GPS) coordinates were used to estimate the geographical proximity of households from five LSLI sugarcane plantations, namely Metehara, Kesem, Tendaho, Omo Kuraz, and Arjo-Didessa, for chapters two and five.

In chapter two, using elements of SLF, I identified the determinants of food insecurity. The distance of households from LSLIs was used as a proxy for the treatment effect from LSLIs. It was assumed that land tenure security is critical for food security in the local community (Keovilignavong and Suhardiman, 2020). In chapter three, a land degradation assessment in drylands was adopted to assess the knowledge and perception of the local community about the causes of land degradation in general and the effect of LSLIs on land degradation in particular (FAO, 2016a). The perception of the land users on the level of land degradation (Qasim et al., 2011) and land quality was rated as excellent, good, fair, and poor (Bojö, 1991; Kapalanga, 2008). In chapter four, the loss of land to LSLI by the household in the last 10 years was used as a possible cause of conflict. I developed an econometric analysis of the determinants of land use conflict based on theories of property rights, environmental scarcity, and political ecology. In chapter five, I assessed two dimensions of household resilience: resilience capacity and welfare resilience. The resilience capacity was measured using the resilience index measurement and analysis (RIMA) model (FAO, 2016b), while a novel method was developed 
Chapter 1

to measure welfare resilience as a composite indicator of the net change in welfare outcomes. For data analysis, the random effects regression model, propensity score matching [chapter two], endogenous switching regressions [chapter three], binary logit models [chapter four], multivariate factor analysis, and the ordered random effects regression model [chapter five] were used. 
Chapter 2

Large-scale Land Investments and Food Security in Agropastoral Areas of Ethiopia 
Chapter 2 


\title{
2 Large-scale Land Investments and Food Security in Agropastoral Areas of Ethiopia ${ }^{3}$
}

\begin{abstract}
In Ethiopia, large-scale land investments have been expanding into pastoral regions. However, little is known about the consequences of these investments on the food security of the pastoral community. Using Living Standard Measurement Survey data of the World Bank, we find that, on average, about $32 \%$ of the respondents from the (agro) pastoral regions are food insecure. After controlling for confounders, proximity to large-scale land investments is associated with an additional food intake of up to 745 kilocalories per day per adult compared to the households located farther away from a large-scale land investment. Proximity to large-scale land investment has no significant effect on the coping strategies based food security. For households located in proximity to large-scale land investment, food intake significantly increases with access to roads and markets. Proximity to a large-scale land investment has a positive effect on household food consumption not necessarily because of direct benefits from large-scale land investments, but due to land and soil quality near the large-scale land investments.
\end{abstract}

Keywords: food security, large-scale land investment, sugar plantations, livelihoods, pastoralism, propensity score matching

\footnotetext{
${ }^{3}$ This chapter is based on the paper published as Bekele, A.E., Dries, L., Heijman, W. \& Drabik, D. (2021). Large scale land investments and food security in agropastoral areas of Ethiopia. Food Sec. 13, 309-327. https://doi.org/10.1007/s12571-020-01131-x
} 


\subsection{Introduction}

Pastoralism and agropastoralism are predominant production systems in the arid and semi-arid drylands of Africa. About 25 million pastoralists and 200 million agropastoralists live in SubSaharan Africa (SNV, 2012). Pastoralists mainly depend on livestock production, while agropastoralists depend on livestock and crop production for their livelihoods. Ethiopia has one of the largest (agro) pastoralist areas in East Africa, covering 61\% of its drylands. Livestock contributes to the livelihoods of $60 \%-70 \%$ of the Ethiopian population (Halderman, 2004). The country also has the largest livestock population on the African continent (FDRE, 2014). Despite this considerable livestock resource, Ethiopia is one of the most food-insecure countries in the world.

Areas used for (agro) pastoralism suffer from several challenges, including insufficient rainfall and droughts, resulting in perishing livestock, losses of human lives, and environmental degradation (Headey et al., 2014). Agropastoralists remain among the poorest groups of the population (FDRE, 2013). Poverty in the (agro) pastoral regions is also a result of political, social, and economic marginalization (Fareh, 2011; McPeak, 2003; Pavanello, 2009). Ethiopian pastoralists have limited access to social services, infrastructure, and education (Halderman, 2004). Poverty reduction and achieving food security in (agro) pastoral regions is one of the main development priorities for Ethiopia (Devereux and Sussex, 2000). Despite economic growth in the last decade and the government's attempts to address food security, the latter remains a major problem. Over $30 \%$ of the Ethiopian population is below the nationally defined food poverty line at the 2,200 kilocalories (kcal) per capita, and 40\% of households are food energy deficient (CSA, 2014).

The Growth and Transformation Plan of Ethiopia aspires to make the country a lower middle-income country by 2025. It considers large-scale land investments (LSLIs) to be a vital tool for developing pastoral areas (Keeley, 2014). About three million hectares in lowland regions have been leased to private and state-owned commercial agricultural interests since January 2005 (Beirne, 2014; Keeley, 2014). With these investments, lands with good pasture, water, and wildlife were taken to create national parks and state-owned and private farms. For instance, in the Rift Valley, Karrayu and Afar rangelands have been chosen for sugar cane plantations. As a result, the original grazing land of the Karrayu pastoralists declined from 150,000 hectares to 40,000 hectares, while Afar and South Omo pastoralists lost over 90,000 hectares and 245,000 hectares, respectively. Many argue that the replacement of pasture land with irrigated arable land has jeopardized pastoral livelihoods (Pavanello, 2009; Said, 1994; Schmidt and Pearson, 2016). Others say that the area available to pastoralists is still substantial 
and that sugar plantations will, therefore, not have a major impact on local livelihoods (e.g., land acquired for sugar plantation in Omo Kuraz takes 245,000 hectares out of 445,501 hectares (Nixon, 2013).

Large-scale land investments may positively affect livelihoods by generating local employment opportunities, access to irrigation, and technologies. However, they may also aggravate the access to grazing lands by displacing pastoralists from their pastures or preventing their access to dry season grazing, resulting in a negative impact on livelihoods. If people directly lose their land without compensation or adequate resettlement, they will likely become worse off and more food-insecure (Keeley, 2014). The impact of LSLIs on household food security in Ethiopia is, however, not yet fully understood. The available empirical studies on the effect of large farms on food security in Ethiopia mainly focus on the crop farmers (Ali et al., 2018; Ali et al., 2019; Daniel et al., 2018; Dheressa, 2013; Dye, 2015; Moreda, 2017; Shete and Rutten, 2015). There is no quantitative research yet conducted in the pastoral context. Therefore, this study investigates the impact of LSLIs on food security of (agro)-pastoral households in Ethiopia. The paper makes two contributions. First, it provides an insight into the effect of proximity to LSLI on pastoral household food security, one of the most debated issues. Second, it applies multiple food security indicators for its multiple dimensions and robust econometric models to address endogeneity and causal effects. In the next sections, we present the conceptual framework, methodology, results, discussion, and conclusions.

\subsection{Conceptual Framework}

Assessing the impact of LSLIs on food security requires a conceptual framework that shows their interactions. Therefore, we have adopted the Sustainable Livelihood Framework (SLF). The SLF was first introduced in 1987 by the World Commission on Environment and Development (Krantz, 2001). Livelihood consists of the capabilities, assets, and activities required for a living (Chambers and Conway, 1992). A livelihood is sustainable when people cope with and recover from stress and shocks, maintain or enhance their capabilities and assets, and provide sustainable livelihood opportunities for the next generation (Chambers and Conway, 1992; DFID, 1999).

The SLF (Figure 2-1) contains five components: context, assets, policies and institutions, livelihood strategies, and livelihood outcomes (DFID, 1999). The arrows indicate the direction of influence and linkages from one component to the other. The context indicates trends and shocks in individuals', households', and communities' external environment that affect 
people's livelihoods (e.g., conflict, illnesses, floods, droughts, pests, diseases) (Serrat, 2017). Livelihood assets are the resources on which people depend to carry out their livelihood strategies. These include human (education, skills, labor, health), natural (land, forest, water), physical (livestock, roads, markets), financial (savings, credit, income), and social (networks and connections) capital (Serrat, 2017). Policies and institutions are the formal and informal rules that enable or hinder access to assets, especially land and livelihood strategies (Kébé and Muir, 2008). Livelihood strategies are the range of activities that people undertake to make a living such as intensification, migration, pastoralism, and non-pastoral activities (Scoones, 1998; Serrat, 2017). Livelihood strategies lead to livelihood outcomes. Outcomes can relate to income, well-being, vulnerability, food security, and sustainable use of natural resources (DFID, 1999).

Food security can be seen as one of the livelihood outcomes in the SLF. It refers to access by all at all times to enough and nutritious foods for a healthy and active life (FAO, 1996). At the household level, food security shows the ability of families to secure enough food to achieve dietary needs (Maxwell 1995; Maxwell and Frankenberger 1995). Access to food is related to the control of households over assets such as land, water, and labor. In the context of this study, the policies and institutions dimension of the SLF describes the policies and institutions that influence households' access to assets. For instance, LSLIs result from the state taking pasture land for the production of sugar, which is driven by development policy. As a result, pastoralists' access to land becomes restricted, which in turn can affect livelihood outcomes, such as the level of food security.

The advantages of applying the SLF to food security studies are three-fold. First, it helps to understand the sources of vulnerability to food insecurity. Second, it gives an insight into livelihood sustainability or the long-term situation with an emphasis on enhancing capabilities. Third, it helps to explore the coping strategies undertaken by households to respond to exogenous shocks (Burchi and De Muro, 2016). There is a growing consensus on the usefulness of livelihood approaches to the analysis of food insecurity (Burchi and De Muro, 2016; Devereux et al., 2004; Hussein, 2002; Slater and Yeudall, 2015). The SLF is appropriate to study food security because it comprehensively combines the key components of factors that influence household food security, including policies leading to LSLI. Henceforth, the SLF helps to identify the explanatory variables used in the empirical analysis. This study will seek an answer to two questions: what are the effects of proximity to LSLI on household food security in agropastoral areas? And what are the possible determinants of household food security in agropastoral areas affected by LSLIs? 


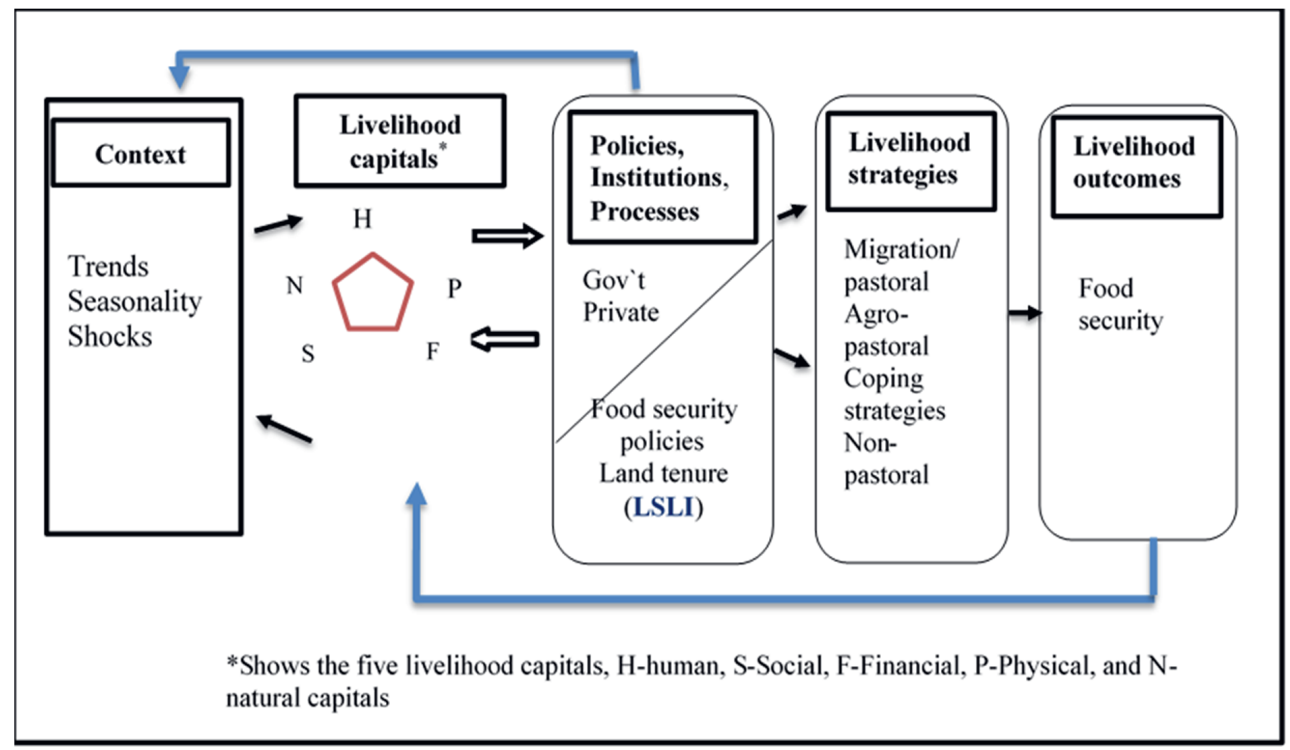

Figure 2-1. Sustainable livelihoods conceptual framework for the study adapted from the Department for International Development of the United Kingdom (DFID, 2019)

\subsection{Data and Methodology}

\subsubsection{Description of the Study Areas}

The main (agro) pastoral areas in Ethiopia are Afar Somalia, part of Oromia and Southern Nations Nationalities Peoples Region (SNNPR), Gambella, and Benishangul regions. According to the Central Statistics Agency of Ethiopia (CSA), 61\% of Ethiopia's land area hosts over 15 million agropastoralists (CSA, 2007). The country is ranked first in Africa by the number of livestock (ILRI, 2017), and the pastoral regions host over $42 \%$ of the livestock (Ibrahim, 2016). Figure 2-2 shows the map of the study areas, the location of LSLIs, and the households. We include 12 zones of major agropastoral regions in our study: Jigjiga, Liben, and Shinile, Afar zone 1 and zone 3, Borana, Guji, Karrayu, Bale, and Hararghe, south Omo and Nuer zones. Table 2-1 gives the total population and the percentage of pastoralism for the zones in the study area.

From our study, more than $80.7 \%$ of the respondents rely on livestock as a primary source of food and income, while $23.1 \%$ solely depend on livestock (pure pastoralists), $67.2 \%$ depend on both livestock and crop (agropastoralists). Few households (3.7\%) also solely depend on crop production; $6.0 \%$ of households also engage in non-pastoral economic activities. 


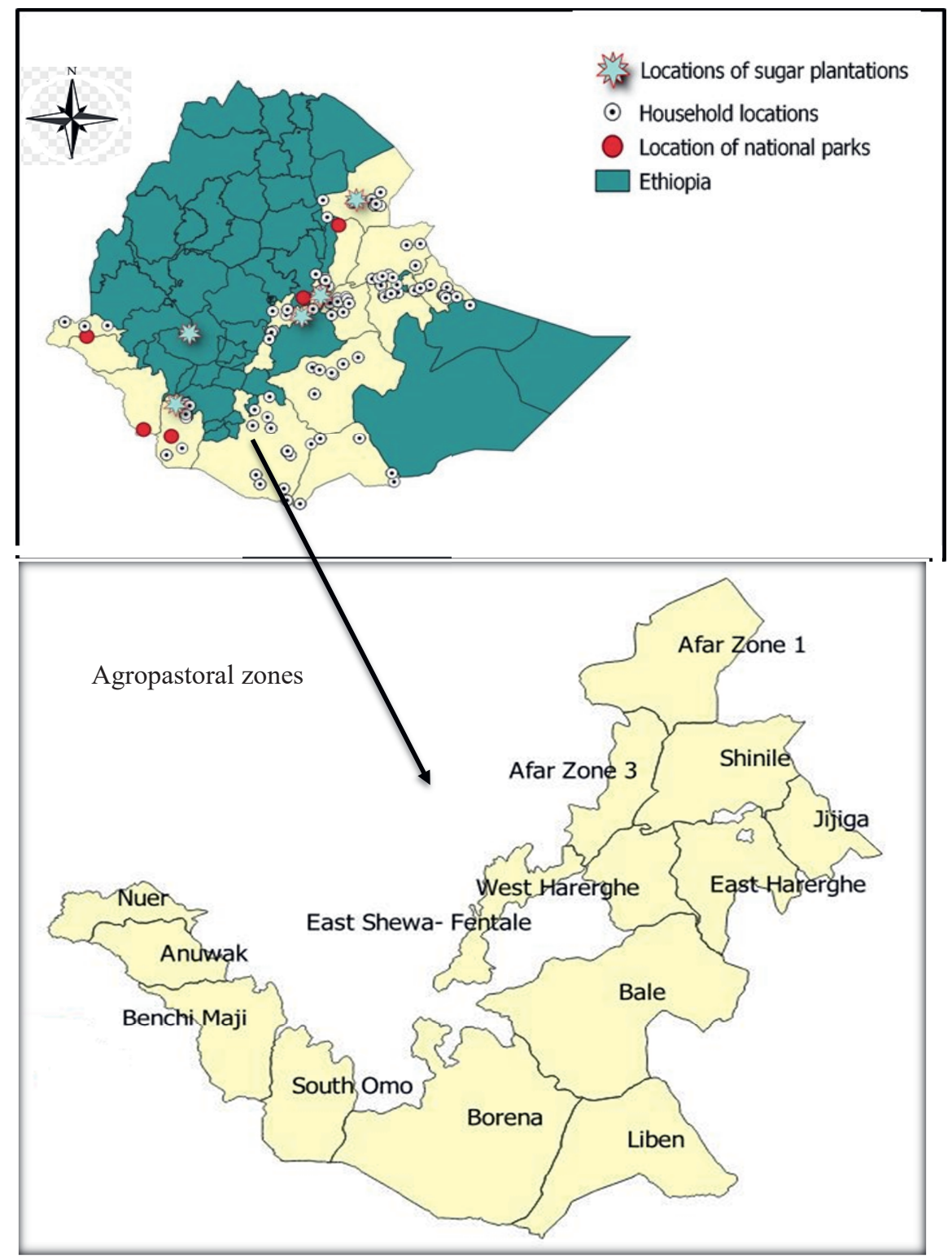

Figure 2-2. Map of the study areas developed by authors based on Ethiopian Shapefiles 2013 
Table 2-1.The study zones and their populations

\begin{tabular}{llll}
\hline Region & Zone & Population & \% pastoralism \\
\hline Afar & Zone-1 & 525,028 & 90 \\
Afar & Zone-3 & 248,357 & 90 \\
Oromia & East Shoa (Fentale) & $1,685,465$ & 11 \\
Oromia & W/Hararge & $2,260,649$ & 28 \\
Oromia & E/Hararge & $3,286,338$ & 12 \\
Oromia & Bale & $1,703,762$ & 42 \\
Oromia & Borena & $1,162,879$ & 85 \\
Oromia & Guji & $1,680,859$ & 85 \\
Somalia & Shinille & 546,168 & 90 \\
Somalia & Jijiga & $1,158,309$ & 90 \\
Somalia & Liben & 643,673 & 90 \\
SNNPR & South Omo & 675,333 & 85 \\
Gambella & Nuer & 138,640 & 85 \\
\hline
\end{tabular}

Source: Central Statistical Agency (CSA, 2014) and authors' calculations (2019)

\subsubsection{Data and Sampling}

We used data from the Living Standard Measurement Survey (LSMS) for Ethiopia for the years 2011/12, 2013/14, and 2015/16. The LSMS is a Rural Socio-Economic Survey from a collaborative project between the Central Statistical Agency of Ethiopia and the World Bank (CSA, 2017). A two-stage probability sampling technique is used in the survey to select enumeration areas and households. Face-to-face interviews were conducted by trained enumerators using a structured questionnaire. The data covers a range of topics, including demography, education, health, savings, labor, welfare, agriculture, food security, and shocks (CSA, 2017). We extracted data for the agropastoral zones listed in Table 2-1. A total of 2,106 households are included in this analysis. We used the household coordinates to calculate the distance of each household to sugar plantations. We targeted sugar plantations because a lot of rangeland has been allocated to sugar plantations and their expansions in recent years (Behnke and Kerven, 2013). Moreover, the location of sugar plantations can easily be detected compared to other large-scale farms. 


\subsubsection{Methodology}

Our objective is to assess whether households differ in their level of food security based on their proximity to LSLI. The proximity of households to LSLI may not be random. The location of LSLI depends critically on the availability of suitable land and water resources (Deininger, 2010; Lay, 2017). As the availability of natural resources may also affect households' food security, this may lead to biased estimates because of endogeneity. Since the assignment of households to the treatment and control groups is not random, the estimation of the effect of treatment may be biased by confounding factors (Becker and Ichino, 2002). Confounding variables are variables that have a potential effect on household food security and LSLIs. Propensity score matching (PSM) is used to avoid this problem of endogeneity, as suggested by several authors (Bishop, 2015; Haji and Legesse, 2017; Shete and Rutten, 2015). We classify respondents as being 'treated,' based on their distance to LSLI, considering livestock mobility (up to $150 \mathrm{~km}^{4}$ ). The untreated households live at least $150 \mathrm{~km}$ away from an LSLI.

$\mathrm{PSM}^{5}$ constructs a statistical comparison group that is based on a model of the probability of participating in the treatment $T$ conditional on observed characteristics $X$, or the propensity score (Khandker et al., 2009; Rosenbaum and Rubin, 1983)

$$
P(X)=\operatorname{Pr}(T=1 \mid X) .
$$

Our goal is to estimate the average treatment effect on the treated (ATT), which is the effect of LSLI proximity on household food security. The ATT is computed by matching LSLI and non-LSLI households that are closest in terms of their propensity scores. According to Becker and Ichino (2002) and Heinrich et al. (2010), the ATT can be estimated as follows:

$$
\mathrm{ATT}=\mathrm{E}(\mathrm{T} / 1=1)=\mathrm{E}(\mathrm{Y} / 1) / \mathrm{D}=1)-\mathrm{E}(\mathrm{Y}(0) / \mathrm{D}=1),
$$

where $E(Y / 1) / D=1$ represents the expected food security outcome of LSLI households, and $\mathrm{E}(\mathrm{Y}(0) / \mathrm{D}=1)$ denotes the counterfactual food security of non-LSLI households.

Different matching methods can be used for treated and control households based on the propensity score (Heinrich et al., 2010; Khandker et al., 2009). To select the best matching algorithm, we considered sample size, the number of insignificant variables and small pseudo-

\footnotetext{
${ }^{4}$ LSLI limits pastoralists' access to grazing. Consequently, pastoralists travel long distance between $50 \mathrm{~km}$ to 250 $\mathrm{km}$ in search of pasture and water during dry seasons (Elias, 2008). Further, we have confirmed that camel travel up to $450 \mathrm{~km}$ during severe dry seasons. The LSLIs (sugar plantations) took between $200 \mathrm{~km}^{2}$ and $2500 \mathrm{~km}^{2}$ of land. We conduct sensitivity analysis by choosing the cut points at the $50 \mathrm{~km}, 100 \mathrm{~km}$, and $150 \mathrm{~km}$ locations. The treatment effects consistently show a positive effects at the $50 \mathrm{~km}, 100$, and $150 \mathrm{~km}$ cut points. Considering livestock mobility and optimal statistical comparisons, we choose the $150 \mathrm{~km}$ cut point to assess the treatment effect of LSLIs.

${ }^{5}$ We chose to match propensity scores using the first wave (2012) and maintain those groups for the other waves to avoid variation in the propensity scores over time (Kupzyk, et al., 2017).
} 
$\mathrm{R}^{2}$ after matching, and the lowest mean standardized bias. Our results indicate that the kernel matching estimator with a bandwidth of 0.08 is the best matching algorithm because of lower bias and improved balancing quality (Appendix Figure 2-a, Appendix Table 2-B, 2-C Table 23, Table 2-4).

We also estimate a random effects model, controlling for confounding variables that may explain households' proximity to LSLI, such as the availability of natural resources, as well as their food security. A random effects model is useful when there is no omitted variable bias, and when a fixed effect model cannot be used because of missing variation in some variables, which in our case. We exhaustively included variables according to the SLF to reduce omitted variable bias. Hence, the random effects model will allow us to evaluate if proximity to an LSLI increases food security or not (Baltagi, 2008; Do et al., 2019). Moreover, the random effect model helps to identify the determinants of food security.

In our random effects model estimation, the dependent variable is household food security in each survey year $\left(y_{i t}\right)$. The independent variables $\left(X_{i t}\right)$ include indicators of households' proximity to LSLIs and other control variables, $r_{i t}$ and $m_{i t}$ indicates interaction variables of distance to road and market respectively for each household and year. The parameters $\beta_{x r}$ and $\beta_{X m}$ measure the interaction between $x$ and $r$ and $x$ and $m$. The general model specification will then be:

$$
y_{i t}=\mu+\alpha_{i}+x_{i t} \beta_{x}+\beta_{x r}\left(x_{i t} r_{i t}\right)+\beta_{X m}\left(x_{i t} m_{i t}\right)+\varepsilon_{i t},
$$

where $\alpha_{\mathrm{i}}$ is the $\mathrm{i}^{\text {th }}$ individual effect that is constant over time and $\varepsilon_{i t}$ is the error term, IID ( $\mu$, $\left.\sigma^{2} \varepsilon\right)$ (Verbeek, 2008).

Before running the panel regressions, we conducted diagnostic tests for multicollinearity (Appendix Table 2-G) found no problems with multicollinearity and normality (Appendix Figure 2-b). The Breusch and Pagan Lagrangian multiplier tests also show a random effects model is appropriate (Appendix Table 2-H). Random effects models are estimated using the logistic (REL) and generalized least squares (GLS) estimation procedures.

\subsubsection{Dependent Variables: Household Food Security}

Food security is a multi-dimensional concept, and a combination of both "subjective" and "objective" indicators is recommended (Maliwichi et al., 2012; Maxwell et al., 2014). There is no one gold standard in measuring food security. Therefore, we use three indicators of household food security that are available from the LSMS data: Food Intake, Self-Assessment (SA), and Coping Strategies Index (CSI). Food Intake measures the number of calories 
consumed by household members over seven days (Hoddinott, 1999). SA is the subjective selfassessment of each household of their food security (Maxwell, 1996). CSI indicates the strategies people use to cope with a shortfall in food (Maxwell et al., 2003).

The principal person responsible for preparing meals in the household was asked how much food is prepared and served over seven days to determine Food Intake. We first converted the amount of food consumed into kilocalories using the food composition table from the Ethiopian Health and Nutrition Research Institute (EHNRI, 1997). Second, we calculated the kilocalories of food consumed per adult per day. Third, we compared the estimated daily caloric intake to the minimum daily subsistence requirement of 2,200 kcal per adult set by the Ethiopian Government (FAO, 2013; FSS, 2002). Finally, we categorized households into food secure (those who consumed at least 2,200 kcal per day per adult) and food insecure (those who did not meet the minimum requirement of 2,200 kcal per day per adult).

To determine the Self-Assessment measure of food security, respondents were asked to assess their food security status. The household head was asked whether there was enough food (either through own production or through purchases from the market) over the last 12 months to sufficiently feed the family. Households who reported that they had enough food were considered food secure, while those who reported shortages were considered food insecure.

The third indicator asks about households' coping strategies. Respondents were asked about what they do when they do not have enough food and do not have money to buy it. Coping strategies relate to a short run and immediate response to a lack of food. CSI is an indicator of food access and captures food security indirectly by measuring behavior related to food consumption (Maxwell et al., 2003). It directly captures notions of adequacy and vulnerability (Hoddinott, 1999). Seven universally validated coping strategies were included in the LSMS data (Appendix Table 2-E). We adopted universal severity weights of Maxwell and Caldwell $(2008)^{6}$ for each coping strategy to determine the CSI (Maxwell and Caldwell 2008). The CSI was calculated by summing up the product of the frequency of each coping strategy and severity weight per household. The higher the value of the CSI, the more severe the problem of food insecurity (Maxwell et al., 2003). Accordingly, a zero CSI score means that a household is food secure and a CSI score above zero means that some food insecurity exists.

The dependent variable, food security, is specified as a dummy, which is 1 for a food secure household and 0 otherwise. In food intake, we use 1 for households that consumed at least 2,200

\footnotetext{
${ }^{6}$ The weights are (1.0) for eating less preferred/expensive foods, (2.0) for borrowing food or relying on help from friends and relatives, (1.0) for limiting portion sizes at meal times, (3.0) for limiting adult intake so that small children can eat and (1.0) reducing the number of meals per day.
} 
kcal/day/adult, 0 otherwise; in self-assessment 1 for households who reported being food secure, 0 otherwise; and in CSI, 1 for households with zero CSI, and 0 otherwise. We specified a continuous variable for two food security indicators, such as the kilocalories per day per adult and CSI. As the kcal/day/adult increases, household food security improves, while as CSI increases, it worsens.

\subsubsection{Independent Variables}

The primary independent variable of interest is LSLI. In the PSM model, LSLI will be the treatment variable, and it takes the value of one for households located within a $150 \mathrm{~km}$ distance from an LSLI, namely a sugar plantation. LSLI takes the value zero for households that live at least $150 \mathrm{~km}$ away from LSLI. Accordingly, 37\% of the households live less than $150 \mathrm{~km}$ from an LSLI. In the estimation of the random effects, the treatment variable, proximity to the LSLIs is included as a key independent variable.

Other independent variables included in the estimation are derived from the conceptual framework of sustainable livelihoods presented in figure 1. We used the FAO classification of livelihood assets under different livelihood components (Carloni and Crowley, 2005). Summary statistics for those variables are provided in Appendix Table 2-F. The key natural assets include the size of land owned, percentage of a forest, soil quality, and access to irrigation. The average area of land owned was 0.9 ha. Land owned indicates the area owned by households and is expected to have a positive relationship with food security. Irrigation refers to access to irrigation water by the household. Irrigation is also the main determinant of treatment because LSLI will be attracted by the availability of natural resources; however, only $9 \%$ of the households have access to irrigation. The average forest cover in the village was $9.2 \%$, while the soil quality was poor for $37 \%$ of the respondents. The percentage of forestlands in the village and the soil quality, as rated by the household, are expected to positively influence both the treatment variable and food security of rural households.

Human capital variables include age, gender, and education of the household head and household size. The average age of the household head is 45 years, and he or she has 1.7 years of education. Age and education capture knowledge and experience and are expected to positively affect household food security (Iftikhar and Mahmood, 2017). About $77.5 \%$ of the households are headed by men. In the pastoral context, men often have a more dominant and decisive role than women. Hence, we expect food security to be higher for households headed by men than those led by women (gender). Household size, measured as the total number of family members living in the household, may affect household food security negatively as more 
members of a family demand more food (Onyango, 2017). A household has five members on average.

We consider livestock and distance to roads and markets as the essential physical assets affecting pastoral livelihoods. The average size of livestock owned by the respondents was 6.4 tropical livestock units. Local people use an animal for insurance against risks, as a source of income and food (Carloni and Crowley, 2005). Livestock ownership is hypothesized to have a positive impact on household food security. Proximity to rural roads and markets eases transactions of livestock and livestock by-products and, hence, is expected to enhance household food security (Dercon and Hoddinott, 2005). The average distance to roads is 23.7 $\mathrm{km}$ and to markets $86 \mathrm{~km}$. This implies households' access to markets is very challenging. A study in Zambia found that LSLIs are located near markets and infrastructure (Lay et al., 2018).

Financial assets such as credit use and household income help pastoralists access inputs and food and are expected to improve household food security (Carloni and Crowley, 2005). The average annual household income was 5312.84 Ethiopian birrs, while only $17.9 \%$ of households had access to credit. Whether a household received cash or in-kind gifts from relatives or friends is a sign of social capital and helps them to cope with food shortages and hence improves food security. About $10 \%$ of the households have received reciprocal in kind or cash gifts.

Participation in institutional services such as extension programs can improve livestock and crop productivity and hence food security. However, only 16.4 of the pastoral households have access to extension services. Drought is a context variable taking a value of 1 if the household reports the incidence of drought during the survey year and 0 otherwise. About $39.3 \%$ of the respondents encountered drought. Drought is expected to negatively influence food security as it is known to perpetually affect East African pastoralists (Fre and Tesfagergis, 2013). The variable livelihoods represent households' livelihood strategies and take the value 1 for pure pastoralism and 0 otherwise. Accordingly, $23 \%$ of the respondents were pure pastoralists. We expect pastoralists to be more vulnerable to food insecurity, and we hypothesize a negative effect of this variable on food security.

\subsection{Results}

\subsubsection{Food Security Status of Surveyed Households}

Table 2-2 shows the shares of food-secure and food-insecure households in the sample based on the three measures of food security and for the three sample years. Based on the food intake 
and self-assessment approach, on average, 34\% of agropastoral households were food insecure. Using the CSI, on average, $27 \%$ of households adopted coping strategies and hence experienced a certain level of food insecurity. Overall, the share of food-insecure households in the agropastoral areas in our sample was $32 \%$, which is higher than the national average of $29.6 \%$ in 2016 (FAO, 2013).

A higher proportion of pastoral households than agropastoral households are food insecure based on Food Intake and Self-Assessment measures. Pure pastoralists rely on the consumption of livestock products and the purchase of grain from the local market, while agropastoralists use their crop produce to supplement consumption. The daily caloric intake is the highest for non-farming households, followed by crop only households. Pastoralists have the lowest amount of caloric intake. Similarly, pure pastoralists have the highest CSI, which indicates that food insecurity is more severe for pure pastoral than for other livelihood strategies.

Table 2-2. The proportion of households by their livelihood strategies and food security

\begin{tabular}{|c|c|c|c|c|c|c|c|c|}
\hline \multirow[t]{2}{*}{$\begin{array}{l}\text { Livelihood } \\
\text { strategies }\end{array}$} & \multicolumn{2}{|c|}{$\begin{array}{l}\text { Food intake } \\
\%\end{array}$} & \multicolumn{2}{|c|}{$\begin{array}{l}\text { Self-assessment } \\
\%\end{array}$} & \multicolumn{2}{|l|}{$\begin{array}{l}\text { CSI } \\
\%\end{array}$} & CSI & \multirow{2}{*}{$\begin{array}{l}\text { Kcal/ } \\
\text { day/adult } \\
\text { Mean }\end{array}$} \\
\hline & $\begin{array}{l}\text { Food } \\
\text { insecure }\end{array}$ & $\begin{array}{l}\text { Food } \\
\text { secure }\end{array}$ & $\begin{array}{l}\text { Food } \\
\text { insecure }\end{array}$ & $\begin{array}{l}\text { Food } \\
\text { secure }\end{array}$ & $\begin{array}{l}\text { Food } \\
\text { insecure }\end{array}$ & $\begin{array}{l}\text { Food } \\
\text { secure }\end{array}$ & Mean & \\
\hline Pure pastoral & 41.77 & 58.23 & 37.40 & 62.60 & 28.81 & 71.19 & 3.53 & 3437 \\
\hline Agropastoral & 32.04 & 67.96 & 33.81 & 66.19 & 26.17 & 73.83 & 2.52 & 3846 \\
\hline Crop only & 33.3 & 66.67 & 23.08 & 76.92 & 34.62 & 65.38 & 2.96 & 4375 \\
\hline Others & 31.5 & 68.5 & 33.07 & 66.93 & 35.43 & 64.57 & 3.48 & 5462 \\
\hline Total & 34.3 & 65.7 & 34.19 & 65.81 & 27.65 & 72.35 & 2.83 & 3868 \\
\hline chi $2 / \mathrm{F}$ & $15.65 * * *$ & $6.66^{*}$ & $7.62 * *$ & $3.78 * *$ & $6.41 * * *$ & & & \\
\hline
\end{tabular}

Results based on Pearson chi2 tests, *** $\mathrm{p}<0.01$, ** $\mathrm{p}<0.05,{ }^{*} \mathrm{p}<0.1, \mathrm{Kcal} /$ day/adult is kilocalorie per day per adult.

Source: Authors' calculations based on LSMS data (2019)

\subsubsection{Propensity Score Matching Results}

Propensity score matching is used to estimate the effect of LSLI on food security while controlling for confounders that can affect household proximity to LSLI as well as the level of food security. About 15 variables were included as potential confounders using the data collected from Wave 1 (Appendix Table 2-A). The logistic regressions fit the data well at the $1 \%$ probability level of the likelihood ratio's chi-square distribution. The results show that the 
percentage of the forest, the number of livestock owned, the distance between market and roads, and household income negatively influence the probability of being treated, whereas extension participation and exposure to drought positively impact the probability of being treated. These results imply that households in areas with more forest, and those who own more livestock and earn higher income are less likely to be treated. Similarly, a longer distance to the market and road makes it less likely that a household is located near an LSLI. The statistically significant negative effect of distance to market and roads might be because LSLI sites are improving access to the market. Livestock ownership also has a significantly negative effect on households' proximity to LSLIs, implying that households with larger herd sizes are farther from LSLIs. On the contrary, the more access to extension and the more exposure to drought entails a high probability of being treated. Against our expectation, soil quality, irrigation access, and demographic variables do not statistically significantly predict the likelihood of a household's proximity to LSLI.

Table 2-3 shows the results for the food security of treated and control households before and after matching. The results show significant differences in food security between households that live in the vicinity of an LSLI (treated) and more remote households (control), except for the measure of Food Intake after matching. The effect of proximity to LSLI on food security is mixed. Daily calorific intake was around $17.1 \%$ higher for the treated households than for the control households. The food intake and self-assessment show an improvement in food security for $4.5 \%$ and $7 \%$ of households, respectively. In comparison, the CSI shows a decline in food security for $9 \%$ of the sample by proximity to LSLI. The food intake shows a large (up to $745 \mathrm{kcal} /$ day/adult) effect in PSM, but the actual number of households who became food-secure is quite low, $4.5 \%$, compared to the $9 \%$ people who became food insecure in CSI. 
Table 2-3. Average Treatment Effects on the Treated (ATT) before and after matching

\begin{tabular}{lllllll}
\hline Variable & Sample & Treated & Controls & Difference & S.E. & T-stat \\
\hline Kcal/AE/Day & Unmatched & 4367.85 & 3575.21 & 792.65 & 214.43 & 3.7 \\
& ATT & 4367.85 & 3623.14 & 744.71 & 287.76 & $2.59 * * *$ \\
Food intake & Unmatched & 0.691 & 0.636 & 0.055 & 0.021 & 2.56 \\
& ATT & 0.691 & 0.646 & 0.045 & 0.029 & 1.55 \\
Self-Assessment & Unmatched & 0.733 & 0.614 & 0.119 & 0.021 & 5.6 \\
& ATT & 0.733 & 0.663 & 0.07 & 0.029 & $2.43^{* * *}$ \\
CSI (continuous) & Unmatched & 2.825 & 2.823 & 0.002 & 0.296 & 0.01 \\
& ATT & 2.825 & 2.224 & 0.601 & 0.401 & 1.5 \\
CSI (dummy) & Unmatched & 0.683 & 0.748 & -0.065 & 0.02 & -3.21 \\
& ATT & 0.683 & 0.77 & -0.087 & 0.027 & $-3.18^{* * *}$ \\
\hline
\end{tabular}

Source: Authors' calculations based on LSMS data (2019)

\subsubsection{Random Effects Logistic and GLS Results}

The results in table 2.4 show that proximity to an LSLI increases the probability of being food secure, and this result holds for the measures of Food Intake, Self-Assessment, and kcal per day.per adult. This result is largely in line with the results of the PSM model.

To quantify the effect of LSLIs on food security, we estimate a model presented in Table 2-4. The key variable in this model is the dummy variable treatment, which equals one for households close to an LSLI (i.e., located less than 150 kilometers from an LSLI) and zero otherwise. The treatment variable may not directly increase or reduce food security. Hence, to get more interesting results of interdependencies between treatment and other policy-relevant variables, we interact this variable with the distance to road and market. We chose these interaction terms because of their policy relevance and possible interactions with LSLI. The interaction terms show whether the treatment effects vary by an increase or decrease in distance to roads and markets.

To quantify the effect of the proximity of a household to an LSLI on a household's food intake, we calculate two counterfactuals: the predicted amount of kilocalories for the treated households (we hold the control variables at their average values for the treated group) and nontreated households (this time holding the control variables at their average values for the nontreated group). If a parameter in Table 2-4 is non-significant at a level of more than $10 \%$, we set it to zero when calculating the counterfactuals (Appendix Table 2-I). The difference between 
the first and second counterfactual then gives the desired net effect, which we quantify to be $330.7 \mathrm{kcal} /$ day/adult.

Following the SLF, other factors that significantly affect households' food security are discussed next. Household natural capital assets land ownership, forest land, access to irrigation, and soil quality had a positive effect on household food intake. This result is supported by many findings in rural Ethiopia (Asefach and Nigatu, 2007; Bogale and Korf, 2007; Bogale and Shimelis, 2009; Christine et al., 2008; Devereux and Sussex, 2000; Feleke et al., 2005; Moreda, 2018). But forest land and irrigation access have negative effects in the SelfAssessment.

Among the human capital assets, the household head's education and gender have a positive effect on food security in CSI (dummy) and Self-Assessment. This is in line with Iftikhar and Mohamood (2017). The age of household head significantly reduces food security in SelfAssessment and CSI (dummy). This is in line with the findings of Sirajea and Bekeleb (2013). Household size has a significant negative effect on the probability of households' food security in all food security measures. Mannaf and Uddin (2012) and Onyango (2017) report similar findings.

Among physical capital, the number of livestock does not significantly affect households' food intake, although it reduces food intake. In CSI, livestock size significantly increases food insecurity. A study from Kenya also reported that households with more livestock are more food insecure (Amwata et al., 2016). As the distance to the major road increases, household food security significantly decreases except in CSI. Distance to the market did not have a significant effect on household food security except in interaction terms.

Financial assets have mixed effects on food security. Household income has a positive but small effect on food security in kilocalories per day. Contrary to expectation, credit use harms food security (Self-Assessment, CSI). A possible explanation may be that credit is taken especially by vulnerable households who want to cover immediate expenditure needs rather than using the loan for investments. Participation in the extension program (Institutions) has a significantly positive effect on household food intake. Finally, pursuing pure pastoralism as a livelihood strategy significantly impacts daily kcal food intake. This implies that pure pastoralists are more vulnerable to food insecurity than agropastoralists. 
Table 2-4. Random effect binary logit and GLS model results on the effect of LSLI on household food security

\begin{tabular}{|c|c|c|c|c|c|c|}
\hline & VARIABLES $^{7}$ & Kcal/day/adult & FI & SA & CSI (dummy) & CSI \\
\hline \multicolumn{7}{|l|}{ Treatment } \\
\hline \multirow[t]{5}{*}{ variable } & TREATMENT & $849.399 * * *$ & $1.110 * * *$ & $1.207 * * *$ & -0.315 & -0.118 \\
\hline & & $(167.872)$ & $(0.232)$ & $(0.293)$ & $(0.515)$ & $(0.698)$ \\
\hline & LAND_own & $90.173 * * *$ & $0.227 * * *$ & $0.107^{*}$ & $0.409 * * *$ & $-0.292 * * *$ \\
\hline & & $(29.75)$ & $(0.054)$ & $(0.056)$ & $(0.107)$ & $(0.103)$ \\
\hline & IRRIGATE & $236.844 *$ & 0.281 & $-0.538 * *$ & $-0.711 * *$ & 0.466 \\
\hline \multirow{7}{*}{$\begin{array}{l}\text { Natural } \\
\text { capital }\end{array}$} & & (141.897) & $(0.196)$ & $(0.226)$ & $(0.342)$ & $(0.511)$ \\
\hline & FOREST & $5.821 * *$ & 0.002 & $-0.014 * * *$ & 0.006 & 0.011 \\
\hline & & $(2.77)$ & $(0.004)$ & $(0.004)$ & $(0.006)$ & $(0.009)$ \\
\hline & SOIL_QUAL & $122.116^{* *}$ & -0.045 & $0.228 * *$ & 0.148 & -0.249 \\
\hline & & $(57.121)$ & $(0.077)$ & $(0.093)$ & $(0.14)$ & $(0.205)$ \\
\hline & AGE & 4.037 & 0.004 & $-0.022 * * *$ & $-0.018^{* *}$ & $0.028 * *$ \\
\hline & & $(2.81)$ & $(0.004)$ & $(0.005)$ & $(0.008)$ & $(0.011)$ \\
\hline \multirow{7}{*}{$\begin{array}{l}\text { Human } \\
\text { capital }\end{array}$} & GENDER & -10.221 & 0.071 & $0.357 * *$ & $0.627 * *$ & $-1.193 * * *$ \\
\hline & & $(104.795)$ & $(0.139)$ & $(0.17)$ & $(0.276)$ & $(0.401)$ \\
\hline & EDUCATION & -6.628 & 0.007 & $0.167 * * *$ & $0.105 * * *$ & $-0.128 * * *$ \\
\hline & & $(12.536)$ & $(0.017)$ & $(0.027)$ & $(0.037)$ & $(0.048)$ \\
\hline & HH_size & $-179.603 * * *$ & $-0.133 * * *$ & $-0.062 * *$ & $-0.084 *$ & 0.082 \\
\hline & & $(16.617)$ & $(0.022)$ & $(0.027)$ & $(0.045)$ & $(0.063)$ \\
\hline & LIVESTOCK & -1.878 & 0.006 & -0.001 & -0.011 & $0.031^{* *}$ \\
\hline \multirow{5}{*}{$\begin{array}{l}\text { Physical } \\
\text { capital }\end{array}$} & & $(4.472)$ & $(0.006)$ & $(0.007)$ & $(0.01)$ & $(0.015)$ \\
\hline & MARKET_km & 1.449 & 0.001 & 0.0001 & 0.0001 & 0.004 \\
\hline & & $(0.983)$ & $(0.001)$ & $(0.002)$ & $(0.003)$ & $(0.004)$ \\
\hline & ROAD_km & $-2.957 *$ & $-0.004 *$ & $-0.005^{* *}$ & $0.019 * * *$ & $-0.018 * * *$ \\
\hline & & $(1.533)$ & $(0.002)$ & $(0.002)$ & $(0.006)$ & $(0.006)$ \\
\hline \multirow{4}{*}{$\begin{array}{l}\text { Financial } \\
\text { capital }\end{array}$} & CREDIT & -41.066 & -0.222 & $-0.637 * * *$ & -0.356 & $0.725 * *$ \\
\hline & & $(101.925)$ & $(0.139)$ & $(0.158)$ & $(0.217)$ & $(0.338)$ \\
\hline & INCOME & $0.012 * *$ & 0.000 & 0.000 & 0.000 & 0.000 \\
\hline & & $(0.005)$ & $(0.000)$ & $(0.000)$ & $(0.000)$ & $(0.000)$ \\
\hline \multirow[t]{2}{*}{ Social capital } & GIFTS & -151.052 & -0.159 & 0.062 & -0.227 & -0.205 \\
\hline & & (127.929) & $(0.175)$ & $(0.198)$ & $(0.296)$ & $(0.431)$ \\
\hline \multirow[t]{2}{*}{ Institutional } & EXTENSION & $338.509 * * *$ & $0.486^{* * *}$ & -0.029 & -0.155 & 0.072 \\
\hline & & (117.485) & $(0.173)$ & $(0.195)$ & $(0.292)$ & $(0.414)$ \\
\hline \multirow[t]{2}{*}{ Context } & DROUGHT & 111.367 & -0.039 & 0.078 & -0.233 & -0.209 \\
\hline & & $(93.272)$ & $(0.125)$ & $(0.152)$ & $(0.24)$ & $(0.346)$ \\
\hline
\end{tabular}

\footnotetext{
${ }^{7}$ Variables with positive coefficients enhance food security, while variables with negative coefficients worsen it.
} 
Chapter 2

\begin{tabular}{lllllll}
\hline LH strategies & LIVELIHOOD & $-334.428^{* * *}$ & $-0.231^{*}$ & -0.267 & 0.106 & 0.412 \\
& & $(105.364)$ & $(0.139)$ & $(0.169)$ & $(0.253)$ & $(0.378)$ \\
\hline \multirow{2}{*}{ Interactions } & TREATMENT* & & & & & 0.009 \\
& ROAD_km & $-8.196^{*}$ & $-0.016^{* * *}$ & 0.001 & $0.035^{* *}$ & $(0.018)$ \\
& TREATMENT* & $(4.611)$ & $(0.006)$ & $(0.008)$ & $(0.016)$ & 0.002 \\
& MARKET_km & $-6.860^{* * *}$ & $-0.009^{* * *}$ & $-0.009^{* * *}$ & -0.007 & $(0.006)$ \\
& & $(1.482)$ & $(0.002)$ & $(0.003)$ & $(0.005)$ & $2.759 * *$ \\
& Constant & $3,707.708^{* * *}$ & $1.534 * * *$ & $1.338^{* *}$ & $2.319 * * *$ & $(1.192)$
\end{tabular}

Observations $=2,106$, Standard errors in parentheses, $* * * \mathrm{p}<0.01, * * \mathrm{p}<0.05,{ }^{*} \mathrm{p}<0.1$

Source: Authors' calculations based on LSMS data (2019) 


\subsection{Discussion}

This study has investigated the impact of proximity to LSLI on food security of agropastoral households in Ethiopia. We found that proximity to LSLI positively influences household food security in all measurement methods except CSI. The average treatment on the treated of propensity score estimation revealed that proximity to LSLI increases food intake by up to 745 kcal per day per adult. This implies that food availability and utilization increase by proximity to LSLI. The random model interaction effect of proximity to LSLI with distance to road and markets shows that the treated households have obtained $330.7 \mathrm{kcal} /$ day/adult extra compared to the non-treated ones. The effect of proximity to LSLI decreases with increasing access to roads and markets. This is because treated households have more access to roads and markets than control households. We do not find proximity to LSLI, particularly sugar plantations to harm household food intake as it has been claimed by different authors in Ethiopia (Dheressa, 2013; Moreda, 2017; Shete and Rutten, 2015) at least by two food security indicators out of three (Self-Assessment \& Food Intake). On the contrary, the CSI method does not indicate a significant effect of treatment on household food security when interaction terms are included. The differences in the effect between CSI and other food security measures can be expected since the indicators measure different dimensions of food security. In particular, the likelihood of misconception of households while responding to coping strategies questions is expected (Hoddinott, 1999; Maxwell et al., 2014).

Once we make sure that LSLIs have a significantly positive effect on the household food security at least by two food security measures, now the most appealing question is, "what are the channels of the effect of LSLI on food security?" There are no specific data in the LSMS on LSLI and their effect on local communities to answer this question. The only incomplete data we have in LSMS is employment opportunities of households in different enterprises (including LSLIs). We found that only fewer than 5\% of agropastoral households were employed in different enterprises during the study periods. In this regard, we suggest that the effects of LSLI on the employment of the agropastoral communities need to be assessed separately. Recent studies suggest that technology transfer from LSLI to the community did not happen in Ethiopia (Moreda, 2018). In pastoral areas, we also expect that there could be no or little technology transfer due to the mismatch between the types of LSLIs that are entirely cropbased (cotton, and sugar cane) whilst the dominant livelihood of rural communities is livestockbased. 
As we cannot rule out whether the increase in food intake for treated households is driven by LSLI or not, our average treatment on the treated result should be interpreted cautiously. The fact that the proximity to LSLI affects food security positively does not necessarily mean households have benefited from the presence of LSLIs. To understand the potential effects of an LSLI on the host community, we run an interaction effect of the treatment variable with road and market access. The finding shows that the effect of proximity to LSLI varies by households' proximity to roads and markets. We also interpret the result in association with significant confounding variables from our regression. Land ownership, forest, and soil quality positively impact Food Intake. In Ethiopia, LSLIs are also located in areas with rivers and rich alluvial soils (Lay et al., 2018; Nicol and Otulana, 2014). Variation in natural resource availability could also influence household food security (Onyango, 2017). Therefore, households proximate to LSLI may benefit from the availability of natural resources.

Another unexpected finding was the non-significant effect of the treatment effect of proximity to LSLI on food security in CSI. The result displays, as expected, the CSI and kcal per day are negatively correlated, which means as CSI increases, kilocalories per day decrease. The CSI and Food Intake correctly classify $66.1 \%$ of the food secure as food secure and $35.4 \%$ of the food insecure as food insecure. Increased reliance on coping strategies, in this case, is associated with lower food availability (Hoddinott, 1999).

Among control variables according to the SLF, the variables associated with high food insecurity were household size, credit use, and livelihood strategies (pursuing pure pastoralism), while land owned, soil quality, forest, proximity to market, and income enhance food intake. Therefore, family planning practices and livelihood diversification strategies need to be introduced into agropastoral regions. There are some unintended results, irrigation access (Self-Assessment), credit, and livestock (kcal per day). Households' access to irrigation water does not show the expected sign in Self-Assessment and Coping strategies methods. Two reasons could cause this. First, the proportion of households with access to irrigation is very small (9\%), which may bring unintended results. Second, the diet of agropastoralists is mainly based on milk and cereals. Once they start using irrigation for vegetable production, they may earn more income from selling vegetables. However, the income may not go back to improve household consumption. Access to irrigation may not affect the food situation directly (Christine et al., 2008).

Similarly, livestock and social capital variables (receiving cash and in-kind gifts) have no significant effect on household food security. In food intake, livestock size has an adverse effect on food security; however, it has no significant effect. These results have been confirmed by 
different authors in Africa (Amwata et al., 2016; Little et al., 2008; Mayanja et al., 2015). The probable justification was agropastoralists close to LSLI keep a small number of livestock as livestock size declines due to sugar plantations (Ibrahim, 2016; Shete and Rutten, 2015). Although they keep small livestock, they have relatively better access to pasture and water than do remote resource-scarce areas (Sirajea and Bekeleb, 2013).

\subsection{Conclusion and Policy Implications}

The finding of the study indicates that $32 \%$ of agropastoral households in Ethiopia suffer from food insecurity. Food insecurity problems vary from region to region, with the most pastoral regions having more food insecurity than agropastoral areas. The finding attests that proximity to an LSLI is associated with better food consumption. The interaction effect of proximity to LSLI with proximity to road and market increases household food intake. Hence, the treatment effect of proximity to LSLIs lowers with better access to roads and markets. However, we argue the food intake of agropastoralists close to LSLIs is increased not necessarily because of the direct benefits from LSLIs but because the LSLIs are in areas with relatively fertile land and rivers. On the other hand, proximity to LSLI did not reduce the coping strategies index of sample households.

The effect of LSLIs in employment generation and technology transfer is one of the debated issues. Past studies confirm no substantial employment and technology transfer from LSLIs to the host communities in Ethiopia. This is because of the mismatch between pastoralists' experience and skill and the types of investments (e.g., sugar farming is different from livestock herding). Future LSLIs in rural areas need to consider the importance of linking their business to the livestock sector to realize technology exchange between the LSLIs and the community. This study shows that less than $5 \%$ of the employment comes from non-farm enterprises, among which the share of LSLIs was small. However, this should by no means be taken as conclusive, rather should be the focus of future studies. LSLIs can be a vital source of economic growth in Ethiopia. However, it should be practiced responsibly so that adequate compensation, technology transfer, and employment opportunity are ensured for the host community. Hence, we suggest that policymakers release policies that guide LSLIs to relate their investments to the livelihoods of the host communities and help them achieve food security. Such actions will also help the sustainability and success of the LSLIs as it minimizes the conflicts that arise over land use. Further research could be done to explore the linkage between LSLI local employment and 
livestock productivity in an agropastoral context. Finally, policymakers must note that food security is a complex issue that cannot be caused and solved by a single factor.

\subsection{Appendices}

Appendix Table 2-A. Logistic regression of factors affecting the probability of treatment

\begin{tabular}{|c|c|c|}
\hline VARIABLES & Coef. & Stad. Err \\
\hline LAND_own & 0.027 & 0.079 \\
\hline IRRIGATE & 0.229 & 0.357 \\
\hline FOREST & $-0.032 * * *$ & 0.008 \\
\hline SOIL_QUAL & 0.194 & 0.135 \\
\hline AGE & -0.007 & 0.006 \\
\hline GENDER & 0.018 & 0.241 \\
\hline EDUCATION & 0.024 & 0.03 \\
\hline HH_size & 0.049 & 0.037 \\
\hline LIVESTOCK & $-0.04 * *$ & 0.016 \\
\hline MARKET_km & $-0.005^{* * *}$ & 0.002 \\
\hline ROAD_km & $-0.016 * * *$ & 0.005 \\
\hline INCOME & $-0.00005 * *$ & 0.00002 \\
\hline EXTENSION & $1.23 * * *$ & 0.286 \\
\hline DROUGHT & $2.127 * * *$ & 0.196 \\
\hline LIVELIHOOD & 0.13 & 0.247 \\
\hline Constant & -0.71 & 0.482 \\
\hline Number of obs & 713 & \\
\hline LR chi2(15) & $=224.57$ & \\
\hline Prob $>$ chi 2 & $=0.000$ & \\
\hline Pseudo R2 & $=0.238$ & \\
\hline Log likelihood & $=-358.70319$ & \\
\hline
\end{tabular}


Appendix Table 2-B. Selection of matching algorithm

\begin{tabular}{lllll}
\hline Caliper & $\begin{array}{l}\text { Number of } \\
\text { insignificant } \\
\text { variables }\end{array}$ & $\begin{array}{l}\text { Psudo } \\
\mathrm{R}^{2}\end{array}$ & $\begin{array}{l}\text { Sample } \\
\text { matched }\end{array}$ & $\begin{array}{l}\text { Mean } \\
\text { Bias }\end{array}$ \\
\hline Caliper (Radius 0.03) & 11 & 0.010 & 1463 & 4.1 \\
Caliper (Radius 0.06) & 11 & 0.020 & 1,463 & 5.9 \\
Caliper (Radius 0.08) & 10 & 0.023 & 1,464 & 5.8 \\
Caliper (Radius 0.1) & 11 & 0.026 & 1,464 & 6.3 \\
\hline Nearest neighbor without & 10 & 0.015 & 2033 & 4.4 \\
replacement & & & & \\
Nearest neighbor with & 8 & 0.011 & 2033 & 4.8 \\
replacement & & & & \\
\hline Kernel (bandwidth 0.01) & 8 & 0.004 & 2033 & 2.7 \\
Kernel (bandwidth 0.08) & 9 & 0.005 & 2033 & 2.6 \\
Kernel (bandwidth 0.1) & 9 & 0.004 & 2033 & 2.7 \\
Kernel (bandwidth 0.25) & 9 & 0.014 & 2033 & 5.1 \\
\hline
\end{tabular}


Chapter 2

Appendix Table 2-C. Matching quality of the propensity score matching

\begin{tabular}{lllllllllr}
\hline Sample & Ps R2 & LR chi2 & $\mathrm{p}>$ chi2 & Mean Bias & Med Bias & B & \multicolumn{2}{c}{ R } & \%ar \\
\hline Unmatched & 0.127 & 341.41 & 0.000 & 18.7 & 16.1 & $87.0^{*}$ & $0.49^{*}$ & 55 \\
Matched & 0.004 & 8.97 & 0.879 & 3.1 & 2.6 & 15.4 & 1.12 & 55 \\
\hline
\end{tabular}


Appendix Table 2-D. Test of covariate balancing for quality of propensity scores

\begin{tabular}{|c|c|c|c|c|c|c|}
\hline Variable & Sample & Treated & Controls & Difference & S.E. & T-stat \\
\hline \multirow[t]{2}{*}{ LAND_own } & Unmatched & 0.963 & 0.908 & 0.055 & 0.068 & 0.81 \\
\hline & ATT & 0.963 & 1.008 & -0.046 & 0.159 & -0.29 \\
\hline \multirow[t]{2}{*}{ IRRIGATE } & Unmatched & 0.117 & 0.080 & 0.037 & 0.013 & 2.8 \\
\hline & ATT & 0.113 & 0.095 & 0.018 & 0.022 & 0.82 \\
\hline \multirow[t]{2}{*}{ FOREST } & Unmatched & 7.558 & 10.095 & -2.537 & 0.657 & -3.86 \\
\hline & ATT & 8.369 & 8.149 & 0.219 & 0.759 & 0.29 \\
\hline \multirow[t]{2}{*}{ SOIL_QUAL } & Unmatched & 1.851 & 1.767 & 0.083 & 0.032 & 2.61 \\
\hline & ATT & 1.820 & 1.747 & 0.072 & 0.050 & 1.43 \\
\hline \multirow[t]{2}{*}{ AGE } & Unmatched & 44.283 & 45.799 & -1.516 & 0.697 & -2.17 \\
\hline & ATT & 46.015 & 44.000 & 2.015 & 1.076 & 1.87 \\
\hline \multirow[t]{2}{*}{ GENDER } & Unmatched & 0.783 & 0.772 & 0.011 & 0.019 & 0.6 \\
\hline & ATT & 0.794 & 0.771 & 0.023 & 0.030 & 0.78 \\
\hline \multirow[t]{2}{*}{ EDUCATION } & Unmatched & 1.789 & 1.567 & 0.223 & 0.156 & 1.43 \\
\hline & ATT & 1.789 & 2.291 & -0.501 & 0.510 & -0.98 \\
\hline \multirow[t]{2}{*}{ HH_size } & Unmatched & 5.125 & 5.313 & -0.189 & 0.122 & -1.55 \\
\hline & ATT & 5.186 & 5.265 & -0.080 & 0.204 & -0.39 \\
\hline \multirow[t]{2}{*}{ LIVESTOCK } & Unmatched & 5.068 & 7.234 & -2.166 & 0.411 & -5.27 \\
\hline & ATT & 4.539 & 4.737 & -0.198 & 0.422 & -0.47 \\
\hline \multirow[t]{2}{*}{ MARKET_km } & Unmatched & 72.012 & 94.466 & -22.454 & 3.084 & -7.28 \\
\hline & ATT & 83.571 & 87.847 & -4.276 & 4.706 & -0.91 \\
\hline \multirow[t]{2}{*}{ ROAD_km } & Unmatched & 15.447 & 28.418 & -12.971 & 1.675 & -7.74 \\
\hline & ATT & 15.447 & 15.894 & -0.446 & 2.538 & -0.18 \\
\hline \multirow[t]{2}{*}{ INCOME } & Unmatched & 4510.125 & 5753.367 & -1243.243 & 362.417 & -3.43 \\
\hline & ATT & 4632.412 & 5184.310 & -551.897 & 546.750 & -1.01 \\
\hline \multirow[t]{2}{*}{ EXTENSION } & Unmatched & 0.218 & 0.134 & 0.083 & 0.017 & 4.98 \\
\hline & ATT & 0.209 & 0.211 & -0.003 & 0.029 & -0.09 \\
\hline \multirow[t]{2}{*}{ DROUGHT } & Unmatched & 0.646 & 0.238 & 0.408 & 0.020 & 20.17 \\
\hline & ATT & 0.646 & 0.706 & -0.060 & 0.066 & -0.91 \\
\hline \multirow[t]{2}{*}{ LIVELIHOOD } & Unmatched & 0.227 & 0.230 & -0.003 & 0.019 & -0.17 \\
\hline & ATT & 0.201 & 0.175 & 0.026 & 0.028 & 0.92 \\
\hline
\end{tabular}

$\mathrm{U}$ and $\mathrm{M}$ indicates unmatched and matched $* * * \mathrm{p}<0.01, * * \mathrm{p}<0.05, * \mathrm{p}<0.1$ 
Appendix Table 2-E. The proportion of households utilizing coping strategies over the past 7 days

\begin{tabular}{lllll}
\hline & \multicolumn{1}{l}{2012} & 2014 & 2016 & Total \\
\cline { 2 - 5 } Universal Food Shortage Coping strategies & $\%$ & $\%$ & $\%$ & \\
\hline Rely on less preferred foods & 16.67 & 27.56 & 26.09 & 23.44 \\
Limit the variety of foods eaten & 14.73 & 21.91 & 25.32 & 20.65 \\
Limit portion size of the meal & 14.49 & 19.69 & 18.38 & 17.52 \\
Reduce the number of meals eaten in a day & 16.57 & 16.09 & 19.28 & 17.31 \\
Restrict consumption by adults & 8.08 & 8.46 & 13.62 & 10.05 \\
Borrow food or rely on help & 4.83 & 6.95 & 10.8 & 7.53 \\
Go a whole day and night without eating & 1.09 & 2.63 & 2.19 & 1.97 \\
\hline Total & 10.92 & 14,76 & 16,63 & 14.10 \\
\hline
\end{tabular}


Appendix Table 2-F. Summary statistics of the independent variables and expected sign

\begin{tabular}{|c|c|c|c|c|c|c|c|}
\hline SLF elements & Variable & Measurement & Mean/\% & Std. Dev. & Min & Max & Expected sign \\
\hline \multicolumn{8}{|l|}{ Treatment } \\
\hline \multirow[t]{2}{*}{ Variable } & LSLI_km & Kilometre (km) & 214.57 & 126.57 & 12 & 482 & \\
\hline & $<150 \mathrm{~km}$ & $\begin{array}{l}1 \text { if }<150 \mathrm{~km}, 0 \text {, } \\
\text { otherwise }\end{array}$ & 0.37 & 0.483 & 0 & 1 & \\
\hline \multirow[t]{8}{*}{ Natural } & LAND_own & Hectare & 0.935 & 1.501 & 0 & 26.2 & + \\
\hline & & 1 if access, 0 & & & & & \\
\hline & IRRIGATE & otherwise & 0.092 & 0.289 & 0 & 1 & + \\
\hline & FOREST & $\%$ & 9.214 & 14.604 & 0 & 95 & + \\
\hline & SOIL_QUAL & $1=$ Poor & 0.37 & 0.708 & 1 & 3 & + \\
\hline & & $2=$ Fair & 0.461 & & & & \\
\hline & & $3=$ Good & 0.169 & & & & \\
\hline & $\mathrm{AGE}$ & Years & 45.168 & 15.373 & 17 & 97 & + \\
\hline \multirow[t]{3}{*}{ Human } & GENDER & $(1=$ male, 0 Female $)$ & 0.775 & 0.418 & 0 & 1 & + \\
\hline & EDUCATION & Years of schooling & 1.668 & 3.475 & 0 & 17 & + \\
\hline & HH_size & Number & 5.237 & 2.681 & 1 & 15 & - \\
\hline \multirow[t]{4}{*}{ Physical } & LIVESTOCK & Tlu & 6.434 & 9.114 & 0 & 85.5 & + \\
\hline & MARKET_km & Kilometre & 86.068 & 68.893 & 0.5 & 283.3 & - \\
\hline & ROAD_km & Kilometre & 23.675 & 37.367 & 0 & 271 & - \\
\hline & & 1 if access, 0 & & & & & \\
\hline \multirow[t]{2}{*}{ Financial } & CREDIT & otherwise & 0.179 & 0.384 & 0 & 1 & + \\
\hline & INCOME & Ethiopian Birr & 5312.84 & 8016.68 & 0 & 75010 & + \\
\hline Social & GIFTS & 1 if yes, 0 otherwise & 0.101 & 0.301 & 0 & 1 & + \\
\hline
\end{tabular}

\begin{tabular}{llllllll}
\hline $\begin{array}{l}\text { Policies \& } \\
\text { Institutions }\end{array}$ & EXTENSION & 1 if yes, 0 otherwise & 0.1639 & 0.37 & 0 & 1 & + \\
\hline Context & DROUGHT & 1 if yes, 0 otherwise & 0.3933 & 0.489 & 0 & 1 & - \\
\hline $\begin{array}{l}\text { Livelihood } \\
\text { strategies }\end{array}$ & LIVELIHOOD & $\begin{array}{l}\text { otherwise } \\
\text { L for pastoral, } 0\end{array}$ & 0.2301 & 0.421 & 0 & 1 & -
\end{tabular}

Source: Authors' calculations based on LSMS data (2019) 
Appendix Table 2-G. Multicollinearity diagnostics

\begin{tabular}{lcccc}
\hline & VIF & SQRT VIF & Tolerance & R-squared \\
\hline LSLI_km & 1.46 & 1.21 & 0.685 & 0.315 \\
LAND_own & 1.25 & 1.12 & 0.797 & 0.203 \\
IRRIGATE & 1.07 & 1.04 & 0.931 & 0.069 \\
FOREST & 1.04 & 1.02 & 0.961 & 0.039 \\
SOIL_QUAL & 1.02 & 1.01 & 0.983 & 0.017 \\
AGE & 1.1 & 1.05 & 0.911 & 0.089 \\
GENDER & 1.14 & 1.07 & 0.874 & 0.126 \\
EDUCATION & 1.13 & 1.06 & 0.887 & 0.113 \\
HH_size & 1.2 & 1.1 & 0.834 & 0.167 \\
LIVESTOCK & 1.09 & 1.05 & 0.913 & 0.087 \\
MARKET_km & 1.35 & 1.16 & 0.739 & 0.261 \\
ROAD_km & 1.56 & 1.25 & 0.639 & 0.361 \\
CREDIT & 1.04 & 1.02 & 0.964 & 0.037 \\
INCOME & 1.11 & 1.05 & 0.900 & 0.100 \\
GIFTS & 1.01 & 1.01 & 0.986 & 0.014 \\
EXTENSION & 1.23 & 1.11 & 0.813 & 0.187 \\
DROUGHT & 1.25 & 1.12 & 0.799 & 0.201 \\
LIVELIHOOD & 1.23 & 1.11 & 0.816 & \\
\hline Mean VIF & 1.18 & & & 0.184 \\
\hline
\end{tabular}


Appendix Table 2-H. Breusch and Pagan Lagrangian multiplier test for random effects

\begin{tabular}{lll}
\hline & var & sd = sqrt(Var) \\
\hline Kcal per day & 3462476 & 1860.77 \\
$\mathrm{e}$ & 2726749 & 1651.29 \\
$\mathrm{u}$ & 361059.1 & 600.882 \\
& $\operatorname{chibar} 2(01)=$ & 14.85 \\
\hline Test: $\operatorname{Var}(\mathrm{u})=0$ & & $0.0001 * * *$ \\
Prob $>$ chibar2 $=$ & & \\
\hline
\end{tabular}




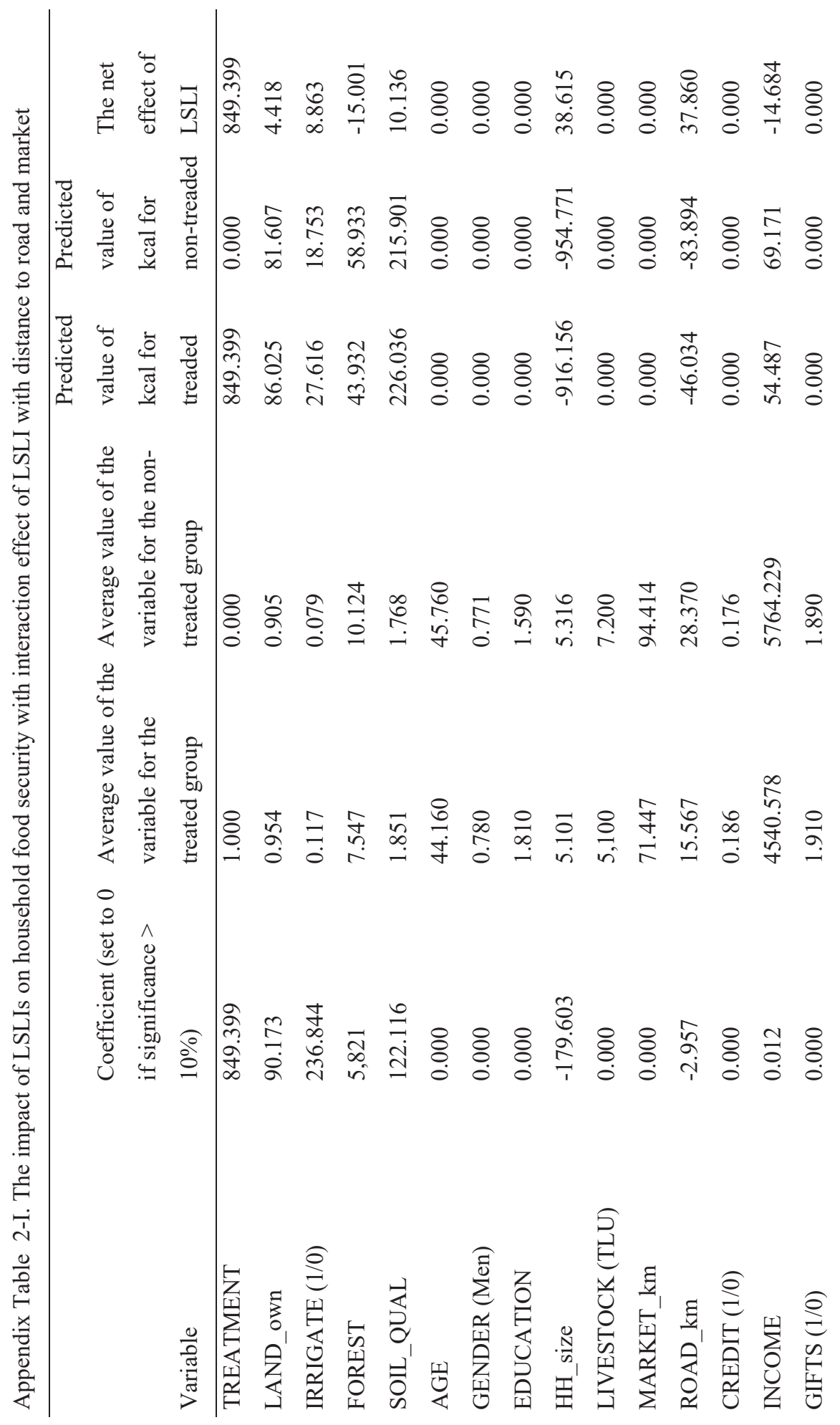




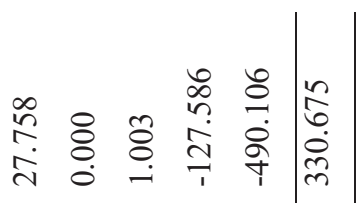

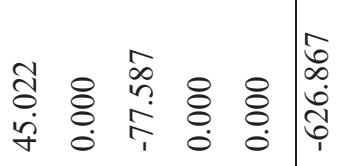

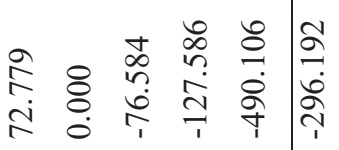

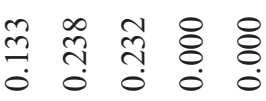

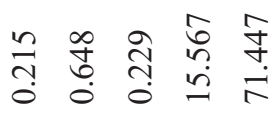

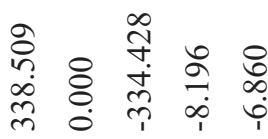




Appendix Figure 2-a. Distribution of propensity score between treatment and control groups

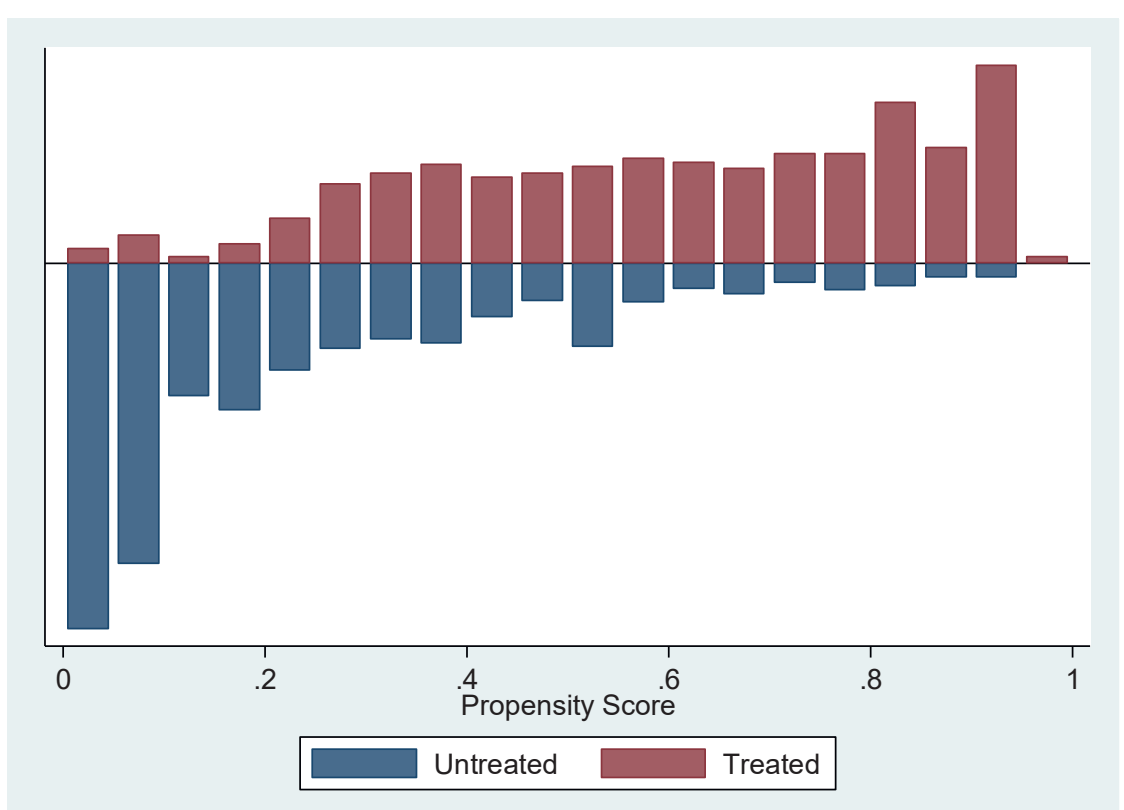

Appendix Figure 2-b. Normality of residuals

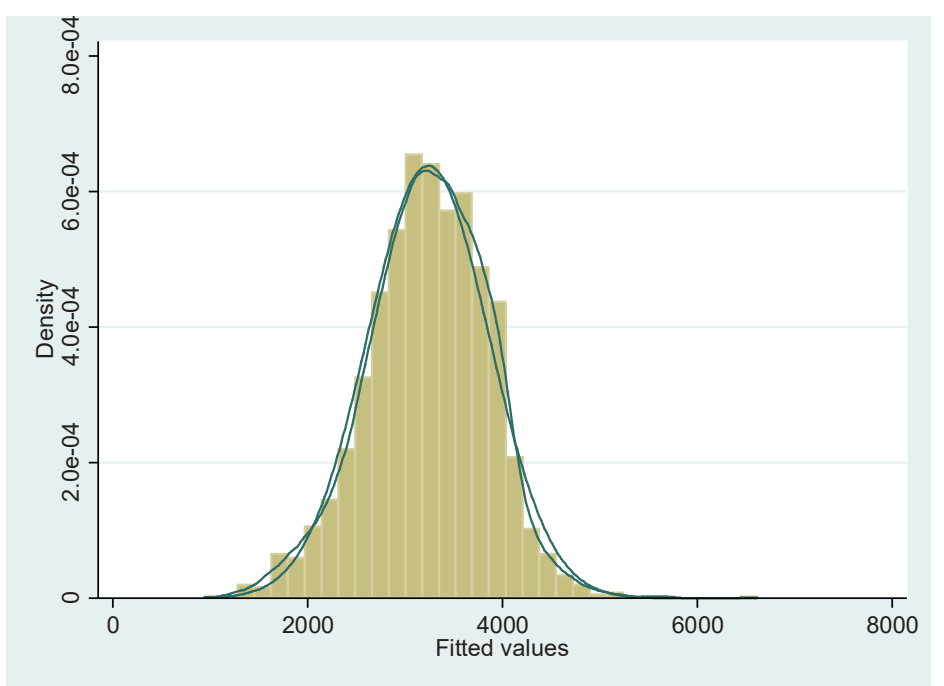


Chapter 3

Large-scale Land Investments, Household Displacement and the Effect on Land Degradation in Semiarid Agropastoral Areas of Ethiopia 
Chapter 3 


\title{
3 Large-scale Land Investments, Household Displacement and the Effect on Land Degradation in Semiarid Agropastoral Areas of Ethiopia ${ }^{8}$
}

\begin{abstract}
Agropastoral areas in Ethiopia have been targeted by large-scale land investments, particularly for the establishment of sugar plantations, since the 1970s. This has led to the displacement of local communities. We investigate the impact of this displacement due to large-scale land investment on land degradation in semiarid agropastoral areas in Ethiopia. We conducted a survey of 866 households in two agropastoral sites in Ethiopia in 2019, where extensive largescale land investment was implemented. We use an endogenous (switching) treatment model to assess the effect of the displacement of households on land degradation. The result shows that $75 \%$ of the surveyed households experienced moderate to severe land degradation. Forestlands and grasslands are ranked as the most degraded areas. About $43.7 \%$ of the households face a reduction in herd size and 55.8\% lost land due to large-scale land investment, while $86 \%$ of the households show a substantial decline in crops and livestock productivity due to land degradation. The results also reveal that the displacement of households leads to a significant increase in land degradation. Household exposure to drought and conflict, the number of livestock, overgrazing, and sharecropping are other drivers of land degradation. Market access, extension services, household income, and mobility, on the other hand, limit the occurrence of land degradation. We conclude that the shifts in property rights from common land used by pastoralists to private land in large-scale plantations aggravate land degradation in semiarid drylands.
\end{abstract}

Keywords: Displacement, drylands, grazing, land use, pastoralism, sugar plantation

\footnotetext{
${ }^{8}$ This chapter is based on the paper published as Bekele, A. E., Drabik, D., Dries, L., \& Heijman, W. (2021). Large-scale land investments, household displacement, and the effect on land degradation in semiarid agro-pastoral areas of Ethiopia. Land Degradation \& Development, 32(2), 777-791. https://doi.org/10.1002/ldr.3756.
} 


\subsection{Introduction}

Land is an essential resource for human existence, and the degradation of land brings severe challenges to the welfare of people. Land degradation is the reduction or loss of biological, economic productivity, and ecosystem services of land resources (Hugo, 2006; Sombroek and Sene, 1993; UNCCD, 1994). It is a negative trend in the land condition caused by direct or indirect human-induced processes (IPPC, 2019). In dryland areas, land degradation includes deterioration in the quantity, quality, and persistence of native pastures, associated with a loss of plant cover and invasion by shrubs of low pastoral value (Sombroek and Sene, 1993). Land degradation is the most serious problem in drylands and a major threat to the world's ability to achieve zero hunger (Nigussie et al., 2017; WASWA, 2012). It is severe in developing countries and particularly in Africa, where the economy is driven by land-based activities such as agriculture and pastoralism (Tilahun, 2015).

Approximately $30 \%$ of the global land area and $40 \%$ of land in developing countries is degraded, affecting 3.2 billion people globally (GEF, 2019; Nkonya et al., 2016). In drylands, $73 \%$ of the rangelands are affected by degradation (Sombroek and Sene, 1993). Globally, \$6.3 trillion worth of ecosystem services per year is lost due to land degradation (Sutton et al., 2016). The annual global cost of milk and meat production losses due to grassland degradation is about $\$ 7$ billion (Nkonya et al., 2016). About 65\% of Africa's agricultural land and one million square kilometers of land in Sub-Saharan Africa is degraded, while $43 \%$ is extreme deserts (Ioras et al., 2014; Kapalanga, 2008; Nana-Sinkam, 1995; Vlek, 2010). Land degradation is a serious global problem affecting livelihoods and sustainable development and has received attention globally. The Rio Summit in 1992 (UNCED, 1992) and the United Nations (UN) Convention to Combat Desertification in 1994 (UNCCD, 1994) set policies for combating land degradation. The UN Sustainable Development Goal (SDG) 15 emphasizes achieving a land degradation neutral world by 2030 (GEF, 2019).

Land degradation is an acute problem in Ethiopia (Bielli et al., 2001); 23\% of the land area in Ethiopia is degraded and $\mathbf{1 7 . 7 \%}$ is severely degraded (Gebreselassie et al., 2016; Sutton et al., 2016). Land degradation is of much concern as $85 \%$ of Ethiopians primarily depend on land (agriculture and pastoralism) for their livelihoods (Alemu et al., 2002) and a quarter of the population lives below the national poverty line (WDI, 2019).

Land degradation in drylands is, to a large extent, a natural process. However, land use changes by humans, and especially agricultural activities, aggravate land degradation (IPPC, 2019). Land use changes by industrial sugar plantations, which we refer to as large-scale land investments (LSLI) in this study, can modify natural habitats and land conditions by intensive 
use of water, agrochemicals discharge, runoff of polluted effluent, and air pollution (WWF, 2005). Moreover, in dryland pastoral areas, LSLIs have been primarily located on fertile and water-abundant lands leading to pasture scarcity and aggravation of land degradation.

The Ethiopian government initiated LSLIs in the 1970s. With the goal of development, the state captured large tracts of land, often with minimal consultation and compensation to the pastoral communities that resided on the land (Rettberg, 2010). This has led to the displacement of several pastoral communities. For instance, in the Afar pastoral region, over 400,000 hectares (ha) of land were taken in the last five decades for LSLIs, parks, and wildlife reserves (Mousseau and Martin-Prével, 2016). Since 2010, the Karrayyu and Afar agropastoralists in Fentale and Dubti have lost over 80,000 ha of pasture land due to sugar plantations (Rettberg, 2010). The LSLIs control fertile lands and large rivers that pass through the dryland regions. As a result, pastoralists have lost access to highly productive commons (pastures, water, and forests) that they have been using for centuries. This further increases the pressure on land resources.

Some reports claim that the introduction of LSLIs in the agropastoral areas of Ethiopia has harmed pastoral welfare and livestock productivity (Mekuyie et al., 2018a; Mousseau and Martin-Prével, 2016). However, these reports are mainly qualitative and largely ignore the potential land degradation effects of LSLIs. The majority of the existing studies in Ethiopia focus on land use and environmental changes (Berihun et al., 2019; Ibrahim, 2016; Meaza et al., 2019; Meaza et al., 2018; Nyssen et al., 2014; Tsegaye et al., 2010), land management (Chesterman et al., 2019; Shiferaw and Holden, 1998), and land tenure (Nega, 2003; Taddese, 2001). Furthermore, these studies have mainly been conducted in highland, non-pastoral areas. No studies have quantitatively investigated the impact of LSLI-induced displacement on land degradation in the agropastoral context. Also, the use of local pastoral knowledge in assessing land degradation has seen little application by scientists. Therefore, this paper investigates the effect of LSLI-induced displacement on land degradation from a community and household perspective. The study addresses the following specific research questions: (i) What is the impact of household displacement due to large-scale land investments on land degradation? (ii) What is the extent of land degradation among households that have been displaced by largescale land investments? (iii) What are the drivers of land degradation in agropastoral areas in Ethiopia that have been affected by large-scale land investments? 


\subsection{Material and Methods}

\subsubsection{Data and Sampling}

In 2019, we conducted a household survey in Fentale and Dubti agropastoral woredas ${ }^{9}$ located in Oromia and Afar states of Ethiopia. These woredas host the Metehara and Tendaho sugar plantations (Figure 3-1). The Metehara sugar plantation was established on 10,000 ha in the early 1970s and expanded by 20,000 ha leading to the establishment of the new Kesem sugar plantation in 2010. The Tendaho sugar plantation was established on 60,000 ha in 2014 . Both LSLIs have displaced people and restricted access to dry season grazing.

We applied a two-stage stratified random sampling method in which we first selected the two woredas purposively for the presence of LSLI, and then we identified four kebeles, ${ }^{10}$ two adjacent kebeles, and two distant (out of five-kilometer radius to the LSLI). The sample was taken from the 2018 population of Fentale $(113,902)$ and Dubti $(102,936)$ (CSA, 2013b), by Yamane's formula (Yamane, 1973) at a 95\% confidence level, $\pm 5 \%$ precision, and $8 \%$ contingency. A sample of 440 households from Fentale and 430 households from Dubti was interviewed. After data screening, 866 households were included in the analysis.

We adopted the methodology for the local-level assessment of land degradation in drylands developed by the Food and Agriculture Organization of the United Nations (FAO) (Nachtergaele and Licona-Manzur, 2008). Following this methodology, we first conducted community focus group discussions (FGDs) before the formal survey. A total of 43 male and 16 female elders participated in eight FGDs. We conducted the FGDs to identify the major land use types, livelihood activities, and indicators, causes, and trends of land degradation over the last 30 years. We follow Nachtergaele and Licona-Manzur (2008) to rank indicators of the severity of land degradation as none, light, moderate, and severe. Based on Willemen et al. (2018), we identified 15 indicators of land degradation common to all kebeles of the study areas. Insights from the FGDs were used to develop the household survey. Apart from the indicators of land degradation, the questionnaire consists of household characteristics, socio-economic, institutional, and environmental factors.

\footnotetext{
${ }^{9}$ Woreda is the fourth administrative level in Ethiopia (Federal-Regional-Zonal-Woreda).

${ }^{10}$ Kebele is the fifth administrative level in Ethiopia (Federal-Regional-Zonal-Woreda-Kebele).
} 


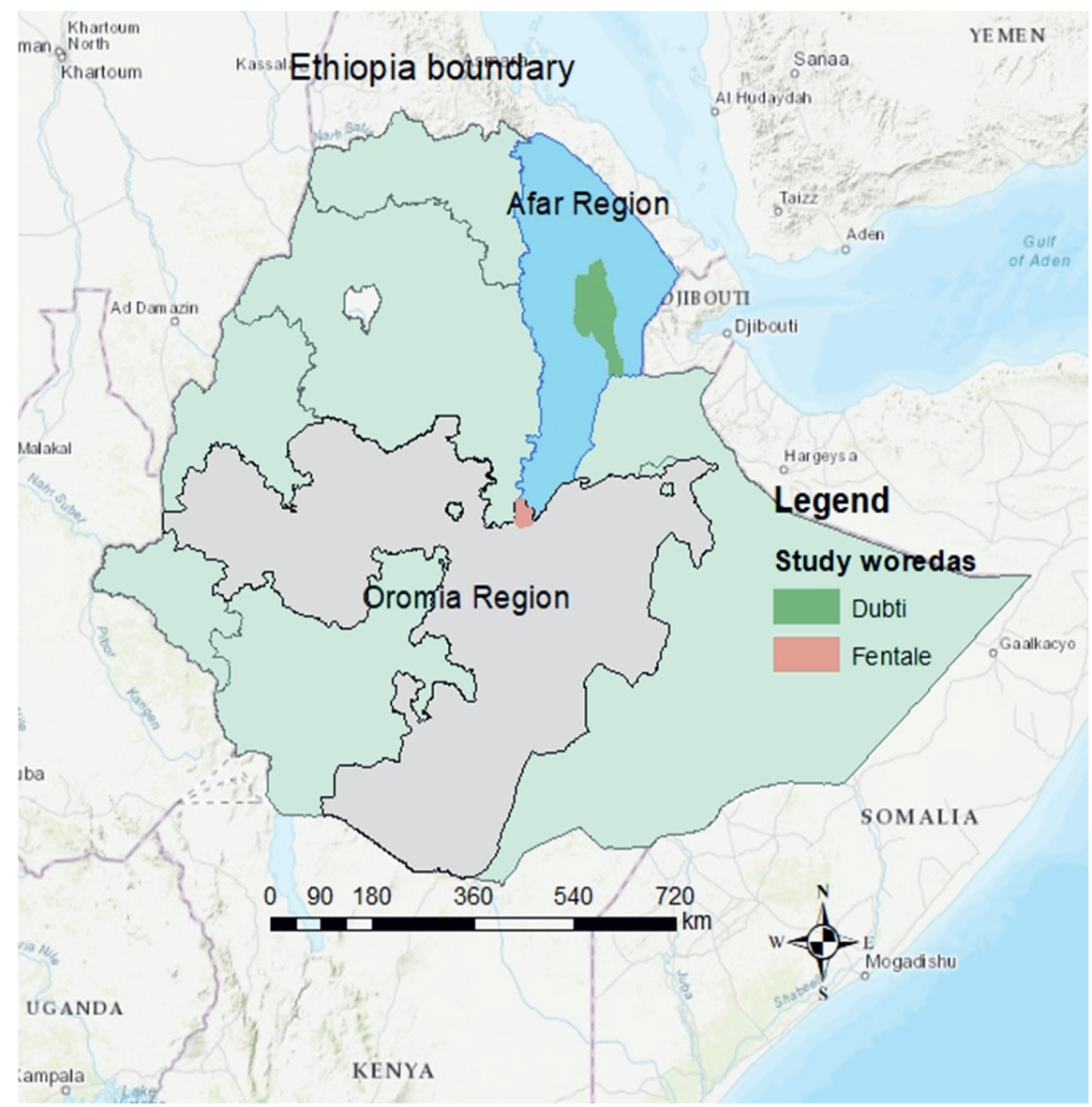

Figure 3-1. Map of the study areas 


\subsubsection{Conceptual and Empirical Models of the Study}

\section{A Conceptual Model}

Large-scale land investments have led to the displacement of pastoral communities, limiting their access to common property resources (grazing, forests, and water) from which the community previously derived their livelihood (Rettberg, 2010). They deprive the customary land rights of the pastoral communities who used the areas as dry season grazing (Ibrahim, 2016). Displaced communities may end up landless or lose entitlements to dry season grazing. Hence the loss of access to common property resources by displaced people increases pressure on forest lands, rivers, and grasslands, negatively affecting their ecological resilience (Terminski, 2013). While pastoral production systems require mobility for access to grazing and water, LSLIs restrict access to dry season grazing by blocking paths to water and pasture (Mousseau and Martin-Prével, 2016). As a result, livestock overgrazes sparse grazing land leading to more land degradation (Mousseau and Martin-Prével, 2016). The denial of grazing land forces the displaced people to destroy natural resources for survival (charcoal and firewood selling) and over-exploitation of the remaining grazing areas (Fernandes, 2001; Terminski, 2013). Hence, displacement leads to natural resources degradation. Figure 3-2 illustrates how land degradation is caused by displacement ${ }^{11}$ via loss of access to common resources and overgrazing. Other factors, such as household and farm characteristics, socio-economic, institutional, and environmental factors also influence land degradation (Berry, 2003; Kertész, 2009; Young, 1994).

\footnotetext{
11 The concept of displacement is adopted from Bartolome, et al., (2000) and refers to the alienation of the individual and community customary rights and permanent dislocation of the social and economic organisation. The displacement is induced by policy (in our case, LSLIs). The dislocation of people from their homeland territory without social support in the new place of residence is a violation of the most fundamental human rights.
} 


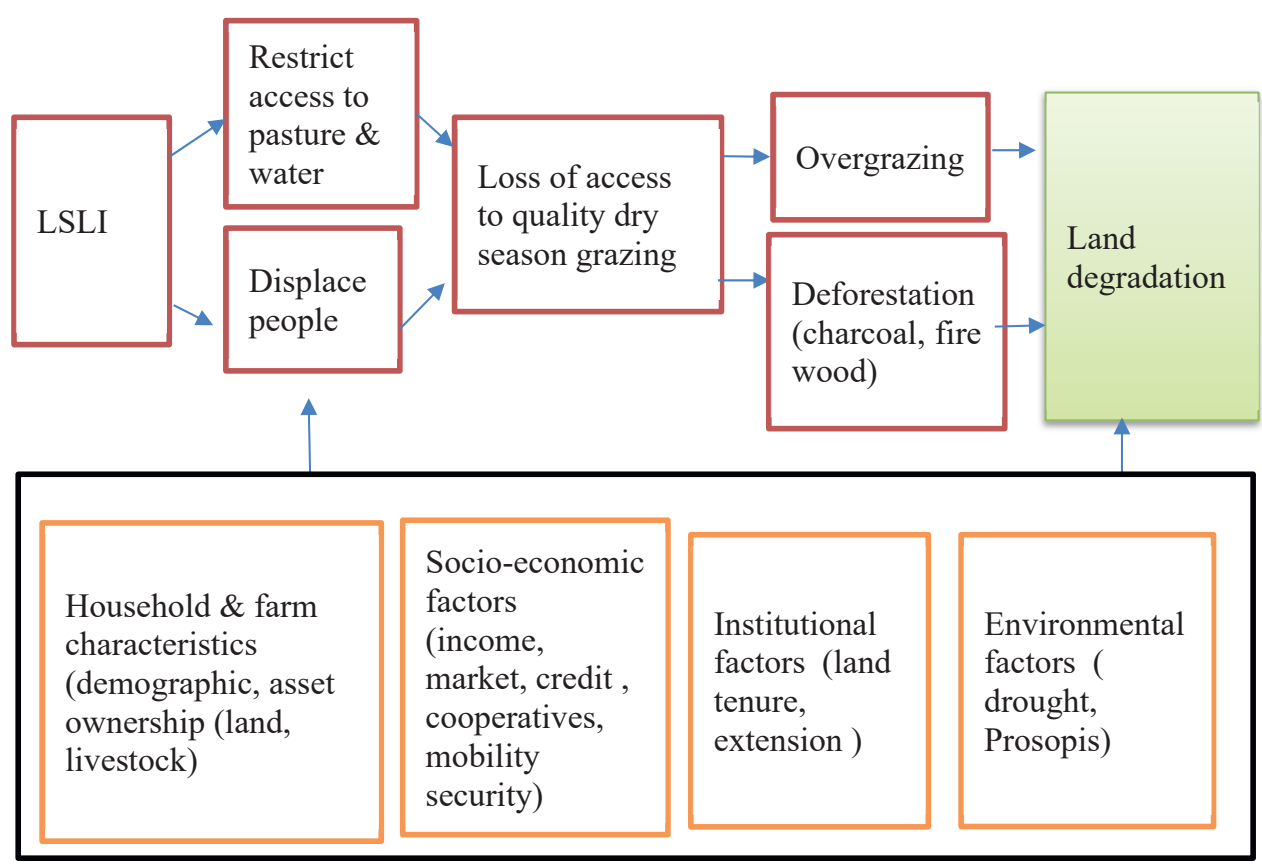

Figure 3-2. Conceptual model of the study

Source: Authors' design

\section{Econometric Model}

In observational studies where there is no baseline information available, quasi-experimental designs such as matching techniques, instrumental variables, endogenous (switching) treatment, and inverse probability weighting methods can be applied (Baker, 2000). The appropriate method depends on the nature of the selection process. In our case, the displacement of households is non-random, and not all agropastoralists are exposed to the treatment of displacement leading to selection bias. Those households living in areas with good soil and water are likely to be more vulnerable to displacement because LSLIs have been located on good quality land (Lay et al., 2018). As a result, unobserved factors that drive LSLIs and hence displacement may also affect land degradation (simultaneity) and therefore, displacement is considered to be endogenous. To address this endogeneity problem, we adopt an endogenous (switching) treatment regression model (Maddala, 1983). The endogenous treatment regression model (ETRM) uses a linear model for the outcome and a constrained normal distribution to model the deviation from the conditional independence assumption imposed. The endogenous switching regression model (ESRM) accounts for observed and unobserved bias by estimating 
a simultaneous equation model (Lokshin and Sajaia, 2004). The ETRM is nested in ESRM and is widely applied in the analysis of the welfare impact of policies and technology adoption (Adebayo et al., 2018; Adego et al., 2019; Adela and Aurbacher, 2018; Heckman et al., 2003; Mekonnen, 2017). Other relevant studies have applied ESRM to analyze the effect of land use changes on water quality (Abildtrup et al., 2015), the effect of a large dam on agricultural production (Chen et al., 2018), the effect of climate exposure on afforestation (Oyekale and Oyekale, 2019), and the effect of forced displacement on income (Do Yun and Waldorf, 2016).

The specification ${ }^{12}$ of the endogenous switching regression model is as follows (Lokshin and Sajaia, 2004):

$$
\begin{gathered}
T_{i}=1 \text { if } \gamma Z_{i}+u_{i}>0 \\
T_{i}=0 \text { if } \gamma Z_{i}+u_{i} \leq 0 \\
Y_{1 i}=X_{i} \beta_{1}+\varepsilon_{1 i} \\
Y_{2 i}=X_{i} \beta_{2}+\varepsilon_{2 i},
\end{gathered}
$$

where, $T_{i}$ is the treatment of the $i$ th household, 1 , if displaced and 0 otherwise

$Y_{j i}$ is the land degradation index for household $i$ in treatment $j$

$Z_{i}$ is a vector of factors that influence the probability of the treatment ${ }^{13}$

$X_{i}$ is a vector of factors that influence the level of land degradation

$\beta_{1}, \beta_{2}$, and $\gamma$ are vectors of parameters, and $\varepsilon_{1}, \varepsilon_{2}$ and $u_{i}$ are the error terms (a trivariate normal distribution with mean vector zero and non-singular covariance matrix).

The average treatment effect of the treated (ATT) and the average treatment effect on controls (ATC) in a counterfactual framework can be defined as :

$$
\begin{aligned}
& A T T=E\left(Y_{1 i}-Y_{0 i} \mid T_{i}=1\right) \\
& A T C=E\left(Y_{1 i}-Y_{0 i} \mid T_{i}=0\right)
\end{aligned}
$$

\footnotetext{
${ }^{12}$ Without loss of generality we specify the models based on treatment effect literature, and we adopt a single equation for the ETRM and ESRM models (Heckman, et al., 2003; Lokshin, and Sajaia, 2004). The ETRM simultaneously estimate the treatment and outcome equation (equation 1 with bivariate endogeneity error terms correlations), while the ESRM estimate (equation $1 \& 2$ ) such as the treatment equation, the outcome equations on treated and the untreated with trivariate endogeneity error terms correlations.

${ }^{13}$ We include in the vector $Z_{i}$ some variables which do not belong to the vector $X_{i}$ to make the estimation more robust and improve identification. We recognize that some of the important determinants of the treatment are exogenous factors (policy decisions) and are difficult to obtain. Hence we use as exclusion restrictions, LSLI_km, MARKET_km, N_employed that affect the selection variable but not the outcome variables.
} 


\section{Dependent Variable}

Land degradation is complex, and there is no widely accepted measurement of land degradation (Dubovyk, 2017; IPPC, 2019). Generally, the use of multiple indicators for land degradation assessment is advised (Walpole, 1992). Following Walpole (1992) and Willemen et al. (2018) and the results of the FGDs in each kebele, we identify 15 local indicators of potential loss in land quality, namely soil loss (erosion), gullies, soil pollution, water pollution, salinity, loss of wildlife, forest loss, depletion of soil nutrients, landslides, dried up water bodies, lost wetlands, weed invasions (Prosopis ${ }^{14}$ ), pollution of the land and loss of soil dry matter. The majority of the indicators of land degradation that were identified by the community in our study were also reported in research in the Ethiopian rift valley areas (Meaza et al., 2017; Nyssen et al., 2014). In the survey, households rated each indicator as not visible, light, moderate, and severe on a 1-4 scale (see Appendix Table 3-A). We then constructed a land degradation index (LDI) for each household which is the average value of the 15 indicators and used this as the dependent variable in the model.

$$
L D I_{i}=\sum_{j=1}^{n}\left(I_{j}\right) / n
$$

where $\mathrm{I}$, is the value of each land degradation indicator, $i$ is a household, $j$ is the type of indicator, and $n$ is the total number of indicators.

\section{Independent Variables}

The main independent variable of interest is the displacement caused by LSLI. This variable measures whether a household was displaced from their land due to LSLI in the last 30 years or not. About $24.5 \%$ of the sample households were displaced because of LSLI in the last three decades. LSLIs locations are determined by land quality, water availability, and infrastructure (Lay et al., 2018). Hence, distance from LSLI (LSLI_km), and the number of family members employed in the formal sector (N_employed), which drive displacement, were used as exclusion criteria $^{15}$.

Table 3-1 displays all the independent variables with their descriptive statistics. The drivers of land degradation are derived from the literature (Berry, 2003; Kertész, 2009; Nyssen et al., 2014; Tsegaye et al., 2010; Vu et al., 2014; WASWA, 2012; Young, 1994). Resource access in developing countries is affected by household characteristics. Women play an important role in

\footnotetext{
${ }^{14}$ Prosopis was introduced into Ethiopia in the 1970 s as a soil conservation measure, with high drought tolerance. In Afar region the plant is now covering over 1.2 million hectares (FDRE, 2017).,

15 Exclusion criteria for treatment in ESRM are not strictly required for identification as the non-linearity assumption of the error term. We include them for a more robust estimation of the regression.
} 
land conservation (Jolejole-Foreman et al., 2012). Education increases farmers' ability to conserve land (Mango et al., 2017). Age of the household head and household size have been found to improve the adoption of land conservation practices and limit the occurrence of land degradation (Kirui and Mirzabaev, 2015). Population density leads to more land degradation in highland Ethiopia (Nyssen et al., 2014). Farm characteristics also influence land degradation (Kirui and Mirzabaev, 2015; Kosmas et al., 2016). The number of livestock may increase land degradation through the effect of overgrazing (Jolejole-Foreman et al., 2012). Cooperative membership helps households to share knowledge, labor, and skills and helps to acquire inputs to combat land degradation (Nkonya et al., 2016). Proximity to the market decreases the adoption of sustainable land management (Kirui and Mirzabaev, 2015). A higher income may help to invest in the sustainable use of land and the conservation of land. Hence, credit access can also contribute to reducing land degradation (Kirui and Mirzabaev, 2015). Mobility is a strategy for the efficient use of scarce pastures (Davies et al., 2016). Extension services can include training on the sustainable use of natural resources (Mango et al., 2017). Farmland tenure helps to combat land degradation (Kirui and Mirzabaev, 2015) because the security of land ownership provides incentives for sustainable land use (Nkonya et al., 2016). Finally, climate factors, such as rainfall and temperature, may also affect the extent of land degradation(Meaza et al., 2017; Meaza et al., 2018). To capture the effect of climate change, we include households' drought exposure. Drought indicates long dry seasons with the absence of rainfall and very high temperatures. Drought shocks are expected to lead to more land degradation (Ariti et al., 2018; Davies et al., 2016; Demeke et al., 2006). Pastoral live in conflict-prone areas because of the nature of mobility and conflict exposure is expected to increase land degradation. 


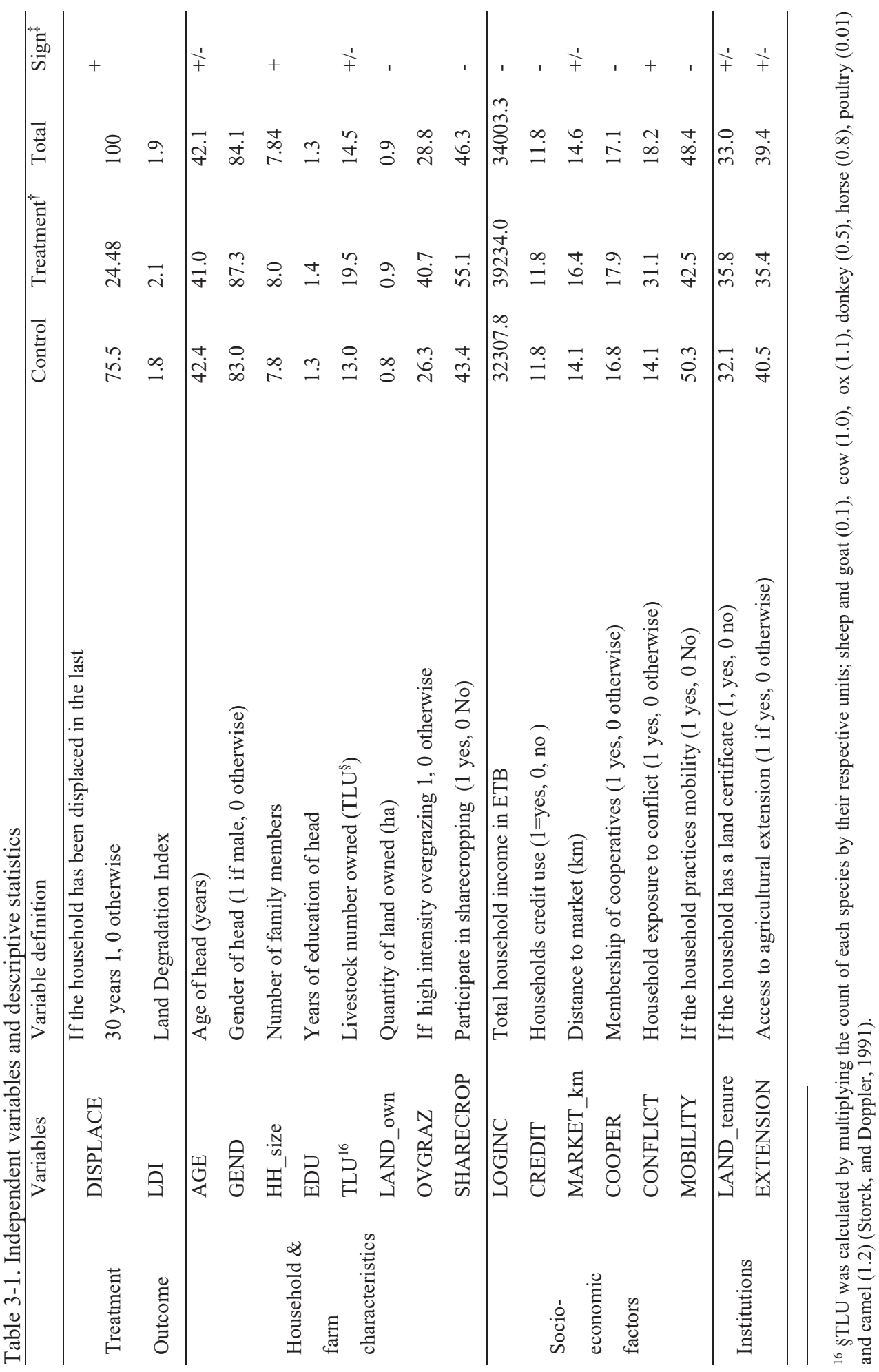









\subsection{Results}

\section{Perceived Impacts of Large-Scale Land Investments}

Table 3-2 compares the perceived impacts of LSLIs by displaced and control households. Over the last 30 years, $55.8 \%$ of households have lost, on average, 2.5 ha of private land due to an LSLI. The average area lost by the control households was 2.44 ha and 3.01 ha for displaced households. Particularly, over $90 \%$ of the displaced households report loss of access to grazing land, displacement of their close relatives during the same period, and deterioration of their livelihoods, while these shares were between $60 \%$ and $80 \%$ for the non-displaced group. Moreover, $57.5 \%$ of displaced and $43.7 \%$ of non-displaced respondents report an increasing trend of land use conflict and a reduction in herd size associated with an LSLI. Regarding the positive impacts of the LSLIs, we assess employment, training, and infrastructure development. The FGDs revealed that there are no efforts made by LSLIs to benefit the community. Consequently, we observe very low responses. $4.62 \%$ of the respondents report infrastructure development (roads, schools, and clinics), 2.32\% training, and $6.8 \%$ employment opportunities (as security guards). The average wage per day for daily laborers ranges between 37.5 to 50 Ethiopian birr, which was approximately 1.33-1.78 USD ${ }^{17}$ per day, below the absolute poverty line of 1.9 USD set by the world bank. Only less than $1 \%$ of the employees in the LSLI are from pastoral communities.

\footnotetext{
${ }^{17}$ In the survey year 2019, for January on average, one USD is equal to 28.11 Ethiopian Birrs.
} 
Table 3-2. Perceived negative impacts of large-scale land investment

\begin{tabular}{llll}
\hline & \multicolumn{3}{l}{ Household category } \\
\hline & Control & Displaced & Total \\
\hline Land lost (per household) (ha) & 2.4 & 3.0 & 2.5 \\
\hline Yes (\%) & & & \\
\hline Lost private land & 30.7 & 69.34 & 55.8 \\
Poverty increases & 71.9 & 87.3 & 75.6 \\
Lost grazing land & 78.0 & 93.9 & 81.9 \\
Conflict increases & 52.8 & 72.2 & 57.5 \\
Natural resources lost & 81.5 & 91.5 & 84.0 \\
Parents \& relatives displaced & 57.6 & 95.3 & 66.9 \\
Deterioration of livelihoods & 61.5 & 93.4 & 69.3 \\
Reduction in herd size & 41.3 & 50.9 & 43.7 \\
\hline
\end{tabular}

Source: Authors' survey (2019)

\section{Level and Causes of Land Degradation}

We asked respondents to rate the extent of land degradation for each land use type. About $89.8 \%$ of households have indicated light to severe levels of land degradation (aggregate average for all land uses). Out of this, $75.3 \%$ estimated a moderate to severe level of land degradation, while $14.5 \%$ and $10.2 \%$ report light or no degradation. Overall, $86.2 \%$ and $65.5 \%$ of the displaced and control households have reported moderate to severe land degradation, respectively (Table 3-3). Forestlands and grasslands were rated as the most severely degraded land use, followed by grazing land (areas grazed by livestock including grasslands and shrublands) and water resources. A higher proportion of the displaced households was affected by moderate/severe land degradation compared to control households. 
Table 3-3. The extent of land degradation by land use type (\%)

\begin{tabular}{|c|c|c|c|c|}
\hline & Level of degradation & Control & Displaced & Total \\
\hline \multirow[t]{3}{*}{ Farm land } & Invisible & 15.2 & 12.7 & 14.8 \\
\hline & Light & 23.9 & 11.3 & 21.7 \\
\hline & Moderate to severe & 60.9 & 76 & 63.5 \\
\hline \multirow[t]{3}{*}{ Grazing land } & Invisible & 10.6 & 14 & 11.2 \\
\hline & Light & 11.2 & 4 & 9.9 \\
\hline & Moderate to severe & 78.2 & 82 & 78.9 \\
\hline \multirow[t]{3}{*}{ Forest land } & Invisible & 6.0 & 1.33 & 5.2 \\
\hline & Light & 8.2 & 8 & 8.2 \\
\hline & Moderate to severe & 85.8 & 90.7 & 86.6 \\
\hline \multirow[t]{3}{*}{ Grassland } & Invisible & 7.4 & 7.3 & 7.4 \\
\hline & Light & 10.8 & 3.3 & 9.5 \\
\hline & Moderate to severe & 81.8 & 89.3 & 83.1 \\
\hline \multirow[t]{3}{*}{ Water bodies } & Invisible & 12.8 & 11.5 & 12.6 \\
\hline & Light & 23.8 & 19.6 & 23.1 \\
\hline & Moderate to severe & 63.4 & 68.9 & 64.4 \\
\hline \multirow[t]{3}{*}{ Aggregate } & Invisible & 13.2 & 5.3 & 10.2 \\
\hline & Light & 21.3 & 8.4 & 14.5 \\
\hline & Moderate to severe & 65.5 & 86.2 & 75.3 \\
\hline
\end{tabular}

Source: Authors' survey (2019)

Figure 3-3 shows pastoralists' perspectives on the causes of severe land degradation in the study areas. The proportion of households for each of the control, treated and total households were determined. Households identified severe drought (54.2\%), deforestation (52.7\%), and LSLI (47.3\%) as the main causes of severe land degradation. In Ethiopia, the incidence and length of severe drought periods have been increasing (Beyene, 2016). Drought is related to declining rainfall and rising temperatures. The average annual precipitation over the last 35 years declined by $17.7 \%$ in Fentale and $35.9 \%$ in Dubti, while the maximum temperature in Fentale rose by $1.85{ }^{\circ} \mathrm{C}$ and in Dubti by $5.5^{\circ} \mathrm{C}$ (Appendix Figures 3-a \& 3-b). Similar observations have been made for the rift valley areas of Ethiopia, with declining and erratic rainfalls (Meaza et al., 2017; Meaza et al., 2018). 
Next to droughts, deforestation is seen as a major cause of land degradation. In this respect, the respondents indicate LSLI (83\%), charcoal (57\%), and firewood collection (54\%) as the main drivers of deforestation. Charcoal production was introduced to the area by the highland labor migrants that were attracted by the LSLIs. Furthermore, LSLIs cleared natural vegetation and forests that had existed on the land before their establishment (Ibrahim, 2016).

Over a quarter of the respondents believe that population growth (human and livestock) drives land degradation. The human and livestock population grew rapidly in the region, by $3.2 \%$ and $1.5 \%$ per annum, respectively, while pastureland availability declined. The population of the study areas increased from approximately 54,056 in 1973 to 113,902 in 2018 and by $65.4 \%$ in Fentale and 90.4\% in Dubti, respectively. From 1995 to 2013, the cattle population grew by $41.2 \%$, sheep by $49.8 \%$, and goats by $58.6 \%$. As was found in other studies, population pressure is harming natural resources (Abate et al., 2010; Berry, 2003; Bielli et al., 2001; Nkonya et al., 2016; Nyssen et al., 2014) and negatively affecting the conservation practices in Ethiopia (Demeke et al., 2006; Shiferaw and Holden, 1998).

About $28.64 \%$ of households point to high-intensity overgrazing, contributing to land degradation. Less than $25 \%$ of households report the causes of severe land degradation to be wind and water erosion, over-cultivation, settlement, and poor irrigation practices. On average, displaced households give a higher weight to the different causes of land degradation than control households, except in the case of poor irrigation practices.



Figure 3-3. Perceived causes of severe land degradation

Authors' survey (2019) 
Figure 3-4 illustrates the perceived effects of land degradation on people's livelihoods by control, treated, and total household categories. More than $86 \%$ of the respondents associate land degradation with lower crop and livestock productivity. Moreover, $71.6 \%$ of households associate land degradation with increased death of livestock and $48.9 \%$ with crop failure. FGD participants explain this by the loss of access to common resources and the poor quality of the soil since LSLIs establishment. For instance, maize yield declined from 1.5 metric ton/ha to 0.7 metric ton/ha in Dubti following the establishment of the plantation (Planel and Labzaé, 2016). In the survey year, a household on average reported the death of 10 goats, six sheep, three cows, five oxen, four camels, two poultry, and two donkeys. This is in line with studies that show increasing livestock mortality in the region (Ariti et al., 2018; Ibrahim, 2016; Ioras et al., 2014). Similarly, milk production has been declining in the past 30 years for camels from 15 liters to less than two liters per day, for cows from ten liters to one liter per day, and goats from five liters to less than one liter per day. As a result, there is no or only a little surplus of milk to be marketed. $97.8 \%$ of the respondents claim that desertification has been rising.



Figure 3-4. Perceived effects of land degradation on livelihoods of agropastoralists Authors' survey (2019)

\section{Empirical Model Results}

Tables 3-4 and 3-5 show the ETRM model results and the average treatment effects of being displaced, and Appendix Table 3-B reports the ESRM regression results. The full information maximum likelihood jointly estimates the selection and treatment equations efficiently (Lokshin and Sajaia, 2004). For both ETRM and ESRM models, the Wald tests show that the 
regression models fit the data well. The likelihood-ratio test for independence of the treatment and outcome equations also suggests the rejection of the null hypothesis of no correlation between the treatment and outcome errors, indicating an endogeneity problem that should be solved. In ETRM, the correlation coefficients between the error terms of the displacement and land degradation equations are negative and significant. The significance and negative correlation between error terms respectively show the presence of a selection bias and unobservables that raise LDI while lowering displacement. In ESRM, the correlation coefficients between the treatment and outcome equation are both negative, but significant only for the correlation between the treatment and the control equations, suggesting that nondisplaced households have higher LDI than they would have if displaced.

The exclusion variables show a significant effect on the probability of treatment in ETRM, but not in ESRM. Accordingly, the number of employed family members (N_employed) significantly reduces the likelihood of being displaced. Whereas, distance from LSLI_km increases the likelihood of displacement. The ESRM result shows that the likelihood of displacement increases with the size of livestock, household income, distance from market, conflict, farmland tenure, and intensity of overgrazing. Conversely, extension access, herd mobility, head age, and conflict significantly reduce the likelihood of displacement. It should be noted that households with farmland tenure did not escape displacement.

The results show that displacement significantly increases the level of land degradation after controlling for unobserved factors. The estimated average treatment effect (ATE) ${ }^{18}$ of being displaced is 0.56 and 0.91 in ETRM and ESRM, respectively. This means that being displaced, on average, increases LDI by approximately 0.56 to 0.91 units per household. Also, control households would have a 0.47 higher LDI if they had been displaced. The heterogeneity effect is related to unobservable differences that could explain land degradation. The heterogeneity effect is negative, implying that the displacement effect is smaller for the displaced households compared to the control.

There are slight differences in terms of significant variables between ETRM and ESRM results. The ESRM provides significant variables separately for treated and control households. Accordingly, household income and market access reduce land degradation for both treated and control groups. For the treated households, the age of household head, size of land owned,

\footnotetext{
${ }^{18}$ We use etregress for ETRM and movestay for ESRM. Both models capture the treatment with high predictive power. The ATT in ETRM is lower than ESRM. This may be because the treatment effects from ETRM are constrained in the absence of interaction between treatment variable and covariates of the outcome variables (except for MARKET_km).
} 
access to credit, and market distance lower the degree of land degradation. Albeit, for control households, cooperative membership, mobility, and land tenure lower the degree of land degradation. Whereas, for both treated and control, sharecropping, conflict, and drought worsen land degradation. For treated households, the intensity of overgrazing worsens land degradation. For control households, the level of education of the household head (which is very low on average) does not help in reducing land degradation. Age and land size in ESRM, but not in ETRM, affect land degradation; households with older household heads and larger land sizes have lower land degradation.

In ETRM, apart from the household characteristics, several of the control variables have good statistical power. Livestock size (TLU) significantly has a worsening but small influence on land degradation, implying that the larger the livestock population, the more land degradation. Household income and distance to the market have a small effect but lead to significantly lower levels of land degradation. We find that cooperative membership leads to a lower level of land degradation. High-intensity overgrazing and sharecropping are associated with more land degradation. Farmland tenure security reduces land degradation. However, in practice, pastoralists are herders who move from place to place to optimize grazing availability. Thus, offering them a certificate for a plot is not compatible with their means of livelihood. Access to extension and mobility leads to a lower degree of land degradation. Exposure to drought and conflicts significantly increase land degradation. Moreover, a connection exists between the two. The burning of forests, crops, and grasslands occurs during severe conflicts. For example, the conflict of Afar and Issa contributed to the deterioration of the pasturelands (Said, 1994), as did the conflicts between the Karrayu and Argoba communities. 
Table 3-4. Endogenous treatment effect of displacement on land degradation

\begin{tabular}{|c|c|c|c|}
\hline & & Coef. & Std. Err. \\
\hline & TREATMENT & $0.564 * * *$ & 0.108 \\
\hline & AGE & -0.001 & 0.001 \\
\hline & GENDER & -0.030 & 0.037 \\
\hline & HH_size & 0.004 & 0.004 \\
\hline & EDU & $0.010^{*}$ & 0.005 \\
\hline Household \& & TLU & $0.003 * * *$ & 0.001 \\
\hline \multirow[t]{7}{*}{ Farm characteristics } & LAND_own & -0.019 & 0.018 \\
\hline & LOGINC & $-0.065 * * *$ & 0.012 \\
\hline & CREDIT & -0.057 & 0.041 \\
\hline & MARKET_km & $-0.009 * * *$ & 0.002 \\
\hline & COOPER & $-0.076^{* *}$ & 0.035 \\
\hline & OVGRAZ & $0.163 * * *$ & 0.030 \\
\hline & SHARCROP & $0.405 * * *$ & 0.031 \\
\hline Socio-economic & CONFLICT & $0.325 * * *$ & 0.037 \\
\hline \multirow[t]{2}{*}{ factors } & MOBILITY & $-0.075 * * *$ & 0.027 \\
\hline & LAND_tenure & $-0.120 * * *$ & 0.029 \\
\hline Institutional & EXTENSION & $-0.037 * *$ & 0.018 \\
\hline \multirow[t]{2}{*}{ Environmental } & DROUGHT & $0.287 * * *$ & 0.033 \\
\hline & cons & $2.224 * * *$ & 0.127 \\
\hline \multicolumn{4}{|l|}{ TREATMENT } \\
\hline \multirow{9}{*}{ Drivers of treatment } & MARKET_km & $0.017 * * *$ & 0.006 \\
\hline & N_employed & $-0.367 * * *$ & 0.109 \\
\hline & LSLI_km & $0.017 * * *$ & 0.008 \\
\hline & _cons & $-1.051 * * *$ & 0.118 \\
\hline & /athrho & $-0.584 * * *$ & 0.179 \\
\hline & /lnsigma & $-0.896 * * *$ & 0.049 \\
\hline & rho & -0.526 & 0.130 \\
\hline & sigma & 0.408 & 0.020 \\
\hline & lambda & -0.215 & 0.062 \\
\hline
\end{tabular}

Wald chi2(18)

$1090.03 * * *$

Log likelihood

$-851.701$ 
Observations

LR test of indep.

eqns. $($ rho $=0): \operatorname{chi} 2(1)=4.4 * *$

TREATMENT (1 displaced, 0 Control),

$* * *, * *, *$ respectively show the $1 \%, 5 \%$ and $10 \%$ significance levels

" +" signs of the coefficients show the variables that worsen land degradation, "-" signs of the variables that reduce land degradation.

Source: Authors' survey (2019)

Table 3-5. Treatment effects of displacement on land degradation (ESRM)

\begin{tabular}{llll}
\hline Treatment effects & Treated (1) & Control $(0)$ & $\begin{array}{l}\text { Heterogeniety } \\
\text { effect }\end{array}$ \\
\hline Treated (1) & $2.13(0.52)$ & $2.25(0.45)$ & -0.12 \\
Control (0) & $1.22(0.37)$ & $1.78(0.33)$ & -0.56 \\
ATT (ATC) & $0.91 * * *$ & $0.47 * * *$ & 0.44 \\
\hline
\end{tabular}

*** indicates $\mathrm{p}<0.01$, Standard deviations (in parentheses), ATT is the average treatment effect on treated and ATC is the average treatment effect on the control.

\subsection{Discussion}

Overall we find evidence that displacement due to LSLI increases the intensity of land degradation, causing the deterioration of livelihoods. The finding is in line with the observation that displacement is causing environmental degradation in Africa (Mohamed, 2016). Over 75\% of the respondents have encountered a moderate to severe level of land degradation. Displaced households, on average, have 0.56 to 0.91 units higher levels of land degradation compared to non-displaced households. Drought, deforestation and LSLI were seen by community members as the key drivers of land degradation. LSLI-induced displacement was also identified as a significant driver of land degradation in the econometric analysis.

Our findings of the drivers of land degradation are to a large extent in line with other studies on this topic. The main factors that we have identified to decrease land degradation are market access (Berry, 2003; Nkonya et al., 2016); household income (Bunning et al., 2011), cooperative memberships (Kirui and Mirzabaev, 2015), access to extension services (Qasim et al., 2011), livestock mobility (Butt, 2010; Said, 1994; Sonneveld et al., 2010) and farmland tenure security (Ariti et al., 2018; Kirui and Mirzabaev, 2015). Some of our findings contradict other studies' results. For instance, market access may lead to more exploitation of natural resources (Douglas, 2006; Mirzabaev et al., 2016). Factors that are found to increase land 
degradation are livestock population and overgrazing (Jolejole-Foreman et al., 2012), sharecropping (Coughlan et al., 2017), drought (CSA, 2001; Said, 1994), and conflict (Said, 1994). In relation to LSLIs and displacements, lack of tenure rights for commons and restriction of mobility were the key drivers of land degradation.

There have been two general debates in the academic literature regarding the causes of land degradation, Hardin's tragedy of the commons (Hardin, 1968) and Ostrom's counter-argument to the tragedy of commons (Ostrom et al., 1999). The 'tragedy of the commons' argues that the communal ownership of resources leads to their degradation and recommends privatizing property rights. In contrast, Ostrom argues that communities can manage their collective resources sustainably and private ownership of land may well lead to resource depletion as individuals want to maximize their private benefits from the land. However, neither of these two debates acknowledges the tragedy that may result when powerful external groups take control of resources to gain personal advantage without consultation or compensation of local communities. ${ }^{19}$

The latter is exactly what was found in the current research: LSLIs restrict pastoralists' access to grasslands and water, leading to increased scarcity of dry season grazing and pressure on pasture lands.

Moreover, as LSLI capture the most productive land that has been used for dry season grazing, the overall productivity of the grazing land declines (Abbink et al., 2014) and, for instance in Afar, the appropriation of land for LSLI has increased the incidence of overgrazing (Sonneveld et al., 2010). In contrast to the tragedy of the commons, overgrazing in the study area is not the result of the accumulation of livestock and the free-rider problem (Cox, 1985; Hardin, 1968). Instead, it is due to the denial of access to grazing land that disrupted the mobility pattern of pastoralists and their livestock (Beza and Assen, 2017) (Beza and Assen, 2017; Cox, 1985; Said, 1994). Two observations support our claim for the absence of the tragedy of commons. First, pastoralists elsewhere in Ethiopia survived for centuries based on the traditional governance of the commons and in harmony with their environment (Dell'Angelo et al., 2017; FDRE, 2019). Second, in Ethiopia, pasture land governance has well-defined user rights, access conditions, set rules and norms (Beyene, 2016) and exclusion criteria to prevent outsiders from exploiting the resource (Beyene, 2006).

\footnotetext{
19 The FGD participants in the Afar study sites report that the government negotiated about taking the land for sugar plantations with clan leaders. Those actually affected by the Tendaho plantation did not receive compensation, but some traditional leaders and elites did receive money and forced the community to relocate for sugar plantations.
} 
As the state owns all the land in Ethiopia, pastoralists can easily be removed from their ancestral land and the result for the effect of farmland tenure on land degradation should be interpreted with caution. On the one hand, we do find that land tenure security reduces land degradation and ensures sustainability (Ariti et al., 2018; Kirui and Mirzabaev, 2015). However, the notion of land certification poorly fits with pastoral livelihoods. Considering the transhumance nature of pastoralist systems, what matters for pastoralists is access to pastures rather than a specific piece of land (Dell'Angelo et al., 2017). Loss of access to the commons undermines pastoralist livelihoods unless there is compensation with land of equivalent or superior quality (Hilhorst and Zomers, 2011; Vanclay, 2017). Therefore, the recognition of collective tenure rights to the commons and mobility is a cornerstone of sustainable development and optimizing scarce pastures (Butt, 2010; Davies et al., 2016).

According to Dwivedi (2002), there are two arguments regarding development-induced displacement (such as LSLIs). The first argument is that development-induced displacement is inevitable and minimizing the effect of displacement is necessary. The second view sees displacement as a disruption in peoples' existing ways of life and the denial of property rights. Without taking either side of these views, this study suggests that LSLIs have displaced indigenous pastoralists in favor of industrial plantations and disturbed their way of life. Hence, revisiting possibilities of ensuring pastoralists' access to common resources will mitigate land degradation. However, if the displacement in the future is inevitable, it should be implemented with community consultation and adequate land improvement strategies.

\subsection{Conclusion and Policy Recommendations}

This study provides evidence on the effect of LSLI-induced displacement on land degradation in agropastoral areas of Ethiopia. The results reveal that LSLI areas expand by displacing households and restricting access to pastures and other resources in the study area. This aggravates the scarcity of pasture lands and hence leads to land degradation.

LSLI aggravated land degradation directly by destroying common resources (clearing of vegetation and grass) in favor of plantation production and by dispossessing grazing land and exacerbating overgrazing. Significant proportions of the households in our study perceive that poverty and conflicts have been increasing while herd size has shown a declining trend as a result.

LSLI-induced displacement significantly worsens land degradation. There is strong evidence that the land of the displaced households has suffered significantly more degradation 
than that of the control households. Loss of access to productive dry season pasture and dispossession of former pasture is major driver of overgrazing. This is also related to the absence of property rights for the commons. We conclude that displacement increased the severity of land degradation. However, also non-displaced households may face negative externalities from LSLI, such as the discharge of polluted water and a decline in ecosystem services (loss of native vegetation and forest products).

Among the confounding variables, access to markets and extension services, membership in cooperatives, farmland tenure, and livestock mobility reduce land degradation. While drought, the number of livestock, and sharecropping aggravate land degradation.

Actions to be taken to halt and minimize land degradation and increase livestock productivity include, creating market integration, allowing mobility, and developing pastoral extension systems. The extension should integrate conservation practices to those highly degraded areas. Evidence from Ethiopia shows that intensive rehabilitation activities have helped to combat land degradation in dryland areas (Nyssen et al., 2014). Hence, effective soil and water management practices could enhance pasture availability. Future LSLIs should engage the local communities in the planning process and recognize the rights of pastoral people. If displacement is inevitable, prior informed consent, compensation, and shared access to communal resources are advisable. A corrective measure is also necessary to help displaced pastoralists gain access to common-pool resources. A stricter implementation of responsible agricultural practices on LSLIs, ensuring pastoralists' access to pasture lands and allowing mobility can mitigate land degradation. 


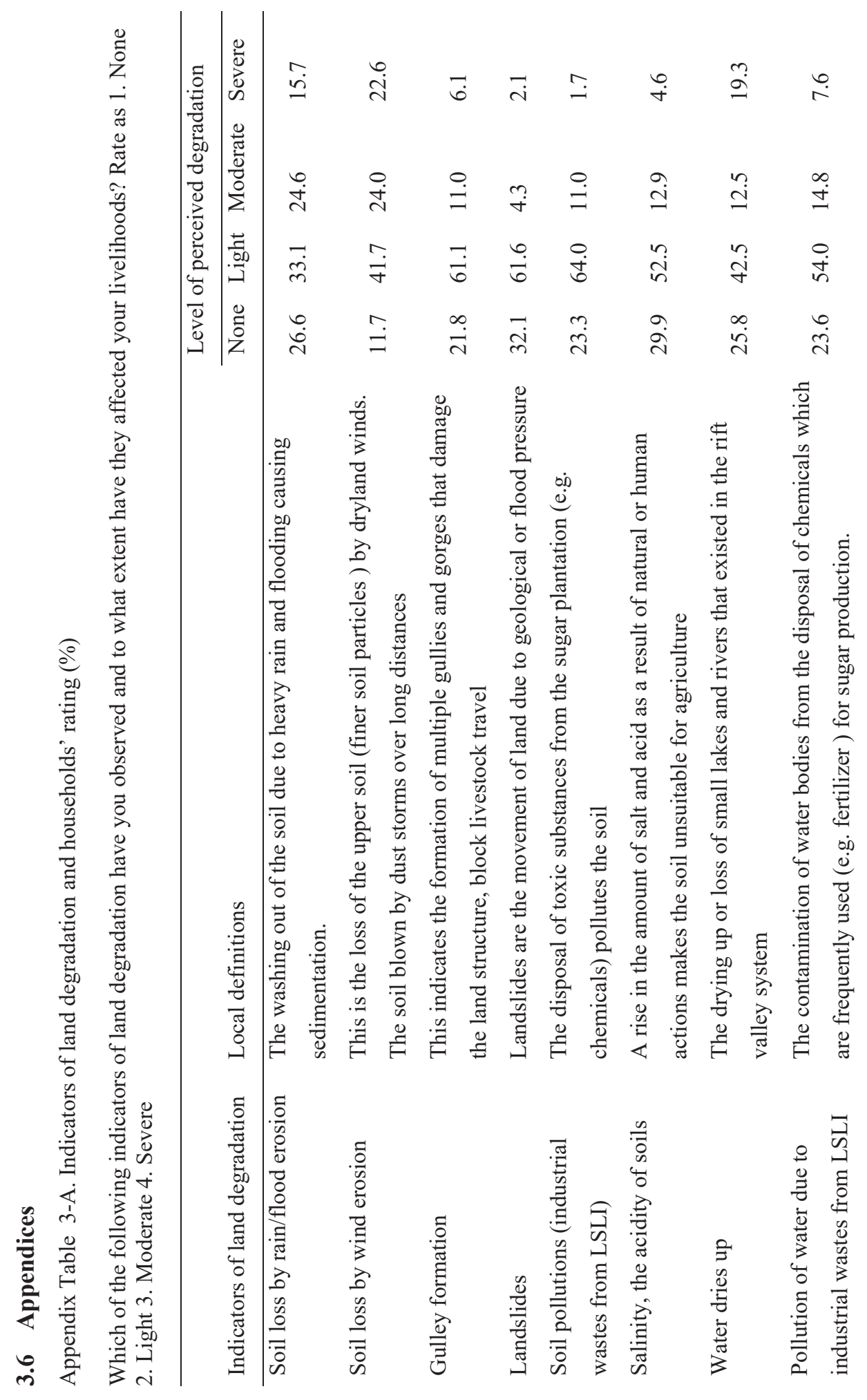







Appendix Table 3-B. Endogenous switching regression model results on the effect of displacement on land degradation

\begin{tabular}{|c|c|c|c|c|c|c|}
\hline \multicolumn{3}{|c|}{ TREATMENT (1/0) } & \multicolumn{2}{|c|}{ TREATED(1) } & \multicolumn{2}{|c|}{ CONTROL (0) } \\
\hline & Coef. & Std. Err & Coef. & Std. Err & Coef. & Std. Err \\
\hline AGE & $-0.008^{*}$ & 0.004 & $-0.006^{*}$ & 0.003 & 0.002 & 0.002 \\
\hline GENDER & 0.076 & 0.137 & -0.117 & 0.083 & -0.034 & 0.047 \\
\hline HH_size & 0.000 & 0.014 & 0.010 & 0.008 & -0.001 & 0.005 \\
\hline EDU & -0.021 & 0.019 & -0.006 & 0.012 & $0.018 * * *$ & 0.007 \\
\hline TLU & $0.009 * * *$ & 0.003 & $0.004 *$ & 0.002 & -0.001 & 0.001 \\
\hline LAND_own & 0.006 & 0.063 & $-0.074 *$ & 0.041 & -0.009 & 0.023 \\
\hline LOGINC & $0.087 * *$ & 0.043 & $-0.099 * * *$ & 0.032 & $-0.061 * * *$ & 0.015 \\
\hline CREDIT & -0.149 & 0.152 & $-0.160 *$ & 0.092 & 0.032 & 0.053 \\
\hline MARKET_km & $0.019 * * *$ & 0.006 & $-0.018 * * *$ & 0.005 & $-0.006 * * *$ & 0.002 \\
\hline COOPER & 0.062 & 0.129 & 0.054 & 0.070 & $-0.149 * * *$ & 0.046 \\
\hline OVGRAZ & $0.284 * * *$ & 0.103 & $0.188 * *$ & 0.080 & 0.044 & 0.040 \\
\hline SHARCROP & -0.111 & 0.125 & $0.476 * * *$ & 0.071 & $0.356 * * *$ & 0.041 \\
\hline CONFLICT & $0.428 * * *$ & 0.127 & $0.247 * *$ & 0.109 & $0.210 * * *$ & 0.050 \\
\hline MOBILITY & $-0.202 * *$ & 0.101 & -0.015 & 0.066 & $-0.066^{* *}$ & 0.036 \\
\hline LAND_tenure & $0.227 * *$ & 0.104 & -0.036 & 0.077 & $-0.178 * * *$ & 0.038 \\
\hline EXTENSION & $-0.110 *$ & 0.065 & -0.013 & 0.045 & -0.013 & 0.024 \\
\hline DROUGHT & -0.095 & 0.120 & $0.361 * * *$ & 0.073 & $0.236 * * *$ & 0.042 \\
\hline N_employed & -0.150 & 0.096 & & & & \\
\hline LSLI_km & 0.011 & 0.007 & & & & \\
\hline cons & $-1.465 * * *$ & 0.465 & $3.285 * * *$ & 0.534 & $2.064 * * *$ & 0.157 \\
\hline$/ \operatorname{lns} 1$ & -0.950 & $0.207 * * *$ & & & & \\
\hline$/ \operatorname{lns} 2$ & -0.791 & $0.045 * * *$ & & & & \\
\hline$/ \mathrm{r} 1$ & -0.456 & 0.693 & & & & \\
\hline$/ \mathrm{r} 2$ & -1.440 & $0.225 * * *$ & & & & \\
\hline sigma_1 & 0.387 & 0.080 & & & & \\
\hline sigma_2 & 0.453 & 0.020 & & & & \\
\hline rho_1 & -0.427 & 0.567 & & & & \\
\hline rho_2 & -0.894 & 0.045 & & & & \\
\hline Log likelihood = & -787 & & & & & \\
\hline Wald chi2(17) & 378 & $2 * * *$ & & & & \\
\hline LR test of indep & $\begin{array}{l}\text { chi2 } \\
863\end{array}$ & & $* * *$ & & & \\
\hline Number of obs & 863 & & & & & \\
\hline
\end{tabular}

"+" signs of the coefficients show the variables that worsen land degradation, "-" signs the variables that reduce land degradation. 
Appendix Figure 3-a. Trends of temperature in Fentale and Dubti, 1984 -2018

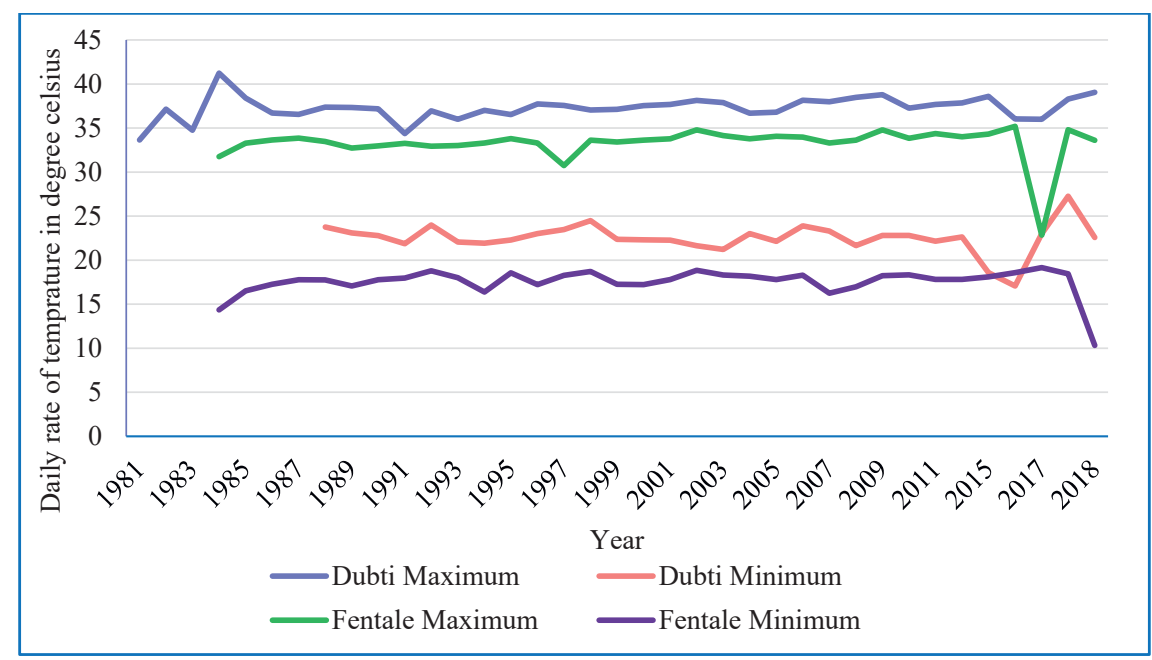

Appendix Figure 3-b. Trends of precipitation in Fentale and Dubti, 1984 -2018

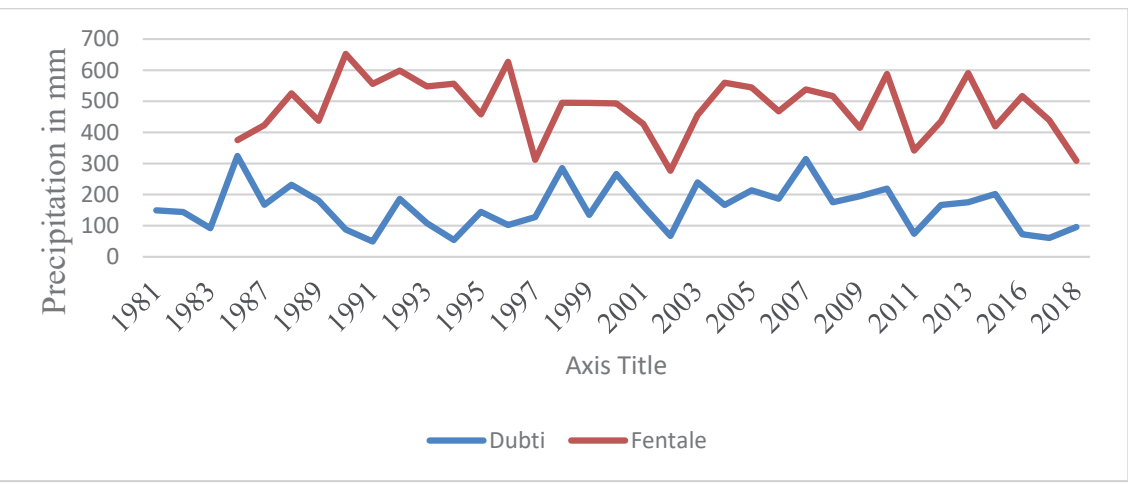


Chapter 4

Large-scale Land Investments and Land Use Conflicts in the Agropastoral Areas of Ethiopia 
Chapter 4 


\title{
4 Large-scale Land Investments and Land Use Conflicts in the Agropastoral Areas of Ethiopia ${ }^{20}$
}

\begin{abstract}
We study the determinants of conflict among agropastoral households in areas affected by large-scale land investments in Ethiopia. A mixed method of household and community surveys was used to collect the data. Descriptive statistics and binary logit were used for data analysis. The results indicate that in the last decade land conflicts were prevalent in more than a quarter of the studied communities and that land conflicts have increased since the establishment of large-scale land investments. The scarcity of pasture land, both from a supply and from a demand-side perspective, and tenure insecurity are the key drivers of land conflict. We conclude that the state appropriation of traditional pastures for industrial plantations and a lack of property rights for the commons exacerbate land conflicts.
\end{abstract}

Keywords: conflict, tenure security, property rights, pastoralism, plantation

\footnotetext{
${ }^{20}$ This chapter is based on the paper by Bekele, A.E., Drabik, D., Dries, L. \& Heijman, W. under review in the journal of Land Use Policy.
} 


\subsection{Introduction}

Land is the main source of livelihood for the majority of people in developing countries. In many of these countries, secure access to land has been a challenge. Farmers' and pastoralists' dispossession of access to land and water has increased land conflict in Africa (Di Falco et al., 2019) and sub-Saharan African countries (Campbell et al., 2000). Increased competition over land and its mismanagement has been aggravating conflicts (Ochieng, 2011). In this paper, we analyze the situation in Ethiopia.

Pastoralism prevails on 43\% of Africa's land (FAO, 2018b) and includes 268 million pastoralists; where the Horn of Africa has the largest population of pastoralists in the world (De Haan et al., 2016; Mkutu, 2001). Pastoral ethnicities are a minority in Africa and suffer from political marginalization (Avis, 2018). As a result, land conflict is much worse for pastoralists (Elias and Abdi, 2010). For instance, less than one percent of the national budget is allocated to pastoralists in Africa (FAO, 2018b). More than $60 \%$ of Ethiopia's drylands are inhabited by pastoralists who make up an estimated $15 \%$ of the population (PFE, 2010). Like in many African countries, pastoralists in Ethiopia suffer from political marginalization.

For pastoralists, land is a communal property that is administered traditionally. However, agropastoralist institutions governing property rights have been deteriorating due to urbanization, population growth, and new local governance structures (Beyene, 2010). Due to overlapping land claims and diminishing access to pastures, pastoralists have been fighting over land (Lind et al., 2016). Consequently, land conflicts in pastoral areas across Africa have become widespread and are increasing in severity (FAO, 2018b; Mkutu, 2001).

In many African countries, land policies permit LSLIs to encroach on pastoral rangelands, leading to displacement and poverty (AU, 2013; Blench, 1997; De Haan et al., 2016). Customary land rights are deteriorating in many African countries. In Ethiopia, all land is owned by the state, which limits the property rights of pastoralists (Lavers, 2018) and Ethiopia's Growth and Transformation Plan favors LSLI in agropastoral areas. As a result, the loss of key dry season grazing areas to large-scale land investments is one of the main sources of conflict in agropastoral areas (Blench, 1997; Little and McPeak, 2014; Ola-Adams and Okali, 2008). The shift from communal to private use of land and pasture enclosures (Dong et al., 2011), and increased government control over land (Schmidt and Pearson, 2016), have increased contradictions between statutory and customary tenure systems (Reda, 2014). Pastoralists manifest strong resistance to formal land appropriations because they undermine their capability to escape poverty (Hundie, 2010). In severe scenarios, such resistance involves 
armed confrontation. Consequently, conflict over grazing and watering resources and boundary claims have become a major livelihood challenge for pastoral communities (Mohamud, 2012).

Conflict has been increasing in Ethiopia in recent years. Since 2016, the government's plan to extend the capital, Addis Ababa, into the Oromia region has triggered major protests in Ethiopia. The land dispute between the Oromia and Somalia pastoral regions has caused the internal displacement of around three million people in 2017-2018. Similarly, land disputes between Guji and Gedeo internally displaced about one million agropastoralists in 2018-2019. Land-related disputes also exist among non-pastoral regions such as the Amhara and Tigray regions (Lavers, 2018). Currently, the political unrest in Ethiopia can also in some way be related to land resources (Habibi, 2017). In the country, the land is a highly politicized resource linked to structural inequality.

Land conflicts have negative effects on households as well as on the economy as a whole. They slow down investment and can result in the loss of property for conflicting parties (Wehrmann, 2008). In Africa, land conflicts have continuously weakened and reduced countries' capacity to achieve their development goals (Beyene, 2009). Land conflicts are linked to broader security and livelihood issues in fragile pastoral areas such as loss of human life, displacement, disruption in education and mobility (Beyene, 2009). Micro conflicts can severely affect economic development and escalate into a community-wide conflict.

Conflicts in the pastoral areas have received widespread attention but the in-depth analysis is missing. The available literature is mainly focused on general conflicts and is based on reports in the media, or from activists and rights groups but not on robust investigations. Some studies exist that investigate the link between insecure property rights and land disputes at the household level in non-pastoral highland areas of Ethiopia (Di Falco et al., 2019; Lucchetti, 2015). Other literature focuses on the macro-level conflict between Ethiopia and other countries (e.g. conflict between Eritrea and Ethiopia) (Uchehara, 2014), or the conflict between different ethnic or inter-ethnic groups (Beyene, 2009; Feyissa, 2015; Tadesse et al., 2015), and the conflict between neighboring pastoralists (Hundie, 2010; McPeak and Little, 2018). These studies either use a case study approach, narrative synthesis or depend on a single theoretical framework such as property rights. This study, however, develops a comprehensive theoretical framework combining resource scarcity, property rights, and political ecology to uncover the complexities of land conflict. More importantly, the land conflict between pastoralists and large-scale commercial plantations is most common in pastoral Ethiopia. However, such conflict at the household level lacks sufficient attention in previous research. Therefore, this study aims to assess the nature of land conflict in pastoral areas in general, between pastoralists 
and large-scale land investments in particular, and identify the determinants of land conflict between pastoral households and LSLIs in Ethiopia. Hence, this study has two contributes. First, it fills the knowledge gap about the existing land conflict and its determinants in LSLIs dominated pastoral areas. Second, it develop a theoretical framework that links resource scarcity-property rights-political ecology theories to unpack the complexity of land conflict.

The Ethiopian Awash Valley is home to different indigenous agropastoralists such as Karrayyu, Ittu, Afar, and Issa. The Awash river basin attracted huge large-scale land investments in the country. However, pastoralists see such large-scale land acquisition as a big enemy, as it has been displacing them and restricting their access to dry season grazing. The Awash Valley, therefore, provides a good example of an area of land conflict in agropastoral Ethiopia. The area is also key for the national economy since the major road that links the country to international trade through Djibouti crosses this area. A better understanding of the complexities of conflict and its specific determinants is needed to design peacebuilding strategies in contested areas like the Awash valley. This study is relevant to other pastoral areas with land conflict worldwide.

\subsection{A Conceptual Model of Land Conflict}

The major theories explaining land use conflicts in agrarian countries are property rights, environmental scarcity, and political ecology theories (Beyene, 2017). The property rights theory argues that poorly defined property rights are sources of conflict (Beyene, 2017). Property rights are the institutions (rules) that specify a bundle of rights over the property (land). Schlager and Ostrom (1992) categorize these as use rights, control rights, and authoritative rights (definition and allocation). Contradictions or overlapping rights over resource use are often the sources of conflict (Ochieng, 2011). The contradictions emanate from the deterioration of traditional authorities' role in commons management and the dominance of government authorities. The contradictions also intensify land users and the state claims to the same land. Thus lack of land tenure security (e.g., dispossession of commons rights) exacerbates mistrust, leading to conflict in times of resource scarcity (Di Falco et al., 2019) In the context of this paper, large-scale land investments claim pastoralists' traditional land and hamper their rights to use, control, and allocate it. This causes conflict among pastoralists and large-scale land investors (Lode and Kassa, 2001; Tadesse et al., 2015).

Environmental scarcity refers to the declining availability of natural resources (HomerDixon, 1994). The environmental scarcity theory is framed into three dimensions, namely, 
supply-induced scarcity, demand-induced scarcity, and structural scarcity (Ochieng, 2011). Land scarcity is the primary driver of land use conflict in general (Bruce and Boudreaux, 2011). Supply-induced scarcity in pastoral areas is caused by environmental degradation, climate change, and recurrent drought (Abdulahi, 2005; Hundie, 2010; Safarzynska, 2018; Tadesse et al., 2015). Demand-induced scarcity results from population growth (Abdulahi, 2005; HomerDixon, 1994). Land scarcity occurs when available land is insufficient to meet the demand for land. For instance, the Ethiopian population has grown by 2.7 folds over the last five decades, while food production has grown by only 2.4 folds over the same period (Hailu, 2016). Structural scarcity ${ }^{21}$ arises from an unequal social distribution of a resource (Percival and Homer-Dixon, 1998), which could be caused by tenure insecurity and unequal power relations. Hence, it stretches along with the political ecology and tenure insecurity. The lack of equal access to land is an important source of conflict (Menbere, 2013). According to the resource scarcity conflict argument, people will engage in conflicts to secure access to resources necessary for their survival (Homer-Dixon, 1994).

In contrast to land scarcities, political ecology emphasizes the societal and political nature of resource use and conflict. It provides insights into the context and processes underlying the land use conflict (Bassett, 1988). The political ecology study uneven power relations over natural resource uses and explains society-state relations that are linked to power, domination, and inequalities. The appropriation of land is shaped by social relations of power and domination (Pichler and Brad, 2016). Land conflicts, according to the political ecology, are struggles associated with unequal power relations related to the distribution of, and control over natural resources.

The imbalance of power between land users and the lack of equitable access to natural resources have contributed to the recurrence of conflict in Ethiopia (Beyene, 2007; Lode and Kassa, 2001; Tadesse et al., 2015). Loss of access to key resources and eviction without compensation are drivers of conflict between affected communities, the government, and the private sector (Ochieng, 2011). Moreover, Ethiopian pastoralists are sidelined from making decisions that affect their livelihoods, which makes it more likely that they oppose decisions made by the government (Ochieng, 2011). Furthermore, a lack of good governance and related

\footnotetext{
21 The structural scarcity is imbadded in a lack of property rights and a lack of power to influence land use decisions. For example loss of land due to the LSLI leads to inequality and structural scarcity. It is difficult to measure this dimention at household level. Hence, a qualitative infomation from the key informants was included in the result section.
} 
grievances are major political factors underlying the conflicts (Berhe and Adaye, 2007). The state usually controls the land to control the economy and rural people.

In addition to the three theoretical perspectives, land use policy affects land conflicts. Before 1974, in the imperial era, land policy in Ethiopia favored landlords who exploited peasants' labor. From 1974 to 1991, during the socialist era, the government abolished the landlord-tenant relationship and declared usufruct rights over land (Di Falco et al., 2019) under the motto of land to the tiller (farmers). Since 1991, according to article 40 of the constitution, the state owns all land and can allocate it to investment at any time, which promotes insecurity of landholding. The state was given unlimited power over the land according to the policy. Under all eras, land transfer rights such as sale, lease and mortgage are prohibited by the rule and the state (Di Falco et al., 2019). For pastoralists, land use was governed by customary clan leaders until 1991; however, this role diminished in more recent years (Mulugeta, 2014). The exclusion of local people and informal institutions from decision making concerning land allocations drives conflict. In Ethiopia, land policies have favored non-pastoral uses of the land (Little and McPeak, 2014). The current Growth and Transformation Plan of Ethiopia aspires to make the country a middle-income country by 2025 through the commercialization and industrialization of agriculture. This includes the development of the sugar industry which is targeted mainly at the low land areas of the country where agropastoralists reside. The communal grazing rights of pastoralists are not protected by law (Mkutu, 2001). As a result, the government has allocated communal land to sugar production, and pastoralists have lost entitlement to dry season grazing. This has led to structural scarcity (Menbere, 2013) and violent conflict (FAO, 2018b).

Figure 4-1 presents the conceptual framework of our research. The framework is based on the three theoretical perspectives and the relevant literature (Bassett, 1988; Homer-Dixon, 1994; Ochieng, 2011). 


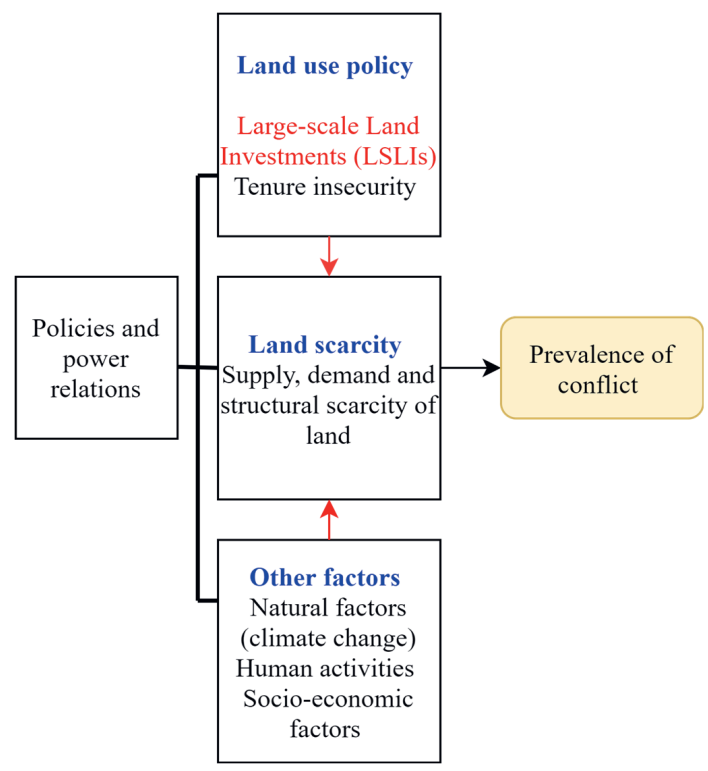

Figure 4-1. Conceptual framework of land use conflict in Ethiopia

Source: Authors' design based on a literature review

\subsection{Methodology}

\subsubsection{Sampling}

The paper combines data from household and community surveys with secondary information from the literature. A cross-sectional household survey was conducted in 2019 in the agropastoral communities of Karrayyu and Afar. These communities have been affected by large-scale land investments that are located in the Rift Valley of Ethiopia. We selected Fentale and Dubti woredas ${ }^{22}$ and eight kebeles $^{23}$. The kebeles were stratified into nearby $(5 \mathrm{~km})$ and distant kebeles from LSLIs and using the Yamane sampling formula (Yamane, 1973) 870 households were randomly selected (440 and 430 from Fentale and Dubti, respectively).

\subsubsection{Data}

Primary data on loss, access, use, control, and management of pasture land, and exposure and frequency of conflict was collected through household interviews. Wehrmann (2008) was

\footnotetext{
${ }^{22}$ Woreda is the fourth lowest adminstrative level in Ethiopia (Federal-Regional-zonal- woreda).

${ }^{23}$ Kebele is the fifth lowest adminstrative unit in Ehiopia (Federal-Regional-zonal- woreda-kebele).
} 
followed for designing and clustering the questionnaire. We asked whether the household has faced conflicts related to LSLIs on grazing or farmland in the last ten years. At the village level, data on the history, causes, and effects of conflicts and the community perception of LSLI was collected through Focus Group Discussions (FGD) and key informant interviews. In total, 8 FGDs that involved 43 male and 16 female elders were conducted, while key informant interviews were conducted among local experts in each kebele.

\subsubsection{Variables and Hypotheses}

\section{Dependent variable}

Respondents were asked retrospective questions about the household's exposure to land conflict with the LSLIs ( 1 if yes, 0 otherwise) in the last ten years. We follow Kisoza (2014) and Wehrmann (2008) to define household conflict exposure. Accordingly, conflict is interpreted as a disagreement on land use, ranging from simple disputes to occasional fighting and severe violence involving killing and loss of property. A conflict here is a situation whereby the pastoralists and LSLIs claim the same scarce land at the same time. It also encompasses forced displacement, loss of access to customary lands, or a combination.

\section{Explanatory variables}

The concept of conflict is complex, and the causes of conflict are multiple. We use the conceptual framework developed in section 2 to investigate the drivers of conflict between pastoralists and LSLIs (Figure 4-1).

Table 4-1 shows the definition, descriptive statistics, and expected sign of the independent variables. The dispossession of property rights measured by a loss of land to LSLI is expected to intensify land conflict. Over $50 \%$ of the respondents have lost land to the LSLIs in the last three decades. As a result, the majority of households do not trust LSLI, and 40\% still very much worry that they will lose their land in the future. Households' proximity to LSLI is expected to increase their vulnerability to land conflict. Beyene (2017) claims that insecure property rights for the commons are the main drivers of land conflict in Ethiopia. Access to irrigation may have a mixed effect on land conflict. Irrigation helps households to diversify their livelihoods and reduce vulnerability to water scarcity. However, the distribution and control of irrigation use are strongly connected to the LSLIs and may bring conflict related to water. Fifty-seven percent of the respondents have access to irrigation. 
Land supply scarcities refer to the shortage of land due to drought, land degradation, and Prosopis $^{24}$ invasions. These threats are expected to increase the likelihood of conflict. About $63.3 \%$ of the respondents own land. The area of an average landholding is below one hectare. If a household owns more land, it is less likely to be faced with land supply scarcity and the likelihood of facing conflict will be small. Over $50 \%$ of households have suffered severe drought and more than 30\% Prosopis invasion. Prosopis is an invasive weed with an adverse effect on biodiversity and livelihoods in pastoral areas. In the Afar region, Prosopis invaded over 1.2 million hectares (FDRE, 2017). Prosopis is one of the worst invasive alien species, causing severe environmental degradation in the arid and semi-arid lowlands. Several key informants reported that Prosopis thorns cause physical injuries to humans and livestock.

Demand-induced scarcity relates to households' requirements for land for grazing livestock and their food production. Land is a fixed asset, while the population increases over time. The size of households and livestock raise the competition over land. The average family size is 8 members, which is higher than the national average of 4.9 for rural areas. The average number of livestock owned is 13.3 tropical units. Sixty percent of the households practice herd mobility to search for pasture and water. Restrictions on mobility weaken pastoralists' coping strategies and in turn, lead to conflict.

The political ecology perspective is captured by the leadership status of the household head. About $19 \%$ of the household heads have leadership positions in their village (as clan and village chiefs). Rangelands belong to a clan and clan chiefs are in charge of distributing the land to clan members. A village chief (kebele chairman) is responsible for land administration as per the government regulations. If the head of the household is a clan leader or a village chief, they receive social respect due to their political capital.

Finally, household characteristics and socio-economic factors are used as independent variables in the analysis. Socio-economic factors include household income, and access to the market, roads, cooperatives, extension, and credit and non-farm activities. These are important in pastoralists' livelihoods and are expected to reduce the likelihood of land conflicts. To access markets and roads, a household, on average, travels $14.6 \mathrm{~km}$ and $2.5 \mathrm{~km}$, respectively. Only $10 \%$ of the households participate in credit and $20 \%$ in cooperatives, while $39 \%$ in extension programs. About $82 \%$ of respondents participate in one or more non-farm activities. Among the household characteristics, the average age and education of the household head are 42.1 and

\footnotetext{
${ }^{24}$ Prosopis Juliflora is a threat to biodiversity and livelihoods in pastoraal and agropastoral areas of Ethiopia. It invades pasturelands, irrigation and crop lands, displace native vegetation. The governmont of Ethiopia developed strategy to prevent the its invasion and restore invaded areas (FDRE, 2017).
} 
1.3 years, respectively. In Ethiopia, $49 \%$ of females and $35 \%$ of males have never attended school. The education of pastoralists is even lower as they have very limited access to education. Young men and less educated people are more vulnerable to conflict than their counterparts. War, defense, and heroism are the roles of men, while women nurse children and serve the family in pastoral gender roles. (Stickler et al., 2018) show that more males than females reported a conflict in Afar. However, the effect of conflict is more severe on women and children.

The comparison of households based on their exposure to land conflict indicates that households with conflict prevalence have higher land degradation, more livestock, and income compared to those who did not report conflict. The mean income of households without conflict is US\$ 1134.4, which is lower than the US\$ 1600.7 for households with conflict. However, both groups live below the nationally defined absolute poverty line set in 2016 (US\$ 2000). Livestock is the major source of pastoralists' income, and households with more livestock earn more income. However, more livestock increases competition over land and the likelihood of conflict. Also household exposure to drought, access to extension, and mobility significantly differed by conflict exposure. The majority of drought-vulnerable households with access to the extension were exposed to land conflict. While lower proportions of mobile households were exposed to conflict. 


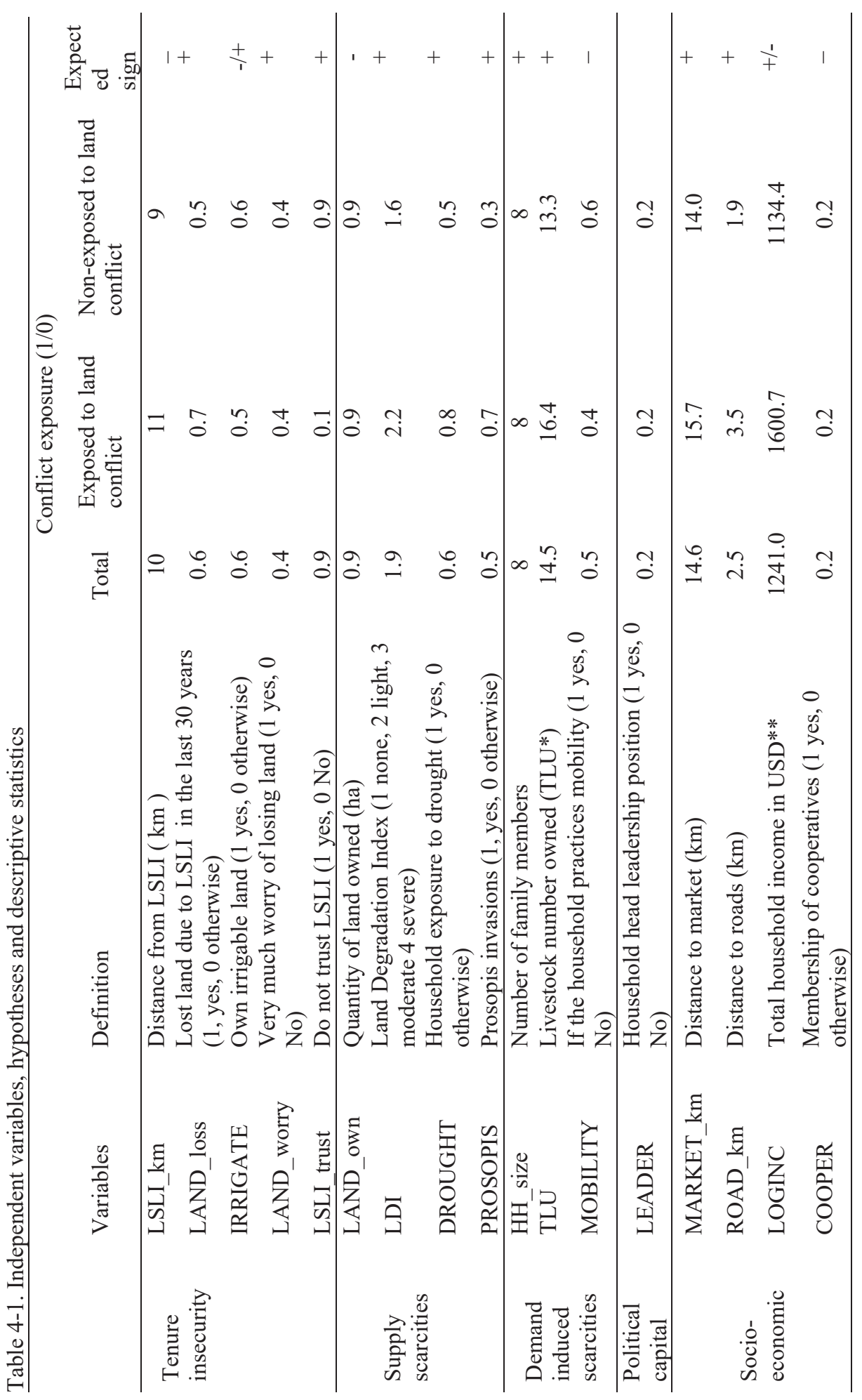




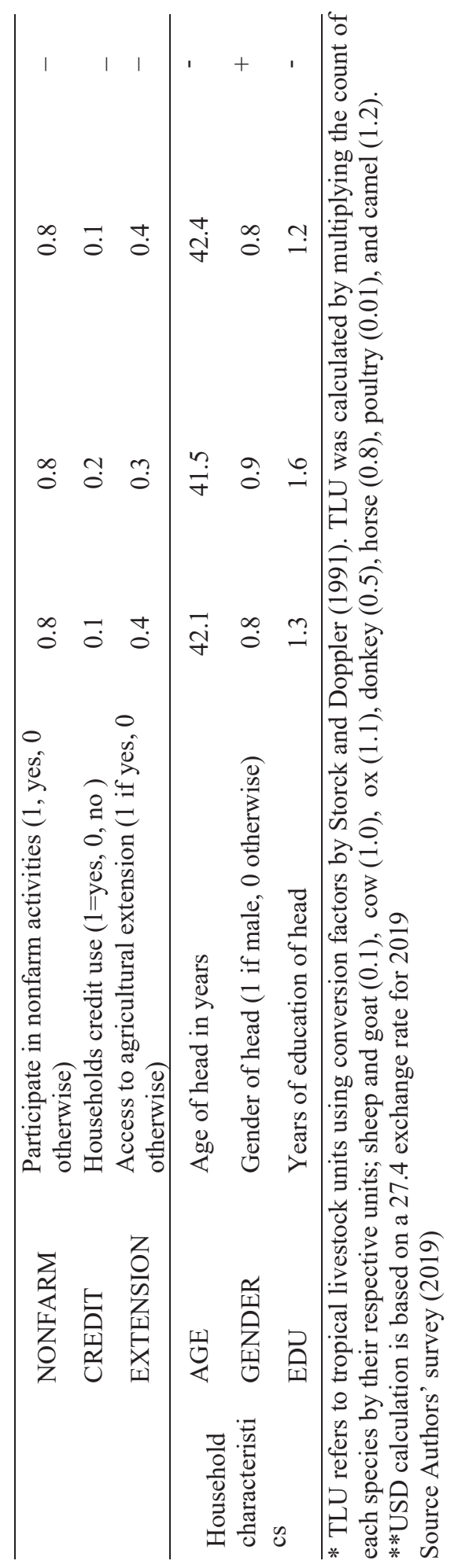




\subsubsection{Econometric Model}

Our dependent variable conflict exposure is a dummy variable. Logit and probit models can be specified to investigate the probabilities of an event occurring as a function of a set of nonstochastic explanatory variables. Although both logit and probit models provide similar results, the logit model is widely used for analyzing conflict (Haslam and Tanimoune, 2016; Kisoza, 2014; Lisansky et al., 1988; Rodríguez and Daza, 2012; Safarzynska, 2018). Hence we chose a binary logit model to identify determinants of conflict in the agropastoral context. Logit does not need normal distribution assumptions and is computationally easy (Gujarati, 2009).

Following Gujarati (2009), the functional form of the logit model is specified as follows:

$$
P_{i}=E\left(Y=1 \mid X_{i}=\beta_{0}+\beta_{i} X_{i}\right.
$$

The logistic model (the log-odds ratio) takes the form:

$$
P_{i}=E\left(Y=1 \mid X_{i}=\beta_{1}+\beta_{2} X_{i}=\frac{1}{1+e^{-\left(\beta_{0}+\beta_{i} X_{i}\right)}}\right.
$$

For ease of exposition, the probability that a given household is exposed to conflict is expressed as:

$$
P_{i}=\frac{1}{1+e^{-Z_{i}}}=\frac{e^{Z}}{1+e^{Z}}
$$

The probability for not encountering conflict is $1-\mathrm{P}_{\mathrm{i}}$

$$
1-P_{i}=\frac{1}{1+e^{Z_{i}}}
$$

\subsection{Results and Discussions}

\subsubsection{Descriptive Results}

\section{Prevalence, Causes, and Trends of Land Use Conflict}

In the last 12 months before the survey, $18.2 \%$ of the agropastoral households were exposed to land conflict. Previous studies report $16 \%$ and $6 \%$ in Oromia and Afar, respectively (Stickler et al., 2018). Over the last 10 years, $27.4 \%$ of the respondents have been exposed to conflict associated with the LSLIs. The average number of conflicts encountered by the household during the last decade is 3.6 (Table 4-2). As the Karrayyu and Afar pastoralists resisted the establishment of LSLIs, the government of Ethiopia deployed federal police forces to control the land. As a result, there have been violent clashes between plantation workers and pastoralists (Mulugeta, 2014). The LSLIs prevent herd movements, jail the herders or the livestock, and 
impose fines whenever livestock encroaches the plantation areas. There are also physical attacks between plantation guards and the livestock herders when negotiations fail.

Table 4-2. The prevalence of conflict in the last 12 months and over ten years

\begin{tabular}{ll}
\hline Household exposure to conflicts & \\
\hline Share of households exposed to conflict, 12 months & $18.2 \%$ \\
Share of households exposed to conflict, 10 years & $27.4 \%$ \\
Average number of conflicts that households have been exposed to, 10 years & 3.6 \\
\hline Conflicting parties, 10 years & $38.6 \%$ \\
\hline Conflicts between pastoralists and LSLIs & \\
Conflicts between pastoralists of neighboring regions & $10.6 \%$ \\
(Karrayyu vs Argoba, Issa vs Afar) & $9.0 \%$ \\
Conflicts between pastoralists and local government & $23.9 \%$ \\
Conflicts between pastoralists and private large scale farms & $57.6 \%$ \\
\hline
\end{tabular}

Source: Authors' survey (2019)

Among competing land users, agropastoral households were facing land conflict mainly with the national parks (57.6\%) and LSLIs (38.6\%). More than half of vital dry season grazing areas of the Afar and the Karrayyu rangelands were appropriated by plantations and this has increased land use competition. In comparison, conflicts with communities in neighboring regions (other ethnic groups) and the government account for around $10 \%$.

The incidence of land conflicts involving LSLIs has increased for $57.5 \%$ of the households over the last ten years, while $35.1 \%$ and $7.4 \%$ report that conflicts have been decreasing or are constant (Table 4-3). The focus group discussions with elders and previous studies also indicate the trend of increasing conflicts (Mulugeta and Hagmann, 2008; Said, 1994; Tadesse et al., 2015; Tafere, 2013). However, trends in land conflict vary by study sites. More households in Fentale report increasing land conflicts while in Dubti more people report a declining trend of land conflict. Stickler et al. (2018) also find a low incidence of conflict in Afar FGDs in Fentale indicate that the establishment of the Metehara sugar estate led to the loss of crucial dry season grazing areas, watering points, and burial sites. In 2016, there was a violent conflict leading to the death of two people from the pastoralist groups following the expansion of the plantation into the burial areas. 
Table 4-3. Share of households indicating an increasing, decreasing, or stable evolution of land conflicts over the last ten years

\begin{tabular}{llll}
\hline Conflict & Fentale & Dubti & Total \\
\hline Increasing & 72.7 & 39.6 & 57.5 \\
Decreasing & 21.8 & 50.9 & 35.1 \\
Unchanged & 5.5 & 9.6 & 7.4
\end{tabular}

Source: Authors' survey (2019)

Table 4-4 presents the distribution of respondents by their perceptions of the causes of land-related conflicts. Based on the literature, we identified ten causes of land conflict for the study areas. The majority of respondents identified livestock mobility (71.3\%), grazing land scarcity $(59.0 \%)$, loss of tenure security $(53.2 \%)$, and farmland shortages $(51.9 \%)$ to be the major causes of land conflict.

Above a quarter of respondents report border-related disputes and national parks encroachment as an important cause of land conflicts. For instance, there have been frequent conflicts between Karrayyu with neighboring Argoba, Karrayyu with Afar, and Issa with Afar communities over bordering rangeland. According to the FGDs, the conflict between Karrayyu and Argoba, and between Issa and Afar has been increasing in intensity and frequency ${ }^{25}$, while that between Karrayyu and Afar is declining following the peace negotiations between Karrayyu and Afar elders.

Livestock raiding is another cause of conflict affecting $16.3 \%$ of respondents. In the past, livestock raiding was practiced between pastoralists of different clans. Recently, urban brokers in consultation with pastoralists raid livestock for commercial purposes. Two weeks before the survey, key informants and media reported that over 400 livestock of Karrayyu were raided to unknown places by using big trucks for sale at urban markets. Such illegal raidings involve the killing of herders and lead to an escalation of the conflict between different ethnic groups. Past studies report that between 1976-1990, 83 Karrayyu were killed and 1,212 livestock units were raided (Mulugeta and Hagmann, 2008). From 1981 to 1992, 86 Afar were killed and 848 livestock units raided. Likewise, a total of 71 and 47 LSLI workers were killed or wounded, respectively, by the Afar between 1979 and 1990 (Said, 1994).

\footnotetext{
${ }^{25}$ During data collection, we observed a total shutdown of Metehara town and blockage of the Addis Ababa Djibouti road because of the conflict between Karrayyu and Argoba. There are fatalities from both sides but there are no official or independent reports to cite.
} 
When grazing and farmlands are scarce, competing claims lead to conflict (Tafere, 2013). Hence, land conflicts are caused by the shrinkage of grazing land by LSLIs (45\%), national parks $(31.5 \%$, ), and private commercial farms (23.9\%). The absence of compensation for the land lost is also a major driver of conflict (Menbere, 2013). In Fentale the Metehara sugar plantation expands into the Kesem sugar plantation and Karrayyu pastoralists have lost access to dry season grazing in the Fentale plain. This has resulted in unsolved grievances and the focus group participants explained the structural scarcities created by the sugar plantations. The FGD participants in Fentale reported:

"During the establishment of the Metehara plantations, the local government and company workers told us that they were going to benefit our community. They promised to employ a lot of local people and establish sugar out-growers, which was a total lie. They employed very few local people, such as security guards, and even those employed gained unfair positions. They neither recruited out-growers nor paid compensation for the land lost. We demonstrated resistance, but the federal and local authorities often reacted with repression rather than with negotiation. Currently, we are more desperate than ever and remain voiceless."

Key informants from the Metehara sugar plantation did not deny these complaints by the community. Less than one percent of the company employees are from the pastoral community because, according to the plantation, they lack skilled labor.

For instance, the Tendaho sugar factory promised to create job opportunities for 50,000 people in Afar (Planel and Labzaé, 2016). However, it failed to keep its promises. The Tendaho company established 16 out-grower cooperatives hosting 2,000 households to produce and supply sugar cane to the factory at US\$2,190 per hectare per year. In 2016, although some cooperatives supplied sugar cane, the company did not settle the payment leaving unsolved grievances. Moreover, participation in sugar outgrower programs in Ethiopia significantly reduced household income (Wendimu et al., 2016). While describing the level of grievances about the loss of pasture land to Tendaho sugar plantation, the FGD participants in Dubti indicate that:

"The land was used by our ancestors for centuries. We have lost access to the land because the sugar plantation took it forcefully. As a result, we have become impoverished. We repeatedly requested that the Ethiopian government return our land, or at least provide us partial access during the dry season. However, we did not receive a favorable response. We hope that one day, we can reclaim our land and that the plantation will be destroyed." FGD discussion in Dubti (2019). 
The Tendaho plantation representatives in Dubti agree with the grievances of the local communities and indicated that the company is underperforming and incurring a loss.

Table 4-4. Households' perceptions of the causes of land conflict

\begin{tabular}{lc}
\hline Causes of conflict & $\%$ \\
\hline Livestock mobility & 71.3 \\
Expanding territory & 24.2 \\
Border dispute / unclear boundary & 25.6 \\
Farm land shortage & 51.9 \\
Grazing land scarcity & 59 \\
Livestock raiding & 16.3 \\
Lack of land tenure & 53.2 \\
Commercial investors & 23.9 \\
LSLIs & 45 \\
National parks & 31.5 \\
\hline Source: Auhts & \\
\hline
\end{tabular}

Source: Authors' survey (2019)

\section{Land conflict resolution and coping strategies}

The majority of the conflicts in the study region were solved by clan leaders (86.4\%), through courts (36.3\%), the police (36.4\%), and political systems (11.8\%) (Table 4- 5). Clan leaders are respected for their wisdom and honesty and deal with conflict in a participatory, transparent, and flexible nature (Tafere, 2013). The traditional governance systems that involve conflict resolution are called the $\mathrm{Gadaa}^{26}$ and $\mathrm{Madaa}^{27}$ respectively in Karrayyu and Afar societies. However, the role of traditional leaders in land conflict resolution has been declining (Beyene, 2007). For instance, $54 \%$ of the conflicts in Afar were solved through the government and only $31 \%$ by the traditional elder's council (Stickler et al., 2018). There is also a weak collaboration between the formal and informal systems involved in conflict resolution. In the formal system, there are no mechanisms for conflict surveillance, monitoring, and controlling, and the federal police usually only intervene after severe damage has occurred.

\footnotetext{
${ }^{26}$ Gadaa is a traditional governance instituion among the karrayyu and wider Oromo communities in Ethiopia. The Gadaa system has a peace keeping and conflict resolution mechanizms.

${ }^{27}$ Mad'aa consists of guidelines and rules on how to handle conflict among the Afar community.
} 
For coping with conflict, more than half of the households sell livestock and seek relatives or external support. $38 \%$ of the respondents borrow money, while more than a quarter of respondents migrate and sell labor.

Table 4-5. Conflict resolution and coping mechanisms

\begin{tabular}{ll}
\hline Conflict resolution & $\%$ \\
\hline Clan/ elders & 86.4 \\
Court \& Sharia & 36.3 \\
Police & 36.4 \\
Politics & 11.8 \\
\hline Coping strategies & \\
\hline Borrow money & 38 \\
Sell livestock & 58.8 \\
Migration & 28.4 \\
Seek relatives' support & 50.2 \\
Relocate children / send to relatives & 24.6 \\
Sell labor & 31 \\
\hline Source: Auntors' survey (2019)
\end{tabular}

Source: Authors' survey (2019)

\section{The Perceived Impact of Land Conflict}

Conflict exposure directly affects household welfare through the death of household members, (9.1\%), livestock death (29.6\%), and damage to houses and assets $(6.1 \%)$, while the indirect effects on the wellbeing of households result from children dropping out of school $(25.5 \%)$, lack of security and stability (31.7\%), forced migration (17.4\%), and market price shocks (32.7\%). These findings are supported by studies that report the loss of human life, and livestock raiding due to conflicts (Ola-Adams and Okali, 2008). The negative welfare effects of conflict are mainly observed among the households that have been exposed to conflicts. 
Table 4-6. Consequences of conflict on household wellbeing

\begin{tabular}{ll}
\hline Consequences of conflict & $\%$ \\
\hline Direct effects & \\
\hline Human death & 9.6 \\
Livestock death & 29.6 \\
Forced migration & 17.4 \\
House and asset burning & 6.5 \\
\hline Indirect effects & 25.5 \\
\hline Children dropping school & 31.7 \\
Lack of security and stability & 32.7 \\
Market price shock &
\end{tabular}

Source: Authors' survey (2019)

\subsubsection{Econometric Model Results}

Model fitness has been checked before and after estimations. The Variance Inflation Factor (VIF) confirms that there is no problem of multicollinearity among the independent variables. The post estimation classification shows that, respectively, $67.3 \%$ and $86.6 \%$ of the sensitivity and specificity were correctly predicted. Overall, the model correctly predicts $79.1 \%$ of the cases, and the likelihood ratio test shows a high predictive power indicating the model is a good fit for the data.

Out of the 23 independent variables that are expected to influence land conflict (see table 1), 13 were statistically significant (Table 4-7). Lack of property rights and tenure insecurity is often the cause of land-related conflicts in Ethiopia. In the country, land rights for farmers have been improving since 1974 (e.g., land for the tiller proclamations, land certification, or registration programs), while they have been deteriorating for pastoralists. There are no specific laws that protect the land rights of pastoralists in Ethiopia and land appropriations by the state have deprived pastoralists of their rights of access to land resources. The loss of access to key pasture and water resources due to LSLIs has disrupted pastoral systems and created land scarcity. This has made pastoral households more vulnerable to land conflict. Moreover, loss of customary land with associated displacements left long-standing grievances among pastoralists that fuel land conflict. The result confirms findings in earlier reports for Ethiopia (De Haan et al., 2016; Debebe, 2016; FAO, 2018b; Ola-Adams and Okali, 2008). Lack of compensation and strong mistrust increase the prevalence of conflict (Adhvaryu et al., 2018; 
Wehrmann, 2008). In addition, access to irrigation also contributes to the likelihood of conflicts between agropastoralists and LSLIs. First, the LSLIs control the distribution of irrigation water and this may disadvantage pastoralists. Second, the allocation of pasture land for irrigation agriculture adversely affects the access of pastoralists to grazing areas (Abdulahi, 2005; Said, 1994).

All supply-induced scarcity variables significantly trigger land conflict. As expected, households that are faced with severe land degradation and drought, and invasive Prosopis are more likely to be exposed to conflict. Pastoral areas in Ethiopia generally receive less than 500 $\mathrm{mm}$ annual precipitation and when there is a severe drought, pastoralists move to river banks and become vulnerable to conflict. The study confirms previous works that show drought as a driver of land-related conflict (De Haan et al., 2016; Mkutu, 2001; Mulugeta and Hagmann, 2008; Ola-Adams and Okali, 2008; Wehrmann, 2008). Some argue that long droughts are the root cause of conflicts in Somalia, Yemen, and Syria (Vidal, 2019). Discussion with elders confirmed that drought shocks are worsening because of the increasing scarcity of grazing areas. Moreover, land degradation and Prosopis invasion minimize the quality and quantity of land available to pastoralists.

Among demand-induced scarcity variables, household size reduces the probability of land conflict. This is contrary to our expectations but can be explained as follows. The size of a household indicates the household's labor endowment. Labor is a crucial asset in herd mobility and livelihood diversification and labor-scarce households are forced to compete for scarce grazing grounds which is likely to lead to more conflicts. For instance, in Afar households due to labor shortage livestock feed sedentary (Botterli, 2015). Moreover, as the number of livestock the household owns increases, the demand for grazing land and water increases, and the likelihood of conflict will also increase. Households with a larger herd size are generally also the wealthier households that have the means to invest in arms, which intensifies conflict. This is in line with a study in Ghana that found that an increase in herd size increases land conflicts (Abdulahi, 2005).

The political ecology variable, the leadership position of the household, does not have a significant effect on the likelihood of conflict between pastoral households and LSLIs.

Among socio-economic factors, contrary to expectation, credit access increases the likelihood of land conflict. A possible explanation is that credit is used for investments and improvements to assets, which leads to a higher likelihood of defending land and assets from expropriation. Easier access to roads reduces transaction costs for pastoralist households to access nearby labor markets and other services (including education, health, and product 
markets). Hence, households that are closer to roads may be less dependent on land compared to remote households that have limited economic opportunities. Moreover, in remote areas, the peacekeeping structure is weak which makes it easier for conflicts to prevail. 
Table 4-7. Determinants of land conflict between pastoralists and large-scale land investments

\begin{tabular}{|c|c|c|c|}
\hline Category & Variables & Coef. & Std. Err. \\
\hline & LSLI_km & -0.003 & 0.018 \\
\hline & LAND_loss & $1.040 * * *$ & 0.194 \\
\hline & IRRIGATE & $0.403 *$ & 0.218 \\
\hline & LAND_worry & 0.072 & 0.201 \\
\hline \multirow[t]{3}{*}{ Tenure insecurity } & LSLI_trust & $1.091 * * *$ & 0.404 \\
\hline & LAND_own & -0.044 & 0.115 \\
\hline & LDI & $1.448 * * *$ & 0.227 \\
\hline Supply induced & DROUGHT & $0.919 * * *$ & 0.230 \\
\hline \multirow{2}{*}{ scarcities } & PROSOPIS & $0.851 * * *$ & 0.241 \\
\hline & HH_size & $-0.049 *$ & 0.029 \\
\hline Demand induced & TLU & $0.012^{*}$ & 0.006 \\
\hline scarcity & MOBILITY & -0.234 & 0.200 \\
\hline \multirow[t]{5}{*}{ Political capital } & LEADER & -0.217 & 0.237 \\
\hline & ROAD_km & $0.064 * * *$ & 0.023 \\
\hline & MARKET_km & 0.012 & 0.013 \\
\hline & LOGINC & 0.045 & 0.084 \\
\hline & COOPER & $-0.507 * *$ & 0.251 \\
\hline \multirow{4}{*}{$\begin{array}{l}\text { Socio- } \\
\text { economic }\end{array}$} & NONFARM & -0.257 & 0.272 \\
\hline & CREDIT & $1.317 * * *$ & 0.283 \\
\hline & EXTENSION & $0.299 * *$ & 0.023 \\
\hline & AGE & 0.005 & 0.009 \\
\hline \multirow{9}{*}{$\begin{array}{l}\text { Household } \\
\text { characteristics }\end{array}$} & GENDER & -0.029 & 0.263 \\
\hline & EDU & -0.020 & 0.036 \\
\hline & cons & $-7.262 * * *$ & 1.092 \\
\hline & Sensitivity & $67.3 \%$ & \\
\hline & Specificity & $86.6 \%$ & \\
\hline & Correctly predicted & $79.1 \%$ & \\
\hline & $\mathrm{N}$ & 863 & \\
\hline & LR chi2(21) & $351.2 * * *$ & \\
\hline & Log-likelihood & -399.9 & \\
\hline
\end{tabular}

***,**,*, respectively show $\mathrm{p}<0.01, \mathrm{p}<0.05$ and $\mathrm{p}<0,1$

Source: Authors survey (2019) 
Cooperative membership significantly reduces land conflict, while access to extension services intensifies land conflict. Cooperatives provide marketing information and training to members on commercialization and complement the traditional collective action of pastoralists. This finding contradicts a study in Burundi which finds no effect of cooperatives on the incidence of land conflicts (McDougal and Almquist, 2014). Extension access intensifies land conflict. Ethiopian extension is generally focused on crop production and not on livestock production or pastoralism (Beyene, 2009). Hence, extension favors the allocation of pasture lands for cropping (supply of seeds, fertilizer), which increases competition and land use conflicts between crop producers and pastoralists. Moreover, the expansion of crop farming reduces the available resources for grazing and increases conflicts (Abdulahi, 2005). Household characteristics show no significant variation by conflict exposure

\subsection{Conclusion}

This study investigates the factors affecting land conflict in agropastoral areas that are affected by large-scale land investments. Data collection was conducted in 2019 in the Awash Valley of Ethiopia on the Afar and Karrayyu agropastoral communities. We used a mixed method that combined household and community surveys with qualitative and quantitative techniques to assess the determinants of land conflict. We applied a conceptual framework that combines theories of property rights, environmental scarcities, and political ecology to disentangle the complexities of the drivers of land conflict.

In the absence of panel data on micro-level conflicts, the dynamic nature of land conflicts is difficult to explain. However, we attempt to assess household-level determinants of conflicts robustly and cross-check the validity through focus group discussions and the available literature. Our study contributes to the sparse literature on land conflicts in large-scale land investment areas that build on micro-level, robust evidence.

Land conflicts have always been part of pastoral livelihoods in Ethiopia. Particularly, conflicts over grazing land have become more severe after the establishment of large-scale investments in pastoral areas. In the last decade, more than a quarter of the agropastoral households in our study area were exposed to land conflicts in general and 38\% with LSLIs. A household, on average, faced four conflicts over the last ten years. With a growing population and competition for land, land conflicts are likely to increase further in the future.

We argue that land conflicts in pastoral areas are the result of a myriad of resource scarcities, political marginalization, and property right distortions. The major determinants of 
land conflict are associated with supply-induced scarcity, demand-induced scarcity and dispossession of property rights, which significantly contribute to the prevalence of land conflict. The dispossession of property rights due to LSLIs and which causes a loss of access to grazing areas for pastoralists is at the center of land conflicts. Lack of trust in LSLIs perpetuates the existence of the land conflict. Severe land degradation, drought, and invasive weeds further cause pasture supply scarcities and land conflict. Increasing herd sizes increase the demand and competition for grazing land, also intensifying land conflicts. The empirical findings confirm many determinants of land use conflicts but the main reason that is identified from community discussions is the insecurity of property rights and land ownership.

The study confirms that land use policies that favor cultivation over herding are a major driver of conflicts over land. There are no clear regulations that guarantee pastoralists' rights for the use of their ancestral lands. Land policies in Ethiopia have neglected the rights of pastoralists with a bias towards large-scale industrial plantations. This has exacerbated the scarcities of pasture and water and further disrupted their livelihoods. Although the pastoral community strongly resisted the forceful evictions from their commons, they are generally voiceless and unheard of due to political marginalization. As far as pastoral people live with a long-standing grievance over the loss of land to sugar plantations, land conflicts will remain intense. Besides, inefficient formal systems, coupled with deteriorating informal systems, fail to provide adequate solutions to existing land conflicts. Therefore, designing effective institutions that monitor land conflicts and empower informal leaders in conflict handling is a necessary step in conflict resolution.

Efforts to prevent and reduce land conflicts involving pastoralists should address each of the factors increasing conflicts, as identified by this study. The most important one is the lack of clear property rights that match the pastoralists' mode of production and protect them from land grabbing by the state and other powerful groups. Hence, legal reforms that ensure property rights for customary and communal land use and that address land grievances are needed. In particular, strategies that aim at building peace need to emphasize the development of a clear land use policy for the commons in large-scale land investment affected areas. Moreover, strategies for mitigating the underlying causes of scarcity such as drought coping, rehabilitation of degraded rangelands, and prevention of Prosopis have to be prioritized to reduce land conflicts in the long run. 
Chapter 5

The Resilience of Ethiopian Agropastoral Households in the Presence of Large-Scale Land Investments 
Chapter 5 


\title{
5 The Resilience of Ethiopian Agropastoral Households in the Presence of Large-Scale Land Investments ${ }^{28}$
}

\begin{abstract}
Agropastoral societies in Ethiopia and elsewhere in Africa are facing challenges in their land use. The shifts in land use towards large-scale land investments have exacerbated the scarcity of pastures, thus affecting the resilience of pastoral systems. In this study, we assess how largescale land investments affect household resilience using data from the Living Standards Measurement Survey in Ethiopia. We estimate household resilience capacity by a multivariate two-step factor analysis and welfare resilience from net changes in welfare outcomes between two survey intervals. We assess the effect of large-scale land investment on household resilience by using an ordered random effects regression model. Factors that enhance the resilience capacities of households include access to livestock markets, social safety nets, extension, mobility, and social services. About one-third of the study population has low resilience capacity, while more than half has low welfare resilience. Households' resilience capacity significantly declines by their proximity to a large-scale land investment. Future resilience programs in agropastoral areas should mitigate the adverse effect of large-scale land investments by enhancing livelihood diversification and households' access to communal pastures.
\end{abstract}

Keywords: multivariate factor analysis, ordered random effects, pastoralism, resilience, Ethiopia

\footnotetext{
${ }^{28}$ This chapter is based on the paper by Bekele, A.E., Drabik, D., Dries, L. \& Heijman, W. under review in the journal Ecological Economics.
} 


\subsection{Introduction}

Building resilience is one of the Sustainable Development Goal targets (Bahadur et al., 2015) and has become one of the development goals in many developing countries in recent years (Alfani et al., 2015; FAO, 2018a; Gelbard et al., 2015). Resilience thinking provides a basis for understanding sustainable development and socio-ecological changes to avoid human crises (Pisano, 2012). Research on resilience in developing countries has been growing in recent years (FAO, 2016b; Levine, 2014). Increased livelihoods vulnerability to shocks and the quest for shock reduction heightened interest in resilience studies (Barrett and Constas, 2014; Speranza et al., 2014).

There is extensive literature on resilience (Asmamaw et al., 2019; Atara et al., 2020; Demeke and Tefera, 2010) and resilience to shocks (Asfaw et al., 2018; Koo et al., 2019; Mekuyie et al., 2018b). Large-scale land investments (LSLIs) are expected to exacerbate households' vulnerability to shocks (Debela et al., 2020; Wayessa, 2020; Yengoh et al., 2016; Zoomers and Otsuki, 2017). Agropastoralists mainly depend on livestock production in combination with some cropping activities. Livestock grazes on extensive communal lands, and mobility is the key strategy for maximizing feed availability (Nori and Scoones, 2019; Osman et al., 2018). The conversion of communal land to LSLIs reduces households' ability to cope in times of crisis (Haller et al., 2020). LSLIs increase community vulnerability to grazing scarcity (Beyene, 2016; McPeak and Little, 2017) and land degradation (Bekele et al., 2020; Semie et al., 2019). Hence, LSLIs are expected to harm household resilience.

Agropastoralists in Africa, and particularly in Ethiopia, face economic, ecological, and societal challenges. The most significant challenge for pastoralism in eastern Africa is the fragmentation of pasturelands (Lind et al., 2016; Rufino et al., 2013; Tsegaye et al., 2013). Land scarcity and access constraints are the main sources of food insecurity in Africa (Moyo, 2007). National policies in Etiopia have historically marginalized pastoralists (McPeak, 2001). In Ethiopia, all the land is controlled by the government, and the government has expanded LSLIs into pastoral areas, for instance, with the establishment of large sugar and cotton plantations. Consequently, in the Ethiopian Rift Valley, the Karrayu pastoralists have lost more than threefourths of their original pastureland, while $60 \%$ of the Afar rangelands have been lost since the 1960s due to LSLIs (Bekele et al., 2021). These LSLIs have restricted the local use of former commons (land, water, and forests). Existing studies on the impact of LSLIs in Ethiopia mainly focus on non-pastoral areas (Baumgartner et al., 2015; Debela et al., 2020; Shete and Rutten, 2015; Wayessa, 2020), with the exceptions of Bekele et al. (2020) and Bekele et al. (2021). 
Despite an increase in research on resilience in recent years, there is little agreement on what constitutes resilience in general and in pastoral areas in particular (Levine, 2014).

Resilience is dynamic and highly context-specific (FAO, 2016b; Speranza et al., 2014). The studies conducted on resilience in Ethiopia do not address these dynamics and the specific context of pastoral areas (Atara et al., 2020; Kebede et al., 2016; Weldegebriel and Amphune, 2017). The few studies on the resilience of pastoral communities in Ethiopia are either based on cross-sectional data without addressing the dynamic nature of resilience (Ambelu et al., 2017; Mekuyie et al., 2018b) or focus on a specific project's impact evaluation (Frankenberger, 2015; McPeak and Little, 2017). Resilience can be captured by a set of capacities that enable households to effectively function in the incidence of disturbances and still achieve a set of welfare outcomes (TANGO, 2018). Thus, two aspects of household resilience can be assessed - resilience capacities and welfare resilience. The resilience capacity refers to the capacities that help households adapt to or recover from shocks, while welfare resilience indicates achieving the desired welfare levels over time (TANGO, 2018). Resilience capacities influence the ultimate welfare outcomes (Ansah et al., 2019) and hence welfare resilience. However, most previous studies only focus on resilience capacity rather than welfare resilience. To fill this gap, we propose methods for measuring welfare resilience and test the effect of resilience capacity on welfare resilience. Moreover, the relationship between resilience and LSLI has not yet been investigated. Therefore, this study aims at investigating the likely effect of proximity to an LSLI on household resilience using panel data from the Living Standards Measurement Survey (LSMS) in Ethiopia.

Our research makes several contributions to the existing resilience literature and policy debates. First, the study provides a quantitative analysis of the effect of LSLIs on households' resilience capacity in an agropastoral context. Second, we identify the most relevant factors that contribute to building resilience capacity at the household level to inform policy and resilience planning. Third, we use unique indicators for measuring resilience capacity, propose a novel method for assessing welfare resilience, and assess the predictive power of resilience capacity on welfare resilience to close the knowledge gap and contribute to the resilience methodology.

\subsection{Conceptual Background}

The concept of resilience originates in ecology to indicate the ability of ecological systems to absorb disturbances and maintain their structure and functions (Folke, 2006; Holling, 1973; Hosseini et al., 2016; Pisano, 2012). The idea of livelihood resilience was introduced in the 
sustainable livelihoods literature (DFID, 1999) and refers to a resilient livelihood as being able to cope with stress and shocks. Tanner et al. (2015) defined livelihood resilience as the capacity of all people across generations to sustain and improve their livelihood opportunities and wellbeing despite environmental, economic, social, and political disturbances. A household is resilient when it is not exposed to shocks or if it can cope effectively when shocks occur (Alfani et al., 2015; Cervigni and Morris, 2016)

Although the concept of resilience originates in the 1970s, its measurement is still contested (Ansah et al., 2019; Jones et al., 2018). Several studies confuse the capacities that allow households to be resilient with households' welfare outcomes (Ambelu et al., 2017; FAO, 2016b; Mekuyie et al., 2018b). Examples are the Resilience Index Measurement and Analysis (RIMA) and Technical Assistance to Non-Governmental Organization (TANGO) methods (FAO, 2016b; TANGO, 2018). Both demonstrate how to construct a multidimensional resilience index. But RIMA fails to distinguish between resilience capacity and resilience outcomes (welfares), while TANGO only addresses the capacity dimension ignoring the outcome. Moreover, most of the available analytical frameworks have been developed to assess resilience to food insecurity (Alinovi et al., 2010; Alinovi et al., 2009; Atara et al., 2020; Ciani and Romano, 2014), which is too narrow for understanding the multidimensionality of resilience.

Past studies on resilience primarily focus on the community level rather than on householdlevel resilience (Quandt, 2018). Moreover, the studies that do have households as their unit of analysis focus on farmers rather than pastoralists. Exceptions include McPeak and Little (2017) and Tanner et al. (2015), who assessed shocks and determinants of vulnerability in pastoral areas, and Weldegebriel and Amphune (2017), who studied the effect of recurring floods on livelihood resilience of pastoralists. Hence further research is needed to ensure the validity of resilience measurements.

\subsection{Methodology}

\subsubsection{Data and Study Areas}

The Living Standard Measurement Survey (LSMS) for Ethiopia provides comprehensive and high-quality data that the Central Statistics Agency of Ethiopia collected in collaboration with the World Bank in 2012, 2014, and 2016. The main pastoral zones in four regions of Ethiopia, Oromia, Southern Nations Nationalities and Peoples (SNNP), Afar, and Somali are included. 
A two-stage probability sampling was used to select the study households. In the first stage, enumeration areas were identified and in the second stage, households were proportionally selected from each enumeration area. We use household- and community-level data on a total of 2106 agropastoral households, including 731 unique households of which $96.7 \%$ of them were retained in the sample each of the three survey periods.

\subsubsection{Measuring Household Resilience}

Several methods have been proposed to measure resilience capacity. The most widely used method is the indicator-based approach, which uses indicators to construct a resilience index (Alinovi et al., 2010; Alinovi et al., 2009; Asmamaw et al., 2019). In this approach, the RIMA developed by the FAO and TANGO developed by the US Agency for International Development (FAO, 2016b; TANGO, 2018) are the most common. RIMA includes assets, adaptive capacity, social safety nets, access to public services, stability, income, and food access as components of the resilience index. TANGO focuses on the absorptive, adaptive, and transformative pillars of resilience. Several authors have proposed similar methods but used different frameworks or components of resilience (Alinovi et al., 2010; Alinovi et al., 2009; Demeke and Tefera, 2010; FAO, 2016b; Quandt, 2018; Sina et al., 2019; Weldegebriel and Amphune, 2017). In the indicator-based methods, resilience is not an end in itself, but rather refers to the household's capacity to maintain or improve a certain welfare level (FSIN, 2015). The higher the household's capacity to prepare, cope, and adapt, the lower the implied impact of shocks on wellbeing (Schipper and Langston, 2015).

Another common method is the welfare approach pioneered by the World Bank (Alfani et al., 2015). In this approach, resilience is interpreted as achieving the standard welfare level or recovering from a welfare loss and rebounding to the original welfare level. A resilient household is one with very little difference in welfare before and after a shock (Alfani et al., 2015; Alinovi et al., 2009; Barrett and Constas, 2014; Cervigni and Morris, 2016; Rasch et al., 2017). Rasch et al. (2017) adopt a Gini coefficient based on the herd size of the household as a proxy for measuring system resilience and indicators of access to resources and asset poverty for measuring household resilience. McPeak and Little (2017) use income variability over time as a proxy for resilience. Others classify households as resilient when their average income is above the international poverty line of US\$1.25 per capita per day (de Haan, 2016).

In our analysis, we use the indicator-based method to estimate the resilience capacity and the welfare-based method to estimate welfare resilience. In the indicator method, we adopt the resilience capacity dimensions of absorptive capacity, adaptive capacity, transformative 
capacity, and their respective indicators (Smith and Frankenberger, 2018; TANGO, 2018). Absorptive capacity (ABS) refers to the household's ability to cope with shocks. From the LSMS, variables of credit, saving, and irrigation access, sale of livestock, and assets were used to estimate ABS. While past studies failed to incorporate households' coping strategies with shocks in estimating absorptive capacities (Ansah et al., 2019), we also include household food shortages coping strategies in the estimation of the ABS.

Adaptive capacity (ADP) refers to the household's ability to adjust to a new livelihood strategy. Household income, access to different income sources, level of education and literacy, health situation, assets owned, participation in crop and livestock extension, and the availability of adult labor have been found to influence household ADP (Brück et al., 2019; Catley, 2013; Frankenberger, 2016). The level of forest coverage in the village may have a positive effect on the household ADP. The transformative capacity (TRANS) is the household's ability to transform their livelihoods and become less vulnerable to shocks. TRANS is constructed from the availability and access to basic social services such as roads, large markets, primary and secondary schools, microfinance and rural saving, hospitals and other health services, phone services, water supply, and cooperatives (Brück et al., 2019; Catley, 2013). Figure 5-1 represents the three dimensions of livelihood resilience capacity.



Figure 5-1. Three dimensions of livelihood resilience capacity

When first exposed to disruptions, the household develops absorptive capacity in the short term and then adapts its livelihood strategies to recover or withstand shocks. Through this process, it transforms structurally. Hence, resilience capacities have a dynamic nature. Household $i$ 's resilience capacity (RC) at time $t$ can be specified as follows:

$$
R C_{i t}=f(A B S, A D P, T R A N S)
$$


The indicators used to measure household resilience capacity take the value of 1 if a household has access to the particular capacity indicator and 0 otherwise. We standardized the continuous variables to 1 for the highest value and 0 for the lowest. Negative values were converted to positive values (e.g., inverse distances or inverse coping strategies). Following FAO (2016b), we use a min-max scaling to transform the RC value into a standardized index between 0 and 1 . We then created three unique terciles within the resilience capacity distribution: low, moderate, and high resilience capacity.

For the welfare method, we use changes in welfare outcome indicators. Households are resilient if they achieve a positive change in the welfare threshold level after being exposed to or having recovered from shocks. Changes in income, consumption expenditure, food intake (2200 kcal/day/adult), and poverty (1.9 USD/day/adult) are used as welfare outcome indicators. The changes in welfare outcomes are reported as 1 (if positive), 0 otherwise. Our approach is supported by theoretical and empirical research (Ansah et al., 2019; Arouri et al., 2015; FSIN, 2015).

\subsubsection{Empirical Model}

Principal component analysis and factor analysis can be used to estimate the resilience capacity index and its different dimensions. Factor analysis is preferable because it does not force all of the components explaining the correlation structure between the indicators (FAO, 2016b). We use two-stage factor analysis to construct RC. In the first stage, we estimate ABS, ADP, and TRANS capacities by using the factor variance (Alinovi et al., 2010). The first factor with an eigenvalue greater than one and the highest variance was used to construct the three resilience capacities. Second, the RC was estimated by aggregating ABS, ADP, and TRANS

$$
R C_{i t}=\sum_{c=1}^{3} v_{i t} F_{i t}
$$

where $F_{i t}$ is the factor generated, $v_{i t}$ is the factor variance for each factor, and $\mathrm{c}$ is the particular resilience capacity.

To assess the effect of proximity to LSLI on household resilience, we classify households as treated ( 1 if the household is located at a distance of less than $150 \mathrm{~km}$ from an LSLI) and control (at least $150 \mathrm{~km}$ ). We conducted sensitivity analysis by choosing the cut-off points at $50 \mathrm{~km}, 100 \mathrm{~km}$, and $150 \mathrm{~km}$ distance from an LSLI. The LSLI treatment effects consistently show similar effects but with some variations in coefficients. Considering herd mobility, statistical comparisons, and spillover effects, we chose the $150 \mathrm{~km}$ cut-off point. We focus on 
sugar plantations because a lot of rangeland has been allocated to sugar plantations in Ethiopia, and their location is easily detectable. We used the household coordinates to calculate the distance of each household to sugar plantations.

A panel data regression - either fixed effects (FE) or random effects (RE) — can be used to handle household heterogeneity and time effects. The Hausman test shows that the RE regression is favored (Appendix Table 5-A). We use the ordered RE logit model to estimate the covariates of resilience capacity and assess the effect of resilience capacity on welfare resilience using the first differenced variables. We detected no problems with multicollinearity (Appendix Table 5-A).

From the standard RE model, let $R C_{i t}^{\prime}$ be a latent variable of the $\mathrm{i}^{\text {th }}$ household's $\mathrm{RC}$ at time $\mathrm{t}$ :

$$
R C_{i t}^{\prime}=\alpha_{i t}+\lambda_{t}+\tau_{i t}^{\prime} \beta+s_{i t}^{\prime} \beta+\left(\tau_{i t}^{\prime} s_{i t}^{\prime}\right) \beta+x_{i t}^{\prime} \beta+\left(u_{i}+\varepsilon_{i t}\right)
$$

$R C_{i t}^{\prime}$ is a function of the LSLI treatment $\tau_{i t}$, the shocks index $s_{i t}$, LSLI treatment shock interactions $\tau_{i t} * s_{i t}$ and a vector $x_{i t}$ which includes demographic factors (age, gender and education status), livelihood strategy representing pure pastoralists who exclusively depend on livestock and agropastoralists who grow crops in addition to livestock, agroecology, and mobility covariates (Table 5-1), while $\alpha_{i t}$ represents the intercept, $\lambda_{t}$ the time effect, $u_{i}$ is the individual effect, $\varepsilon_{i t}$ is the unobserved random effect: $u_{i} \sim N\left(0, \delta^{2}{ }_{u_{i}}\right)$ and $\varepsilon_{i t} \sim N\left(0, \delta^{2} \varepsilon_{i t}\right)$. The variable $y_{i t}^{\prime}$ is estimated by the maximum likelihood method with a set of cut-off points $\mathrm{k}$ simultaneously estimated with $\beta$ and that differentiate the low resilient from middle and high resilient households respectively when the values of the predictor variables are zero and specified as:

$$
R C_{i t}=\left\{\begin{array}{c}
1 \text { if } y_{i, t}^{*} \leq k_{1} \\
2 \text { if } y_{i, t}^{*} \leq k_{2} \\
3 \text { if } y_{i, t}^{*} \geq k
\end{array}\right.
$$

The probability of households falling into a particular resilience status can then be derived as:

$$
p\left(y_{i}>j\right)=\frac{\exp ^{\left(x_{i} \beta_{i}-k_{j}\right)}}{1+\exp ^{\left(x_{i} \beta_{i}-k_{j}\right)}}, \mathrm{j}=1, \ldots, \mathrm{J}
$$

where $J$ is the highest resilience index with $j=1$ for low resilience, $j=2$ for moderate resilience and, $\mathrm{j}=3$ for high resilience.

Next, we develop a first differenced model to estimate the effect of RC on WR to test the relevance of RC in predicting future welfare attainments. First-differencing eliminates individual effects and serial correlation and yields a more robust model (Baltagi, 2008). 


$$
\Delta W R_{i t}=\delta_{i t}+\tau_{\mathrm{it}} \beta+\Delta \mathrm{RC}_{i t}+\Delta s_{i t} \beta+\Delta\left(s_{i t} * \mathrm{RC}_{i t}\right) \beta+\Delta \mathrm{z}_{\mathrm{it}} \beta+x_{i t} \beta+\Delta u_{i, t}+\Delta \varepsilon_{i t}
$$

where $W R_{i t}$ indicates changes in welfare indicators, $\tau_{i}$ is LSLI treatment, $z_{i}$ and $\mathrm{xi}_{\mathrm{i}}$ are vectors of time-varying and time-invariant variables (Table 5-1) at time t, $\delta_{i}$ is a constant, $u_{i t}$ the individual effects, and $\varepsilon_{i t}$ the random error, $u_{i} \sim N\left(0, \delta^{2}{ }_{u_{i}}\right)$ and $\varepsilon_{i t} \sim N\left(0, \delta^{2} \varepsilon_{i t}\right)$.

Table 5-1. Summary of LSLI treatment and covariate variables

\begin{tabular}{lllll}
\hline Variables & Measurement & Mean & Std. Dev. Hypothesis \\
\hline LSLI Treatment & 1 if $<150 \mathrm{~km}, 0$, otherwise & 0.37 & 0.48 & - \\
Shock index & Continuous & 10.10 & 10.59 & - \\
Livelihoods & 1 for pastoral, 0 otherwise & 0.23 & 0.42 & - \\
Agroecology & 1 for warm/arid, 0 otherwise & 0.52 & 0.50 & - \\
Gender & 1 for men, 0 otherwise & 0.77 & 0.42 & + \\
Age & Years & 45.17 & 15.37 & + \\
Education level & Years of schooling & 1.67 & 3.48 & + \\
Mobility & 1 if the herd feed out of the village, 0 & & + \\
& otherwise & 0.53 & 0.50 & \\
\hline
\end{tabular}

*The LSMS data consists of data on household exposure to 16 shocks, and their severity is rated as most severe, second-most severe, and third-most severe by their impact. We calculate the shock index as the weighted sum of the product of the frequency and severity of a given shock. Source: Authors' calculations from LSMS data (2021)

\subsection{Results and Discussions}

\subsubsection{Household Resilience}

We first determine the household resilience capacity index. Indexes of absorptive, adaptive, and transformative capacities have been constructed using the first factor components from uniquely assigned indicators. Only including the indicators that have a positive coefficient, as hypothesized in the final estimation is a common practice (Smith and Frankenberger, 2018; TANGO, 2018). Therefore, we remove the health status of the household head and assets from adaptive capacity and inverse distance to the market from transformative capacity in the final analysis as they show a negative correlation with resilience capacity. The Bartlett's score test and the Kaiser-Meyer-Olkin (KMO) test statistic indicate the fitness of the factor analysis. Social safety nets and the sale of livestock and other assets strongly contribute to household 
ABS (Table 5-2). Social safety nets include in-kind/cash transfers, cash assistance, receiving unconditional help from relatives, the government, and NGOs. In countries like Ethiopia, where access to formal insurance schemes is lacking, social safety nets are the most common means of coping with adverse shocks. Likewise, saving and irrigation access contribute to the absorptive capacity; households with more savings and access to irrigation can better absorb disturbances.

Table 5-2. Variables and factor loadings for absorptive capacity (ABS)

\begin{tabular}{lll}
\hline Absorptive variables & Average & Factor loadings \\
\hline Inverse CSI* & 2.830 & 0.127 \\
Safety nets & 0.312 & 0.654 \\
Saving & 0.175 & 0.391 \\
Credit & 0.179 & 0.215 \\
Migrate (labor, jobs) & 0.033 & 0.199 \\
Sale of livestock and other assets & 0.245 & 0.648 \\
Irrigation access & 0.093 & 0.378 \\
\hline KMO & 0.54 & \\
\% variance & $17.33 \%$ & \\
Eigenvalue & 1.193 & \\
Bartlett test (chi2) & $105.085^{* * *}$ & \\
Alpha & 0.180 & \\
\hline
\end{tabular}

*We calculate the Coping Strategies Index (CSI) by using universal severity weights for each coping strategy following Maxwell and Caldwell (2008). The LSMS data contains household coping strategies and how often each coping strategy was used over seven days.

Source: Authors' calculations from LSMS data (2021)

Table 5-3 presents factors that contribute to the adaptive capacity of households. Access to livestock and crop extension, number of literate household members, adult labor, and cultivated land size highly contribute to the ADP. The income and number of income sources also contribute to the ADP of a household. Livestock size and herd diversification have the lowest contribution to adaptive capacity. 
Table 5-3. Variables and factor loadings for adaptive capacity (ADP)

\begin{tabular}{lll}
\hline Adaptive Variables & Average & Factor loadings \\
\hline \% literate household members & 0.35 & 0.538 \\
Number of adult workers & 0.31 & 0.558 \\
Land size (ha) & 0.94 & 0.427 \\
Tropical livestock units (TLU) & 6.24 & 0.020 \\
Number of income sources & 1.46 & 0.269 \\
Livestock diversity index & 5.91 & 0.114 \\
Annual income (ETB) & 5329 & 0.248 \\
Livestock extension & 0.16 & 0.779 \\
Crop extension & 0.151 & 0.806 \\
Soil quality & 0.399 & 0.043 \\
\% forest land & 9.21 & 0.079 \\
\hline KMO & 0.596 & \\
\% variance & $57.61 \%$ & \\
Eigenvalue & 2.189 & \\
Bartlett test (chi2) & $8311.92 * * *$ & \\
Alpha & 0.527 & \\
\hline Source: Authors & & \\
\hline
\end{tabular}

Source: Authors' calculations from LSMS data (2021)

Table 5-4 shows the factor loadings on the transformative capacity of households. The availability of health centers, hospitals and pharmacies, phone services, micro-credit, and proximity to asphalt roads and primary schools enhance the household's transformative capacity. 
Table 5-4. Variables and factor loadings for transformative capacity (TRANS)

\begin{tabular}{lll}
\hline Transformative variables & Average & Factor loadings \\
\hline Availability of pharmacy & 0.68 & 0.516 \\
Availability of health post & 0.79 & 0.427 \\
Availability of water supply & 0.28 & 0.209 \\
Inverse distance to asphalt road (km) & 48.4 & 0.408 \\
Availability of large market & 0.43 & 0.290 \\
Inverse distance to primary school $(\mathrm{km})$ & 0.35 & 0.383 \\
Inverse distance to secondary school $(\mathrm{km})$ & 18.9 & 0.084 \\
Availability of hospital & 0.32 & 0.731 \\
Availability of micro-credit & 0.068 & 0.287 \\
Availability of phone services & 0.076 & 0.403 \\
\hline KMO & 0.53 & \\
E variance & $34.2 \%$ & \\
Bigenvalue & 1.676 & \\
alpha & $2237.196 * * *$ \\
\hline Sourtlett test (chi2) & 0.5079 & \\
\hline
\end{tabular}

Source: Authors' calculations from LSMS data (2021)

The resilience capacity is estimated by aggregating the ABS, ADP, and TRANS capacities (Table 5-5). Overall, the study population achieves $39.1 \%$ of the potential resilience capacity. This is low and consistent with Melketo et al. (2021). TRANS contributes the most to household resilience (0.588) followed by the ABS (0.356) and ADP (0.296) capacities. ADP's contribution to the resilience index is low compared to the other two resilience capacity dimensions. By geographical location, households in Oromia and Gambella regions seem to have better resilience capacity, while Somalia and Afar pastoralists have the lowest (Appendix Figure 5-a).

We estimate welfare resilience (WR) from changes in welfare outcomes between two survey intervals; a positive change indicates resilience, while a negative change points to a lack of resilience. The literature supports this approach (Alinovi et al., 2009; Barrett and Constas, 2014; Ciani and Romano, 2014; Verschuur et al., 2020). Households that can maintain a positive gain in their welfare are defined as resilient (1), 0 otherwise (Table 5-5). WR is estimated from the gain (loss) in income, food intake (kcal/day/adult), consumption 
expenditure, and poverty as a composite index. The income per capita is estimated from the farm and nonfarm sources for each survey year. The food intake was estimated from the seven days food consumption data and calculated as kilocalories of food consumed per adult per day (Bekele et al., 2021). The consumption expenditure is the annual value of food and non-food consumption expenditure per adult per day. The poverty line was set at the $1.9 \mathrm{USD} /$ day/adult global poverty line. Accordingly, most (75.7\%) agropastoral households are living in extreme poverty, which is comparable to the proportion of poor agropastoralists in Africa (77\%) (de Haan, 2016). The results show that the study population has achieved $32.6 \%$ of the possible WR. About $58.2 \%, 48.4 \%, 53.2 \%$ of the households have a positive gain in their income, consumption, and food intake, respectively. The gain in income between two survey intervals is higher than in other welfare dimensions. On the contrary, $41.8 \%$ of households have encountered a decline in total income, while above half suffer a loss in consumption expenditure; $47.0 \%$ and $8.1 \%$ of households experienced a worsening of food security and poverty.

Table 5-5. Household resilience by category

\begin{tabular}{ll}
\hline Resilience capacities & Mean \\
\hline Absorptive & 0.356 \\
Adaptive & 0.296 \\
Transformative & 0.588 \\
RC & 0.391 \\
\hline Welfare resilience & \\
\hline Total income & 0.582 \\
Consumption expenditure & 0.484 \\
Food intake (Kcal/day/adult) & 0.532 \\
Poverty & 0.081 \\
WR & 0.362 \\
\hline
\end{tabular}

Source: Authors' calculations from LSMS data (2021)

Finally, we cluster households into the less, moderate, and high resilient groups by their RC and WR status. Table 5-6 indicates that $28.6 \%$ of the sample fall under low, $47.72 \%$ under moderate, and $13.69 \%$ under the high resilience capacity categories. At the same time, $54.0 \%$ 
of households fall in the low WR category, implying that most households often fall into extreme poverty and food insecurity.

Table 5-6. Household resilience levels

\begin{tabular}{lllll}
\hline & Resilience capacity & \multicolumn{2}{l}{ Welfare resilience } \\
Resilience & Average Score & $\%$ & Average Score & $\%$ \\
\hline Low & 0.216 & 28.58 & 0.19 & 53.96 \\
Moderate & 0.393 & 47.72 & 0.5 & 34.62 \\
High & 0.598 & 23.69 & 0.77 & 11.42 \\
Total & 0.391 & 100 & 0.362 & 100 \\
\hline F/chi2 & $4793.7 * * *$ & & $4209.4^{* * *}$ \\
\hline
\end{tabular}

Source: Authors' calculations from LSMS data (2021)

\subsubsection{LSLI Proximity and Household Resilience}

Table 5-7 shows the resilience capacity, shock intensity, and welfare indicators by LSLI proximity. Proximity to LSLI is significantly associated with lower RC, absorptive and adaptive capacity. Households nearby the LSLIs are significantly more vulnerable to livelihood shocks compared to their counterparts. There is no significant variation between treated and control households based on their net gain in income and consumption. Moreover, there is no significant difference between treated and control households in their poverty reduction. However, income and WR significantly increase with proximity to LSLI. This could be due to the availability of good natural resources and wage opportunities as one moves closer to the LSLIs (Bekele et al., 2021). 
Table 5-7. The association of LSLI proximity with household resilience

\begin{tabular}{lllll}
\hline & \multicolumn{5}{l}{ LSLI proximity } \\
\hline Resilience capacities & Total & Treated & Control & t-test /chi2 \\
\hline Absorptive & 0.356 & 0.347 & 0.361 & $1.794^{*}$ \\
Adaptive & 0.296 & 0.288 & 0.30 & $1.804^{*}$ \\
Transformative & 0.588 & 0.588 & 0.587 & -0.065 \\
RC & 0.391 & 0.375 & 0.387 & $1.719^{*}$ \\
\hline Shock index & 10.1 & 11.32 & 9.38 & $-4.073^{* * *}$ \\
\hline Welfare indicators & Net change & Treated & Control & \\
\hline Total income* & 1700.1 & 2158.8 & 1433.9 & -1.317 \\
Consumption expenditure & -137.1 & -61.04 & -181.2 & -0.318 \\
Food intake (Kcal/day/adult) & 160.5 & 326.7 & 64.0 & $-2.056^{* *}$ \\
\% non-poor households & 16.22 & 17.43 & 15.52 & 0.856 \\
WR & 0.362 & 0.375 & 0.355 & $-1.661^{*}$ \\
\hline
\end{tabular}

${ }^{*}$ The currency for total income and consumption expenditure is in Ethiopian Birr (ETB). ***,**, * respectively indicates $\mathrm{P}<0.01, \mathrm{P}<0.05$ and $\mathrm{P}<0.1$

Source: Authors' calculations from LSMS data (2021)

An important feature of agropastoral livelihoods is their heterogeneity and dynamic nature. To incorporate this heterogeneity and dynamics in the estimation of the implications of LSLI proximity on livelihood transitions, we cluster agropastoral households as described in McPeak and Little (2017). We identify four groups of agropastoral households based on their household income and herd size; above or below the median: withdrew from pastoralism; exclusive pastoralists; combining pastoralism with other activities and progressing for moving out of pastoralism.

The groups who withdrew from pastoralism have exited traditional herding and engaged in low return activities (below median herd and income); the moving out groups have a high income, but a low number of herds. They are moving from a livestock-dominated economy to a cash-based economy with access to non-pastoral economic activities; exclusive pastoralists are still pursuing traditional pastoralism and are less integrated into the cash economy (they have below the median income and above the median herd size), and the fourth group is combining pastoralism with other income sources such as commercialization. Similar classification approaches are used by McPeak and Little (2017) and Lind et al. (2016). The 
result shows that a higher proportion of the treated households than control households have withdrawn $(32.3 \%)$ or are moving out of pastoralism $(25.0 \%)$, while more of the control households are diversifying (29.7\%) and exclusive pastoralism (24.6\%) (Table 5-8). This suggests that the expansion of LSLI into pastoral areas will eventually lead to the abandonment of pastoralism in the long run. Households moving from pastoralism to the cash economy and the combining groups have higher resilience. Both those who withdrew or exclusive pastoralists have lower resilience capacity (Figure 5-2). Households with the highest absorptive capacity are moving from pastoralism, while those with the highest adaptive capacity combine pastoralism with other income-enhancing activities. Households with the highest transformative capacity have withdrawn pastoralism.

Table 5-8. Livelihood transitions by resilience and LSLI proximity

\begin{tabular}{|c|c|c|c|c|c|c|c|}
\hline & $\begin{array}{l}\text { Livelihood } \\
\text { groups }\end{array}$ & Withdrew & Combining & $\begin{array}{l}\text { Moving } \\
\text { out }\end{array}$ & $\begin{array}{l}\text { Exclusive } \\
\text { pastoralists }\end{array}$ & Total & Chi2/F \\
\hline \multirow{2}{*}{$\begin{array}{l}\text { LSLI } \\
\text { treatment }\end{array}$} & Control & 22.3 & 29.7 & 23.5 & 24.6 & 62.9 & \multirow{2}{*}{$39.8 * * *$} \\
\hline & Treated & 32.3 & 19.5 & 25.0 & 23.2 & 37.1 & \\
\hline \multirow{5}{*}{ Resilience } & Absorptive & 0.345 & 0.359 & 0.372 & 0.347 & 0.355 & $2.72 *$ \\
\hline & Adaptive & 0.215 & 0.358 & 0.324 & 0.272 & 0.292 & $138.9 * * *$ \\
\hline & Transformative & 0.615 & 0.555 & 0.608 & 0.569 & 0.587 & $21.6 * * *$ \\
\hline & $\mathrm{RC}$ & 0.351 & 0.397 & 0.417 & 0.353 & 0.379 & $31.0 * * *$ \\
\hline & WR & 0.324 & 0.396 & 0.419 & 0.292 & 0.362 & $26.5 * * *$ \\
\hline
\end{tabular}

Source: Authors' calculations from LSMS data (2021) 


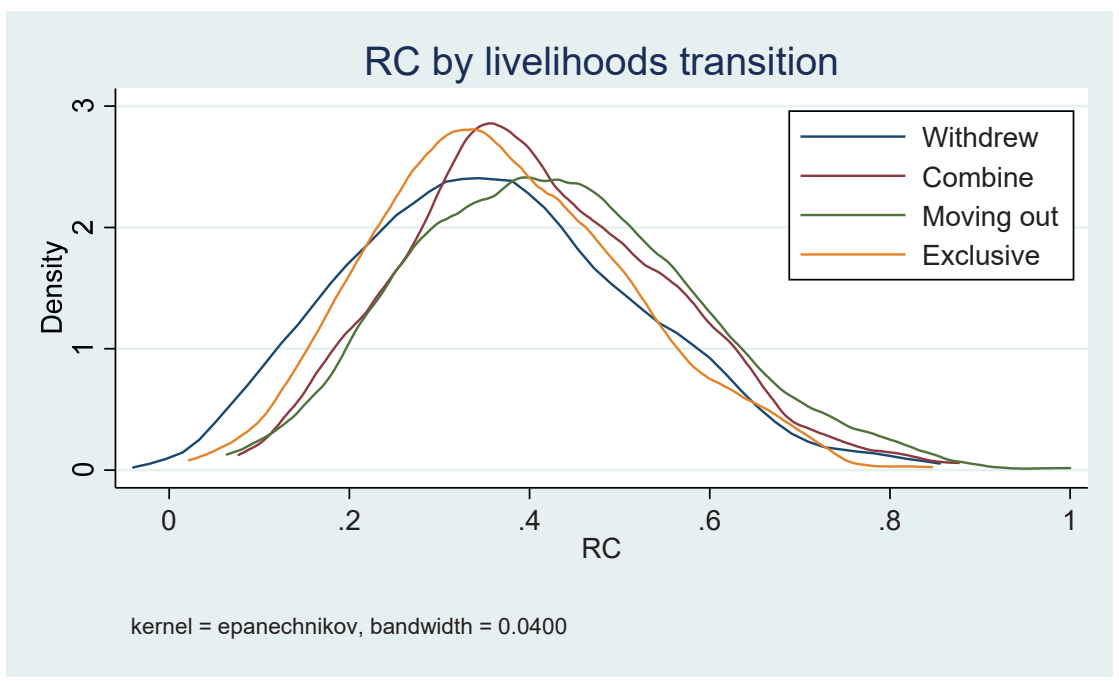

Figure 5-2. Resilience capacity by livelihood transitions

\subsubsection{The Effect of LSLI Proximity on Household Resilience Capacity}

Table 5-9 presents an ordered RE model result on the effects of LSLI proximity on resilience capacity and welfare resilience and the effect of resilience capacity on welfare resilience, controlling for confounders. The Wald and LR tests show that the model fits the data well. As expected, proximity to LSLI has a negative correlation with resilience capacity, but no significant effect on WR. This implies that LSLI proximity reduces the likelihood of households becoming highly resilient. Likewise, shock intensity adversely affects the resilience capacity of agropastoral households. Households who pursue pure pastoralism are less resilient compared to those who practice livestock and cropping. Likewise, women-headed households are less resilient than those led by men, and households in warm semi-arid are less resilient.

Moreover, to investigate the association between changes in welfare outcomes and resilience capacity, ordered RE logistic regression models were fitted for households experiencing gain (1) or reduction (0) in income, per capita, caloric intake, consumption expenditure, poverty, and WR, respectively. The findings indicate that resilience capacity increases the likelihood of households to improve income, per capita food intake, poverty, and WR between two survey intervals, controlling for shocks and LSLI treatment. Hence, RC is a good predictor of WR. The significant positive effect of the RC-shock interaction indicates that $\mathrm{RC}$ helps households to recover from shocks. No significant difference in food expenditure was observed by resilience capacity. Proximity to LSLI has a significant positive effect on food intake and poverty. This is because of relatively better access to roads and markets near LSLIs 
Chapter 5

(Bekele et al., 2021). A unit change in shock intensity would minimize the likelihood of growth in households' consumption expenditure. Herd mobility increases the likelihood of gain in income and consumption in the face of shocks. 


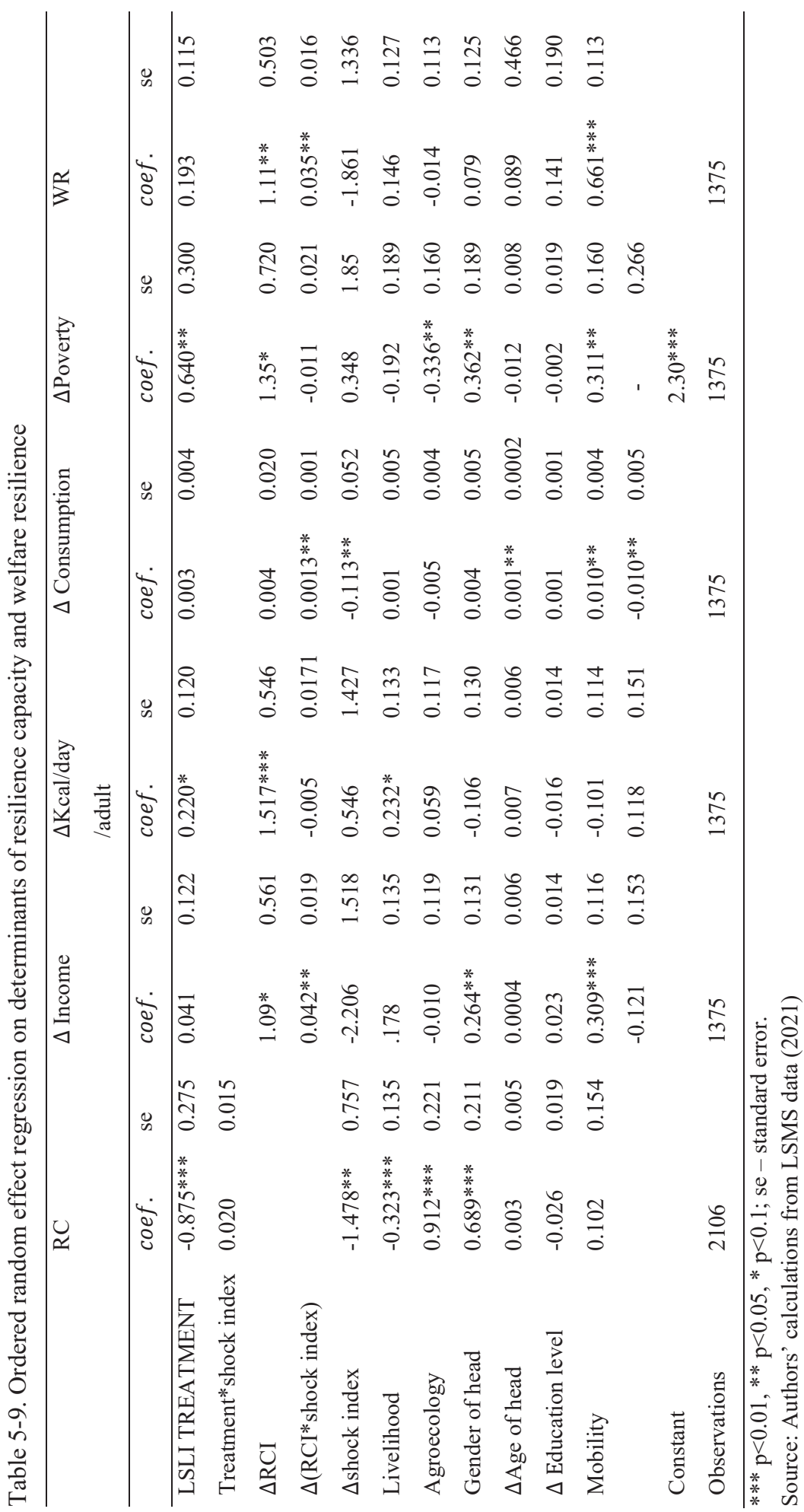




\subsection{Discussion}

Our findings confirm that LSLIs, which convert rangelands into sugar plantations, have profound impacts on household resilience capacity. LSLIs are mainly associated with lower absorptive and adaptive capacities and overall resilience capacity. As LSLIs took good lands, people became more vulnerable to grazing scarcity and less resilient. This finding is consistent with the existing empirical evidence (Koo et al., 2019; Lind et al., 2020; Moyo, 2007; Osman et al., 2018). LSLIs were also found not to benefit the host community (Bekele et al., 2020; Bekele et al., 2021; Debela et al., 2020). The study population has a low level of resilience, while LSLI proximity further reduces household resilience capacity by increasing household vulnerability to grazing scarcity and shocks. Thus, more effort is required for building resilience capacity in the agropastoral areas affected by LSLIs. On the contrary, LSLI proximity did not have a significant effect on household welfare resilience.

The study shows that livelihood strategy, shock intensity, gender, and mobility are significant factors influencing resilience capacity. Agropastoral households have better resilience capacity compared to pastoral households, implying that households who practice crop cultivation in addition to livestock have higher resilience than pure pastoralists. This is in line with Tsegaye et al. (2013). However, it is difficult for pastoral communities to access suitable land for cropping especially in regions where land was already taken by LSLIs. As a consequence, households' dependence on diverse income sources has increased (McPeak and Little, 2017). Households who withdrew from pastoralism are found to be less resilient, while those commercializing and those who combine pastoralism with other income sources have higher resilience. Thus, diversification strategies that integrate livestock husbandry with markets could improve household resilience capacity. The result is consistent with studies that report how diversification improves welfare in rural Africa (Barrett et al., 2001; McPeak, 2001). However, a study from China finds that livelihood diversification did not improve pastoral welfare (Liao et al., 2015). Households with better income, even though they own few numbers of livestock, have higher resilience, although some studies state the importance of herd size for household resilience (Cervigni and Morris, 2016; Rasch et al., 2017).

As expected, proximity to LSLI increases household vulnerability to shocks, and the shock index has an adverse effect on household resilience. This implies that a household's vulnerability to livelihood shocks is linked to its inability to access critical grazing and water resources. The result is in line with a report from Ethiopia (Behnke and Kerven, 2013). However, it is worth noting that while shock incidence reduced the overall resilience capacity 
of households, it led to an increase in food intake. This could be due to recurrent shocks that might have improved the household's knowledge of adaption strategies (Asfaw et al., 2018; Asmamaw et al., 2019). Our study also reveals gender as a key determinant of resilience capacity; male-headed households have higher resilience than female-headed ones. This result is in line with previous studies (Catley, 2013; Gmür, 2020; Mekuyie et al., 2018b). Generally, women have limited access to resources and livelihood opportunities (Barrett et al., 2001; Bottazzi et al., 2018). The effect of proximity to LSLI on women-headed households could be worse than men-headed households. Hence, strategies that enhance women's opportunities can improve their resilience. Finally, mobility is an important factor in enhancing household resilience. This is in line with the new rangeland paradigm (Nori and Scoones, 2019; Osman et al., 2018). Thus, policies that promote pastoralists' access to restricted common pastures can improve household resilience.

These results have important implications for pastoral development policy in Ethiopia and are likely to offer useful insights for pastoral development in Sub-Saharan Africa. Hence, we expect our findings to be relevant also to other agropastoral settings with LSLIs. First, LSLIs are important drivers of livelihood transitions in agropastoral areas. Consequently, agropastoralists become heterogeneous by their livelihood patterns (e.g., the withdrew, exclusive, combining, and moving out pastoralists). Hence, policy options for enhancing resilience need to be specific to each group, and the "one size fits all" development approach will not work. Second, the increasing allocation of pastoral rangelands for LSLIs (e.g., sugar plantations, cotton) will lead to further scarcity of communal grazing areas. Therefore, future LSLI plans should consider inclusive plans for building agropastoral households' resilience against such resource scarcity. For households exclusively being pastoralists, securing access to land and water will help build their resilience. Thus, the government needs to ensure land rights to prevent household vulnerability to pasture scarcity. Third, the agropastoral dryland areas are vulnerable to climatic shocks. LSLIs further increase household vulnerability to such shocks. Therefore, strategies that enhance the adaptive capacities of households are critical for mitigating the adverse effect of shocks. Fourth, livelihood diversification and moving from pastoralism positively influence household resilience. Policy options that enhance households' access to markets, irrigation, extension services, and alternative livelihoods could improve household resilience.

There are data limitations worth mentioning. We could not directly assess the positive or negative effect of LSLIs on household resilience because of the absence of baseline data, and the LSMS lacks data on LSLIs. Nevertheless, this study provides a valuable insight into how 
proximity to LSLIs impacts household resilience. Therefore, future research that includes baseline data is important to understand the effect of LSLIs on household resilience.

\subsection{Conclusion}

This study assesses the effect of proximity to LSLIs on household resilience in agropastoral areas of Ethiopia by using LSMS panel data. A multivariate factor analysis was used to construct a resilience capacity index. A composite index of welfare resilience is estimated from a net change in welfare outcomes between two survey intervals, while ordered RE regression models were used to assess the association between LSLI proximity and resilience.

Our findings show that the study population has a low level of resilience, and LSLIs further lower household resilience capacity by limiting access to grazing and increasing household vulnerability to shocks. Therefore, enhancing access to communal grazing and shock adaptation strategies in pastoral areas affected by LSLIs is useful. The study identified access to livestock markets, social safety nets, extension, and social services to be the most important factors that enhance the resilience capacities of households. Enhancing household access to extension, literacy programs, and alternative income sources can improve household adaptive capacities. The study also assesses the predictive power of resilience capacity on welfare status. The result confirms that household resilience capacity is a good predictor of welfare resilience, indicating our proposed welfare resilience method to be a good indicator for measuring household resilience.

The study also revealed livelihood diversification, gender, and mobility as key determinants of resilience capacity. Male-headed households have higher resilience than female-headed ones. Strategies that aim to empower women in the study area would therefore be beneficial. Proximity to LSLIs also influences livelihood transitions that may lead to the moving out of pastoralism in the long term. Households with mixed livelihoods and moving from pastoralism have higher resilience. This implies that enhancing livelihood diversification strategies into crop and non-farm enterprises would improve resilience outcomes. Besides, most agropastoral households live in extreme poverty, which requires development strategies that target poverty reduction. 
Appendix Table 5-A. Hausman test

\begin{tabular}{|c|c|c|c|c|}
\hline & \multicolumn{4}{|c|}{ Coefficients } \\
\hline & (b) & (B) & (b_B) & $\operatorname{sqrt}\left(\operatorname{diag}\left(V_{-} b\right.\right.$ \\
\hline & (fe) & (re) & \multicolumn{2}{|l|}{ Difference } \\
\hline Treatment & -0.876 & -0.877 & 0.001 & 0.013 \\
\hline Treatment*shock index & 0.019 & 0.019 & 0.001 & 0.001 \\
\hline Shock index & -1.463 & -1.441 & -0.022 & 0.040 \\
\hline Livelihoods & -0.313 & -0.304 & -0.010 & 0.008 \\
\hline Agroecology & 0.900 & 0.897 & 0.003 & 0.009 \\
\hline Gender & 0.684 & 0.653 & 0.031 & 0.018 \\
\hline Age & 0.003 & 0.005 & -0.001 & 0.001 \\
\hline Education level & -0.026 & -0.026 & 0.000 & 0.001 \\
\hline Mobility & 0.102 & 0.237 & -0.135 & 0.108 \\
\hline \multirow[t]{3}{*}{ Test: } & \multicolumn{4}{|c|}{ Ho: difference in coefficients not systematic } \\
\hline & & $\operatorname{chi} 2(10)$ & \multicolumn{2}{|c|}{$\begin{array}{l}=(b-B)^{\prime}\left[\left(V_{-} b-V \_B\right)^{\wedge}(-1)\right](b-B) \\
9.98\end{array}$} \\
\hline & & Prob $>$ chi 2 & \multicolumn{2}{|l|}{0.4418} \\
\hline
\end{tabular}


Chapter 5

Appendix Table 5-B. Collinearity Diagnostics

\begin{tabular}{lllll}
\hline Variable & SQRT & & R- \\
Treatment & VIF & VIF & Tolerance & Squared \\
Treatment*shock index & 1.96 & 1.4 & 0.510 & 0.490 \\
Shock index & 3.23 & 1.8 & 0.310 & 0.691 \\
Livelihoods & 2.1 & 1.45 & 0.477 & 0.523 \\
Agroecology & 1.09 & 1.04 & 0.921 & 0.079 \\
Gender & 1.2 & 1.09 & 0.836 & 0.164 \\
Age & 1.05 & 1.02 & 0.957 & 0.043 \\
Education level & 1.04 & 1.02 & 0.962 & 0.038 \\
Mobility & 1.01 & 1.01 & 0.986 & 0.014 \\
Mean VIF & 1.01 & 1 & 0.991 & 0.009 \\
\hline
\end{tabular}


Appendix Figure 5-a. Resilience capacity by regions

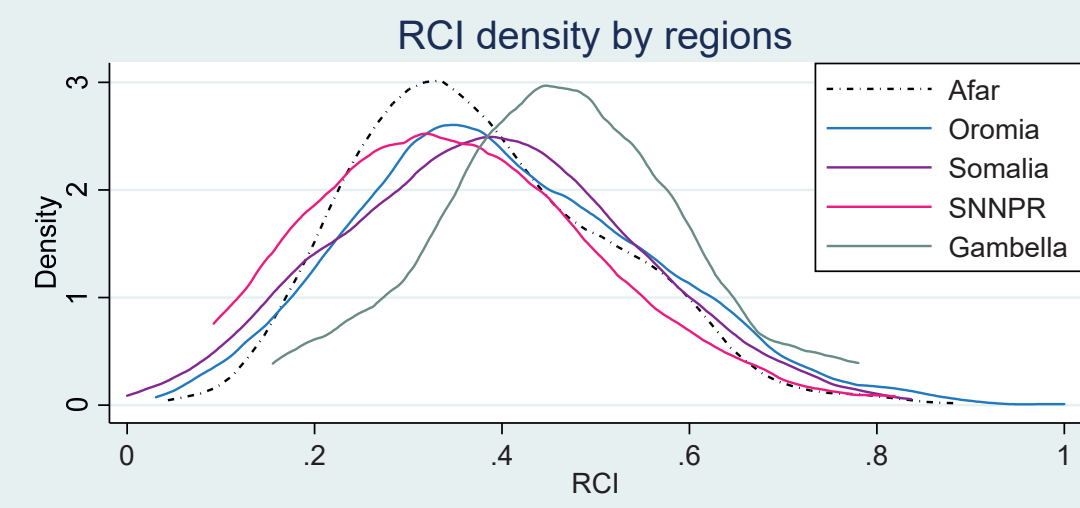

kernel $=$ epanechnikov, bandwidth $=0.0369$ 
Chapter 6

Discussion and Conclusions 
Chapter 6 


\section{Discussion and Conclusions}

This thesis was conducted to understand the impacts of LSLIs in sugar plantations on the livelihoods of Ethiopian agropastoral households. In this chapter, the synthesis of the dissertation under four sub-sections is discussed. In section 6.1, the key results are shown. In section 6.2, the main contributions to societal debate and literature are discussed. In section 6.3, the policy implications are illustrated, and section 6.4 is concluded with limitations and future research.

\subsection{Key Results of this Thesis}

In this thesis, I stated four research questions on the impact of LSLIs on Ethiopian agropastoral livelihoods. The answers to each research question are discussed below.

What is the impact of large-scale land investments on the food security of agropastoral households?

In chapter two, a mixed impact of the proximity to LSLI on food security was shown with the propensity score matching (PSM) model results. Food intake and self-assessed food security were positively affected by proximity to LSLIs, while food security, measured by the coping strategies index (CSI), was negatively affected by proximity to LSLIs. In $4.5 \%$ of households, food intake was improved by up to 745 kilocalories ( $\mathrm{kcal}$ )/day/adult with the proximity to LSLIs, whereas $9 \%$ of households became food insecure in proximity to LSLIs in the CSI. Similarly, a positive impact of proximity to LSLI on household food intake was shown by the random effects regression results. However, caution is required to interpret this result because food access may not be directly increased or reduced with proximity to LSLIs. Although the result is robust, it should be considered suggestive rather than conclusive. Thus, I relied on the control variables and the interaction terms of the regression results to better interpret the main results.

First, the impact of LSLIs varies according to food security indicators. Second, household food intake is positively affected by natural resources, such as land, soil quality, access to irrigation, and forest. Third, regarding the impact of proximity to LSLIs on households, food intake declined from $745 \mathrm{kcal} /$ day/adult in the PSM model results to $330 \mathrm{kcal} /$ day/adult in the results 
of the random effects regression when access to roads and market interaction terms were used. The importance of access to natural resources, markets, and roads for the food security of households in the presence of LSLIs is indicated by these results. With proximity to roads and markets, households are provided with an opportunity to engage in diverse livelihood options. Additionally, the engagement of households in non-pastoral activities close to LSLIs could also be a reason for the positive impact of proximity to LSLIs on food intake.

What is the impact of large-scale land investments on pasture land degradation in agropastoral drylands?

In chapter three, it was shown that about a quarter of the study households had been displaced by LSLIs, while lands had been lost by $55.8 \%$ of the households in recent decades. With endogenous switching or treatment regressions, LSLIs induced displacement was confirmed to increase land degradation. More severe land degradation was faced by displaced households compared to non-displaced households. Herd mobility and the access of pastoralists to dry season grazing have been restricted by LSLIs. Consequently, overgrazing has been exacerbated, leading to land degradation. However, overgrazing here is not due to a free-rider problem, but because of the lack of access to dry season grazing options. Hence, LSLIs are the primary drivers of overgrazing and land degradation, a finding that has also been supported by previous studies (Charnley, 1997; Garedew et al., 2009; Hundie, 2006; Mousseau and MartinPrével, 2016). Land degradation is further linked to food insecurity and poverty, leading to a livelihood deterioration cycle (Mussa et al., 2016).

What are the drivers of land use conflicts between agropastoral households and large-scale land investments?

In chapter four, it was shown that in more than a quarter of the studied households, land use conflicts had been encountered, and there were disputes with LSLIs in the last decade in about $38 \%$ of them. Moreover, the frequency and intensity of land use conflicts have increased because of LSLIs. As a result, state-owned LSLIs have been perceived by the local community as outside intrusions of their property rights. With binary logit model results, tenure insecurity indicators (e.g., loss of land to and lack of trust in LSLIs), supply-induced scarcities (e.g., land degradation, drought, and invasion by Prosopis. juliflora), demand-induced scarcities (e.g., number of livestock owned), and socioeconomic factors (e.g., access to credit and extension) were shown to be the most significant land conflict drivers. Dispossession of property rights by 
LSLIs is implied to be at the center of land conflicts. On the contrary, the likelihood of land use conflict is reduced by household size, access to roads, markets, and cooperatives.

What is the impact of large-scale land investment on agropastoral household resilience?

In chapter five, it was shown that the study populations had achieved only $39.1 \%$ of the resilience capacity and $36.2 \%$ of the welfare resilience. About one-third of the study population had a low resilience capacity, while more than half had low welfare resilience. Several factors were indicated to influence the resilience capacity dimensions of absorptive, adaptive, and transformative capacities. Results showed that household absorptive capacity was enhanced by social safety nets, participation in saving, and livestock sales, while the adaptive capacity was improved by access to extension, literacy levels, adult labor, and the size of cultivated land. The number of livestock units had the lowest contribution to adaptive capacity. Transformative capacity is improved by the availability of health and telecom services, microcredit, and access to roads. With the random effects regression model, household resilience capacity was reduced by proximity to LSLIs, while no significant effect was observed on household welfare capacity. Moreover, households specializing in herding were less resilient than those with diversified livelihoods. People from households moving out of pastoralism and with adequate market access were more resilient than those who remained specialized pastoralists. Likewise, households headed by women were less resilient than those led by men, and households from warm, semi-arid regions were less resilient. Further, households close to the LSLIs had fewer livestock units than their counterparts. As livestock ownership declined, local people looked for other means of livelihood, and hence, LSLIs were gradually forcing households to exit pastoralism.

\subsection{Main Contributions of the Thesis}

The findings of this thesis have several theoretical and empirical contributions, providing insights for future research in pastoral areas affected by LSLIs. I first provide the contributions of this thesis to societal and policy debates, followed by contributions to science, knowledge and literature

\section{Contributions to societal and policy debates}

Ethiopian government leaders and policymakers allocate rangelands to LSLIs based on two misconceptions. One of the misconceptions is the expectation bias, which puts an exaggerated 
expectation about the potential benefits resulting from LSLIs to the local community to justify the transfer of communal lands (Ali et al., 2018; Keeley, 2014; Rahmato, 2011). However, a negligible contribution to the livelihoods of the local population was provided by state-owned LSLIs in Ethiopian pastoral areas. It is unlikely to see unskilled pastoralists employed by sugar production companies, as intensive mechanized machinery is used to do most activities. It is also less likely to see technology transfer between sugar cane production and herding. Moreover, LSLIs are not enforced by any legal or contractual bindings to help the community. The other misconception is about the assumption of resource abundance in pastoral areas. In Ethiopia, rangeland allocation for LSLIs is based on the paradigm of "idle land" or "abundant land" (Keeley, 2014; Moreda, 2017). In the idle land paradigm, it is assumed that there is vast idle and abundant land in pastoral areas that need to be developed. However, pastoralists have been using these lands for centuries. Generally, the land in pastoral areas is not suitable for farming. Also, almost all suitable lands were taken by LSLIs. Hence, I argue that land in pastoral areas is neither idle nor abundant but scarce instead.

In this thesis, I contributed to the debate on livelihood diversification or specialization among scholars (Barrett et al., 2001; Bollig and Schnegg, 2013; Ellis, 2000; Headey et al., 2014). The capacity of rangelands to support viable pastoralism has been declining due to LSLIs and other challenges. Consequently, the majority of pastoral households have diversified their livelihoods to crop cultivation or wage labor. Households in which people pursue diverse livelihoods, have better food security and resilience than people from households specializing in herding, was also shown in other studies (Barrett et al., 2001; Müller-Mahn et al., 2010; Tsegaye et al. (2013). With that contention, I criticize the development model in which pastoralism is shown as the only and best alternative (FAO, 2018b), particularly in areas dominated by LSLIs. Moreover, I counterargue the "Too many people, too few livestock" hypothesis by Sandford (Devereux and Scoones, 2008). The authors emphasized the importance of herd size for sustainable livelihoods, while I confirmed the small contribution of herd size to household food security and resilience. Thus, the people-livestock ratio may not be applicable. I also asserted that many households have diversified livelihoods, while others abandon pastoralism, and only a small share of the population $(23 \%)$ remain specialized as pure pastoralists. About $60 \%$ of all livestock is concentrated in a few households (10\%) in Ethiopian pastoral areas (Coppock et al., 2018). Although the pastoral population has been growing, as argued by the authors Devereux and Scoones, (2008), the number of people remaining as specialized pure pastoralists have been declining. Moreover, when good lands are encroached by LSLIs, livestock is concentrated on a few rangelands. Hence, the main problem of 
pastoralists in areas affected by LSLIs is not the "too many people, too few livestock," but the "too many livestock, too few rangelands," which deteriorates herd quality.

Agencies seeking to promote resilience and sustainable development in pastoral areas and policymakers seeking to solve the adverse effects of LSLIs are expected to be aided by the findings of this thesis. Thus, decision-making by development organizations and policymakers will be aided by the specific recommendations in each chapter. Although the conclusions of this thesis are pertinent to the pastoral areas influenced by LSLIs in Ethiopia, the results may apply to similar African countries (e.g., a similar level of infrastructure, poverty, weak land governance, and low human capital). Therefore, the results of this study could have a broader significance for rangeland policy outside Ethiopia. However, specific country laws and regulations on land should be taken into account.

\section{Contributions to science, knowledge, and literature}

Within the land policy literature, tendencies have been concentrated on the links between land tenure and sustainability in the context of pastoral areas without addressing LSLI-related issues (Abate et al., 2010; Belay et al., 2013; Berihun et al., 2019; Tilahun et al., 2016). In Ethiopia, little attention has been paid to state-run LSLIs by the majority of existing studies, as LSLIs owned by foreign investors are commonly focused on (Baumgartner et al., 2015; Dheressa, 2013; Hules and Singh, 2017; Rahmato, 2011; Shete and Rutten, 2015). I am not aware of any previous study investigating LSLI-related impacts in Ethiopia with similar content and depth. Therefore, below I discuss three main contributions of this work to science, knowledge, and literature.

A contribution to the scant quantitative literature regarding LSLI-related impacts on food security and land conflict is provided in this thesis. One of the dominant arguments in the existing literature is that the food security of local populations is undermined by LSLIs (Dye, 2015; McPeak, 2003; Shete and Rutten, 2015). This conjecture, in which LSLIs may not harm household food security, is challenged in this thesis, at least regarding food intake and selfassessment indicators, although food insecurity based on coping strategies increased. Hence, the food security impact of LSLIs varied with the food security indicators. I also departed from previous studies, in which land conflict among pastoralists or pastoralists and farmers were focused on (Abdisalem, 2012; Abdulahi, 2005; Abebaw, 2016; Belay et al., 2013; Tache and Oba, 2009) by providing evidence on the drivers of land use conflict between LSLIs and agropastoralists. 
In this thesis, I brought new insights to science and knowledge on the impact of LSLIinduced displacement on land degradation and the effects of LSLIs on the resilience of Ethiopian households. To my knowledge, there are no studies in Ethiopia linking LSLI-induced land displacement to land degradation and LSLIs to resilience. Hence, these knowledge gaps in Ethiopia are filled by this work. Accordingly, in this study, the impact of displacement from LSLI on land degradation was highlighted, unlike previous studies, which were focused on land use and environmental changes in Ethiopia (Berihun et al., 2019; Meaza et al., 2019; Meaza et al., 2018; Nyssen et al., 2014; Tsegaye et al., 2010). More importantly, with this thesis, I contributed to the widely debated but still important paradigm on the tragedy of the commons or the tragedy of land grabbing. It is often assumed that the communal rangeland systems of pastoralists are the cause of land degradation, called the tragedy of the commons by Hardin (1968). Still, Ostrom et al. (1999) counterargue the tragedy of commons by indicating the ability of communities to manage their communal resources. However, in neither of these two debates, the tragedy that may result when powerful groups or the state control resources is acknowledged. I concluded that land degradation was increased by the tragedy of land grabbing, rather than by the tragedy of the commons, which is in agreement with other recent studies (Dell'Angelo et al., 2017; Ostrom, 2008). Likewise, in this thesis, I added new insights to the missing literature on the impacts of LSLIs on household resilience in Ethiopia. Unlike previous studies in which one dimension of household resilience was measured (Alinovi et al., 2010; Demeke and Tefera, 2010; FAO, 2016b), I assessed two resilience dimensions (resilience capacity and welfare resilience) and introduced the concept of welfare resilience to the resilience literature.

In this thesis, I have contributed to the methodology regarding assessing the impacts of LSLIs on local livelihoods in various aspects. I used GPS coordinates to approximate the geographical proximity to LSLIs to treat their effects on household food security and resilience. With such a methodology, insights into handling complex impact assessments are provided without baseline information. In the past, qualitative designs were widely used to assess the impacts of LSLIs on the livelihoods of local people (Dye, 2015; Hules and Singh, 2017; Moreda, 2017; Rahmato, 2011; The Oakland Institute, 2016). In this thesis, I applied a quantitative design blended with qualitative methods to obtain better results. In previous studies, a single indicator for measuring household food security or those based on simple theoretical narratives were used (Dye, 2015; Jambo et al., 2021; The Oakland Institute, 2016), with the exception of Shete and Rutten (2015). 
Specifically, contrary to past studies, I applied multiple food security indicators, such as household food intake (caloric acquisitions), household self-assessment of food security, and household coping strategies index, to capture both the subjective and objective aspects of food security. I have developed a two-stage novel method for measuring land degradation from community and household perspectives, contributing to the literature and providing a valuable method for future researchers. Similarly, the procedure I developed for measuring land degradation and household welfare resilience is a new contribution. I created a novel method for measuring household welfare resilience while complementing existing resilience capacity methods (FAO, 2016b). Land use conflict research often uses qualitative methods (Beyene, 2009; Hundie, 2006; Lavers, 2018; Ola-Adams and Okali, 2008; Tache and Oba, 2009). I applied quantitative methods to the land conflict. Moreover, I have not seen in most previous studies a combination of multiple theories to understand the drivers of land use conflict quantitatively. Hence, I quantitatively combined theories of property rights, environmental scarcity, and political ecology to better comprehend land use conflicts. The thesis belongs to the strand of literature developing more advanced methods of quantifying the impact of LSLIs on agropastoral livelihoods in the absence of baseline data.

\subsection{Policy Implications}

The findings of this thesis have many policy implications for pastoral development and land use in Ethiopia and other similar African contexts. In the next section, I discuss the policy implications of this thesis.

Food insecurity is faced by one-third of agropastoral households, while less than $40 \%$ of the possible resilience levels are achieved in the study areas. Therefore, urgent actions to address food insecurity should be taken by the Ethiopian government and development agencies to enhance household resilience in pastoral regions. With such actions, access to natural resources, such as land and irrigation, which could help improve household food security and resilience, should be promoted. Future investment in road and market development in Ethiopian pastoral areas is essential to improving the food security and resilience of agropastoralists. Specifically, the absorptive capacities of households can be enhanced by promoting household savings, livestock markets, and access to irrigation. The transformative capacities of households can be improved by improving their access to social infrastructures, such as health, schools, and roads. The adaptive capacities of households can be enhanced by improving household 
literacy and extension services. Providing resilience-enhancing interventions exclusively for women-headed households would improve their resilience capacities.

More than $75 \%$ of the study population is affected by land degradation, and land degradation is intensified by the displacement of people caused by LSLIs. Attention should be given to sustainable land management, the rehabilitation of degraded lands, and the prevention of people displacement. The invasion by Prosopic. juliflora should be prevented and controlled by strategies to rehabilitate degraded lands in Ethiopian pastoral areas. Specific actions for halting land degradation include enhancing the capacity of traditional land governance systems, building capacity for local communities, market integration to allow mobility, and the development of pastoral extension systems. The extension should integrate conservation practices into highly degraded areas. Equally important is that environmental protection responsibility is taken in areas with LSLI operations.

Land use conflicts have been increasing, affecting more than a quarter of the study population over the past decade. Therefore, urgent actions should be taken by the Ethiopian government and stakeholders to resolve the conflict over land between LSLIs and local communities. Hence, empowering local institutions, such as clan leaders, is paramount for land conflict resolution. However, as clan leaders are part of the dispute over land with LSLIs, traditional conflict resolution mechanisms should be blended with formal institutions. Sustainable peace over land use can only be ensured through legal frameworks that protect the land rights of pastoralists.

In the study areas, pastoral people have been dispossessed of their land rights by the state for LSLIs. For pastoralists, the land is more than a means of livelihood, as it is part of their identity and culture. In general, people with extensive land rights have a more sustainable livelihood than those with limited land rights (FAO, 2002). Therefore, ensuring land tenure security for communal lands is necessary to improve land governance and the livelihoods of pastoral people. Specifically, communal land rights need to be protected by Ethiopian land policy. The policies should clearly show (i) exclusive rights to communal land for pastoralists, (ii) rights and strategies for sufficient compensation and resettlement, and (iii) strategies for mobility. In this regard, inclusive decision-making is necessary for land use in pastoral areas. More importantly, land policies in pastoral regions should be framed within broader strategies for poverty reduction, achieving food security, and environmental sustainability. In future LSLIs, local communities should be engaged in the planning process and recognize the rights of pastoral people. If displacement is inevitable, prior informed consent, compensation, and shared access to communal resources are advisable. 
Pastoralists are diverse. Depending on their livelihood patterns, some move toward nonpastoral livelihoods, others integrate livestock with crop production, while others continue with herding. Hence, diversifying policy options to address each of the livelihood systems for pastoral people is essential. For those who are moving toward nonpastoral activities, an alternative with adequate market integration should be promoted. For those who abandon pastoralism, programs that develop their skills to diversify their activities are essential. For the remaining pastoralists, access to communal rangelands and herd mobility is necessary. In the presence of LSLIs and climate extremes, such as drought, options to sustain pastoralism are limited. Thus, it is essential to acknowledge the significance of promoting multiple strategies for sustainable pastoral development.

The trade-off between maximizing export revenue from LSLIs and improving local livelihoods needs to be balanced. Ethiopian government leaders use rangelands for LSLIs to increase export earnings (ESC, 2017; Rahmato, 2011). Government leaders also have a responsibility to ensure secure livelihoods for pastoralists. I provide evidence that LSLIs increase the vulnerability of local people to shocks, land conflicts, and land degradation. Therefore, policies on LSLIs and local livelihoods need to be harmonized, and the risk of LSLIs on local livelihoods needs to be considered in future decisions.

\subsection{Limitations and Future Research}

With this thesis, I have contributed in many ways to the current debate on the impact of LSLIs on household food security, land degradation, land use conflict, and household resilience with a case study on sugar plantations. I have achieved this by using a quasi-experimental methodology in which cross-sectional data and panel data were combined. However, as every study inherently has limitations, this study is not exempt.

While this thesis aimed to investigate the impact of LSLIs on the livelihoods of agropastoral households in Ethiopia, I acknowledge that the results presented cannot cover all the LSLIs, as the emphasis was given to the sugar plantations. After recognizing these limitations, I believe that further research could benefit other LSLIs, such as cotton. It will also be worth studying the LSLI impacts on livestock productivity and local development. I also suggest multi-level studies comparing diverse LSLIs to gain a complete understanding of the impacts of LSLIs.

The lack of baseline information about LSLIs and the nonrandom selection of respondents limits the application of experimental designs in the data analysis, which ideally would yield 
better results. However, I applied quasi-experimental methods, which are arguably the next best method after experimental designs, such as propensity score matching methods [chapter two], endogenous switching regression models [chapter three], random effect models [chapters two and five], and factor analysis [chapter five], to provide a causal relationship between outcome variables and the treatment variable, controlling for selection bias. Also, I controlled for confounding observable factors that seemed to influence the outcome variables [chapters two, three, and five] and included interaction terms [chapter two] to ensure internal analytical validity. Although I controlled for observable differences using matching methods, unobserved differences could not be controlled for. Therefore, future research that uses baseline data and experimental approaches is essential.

In chapters two and five, the LSMS data limitations are worth mentioning. First, I could not assess the direct impact of LSLIs on household food security and resilience because the LSMS data did not contain information on LSLIs. A direct measure of the effects of future LSLIs would offer more robust results. However, I followed the study by Deininger and Xia (2016) and used GPS coordinates on proximity to LSLI as a treatment variable for assessing the impact of LSLI on pastoral livelihoods. Second, the LSMS sample is not nationally representative of the pastoral region. However, the sample I extracted from LSMS is adequate for conducting the necessary econometric analysis.

In chapters three and four, I used cross-sectional data on community and household perceptions that provide observable land conflict and degradation drivers. Nonetheless, panel or time-series data would offer better results on the dynamism of land use conflict and land degradation. Hence, future research will be beneficial in combining community and household perceptions with historical data on land use conflict and temporal and spatial land use changes. 


\section{$7 \quad$ Appendices of the Survey Instruments}

\subsection{Household Survey ${ }^{29}$}

Pretested Interview Questionnaire on the Impacts of Large-Scale Land Investment on the

\section{Livelihoods of Agropastoral Households}

Name of enumerator signature

Date of interview

Woreda 1) Fentale 2) Dubti

Place / kebele Village Name

GPS coordinates: latitude longitude

A HOUSEHOLD PROFILE (write the number that belongs to your answer in R column)

\begin{tabular}{|l|l|l|}
\hline CODE & Name of respondent_ & $\mathrm{R}$ \\
\hline & Household type 1) Sedantarist 2) Semi-sedantarist & \\
\hline & Wealth status 1) Very poor 2) Poor 3) Medium 4) Rich & \\
\hline & Age of head in years & \\
\hline & Total number of family size including household head & \\
\hline & Total number of children under the age of 15 & \\
\hline & Total number of old's above the age of 64 & \\
\hline & No of the active labor force (>15 \&<64 age members) & \\
\hline & $\begin{array}{l}\text { Did the household head face any health problems within the last 12 months (1) } \\
\text { Yes (2) No }\end{array}$ & \\
\hline & Highest education attained by the head in years (record 0 for no education) & \\
\hline & Highest education attained by a spouse in years (record 0 for no education) & \\
\hline & No of family members who are employed and salaried & \\
\hline & How long did you live in this area (in years) & \\
\hline What is your main source (s) of income? (Multiple responses are possible) & \\
\hline
\end{tabular}

\footnotetext{
${ }^{29}$ This is English version of the household survey questionnaire. The ones used during interview are translated to Afaan Oromo and Amharic respectively for Fentale and Dubti woredas.
} 


\begin{tabular}{|l|l|l|}
\hline & $\begin{array}{l}\text { 1. Livestock 2. Crop 3. Petty trading 4. Salaried employment 5. Wage labor 6. } \\
\text { Handcrafts 7. Cash for work (PSNP) 8) Bee keeping }\end{array}$ & \\
\hline & Distance to all-weather road from a residence in km & \\
\hline & Distance from the nearest market in km & \\
\hline & Distance from the nearest health post in km & \\
\hline & $\begin{array}{l}\text { Distance from the nearest veterinary clinic in km } \\
\text { Distance of residence from a sugar plantation in km }\end{array}$ & \\
\hline $\begin{array}{l}\text { Do you think that you have a better livelihood before 30 years than today? 1) Yes } \\
\text { 2) No }\end{array}$ & \\
\hline $\begin{array}{l}\text { Do you think that you can sustain the present level of livelihoods in the next } 10 \\
\text { years } 2) \text { No }\end{array}$ & \\
\hline & & \\
\hline
\end{tabular}


B) LIVESTOCK PRODUCTION AND MARKETING

\begin{tabular}{|c|c|c|c|c|c|c|c|c|}
\hline & Please in & icate th & numb & of live & ock owned & ithin the last & months & \\
\hline $\begin{array}{l}\mathrm{CO} \\
\mathrm{DE}\end{array}$ & Species & $\begin{array}{l}\text { Total } \\
\text { No } \\
\text { owned }\end{array}$ & $\begin{array}{l}\text { No. } \\
\text { sold }\end{array}$ & $\begin{array}{l}\text { No } \\
\text { died* }\end{array}$ & $\begin{array}{l}\text { No. } \\
\text { consumed }\end{array}$ & $\begin{array}{l}\text { Average } \\
\text { price (ETB) }\end{array}$ & $\begin{array}{l}\text { Income } \\
\text { from } \\
\text { sale (ETB) }\end{array}$ & $\begin{array}{l}{ }^{*} \text { Cause } \\
\text { of death }\end{array}$ \\
\hline & Goat & & & & & & & \\
\hline & Sheep & & & & & & & \\
\hline & $\begin{array}{l}\text { Cow/hei } \\
\text { fer }\end{array}$ & & & & & & & \\
\hline & $\begin{array}{l}\text { Oxen/b } \\
\text { ull }\end{array}$ & & & & & & & \\
\hline & Poultry & & & & & & & \\
\hline & Donkey & & & & & & & \\
\hline & Horse & & & & & & & \\
\hline & Camel & & & & & & & \\
\hline & Total & & & & & & & \\
\hline & ${ }^{*}$ Cause $\mathrm{o}$ & ivesto & death & ) Dise & 2) Drougl & 3) Feed short & & \\
\hline & Did you & wn mor & livest & $\mathrm{k}$ befor & 30 years. 1 & es $2=$ No & & \\
\hline
\end{tabular}




\begin{tabular}{|c|c|c|c|c|c|c|}
\hline \multicolumn{7}{|c|}{ Livestock product produced sold \& income earned within the last 12 months } \\
\hline & $\begin{array}{l}\text { Quantity } \\
\text { (Qt) } \\
\text { produced }\end{array}$ & $\begin{array}{l}\text { Qt } \\
\text { consu } \\
\text { med }\end{array}$ & Qt sold & $\begin{array}{l}\text { Income } \\
\text { (ETB) }\end{array}$ & $\begin{array}{l}\text { What are your } \\
\text { source of } \\
\text { livestock feed }\end{array}$ & $\begin{array}{l}1=\text { yes } \\
2=\text { No }\end{array}$ \\
\hline Milk (litre) & & & & & Crop residue & \\
\hline Egg (No) & & & & & $\begin{array}{l}\text { My own private } \\
\text { grazing }\end{array}$ & \\
\hline $\begin{array}{l}\text { Butter } \\
(\mathrm{Kg})\end{array}$ & & & & & $\begin{array}{l}\text { Communal } \\
\text { grazing }\end{array}$ & \\
\hline $\begin{array}{l}\text { Honey } \\
(\mathrm{kg})\end{array}$ & & & & & Growing forage & \\
\hline Total & & & & & Purchasing feeds & \\
\hline & & & & & $\begin{array}{l}\text { Migrate/ } \\
\text { mobility }\end{array}$ & \\
\hline & & & & & $\begin{array}{l}\text { Sugar factory } \\
\text { byproducts }\end{array}$ & \\
\hline
\end{tabular}

C) LAND OWNERSHIP \&CROP PRODUCTION within the last 12 months

\begin{tabular}{|c|c|c|c|c|c|c|}
\hline \multicolumn{6}{|c|}{ Does this household, or one of its members possess agricultural land? } & $\begin{array}{l}\text { 1) Yes } \\
\text { 2) No }\end{array}$ \\
\hline \multicolumn{6}{|c|}{ Does this household, or one of its members possess pasture land? } & \\
\hline \multicolumn{6}{|c|}{$\begin{array}{l}\text { What is the trend in land accessible to pastoralists? 1) Increasing 2) } \\
\text { Decreasing 3) Constant }\end{array}$} & \\
\hline $\begin{array}{l}\text { If you } \\
\text { possess } \\
\text { land, } \\
\text { indicate the } \\
\text { quantity of }\end{array}$ & $\begin{array}{l}\text { size of the } \\
\text { land (ha) }\end{array}$ & $\begin{array}{l}\text { acquisition of } \\
\text { land (a) }\end{array}$ & $\begin{array}{l}\text { Soil } \\
\text { type (b) }\end{array}$ & $\begin{array}{l}\text { Topogr } \\
\text { aphy } \\
\text { (c) }\end{array}$ & $\begin{array}{l}\text { Who owns } \\
\text { (d) }\end{array}$ & $\begin{array}{l}\text { Overall } \\
\text { quality } \\
\text { of land } \\
\text { (e) }\end{array}$ \\
\hline $\begin{array}{l}\text { Pasture } \\
\text { land }\end{array}$ & & & & & & \\
\hline Farm land & & & & & & \\
\hline
\end{tabular}




\begin{tabular}{|l|l|l|l|l|l|}
\hline $\begin{array}{l}\text { Irrigable } \\
\text { land }\end{array}$ & & & & \\
\hline & Total & & & & \\
\hline & & & & \\
Who decides land distribution in your community? 1) Central government 2) & & \\
\hline & $\begin{array}{l}\text { Who manages communal lands 1) Central government 2) Local authorities 3) } \\
\text { Customary leaders }\end{array}$ & \\
\hline & \begin{tabular}{l} 
Are women allowed to own land? 1) Yes 2) No \\
\hline
\end{tabular}
\end{tabular}

(a) How do you acquire this land 1) Inheritance 2) Purchased 3) allocated by government 4) Rented 5) grabbed it

(b)What is the type of soil of your land? 1) sandy 2) silty 3) clay 3) Rocky

(c)What is the topography of this parcel? 1) Hill 2) plain 3) Gentle 4) steep 5) Valley

(d)Who owns the land? 1) Owned by men 2) owned by women 3) Jointly owned by couples 4) communally owned

(e) Rate the overall quality of land 1) very poor 2) poor 3) good 4) very good 4) unknown

\begin{tabular}{|c|c|c|c|c|c|c|c|c|}
\hline $\begin{array}{l}\text { Crop types } \\
\text { Within the } \\
\text { last } 12 \\
\text { months }\end{array}$ & $\begin{array}{l}\text { seed used } \\
\text { 1) local } \\
\text { 2) } \\
\text { Improved }\end{array}$ & $\begin{array}{l}\text { Fertiliz } \\
\text { er used } \\
\text { 1) Yes } \\
\text { 2) No }\end{array}$ & $\begin{array}{l}\text { Are } \\
\text { a of } \\
\text { land } \\
\text { (ha) }\end{array}$ & $\begin{array}{l}\text { Quantit } \\
\text { y } \\
\text { produc } \\
\text { ed } \\
\text { qt/yr }\end{array}$ & $\begin{array}{l}\text { Quantit } \\
\text { y } \\
\text { consu } \\
\text { med } \\
\text { qt/yr }\end{array}$ & $\begin{array}{l}\text { Quantit } \\
\text { y sold } \\
\text { qt/yr }\end{array}$ & $\begin{array}{l}\text { Pri } \\
\text { ce } \\
\text { per } \\
\mathrm{kg}\end{array}$ & $\begin{array}{l}\text { Income } \\
\text { earned } \\
\text { ETB }\end{array}$ \\
\hline Maize & & & & & & & & \\
\hline Tomato & & & & & & & & \\
\hline Onion & & & & & & & & \\
\hline Cabbage & & & & & & & & \\
\hline Paper & & & & & & & & \\
\hline
\end{tabular}




\section{LAND USE / PROPERTY RIGHTS}

\begin{tabular}{|c|c|c|}
\hline $\mathrm{CO}$ & LAND USE RIGHTS & 1) Yes \\
\hline & Do vou have a formal land title or certificate for vour land? & \\
\hline & Are you afraid of being evicted from your land in the next 10 years? & \\
\hline & Do you have the right to own private land in your community? & \\
\hline & Do you have access to enough grazing land currently? & \\
\hline & Are you confident that your land use rights would be respected? & \\
\hline & Is it possible to get more land in the future? & \\
\hline & Which of the following rights do you have on the land you own? & \\
\hline & Right to sell & \\
\hline & Right to farm and or grazing- use right & \\
\hline & Right to manage and control & \\
\hline & Right to lease out & \\
\hline & Right to transfer or give for someone & \\
\hline & $\begin{array}{l}\text { LARGE-SCALE LAND INVESTMENT AND ITS PERCEIVED } \\
\text { IMPACTS }\end{array}$ & $\begin{array}{lll}\text { 1) } & \text { Yes 2) } \\
\text { No } & & \end{array}$ \\
\hline & Have you lost any land due to the investment in the last 30 years? & \\
\hline & $\begin{array}{l}\text { Were you evicted from your land due to the investment in the last } 30 \\
\text { years? }\end{array}$ & \\
\hline & Were you consulted when the land is allocated for investment & \\
\hline & If you have been consulted, is your opinion taken into consideration? & \\
\hline & Do you think that the land transfer was made in a transparent manner? & \\
\hline & Does the investment have a negative effect on your means of living? & \\
\hline & What is your preference of land ownership 1) communal 2) private & \\
\hline & Are you aware of any laws that govern the use of land? & \\
\hline Code & $\begin{array}{l}\text { Pick a number from the scale to show how you agree or disagree wi } \\
\text { following statements. } 1 \text {. Strongly disagree, } 2 \text {. Disagree, } 3 \text {. Undecide } \\
\text { strongly agree }\end{array}$ & $\begin{array}{l}\text { th each of the } \\
\text { d, } 4 \text {. Agree 5) }\end{array}$ \\
\hline & The presence of LSLI increased our vulnerability to poverty & \\
\hline & LSLI built infrastructure such as roads and irrigation for our commun & \\
\hline & LSLI increased conflict between pastoralists and the sugar corporatio & \\
\hline & LSLI degraded the environments (soil and water degradation) & \\
\hline
\end{tabular}




\begin{tabular}{|l|l|l|}
\hline & LSLI introduced modern technology to our community & \\
\hline & LSLI increased the availability of feed for our livestock & \\
\hline & LSLI restricted our access to dry season grazing & \\
\hline & I or a member of my family was displaced due to THE LSLI in the past & \\
\hline
\end{tabular}

\section{E. NON-FARM INCOME SOURCES \& LIVELIHOOD CONSTRAINTS}

Participation of the household head or members in non-farm activities and amount of income earned within the last 12 months

\begin{tabular}{|c|c|c|c|c|c|c|}
\hline 音 & $\begin{array}{l}\text { SOURCE OF } \\
\text { INCOME }\end{array}$ & $\begin{array}{l}\text { Did you } \\
\text { participate } \\
\text { in the } \\
\text { following } \\
\text { activities? } \\
\text { Yes=1 } \\
\mathrm{No}=2\end{array}$ & $\begin{array}{l}\text { If yes, } \\
\text { how much } \\
\text { income } \\
\text { did you } \\
\text { get within } \\
\text { the last } 12 \\
\text { months } \\
\text { (ETB) }\end{array}$ & Оิ & $\begin{array}{l}\text { Rate the constraints } \\
\text { of your livelihoods? }\end{array}$ & $\begin{array}{l}\text { 1) None } \\
\text { 2) Little } \\
\text { 3) Moderate } \\
\text { 4) High } \\
\text { 5. Very } \\
\text { high }\end{array}$ \\
\hline & $\begin{array}{l}\text { Wage/ causal } \\
\text { labour }\end{array}$ & & & & Poor roads & \\
\hline & Charcoal sale & & & & lack of transport & \\
\hline & Fire wood sale & & & & lack of finance & \\
\hline & Petty trade & & & & land shortage & \\
\hline & Handcrafts sale & & & & lack of farm inputs & \\
\hline & PSNP Safety nets & & & & Animal disease & \\
\hline & Donkey/ horse cart & & & & conflict & \\
\hline & Remittance & & & & shortage of rain & \\
\hline & $\begin{array}{l}\text { Cash } \\
\text { Transfers/Gifts) }\end{array}$ & & & & Drought & \\
\hline & & & & & Feed shortage & \\
\hline & & & & & Market Brokers & \\
\hline & & & & & Water scarcity & \\
\hline
\end{tabular}


F. INSTITUTIONS AND SOCIAL CAPITAL

\begin{tabular}{|c|c|c|c|c|c|}
\hline & INSTITUTIONAL SUPPORT & $\mathrm{R}$ & & SOCIAL CAPITAL & $\mathrm{R}$ \\
\hline \multirow[t]{2}{*}{ อิ } & $\begin{array}{l}\text { In the last } 12 \text { months did you or } \\
\text { a member of your household has } \\
\text { access to (Rating) }\end{array}$ & $\begin{array}{l}\text { 1. None } \\
\text { 2. Limited } \\
\text { 3. Good } \\
\text { 4.Very } \\
\text { good }\end{array}$ & 仓ิ & $\begin{array}{l}\text { In the last } 12 \text { months did } \\
\text { you or a member of your } \\
\text { household participate in }\end{array}$ & $\begin{array}{l}\text { 1) Yes } \\
\text { 2) No }\end{array}$ \\
\hline & Animal extension service & & & Cooperatives & \\
\hline & Human health service & & & Village leadership & \\
\hline & Veterinary service & & & Eddir (informal insurance) & \\
\hline & Primary school & & & Iquib (informal credit) & \\
\hline & Potable water & & & Received gifts and transfers & \\
\hline & $\begin{array}{l}\text { Contact with Agri extension } \\
\text { worker }\end{array}$ & & & labor sharing (e,g. debo) & \\
\hline & $\begin{array}{l}\text { Contact with a health extension } \\
\text { worker }\end{array}$ & & & women associations & \\
\hline & Market information & & & $\begin{array}{l}\text { Do you have a good trust } \\
\text { towards }\end{array}$ & \\
\hline & & & & the regional government & \\
\hline & $\begin{array}{l}\text { Do you have access to credit? 1) } \\
\text { yes } 2 \text { ) No }\end{array}$ & & & the kebele administration & \\
\hline & If yes, how much you browed? & & & customary leaders & \\
\hline & $\begin{array}{l}\text { If yes, from whom you } \\
\text { borrowed? }\end{array}$ & & & the private investors & \\
\hline
\end{tabular}


G. VULNERAABILITY, SHOCKS \& PHISICAL ASSETS

\begin{tabular}{|c|c|c|c|c|c|c|c|c|}
\hline $\begin{array}{l}\text { COD } \\
\text { E }\end{array}$ & $\begin{array}{l}\text { During the last } 12 \\
\text { months, was your } \\
\text { household } \\
\text { affected } \\
\text { negatively by } \\
\text { shocks }\end{array}$ & $\begin{array}{l}1= \\
\text { Yes } \\
2=N \\
0\end{array}$ & $\begin{array}{l}\text { Frequen } \\
\text { cy of } \\
\text { shocks } \\
\text { during } \\
\text { the last } \\
12 \\
\text { months }\end{array}$ & $\begin{array}{l}\text { Frequen } \\
\text { cy of } \\
\text { shocks } \\
\text { during } \\
\text { the last } \\
10 \text { years }\end{array}$ & $\begin{array}{l}\text { COD } \\
\text { E }\end{array}$ & $\begin{array}{l}\text { ASSET } \\
\text { S }\end{array}$ & $\begin{array}{l}\text { Do } \\
\text { you } \\
\text { own } \\
1= \\
\text { Yes } \\
2=\mathrm{N} \\
\text { o }\end{array}$ & $\begin{array}{l}\text { Number } \\
\text { owned? } \\
\text { IF none } \\
\text { record } 0 \\
\text { number } \\
\text { of items }\end{array}$ \\
\hline & Death of head & & & & & $\begin{array}{l}\text { Telepho } \\
\text { ne }\end{array}$ & & \\
\hline & Death of animals & & & & & Radio & & \\
\hline & Severe drought & & & & & $\begin{array}{l}\text { Televisi } \\
\text { on }\end{array}$ & & \\
\hline & Flood damage & & & & & Bicycle & & \\
\hline & crop damage & & & & & $\begin{array}{l}\text { Motor } \\
\text { cycle }\end{array}$ & & \\
\hline & $\begin{array}{l}\text { price fall for } \\
\text { livestock }\end{array}$ & & & & & $\begin{array}{l}\text { Manual } \\
\text { Cart }\end{array}$ & & \\
\hline & Livestock Theft & & & & & $\begin{array}{l}\text { Animal } \\
\text { Cart }\end{array}$ & & \\
\hline & displacement & & & & & & & \\
\hline & conflict & & & & & & & \\
\hline & & & & & & & & \\
\hline
\end{tabular}

H. CONFLICT PREVALENCE, CAUSES, EFFECTS AND COPING STRATEGIES

\begin{tabular}{|c|c|c|}
\hline $\begin{array}{l}\text { COD } \\
\mathrm{E}\end{array}$ & Prevalence and type of conflict in the last 12 months & $\begin{array}{l}1=\text { yes } \\
2=\text { no }\end{array}$ \\
\hline & Is there a history of land use conflict in your village? & \\
\hline & $\begin{array}{l}\text { Have you or any member of your family ever experienced conflict within } \\
\text { the last } 10 \text { years? }\end{array}$ & \\
\hline & $\begin{array}{l}\text { If yes, how many / number of conflict incidences have you encountered } \\
\text { in the last } 10 \text { years }\end{array}$ & \\
\hline
\end{tabular}




\begin{tabular}{|l|l|}
$\begin{array}{l}\text { If yes, with whom have you had conflict frequently? (multiple answers } \\
\text { possible) 1) Sugar factory 2) National park 3) Neighboring Afar 2) } \\
\text { Neighboring Argoba 3) Neighboring Karrayyus 4) private investors 4) } \\
\text { government/land administrators }\end{array}$ & \\
\hline $\begin{array}{l}\text { On which of the land use system is the conflict frequent? 1) Forest 2) } \\
\text { Water Farm land 4) Grazing land 5) wetlands }\end{array}$ & \\
\hline Increasing 2) Decreasing 3) Unchanged &
\end{tabular}

\begin{tabular}{|c|c|c|c|}
\hline $\begin{array}{l}\text { What are the common } \\
\text { causes of resource-use } \\
\text { conflicts in this area? }\end{array}$ & $\begin{array}{l}1=\text { yes } \\
2=\text { no }\end{array}$ & $\begin{array}{l}\text { Are the following methods of } \\
\text { conflict resolution practiced } \\
\text { frequently? }\end{array}$ & $\begin{array}{l}1=\text { yes } \\
2=\text { no }\end{array}$ \\
\hline $\begin{array}{l}\text { Livestock migration into } \\
\text { neighboring areas }\end{array}$ & & $\begin{array}{ll}\text { traditional } & \text { leader's } \\
\text { intervention } & \end{array}$ & \\
\hline $\begin{array}{l}\text { Violating boundaries or } \\
\text { crossing borders for land } \\
\text { use by neighboring } \\
\text { communities }\end{array}$ & & $\begin{array}{l}\text { Payment of compensation to } \\
\text { victims }\end{array}$ & \\
\hline $\begin{array}{l}\text { Border disputes over land } \\
\text { ownerships }\end{array}$ & & Court verdicts/ Sharia & \\
\hline Farm land scarcity & & Negotiation between parties & \\
\hline Grazing land shortage & & Intervention by police & \\
\hline $\begin{array}{l}\text { Land transfers to } \\
\text { investors }\end{array}$ & & Political solutions & \\
\hline $\begin{array}{l}\text { Displacement due to } \\
\text { investment/ sugar factory }\end{array}$ & & $\begin{array}{l}\text { Do the land use conflict fully } \\
\text { solved in this area? }\end{array}$ & \\
\hline $\begin{array}{l}\text { Water pollutions from } \\
\text { the sugar factory }\end{array}$ & & $\begin{array}{l}\text { What strategies have you } \\
\text { been using to cope with } \\
\text { conflict? }\end{array}$ & $\begin{array}{l}1=\text { yes } \\
2=\text { no }\end{array}$ \\
\hline $\begin{array}{l}\text { Livestock riding by } \\
\text { neighboring pastoralists }\end{array}$ & & $\begin{array}{l}\text { Borrowed money from } \\
\text { relatives \& friends }\end{array}$ & \\
\hline
\end{tabular}




\begin{tabular}{|c|c|}
\hline $\begin{array}{l}\text { Violation of land use } \\
\text { rights by land } \\
\text { administrators }\end{array}$ & sale animals \\
\hline $\begin{array}{l}\text { what is the impact of } \\
\text { land based conflict on } \\
\text { your family? }\end{array}$ & Migrate to other safe places \\
\hline $\begin{array}{l}\text { Interrupted children } \\
\text { education }\end{array}$ & $\begin{array}{l}\text { seek relatives support or } \\
\text { protection }\end{array}$ \\
\hline $\begin{array}{l}\text { Reduction in farm } \\
\text { production }\end{array}$ & Sell asset and property \\
\hline $\begin{array}{l}\text { Social insecurity and } \\
\text { instability }\end{array}$ & send children to relatives \\
\hline $\begin{array}{l}\text { distortion in price of } \\
\text { foods }\end{array}$ & Reduce overall consumption \\
\hline Livestock death & $\begin{array}{l}\text { Migrate in search of wage } \\
\text { employment }\end{array}$ \\
\hline displacement & \\
\hline $\begin{array}{l}\text { Challenges for livestock } \\
\text { mobility }\end{array}$ & \\
\hline $\begin{array}{l}\text { Death of household } \\
\text { members' }\end{array}$ & \\
\hline
\end{tabular}


I. LAND DEGRADATION, CAUSES, AND EFFECTS

\begin{tabular}{|c|c|c|c|c|}
\hline $\begin{array}{l}\mathrm{CO} \\
\mathrm{DE}\end{array}$ & $\begin{array}{l}\text { What is the extent of land } \\
\text { degradation in your village? } \\
\text { Rating }\end{array}$ & $\begin{array}{l}\text { 1) Light } \\
\text { 2) Moderate } \\
\text { 3) Strong } \\
\text { 4) Severe }\end{array}$ & $\begin{array}{l}\text { Natural causes of land } \\
\text { degradation }\end{array}$ & $\begin{array}{l}\text { 1) None } \\
\text { 2) Little } \\
\text { 3) Moderate } \\
\text { 4) Severe }\end{array}$ \\
\hline & Crop land degradation & & floods & \\
\hline & Grazing land degradation & & soil erosion & \\
\hline & Forest land degradation & & rugged topography & \\
\hline & Grass land degradation & & Heavy rain & \\
\hline & Water resource degradation & & Frequent drought & \\
\hline & $\begin{array}{l}\text { Have you ever faced the } \\
\text { following hazards in the last } \\
10 \text { years? Rating }\end{array}$ & & $\begin{array}{l}\text { Effects of land } \\
\text { degradations }\end{array}$ & \\
\hline & Soil erosion & & Loss of topsoil & \\
\hline & Gully formation & & Reduced Organic Matter & \\
\hline & Landslides & & Pollution & \\
\hline & Soil siltation & & Loss of Biodiversity & \\
\hline & Soil pollution & & Nutrient Depletion & \\
\hline & Salinisation, acidity & & Water Deterioration & \\
\hline & Surface water reduction & & Declining of soil fertility & \\
\hline & Groundwater reduction & & $\begin{array}{l}\text { Declining of farm land } \\
\text { productivity }\end{array}$ & \\
\hline & $\begin{array}{l}\text { The decline of surface water } \\
\text { quality }\end{array}$ & & Gully formation & \\
\hline & $\begin{array}{l}\text { The decline of groundwater } \\
\text { quality }\end{array}$ & & $\begin{array}{l}\text { declining in livestock } \\
\text { productivity }\end{array}$ & \\
\hline & Reduction of wetland areas & & Desertification & \\
\hline & Reduction of vegetation cover & & Decline forest cover & \\
\hline & Loss of habitats \& diversity & & decline grazing land & \\
\hline & Invasive plants (e,g. Striga ) & & Water borne diseases & \\
\hline & $\begin{array}{l}\text { What are the causes of land } \\
\text { degradation }\end{array}$ & $\begin{array}{l}\text { 1) Yes } \\
\text { 2) N0 }\end{array}$ & Increase of pests/diseases & \\
\hline & over cultivation & & & \\
\hline
\end{tabular}




\begin{tabular}{|l|l|l|l|l|}
\hline & over grazing & & & \\
\hline & Sugar plantation & & & \\
\hline & Deforestation & & & \\
\hline & expansion of settlement areas & & & \\
\hline & bush encroachment & & & \\
\hline & Insufficient conservation & & & \\
\hline & Population pressure/density & & & \\
\hline
\end{tabular}

\section{THANK YOU}

Thanks for taking the time to help me with my educational endeavors. The information gathered will be confidentially used for my Ph.D study.

\subsection{Key Informant Interview Checklist for Agricultural Experts}

Date of interview

1. Name signature

2. Age: Sex

$\square$ Male

$\square$ Female

3. What is your professional background?

$\square$ Natural resource management

$\square$ Plant science

$\square$ Animal science

$\square$ Rural development

$\square$ Animal health

$\square$ Other: (please describe)

4. What are your main activities and responsibilities?

5. How many years of experience have you had in this current job?
$\square<1$ Year
$\square$ 1-2 Years
$\square$ 2-5 Years
口 5-10 Years
$\square>10$ Years

6. What are the major livelihood constraints in this community (ranking)?

$\square$ land degradation $\quad \square$ climate change

$\square$ Conflict $\quad \square$ hunger $\square$ water scarcity 
7. Is land-related conflict $\square$ increasing $\square$ decreasing uunchanged and how?

8. Have the LSLIs displaced the local people? $\square$ voluntary $\square$ forceful

8. What are the benefits of the presence of large-scale land investment for the local community?

$\square$ employment opportunity

$\square$ technology transfer

$\square$ Irrigation access

$\square$ improved water access

$\square$ training and knowledge transfer

$\square$ No benefits at all

9) what are the disadvantages of large-scale land investment in the local community

$\square$ displacement from their land

$\square$ dispute over land use

$\square$ restricted access to water sources

$\square$ soil and grazing land degradation

$\square$ deterioration of livelihoods

10. the attitude of local people towards large-scale land investment is

$\square$ positive

$\square$ negative

Why?

11. what is the nature of property right over land use in this area

$$
\begin{aligned}
& \square \text { private } \\
& \square \text { communal } \\
& \square \text { both private and communal }
\end{aligned}
$$

12. if the land ownership is both private and communal how much is the proportion of private land ownership in your village

$\square$ less than $10 \%$

$\square$ Between $10-25 \%$

$\square$ between $25-50 \%$

$\square$ Between 50-75\%

$\square$ more than $75 \%$

13. Do settled households have a land certificate that shows their ownership? $\square$ yes $\square$ No

14. Is land degradation a serious problem in this village? $\square$ yes $\square$ No

15. If yes, what are the indicators for the existence of land degradation?

16. What is the extent of deforestation ( fire wood, charcoal, timber, etc? 


\subsection{Key Informant Interview Checklists for Sugar Plantations}

Instruction: the facilitator interviews the manager of the plantation or a key informant person among factory workers or managers

\section{Date}

Name of the sugar plantation 1) Tendaho 2) Metehara

Name of Respondent: position

Address Mobile

\section{A) PROFILE OF THE SUGAR FACTORY}

1. Year sugar plantation established [

2. Year sugar plantation operational [

3. Total area of the sugar plantation [ ] in hectare

4. Distance to all weather road from the sugar plantation [ ] in $\mathrm{km}$

5. Who are the major employers of the factory 1) pastoralists 2) None pastoralists

6. Total number of permanent employees in the factory \& plantation ] men [ female ] total

7. Total number of temporary employees in the factory \& plantation ] men [ female ] total

8. Total number of permanent \& temporary employees from pastoral community in the factory \& plantation [ ] men [ ] female [ ] total

9. Total number of sugar cane out growers in the plantation men [ ] female [ ] total

10. What is the average wage salary for temporary employees in the plantations? ] birr per day and [ ] birr per month.

B) Who are the majority employees of the factory 1) local people from the area 2) migrant people from highlands 3) both local and migrant people 


\section{B) PERCEIVED IMPACT OF SUGAR PLANTATIONS}

11. Total population hosting the factory (include all woredas population under the factory)

\begin{tabular}{|l|l|l|l|}
\hline Name of woreda & Total population & Men & Women \\
\hline & & & \\
\hline & & & \\
\hline & & & \\
\hline & & & \\
\hline
\end{tabular}

12. Is there any population on the land allocated for sugar plantations before the establishment of the plantation? 1) yes 2) No

13. Are there populations displaced or resettled from the land used for this plantation? 1) yes 2) No

14. If yes for no 5, how many (number of) households displaced or re-settled from this place men women total

15. Are the local community adequately consulted before the start of this plantation? 1) yes 2) No

16. If yes for number 7 . Who is consulted and what is their opinion?

17. Is there any disagreement between the host community and sugar cane managers when the operation starts? 1) yes 2) No

18. If yes for no 9, what are the causes of disagreement?

19. Is any compensation paid for the inhabitants who left the place for sugar cane? 1) yes 2) No

20. If yes, for no 15 how much money paid per household on average

21. If no what are the reasons 
22. Number of employees in this sugar factory

\begin{tabular}{|l|l|l|l|l|l|}
\hline \multicolumn{2}{|l|}{ Temporary } & & \multicolumn{2}{l|}{ Permanent } & Total \\
\hline Men & women & Total & Men & Women & \\
\hline & & & & & \\
\hline & & & & & \\
\hline
\end{tabular}

23. Among permanent employees how many employs are from local area/ pastoral communities number $\%$

24. Among permanent employees how many employees are in-migrants from other parts of Ethiopia number $\%$

25. What is the average rate of wage per day for daily laborers birr/ person

26. What is the contribution of the factory/ plantation to the local development

\begin{tabular}{|l|l|l|}
\hline & Yes/ no & Explanation (give how much in number if yes) \\
\hline Built schools & & \\
\hline Constructed roads & & \\
\hline Irrigation infrastructure & & \\
\hline $\begin{array}{l}\text { Water supply for } \\
\text { livestock }\end{array}$ & & \\
\hline $\begin{array}{l}\text { Livestock feed } \\
\text { supplements }\end{array}$ & & \\
\hline $\begin{array}{l}\text { Employment } \\
\text { opportunity }\end{array}$ & & \\
\hline Others & & \\
\hline
\end{tabular}

27. According to your own perception, the attitude of local community towards the sugar factory is 1) Very poor 2) Poor 3) Good 4) Very Good

28. According to your own perception the interaction of the factory and local community 1) Very poor 2) Poor 3) Good 4) Very Good

29. If there are conflicts between the community and factory what are the causes of conflict between factory and local communities

30. Is there any 
environmental effects from the sugar factory? If there are any which of the following are the major ones

\begin{tabular}{|l|l|}
\hline Environmental effects & None 2) Little 3) High 4) Very high \\
\hline Water pollution & \\
\hline Soil siltation & \\
\hline Salinity & \\
\hline Water resource degradation & \\
\hline Deforestation & \\
\hline
\end{tabular}

30. Total, irrigable area: ha. Used for the plantation

31. Total, irrigation áreas accessible to rural people

32. Number of households who got access to irrigation due to the plantation

33. Is the plantation area free for communal grazing? 1) yes 2) No

34. How much hectare of land is used for free grazing?

35. How many livestock on average feed on this grazing land during the dry season?

36. Does this plantation supply any kind of agricultural input to the local community?

1. If yes, which of the following is supplied by the plantation? (*Multiple responses is expected)

\begin{tabular}{|l|l|l|}
\hline Types of inputs used & $\begin{array}{l}\text { Yes } \\
\text { 2) No }\end{array}$ & $\begin{array}{l}\text { Number of beneficiaries in the } \\
\text { last year }\end{array}$ \\
\hline Improved seed, specify & & \\
\hline Fertilizers & & \\
\hline Pesticides/herbicides & & \\
\hline irrigation equipment & & \\
\hline Livestock feeds & & \\
\hline Access to credit services & & \\
\hline Access to training & & \\
\hline Out growers & & \\
\hline
\end{tabular}

38) any additional information and comment

Thank you so much for your information. The information you provided is confidential. It will be used only for academic purpose and your identity by no means is not going to be disclosed. 


\subsection{Focus group discussions (FGD) Checklists}

Date

Name of Kebele

Introduction by the facilitator

My name is and I am here to collect data on drivers of land degradation and

land conflict for academic purposes. The project aims to understand the drivers of change in pastoral livelihoods with emphasis on large-scale land investment. I'll ask you some questions about your village and community. Your information will help the research to be based on ground reality and facts. The discussion will take around 2.00 hours or so depending on your interest and participation. Any information that you provide will be kept strictly confidential and will not be shown to other people. The discussion is voluntary and you are free to choose not to answer any or all the questions, or to leave the discussion at any time. This survey is not related to any humanitarian or government program, and therefore not linked to any assistance.

\section{Guidelines for facilitators}

FGD facilitators should follow the following instruction carefully

Make sure that all FGD participants should not be less than 40 years of age

The minimum and maximum number of one FGD participants should be 6 and 12 respectively Allow every participant to introduce him/herself before starting discussions

Before starting the discussion inform ground rules that help establish the group norms

The information they give us will be kept anonymously.

Only one person talks at a time

There are no right or wrong answers to questions

Do not interrupt when someone is speaking

\section{FGD Participants Roster}




\begin{tabular}{|c|c|c|c|c|c|}
\hline & Name & facilitator & & $\begin{array}{l}\text { Date } \\
\text { Time Started: } \\
\text { Time Ended }\end{array}$ & $\bar{L}$ \\
\hline & Regior & & & & \\
\hline & Distric & & & & \\
\hline & Kebele & & & & \\
\hline $\mathrm{NO}$ & Name & age & $\operatorname{sex}$ & & contact \\
\hline 1 & & & & & \\
\hline 2 & & & & & \\
\hline 3 & & & & & \\
\hline 4 & & & & & \\
\hline 5 & & & & & \\
\hline 6 & & & & & \\
\hline 7 & & & & & \\
\hline 8 & & & & & \\
\hline 9 & & & & & \\
\hline 10 & & & & & \\
\hline 11 & & & & & \\
\hline \begin{tabular}{|l|}
12 \\
\end{tabular} & & & & & \\
\hline & & & & & \\
\hline
\end{tabular}

\section{Main Checklists and Questions}

\begin{tabular}{|c|c|c|c|}
\hline Q No & \multicolumn{2}{|l|}{ Questions } & Description of answer \\
\hline & \multicolumn{2}{|c|}{ LIVELIHOODS, ASSETS, AND VULNERABILITY } & \\
\hline 1 & \multicolumn{3}{|c|}{$\begin{array}{l}\text { What are the major means of livelihood in this community (Crop production, livestock, } \\
\text { remittance, migration, wage, bee keeping)? }\end{array}$} \\
\hline 1.1 & \multicolumn{3}{|c|}{ Rank the following by using the contribution to food and income } \\
\hline & & $\begin{array}{l}\text { Food source } \\
\text { 1. Low 2. Moderate 3. High } \\
\text { ) }\end{array}$ & $\begin{array}{l}\text { Income source } \\
\text { Low 2. Moderate 3. High ) }\end{array}$ \\
\hline \multicolumn{2}{|c|}{ Camel } & & \\
\hline
\end{tabular}




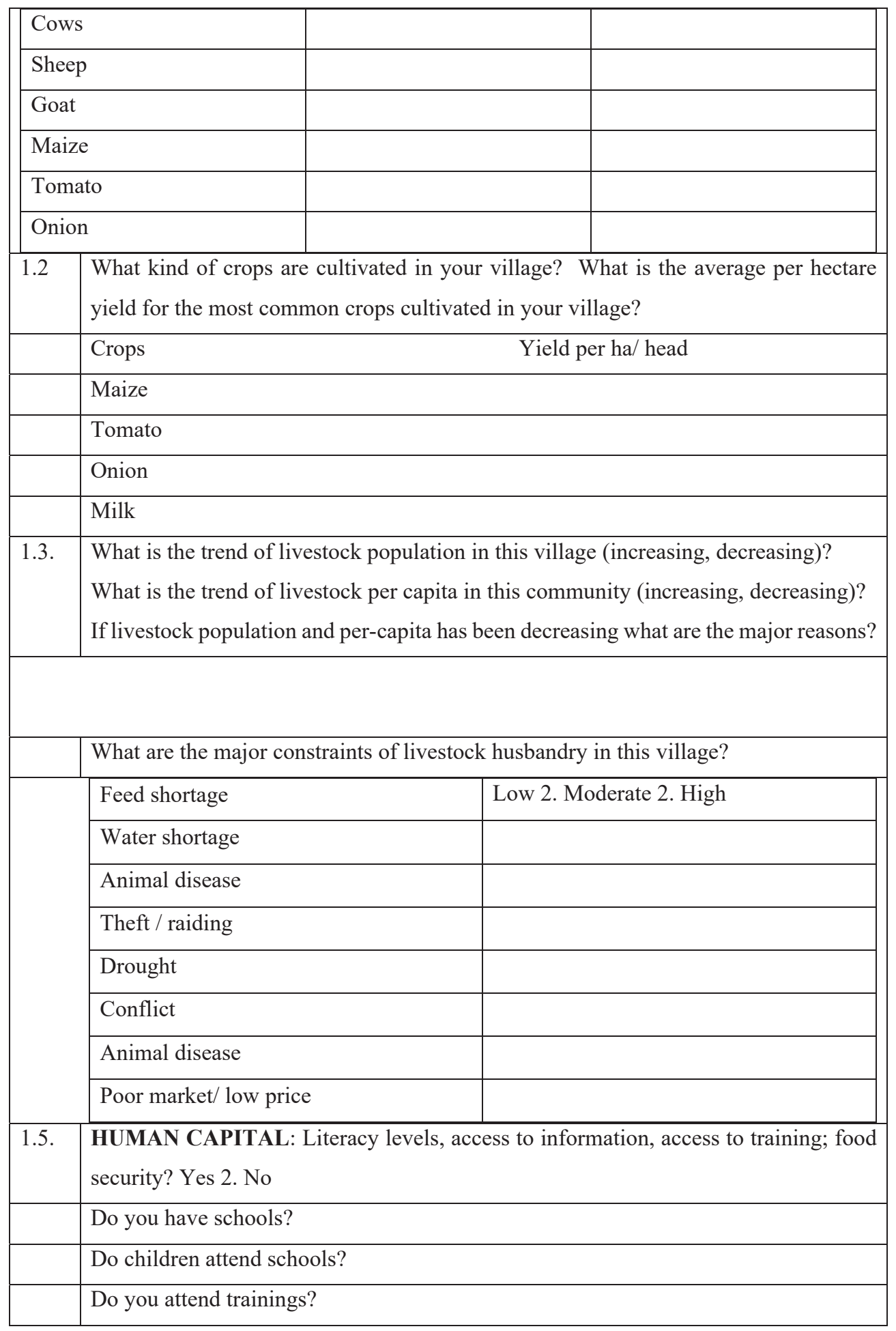




\begin{tabular}{|c|c|c|}
\hline & \multicolumn{2}{|l|}{ Is there food aid in this village? } \\
\hline & \multicolumn{2}{|c|}{ How many households depend on food aid? } \\
\hline & \multicolumn{2}{|c|}{ Do the community have access to health services/facility? } \\
\hline 1.6 & \multicolumn{2}{|l|}{ SOCIAL CAPITAL } \\
\hline & \multicolumn{2}{|l|}{ How is the inter clan interactions going? } \\
\hline & \multicolumn{2}{|c|}{ Types of mutual supports in the community } \\
\hline & \multicolumn{2}{|l|}{ Who are mostly marginalized people? } \\
\hline & \multicolumn{2}{|l|}{ Extent of mutual support } \\
\hline 1.7 & \multicolumn{2}{|c|}{$\begin{array}{l}\text { NATURAL CAPITAL: what is the nature of access to natural capitals (privatized or } \\
\text { communal). Is there evidence of significant conflict over resources? Do the } \\
\text { community have access to training and knowledge on NR conservations? Is access to } \\
\text { grazing lands diminishing? If yes what are the causes? }\end{array}$} \\
\hline 1.8 & \multicolumn{2}{|c|}{$\begin{array}{l}\text { PHYSICAL CAPITALS: what is the nature of road access and network in this } \\
\text { district? What is the sources of water for human and animal consumptions? Is there } \\
\text { water infrastructure? Are there irrigation facilities in your village? - How many people } \\
\text { (proportion) had access to irrigation? Explain extent of agricultural inputs utilization } \\
\text { (improved seeds, fertilizer, feeds, pesticides) }\end{array}$} \\
\hline 1.9 & \multicolumn{2}{|c|}{$\begin{array}{l}\text { FINANCIAL CAPITAL: what formal and informal sources of finance exist in this } \\
\text { community? What is situation on access to markets in this village? }\end{array}$} \\
\hline 1.10 & \multicolumn{2}{|c|}{$\begin{array}{l}\text { VULNERABILITY: What are the major hazards existing in this village (Drought } \\
\text { flood, conflict, livestock disease, human disease, land slide)? State its rate and } \\
\text { frequency? }\end{array}$} \\
\hline 2. & \multicolumn{2}{|c|}{ LAND DEGRADATION, CAUSES AND EFFECTS } \\
\hline 2.1 & \multicolumn{2}{|c|}{ What is the situation of land degradation in this community? } \\
\hline 2.2 & \multicolumn{2}{|c|}{ What types of land degradation are common in this village? } \\
\hline \multicolumn{2}{|c|}{$\begin{array}{l}\text { What is the level of the folloing indicators } \\
\text { of land degradation? }\end{array}$} & Little 2. Low 3. Moderate 4. High \\
\hline \multicolumn{2}{|c|}{ siltation } & \\
\hline \multicolumn{2}{|c|}{ salinity } & \\
\hline \multicolumn{2}{|c|}{ acidity } & \\
\hline \multicolumn{2}{|c|}{ erosion } & \\
\hline $\operatorname{def}$ & estation & \\
\hline
\end{tabular}




\begin{tabular}{|l|l|l|}
\hline \multicolumn{2}{|l|}{ declining fertility } & \\
\hline Gully & \\
\hline \multicolumn{1}{|l|}{ Prosopis invasions } \\
\hline 2.3 & What are the causes of land degradation in this village? \\
\hline Poor irrigation techniques & Low 2. Moderate 2. High \\
\hline drought & \\
\hline low conservation practices & \\
\hline topography & sugar & \\
\hline $\begin{array}{l}\text { Large-scale land investments/ } \\
\text { plantations }\end{array}$ & \\
\hline Livestock population/ overgrazing & \\
\hline Human population & \\
\hline Deofrestation & $\begin{array}{l}\text { What are the effects of land degradation? Increased desertification, low grass land, } \\
\text { poor soil fertility, declining livestock productivity, more frequent hunger, etc }\end{array}$ \\
\hline 2.4 & MOBILITY/MIGRATION WITH LIVESTOCK \\
\hline 4.3 & How far/ distance/ does the community move for the search of pasture and water? \\
\hline 4.4 & What are the obstacles of mobility? \\
\hline
\end{tabular}

\begin{tabular}{|l|l|}
\hline 5 & LARGE-SCALE LAND INVESTMENT AND ITS PERCEIVED EFFECT \\
\hline 5.2 & $\begin{array}{l}\text { Does the investment have any direct effect on your means of living? If yes, how did } \\
\text { it affect you? }\end{array}$ \\
\hline 5.3 & $\begin{array}{l}\text { What is the trends of large-scale land investment in your villages } \\
\text { (Increasing/decreasing not changes)? }\end{array}$ \\
\hline 5.4 & $\begin{array}{l}\text { Did those who directly affected have get any direct compensation for lost } \\
\text { opportunities? }\end{array}$ \\
\hline 5.5 & $\begin{array}{l}\text { Did the investment created employment (temporary or permanent) for the local } \\
\text { community? If so how much proportion employed? }\end{array}$ \\
\hline 5.6 & $\begin{array}{l}\text { Has any infrastructure been provided by the investment in your village (irrigation, } \\
\text { road, school, clinic)? }\end{array}$ \\
\hline
\end{tabular}




\begin{tabular}{|c|c|c|}
\hline 5.7 & \multicolumn{2}{|c|}{$\begin{array}{l}\text { Are there technology transfer and exchange between the investment and the } \\
\text { community? If yes, what kind of technology? }\end{array}$} \\
\hline 6 & \multicolumn{2}{|c|}{ LAND USE CONFLICT PREVALENCE, CAUSES AND EFFECTS } \\
\hline 6.1 & \multicolumn{2}{|c|}{ Are there land disputes in your village from past to present? } \\
\hline 6.2 & \multicolumn{2}{|c|}{$\begin{array}{l}\text { If there are land related disputes, what are the causes for such conflict, boundary } \\
\text { disputes etc }\end{array}$} \\
\hline \multicolumn{2}{|c|}{ Land scarcity } & Low 2. Moderate 2. High \\
\hline \multicolumn{3}{|c|}{ LSLIs } \\
\hline \multicolumn{3}{|c|}{ Livestock mobil } \\
\hline \multicolumn{3}{|c|}{ Water shortage } \\
\hline \multicolumn{3}{|c|}{ Border expansion } \\
\hline \multicolumn{3}{|c|}{ Livestock raiding } \\
\hline \multicolumn{3}{|c|}{ Drought } \\
\hline 6.3 & \multicolumn{2}{|c|}{$\begin{array}{l}\text { what are the effects of conflict in this community? Displacement, livestock and } \\
\text { property loss, death of community members, etc }\end{array}$} \\
\hline 6.4 & \multicolumn{2}{|c|}{$\begin{array}{l}\text { What kind of practices are followed for conflict management? How effective are the } \\
\text { various methods? }\end{array}$} \\
\hline 6.5 & \multicolumn{2}{|c|}{ Are you satisfied with government support in conflict resolutions? } \\
\hline 6.6 & \multicolumn{2}{|c|}{$\begin{array}{l}\text { What are the trends of land-related conflict in this village? Increasing, decreasing, } \\
\text { etc }\end{array}$} \\
\hline & \multicolumn{2}{|c|}{$\begin{array}{l}\text { What recommendations can you propose to reduce land conflicts in your area? How } \\
\text { to reduce the conflict? }\end{array}$} \\
\hline 7 & \multicolumn{2}{|c|}{ LAND ACCESS AND USE RIGHTS } \\
\hline 7.1 & \multicolumn{2}{|c|}{ Do you have full rights over land uses? } \\
\hline 7.2 & \multicolumn{2}{|c|}{ Do you think that land use rights were respected in this area? } \\
\hline 7.3 & \multicolumn{2}{|c|}{$\begin{array}{l}\text { What is the role of traditional elders (customary/clan system) in the management of } \\
\text { public land and land dispute resolution? Clan leader's role in land management: } \\
\text { Clan leaders' role in dispute management }\end{array}$} \\
\hline 7.4 & \multicolumn{2}{|c|}{$\begin{array}{l}\text { What is the role of the formal legal system in appropriation, management of public } \\
\text { land, and land dispute resolution }\end{array}$} \\
\hline 7.5 & \multicolumn{2}{|c|}{ Who in this village is allowed to own land (men, women, clan, collectively)? } \\
\hline 7.6 & \multicolumn{2}{|c|}{$\begin{array}{l}\text { Which of the following land rights were respected for land users in this village? } \\
\text { Indicate by } \checkmark\end{array}$} \\
\hline
\end{tabular}




\begin{tabular}{|l|l|l|l|}
\hline & & Communal & Private \\
\hline & Decide what to grow on the land? & & \\
\hline & Use for grazing and other purposes? & & \\
\hline & Transfer to someone if interested? & & \\
\hline & Decides who can and cannot use the land? & & \\
\hline & Decides to sell the land? & Decides to rent the land? & \\
\hline 7.6 & $\begin{array}{l}\text { Wecides to give the land to someone else? } \\
\text { some of the main characteristics of communal land as compared to land owned by } \\
\text { individuals? }\end{array}$ \\
\hline
\end{tabular}

- Thank you for participating in this discussion. 


\section{References}

Aabø, E., and Kring, T. (2012). The political economy of large-scale agricultural land acquisitions: Implications for food security and livelihoods/employment creation in rural Mozambique. United Nations Development Programme Working Paper 4, 1-61.

Abate, T., Ebro, A., and Nigatu, L. (2010). Traditional rangeland resource utilization practices and pastoralists' perceptions on land degradation in south-east Ethiopia. Tropical grasslands 44, 202-212.

Abbink, G., Askew, K., Dori, D. F., Fratkin, E., Gabbert, E. C., Galaty, J., LaTosky, S., Lydall, J., Mahmoud, H. A., and Markakis, J. (2014). Abbink, G., Askew, K., Dori, D. F., Fratkin, E., Gabbert, E. C., Galaty, J., LaTosky, S., Lydall, J., Mahmoud, H. A., and Markakis, J. (2014a). Lands of the future: transforming pastoral lands and livelihoods in eastern Africa. In "Max Planck Institute for Social Anthropology working papers 154. ", pp. 28. Max Planck Institute. http://hdl.handle.net/1887/27586.

Abdisalem, Y. (2012). Study of Conflict among Pastoralists of Ethiopia: A Review of Cases and Experiences, MSc. Thesis, Haramaya University, Haramaya, Ethiopia.

Abdulahi, M. (2005). "The changing nature of pastoral conflicts in South-Eastern Ethiopia. Witsenburg WR, Pastoral Sedentarisation, Natural Resource Management, and Livelihood Diversification in Marsabit District, Northern Kenya.."

Abebaw, S. (2016). Impact and associated factors of conflict over resource and livelihood in pastoralist community: the case of Afar-Issa conflict in Amibara woreda, afar regional state, St. Mary's University.

Abildtrup, J., Garcia, S., and Kere, E. (2015). Land use and drinking water supply: a spatial switching regression model with spatial endogenous switching. Revue dEconomie Regionale Urbaine 2, 321-342.

Adebayo, O., Bolarin, O., Oyewale, A., and Kehinde, O. (2018). Impact of irrigation technology use on crop yield, crop income and household food security in Nigeria: A treatment effect approach. AIMS Agriculture and Food 3, 154-171.

Adego, T., Simane, B., and Woldie, G. A. (2019). The impact of adaptation practices on crop productivity in northwest Ethiopia: an endogenous switching estimation. Development Studies Research 6, 129-141.

Adela, F. A., and Aurbacher, J. (2018). Access to irrigation water-poverty nexus: Application of an Endogenous Switching Regression in Ethiopia. In "International Association of Agricultural Economists (IAAE) ". International Association of Agricultural Economists, Vancouver, British Columbia. http://10.22004/ag.econ.277521.

Adhvaryu, A., Fenske, J. E., Khanna, G., and Nyshadham, A. (2018). "Resources, Conflict, and Economic Development in Africa. NBER Working Paper No. 24309." National Bureau of Economic Research.

Adnew, D., Assen, M., Satyal, P., and Budds, J. (2019). Villagization and access to water resources in the Middle Awash Valley of Ethiopia: implications for climate change adaptation. Climate and Development.

African Union (2013). "Policy framework for pastoralism in Africa: Securing, protecting and improving the lives, livelihoods and rights of pastoralist communities. African Union (AU)."

AFSA (2017). Pastoralism, policy and law in the EAC and IGAD regions (East African Community \& Intergovernmental Authority on Development Regions), Alliance for Food Sovereignty in Africa (AFSA). https://afsafrica.org/wpcontent/uploads/2019/05/pastoralism-policy-and-law-in-the-eac-booklet.pdf. 
Alemu, Z. G., Oosthuizen, L. K., and van Schalkwyk, H. D. (2002). Agricultural development policies of Ethiopia since 1957. South African Journal of Economic History 17, 1-24.

Alfani, F., Dabalen, A., Fisker, P., and Molini, V. (2015). "Can we measure resilience? A proposed method and evidence from countries in the Sahel. Policy Research Working Paper;No. 7170. Washington, DC," The World Bank.

Ali, D., Deininger, K., and Harris, A. (2018). Does large farm establishment create benefits for neighboring smallholders? Evidence from Ethiopia. pp. 4. World Bank, Washingiton DC.

Ali, D., Deininger, K., and Harris, A. (2019). Does large farm establishment create benefits for neighboring smallholders? Evidence from Ethiopia. Land Economics 95, 71-90.

Alinovi, L., D'errico, M., Mane, E., and Romano, D. (2010). Livelihoods strategies and household resilience to food insecurity: An empirical analysis to Kenya. European report on development, 1-52.

Alinovi, L., Mane, E., and Romano, D. (2009). Measuring household resilience to food insecurity: application to Palestinian households. EC-FAO Food Security Programme Rom.

Alkire, S., Kanagaratnam, U., and Suppa, N. (2020). "The Global Multidimensional Poverty Index (MPI) 2020. Oxford Poverty and Human Development Initiative, ." University of Oxford.

Ambelu, A., Birhanu, Z., Tesfaye, A., Berhanu, N., Muhumuza, C., Kassahun, W., Daba, T., and Woldemichael, K. (2017). Intervention pathways towards improving the resilience of pastoralists: A study from Borana communities, southern Ethiopia. Weather and Climate Extremes 17, 7-16.

Amel, B., and Stefano, M. (2017). Pastoralism: a resilient lifestyle faced with many challenges. Online Knowledge BaseNatural Resource Governance around the World. https://www.agter.org/bdf/en/corpus_chemin/fiche-chemin-623.html.

Amwata, D. A., Nyariki, D. M., and Musimba, N. R. (2016). Factors influencing pastoral and agropastoral household vulnerability to food insecurity in the drylands of Kenya: a case study of Kajiado and Makueni Counties. Journal of International Development 28, 771787.

Ansah, I. G. K., Gardebroek, C., and Ihle, R. (2019). Resilience and household food security: a review of concepts, methodological approaches and empirical evidence. Food Security 11, 1187-1203.

Ariti, A. T., van Vliet, J., and Verburg, P. H. (2018). Farmers' participation in the development of land use policies for the Central Rift Valley of Ethiopia. Land Use Policy 71, 129137.

Arouri, M., Nguyen, C., and Youssef, A. B. (2015). Natural Disasters, Household Welfare, and Resilience: Evidence from Rural Vietnam. World Development 70, 59-77.

Asefach, A., and Nigatu, R. (2007). Correlates of household food security in densely populated areas of Southern Ethiopia: does the household structure matter? Studies on Home and Community Science 1, 85-91.

Asfaw, S., Maggio, G., and Palma, A. (2018). Climate Resilience Pathways of Rural Households. Evidence from Ethiopia. Evidence from Ethiopia (October 2018). SWPS 18.

Asmamaw, M., Mereta, S. T., and Ambelu, A. (2019). Exploring households' resilience to climate change-induced shocks using Climate Resilience Index in Dinki watershed, central highlands of Ethiopia. PloS one 14, e0219393.

Atara, A., Tolossa, D., and Denu, B. (2020). Analysis of rural households' resilience to food insecurity: Does livelihood systems/choice/ matter? The case of Boricha woreda of sidama zone in southern Ethiopia. Environmental Development 35, 100530. 
AU (2013). "Policy framework for pastoralism in Africa: Securing, protecting and improving the lives, livelihoods and rights of pastoralist communities. African Union (AU)."

Avis, W. (2018). "Rebuilding pastoralist livelihoods during and after conflict."

Ayantunde, A. A., de Leeuw, J., Turner, M. D., and Said, M. (2011). Challenges of assessing the sustainability of (agro)-pastoral systems. Livestock Science 139, 30-43.

Bahadur, A., Lovell, E., Wilkinson, E., and Tanner, T. (2015). Resilience in the SDGs: Developing an indicator for Target 1.5 that is fit for purpose. London: Overseas Development Institute Briefing.

Baker, J. L. (2000). "Evaluating the impact of development projects on poverty: A handbook for practitioners," The World Bank. Washington, DC. http://documents.worldbank.org/curated/en/762341468278363048/

Baltagi, B. (2008). "Econometric analysis of panel data (vol 4). Chichester, John Wiley \& Sons ".

Barrett, C., and Constas, M. (2014). Toward a theory of resilience for international development applications. Proceedings of the National Academy of Sciences of the United States of America 111, 14625-14630.

Barrett, C., Reardon, T., and Webb, P. (2001). Nonfarm income diversification and household livelihood strategies in rural Africa: concepts, dynamics, and policy implications. Food Policy 26, 315-331.

Bartolome, L. J., De Wet, C., Mander, H., and Nagraj, V. K. (2000). "Displacement, resettlement, rehabilitation, reparation and development," World Commission on Dams. Cape Town, South Africa. http://www.dams.org

Bassett, T. J. (1988). The political ecology of peasant-herder conflicts in the northern Ivory Coast. Annals of the association of American geographers 78, 453-472.

Basupi, L. V., Quinn, C. H., and Dougill, A. J. (2019). Adaptation strategies to environmental and policy change in semi-arid pastoral landscapes: Evidence from Ngamiland, Botswana. Journal of Arid Environments 166, 17-27.

Baumgartner, P., von Braun, J., Abebaw, D., and Müller, M. (2015). Impacts of Large-scale Land Investments on Income, Prices, and Employment: Empirical Analyses in Ethiopia. World Development 72, 175-190.

Becker, S. O., and Ichino, A. (2002). Estimation of Average Treatment Effects Based on Propensity Scores. The Stata Journal 2, 358-377.

Behnke, R., and Kerven, C. (2011). Replacing pastoralism with irrigated agriculture in the Awash Valley, North-Eastern Ethiopia: Counting the costs. In "International Conference on the Future of Pastoralism", pp. 21-23. Citeseer.

Behnke, R. H., and Kerven, C. (2013). "Counting the costs: replacing pastoralism with irrigated agriculture in the Awash Valley, north-eastern Ethiopia," IIED London.

Beirne, J. (2014). Gilgel Gibe III: Dam-Induced Displacement in Ethiopia and Kenya.

Bekele, A. E., Dries, L., Drabik, D., and Heijman, W. (2020). Large-scale land investments, household displacement, and the effect on land degradation in semiaridagro-pastoral areas of Ethiopia. Land Degrad Dev. 2021;32:777791.https://doi.org/10.1002/ldr.3756.

Bekele, A. E., Dries, L., Heijman, W., and Drabik, D. (2021). Large scale land investments and food security in agropastoral areas of Ethiopia. Food Security.

Belay, S., Amsalu, A., and Abebe, E. (2013). Awash National Park, Ethiopia: use policy, ethnic conflict and sustainable resources conservation in the context of decentralization. African journal of ecology 51, 122-129.

Berhe, T., and Adaye, Y. (2007). "Afar: The Impact of Local Conflict on Regional Stability. ," Institute for Security Studies. https://www.files.ethz.ch/isn/123909/2007_05_01_Afar.pdf. 
Berihun, M. L., Tsunekawa, A., Haregeweyn, N., Meshesha, D. T., Adgo, E., Tsubo, M., Masunaga, T., Fenta, A. A., Sultan, D., and Yibeltal, M. (2019). Exploring land use/land cover changes, drivers and their implications in contrasting agro-ecological environments of Ethiopia. Land Use Policy 87, 1-15.

Berry, L. (2003). "Land degradation in Ethiopia: Its extent and impact. Commissioned by the Global Mechanism with World Bank support, 2-7."

Beyene, F. (2006). Informal Institutions and Access to Grazing Resources: Practices and Challenges among Pastoralists of Eastern Ethiopia. In "Survival of the Commons: Mounting Challenges and New Realities, the Eleventh Conference of the International Association for the Study of Common Property". International Association for the Study of Common Property, Bali Indonesia http://hdl.handle.net/10535/1200.

Beyene, F. (2007). The role of customary institutions in managing conflict on grazing land: a case study from Mieso District, Eastern Ethiopia.

Beyene, F. (2009). Property rights conflict, customary institutions and the state: The case of agro-pastoralists in Mieso district, eastern Ethiopia. The Journal of Modern African Studies 47, 213-239.

Beyene, F. (2010). Driving forces in the expansion of enclosure among pastoral and agropastoral herders in Ethiopia. Quarterly Journal of International Agriculture 49, 127-146.

Beyene, F. (2016). Land use change and determinants of land management: Experience of pastoral and agro-pastoral herders in eastern Ethiopia. Journal of Arid Environments 125, 56-63.

Beyene, F. (2017). Natural Resource Conflict Analysis Among Pastoralists in Southern Ethiopia. Journal of Peacebuilding \& Development 12, 19-33.

Beza, S., and Assen, M. (2017). Expansion of sugarcane monoculture: associated impacts and management measures in the semi-arid East African Rift Valley, Ethiopia. Environmental monitoring and assessment 189, 1-14.

Biazin, B., and Sterk, G. (2013). Drought vulnerability drives land-use and land cover changes in the Rift Valley dry lands of Ethiopia. Agriculture, ecosystems \& environment 164, 100-113.

Bielli, C., Berhanu, G., Isaias, A., and Orasi, A. (2001). "Population growth and environment in Ethiopia. Central Statistical Agency (CSA) and Institute for Population Research National Research Council ", Addis Ababa, Rome. https://www.irpps.cnr.it/etiopia/pdf/Population_Growth_and_Environment.PDF.

Bishop, D. (2015). Livelihoods in Zimbabwe: Evaluation of food security and strengthening livelihood options.

Blench, R. (1997). "Aspects of resource conflict in semi-arid Africa," Overseas Development Institute London.

Bogale, A., and Korf, B. (2007). To share or not to share? (non-)violence, scarcity and resource access in Somali Region, Ethiopia. The Journal of Development Studies 43, 743-765.

Bogale, A., and Shimelis, A. (2009). Household level determinants of food insecurity in rural areas of Dire Dawa, Eastern Ethiopia. African Journal of Food, Agriculture, Nutrition and Development 9.

Bojö, J. P. (1991). Economics and land degradation. Ambio, 75-79.

Bollig, M., and Lesorogol, C. (2016). The "new pastoral commons" of Eastern and Southern Africa. International Journal of the Commons 10.

Bollig, M., and Schnegg, M. (2013). Introduction: Specialisation and diversification among African pastoral societies. Pastoralism in Africa: Past, present, and futures, 1-28. 
Bottazzi, P., Crespo, D., Bangura, L. O., and Rist, S. (2018). Evaluating the livelihood impacts of a large-scale agricultural investment: Lessons from the case of a biofuel production company in northern Sierra Leone. Land Use Policy 73, 128-137.

Botterli, A. (2015). Adapting to climate change through villagization?: the context of sedentary vulnerability in Afar region, Ethiopia, Norwegian University of Life Sciences, Ås. http://hdl.handle.net/11250/293843.

Bowie, B., and Feyertag, J. (2019). Tenure risk in the African sugar sector can cause companies to lose up to US \$100 million. International Sugar Journal 121, 514-516.

Bruce, J., and Boudreaux, K. (2011). Land and conflict, land disputes and land conflicts. USAID Issue Brief, Property Rights and Resource Governance Briefing Paper No 12.

Brück, T., d'Errico, M., and Pietrelli, R. (2019). The effects of violent conflict on household resilience and food security: Evidence from the 2014 Gaza conflict. World Development 119, 203-223.

Bunning, S., McDonagh, J., Rioux, J., and Woodfine, A. (2011). "Manual for local level assessment of land degradation and sustainable land management," LADA Technical Report.

Burchi, F., and De Muro, P. (2016). From food availability to nutritional capabilities: Advancing food security analysis. Food Policy 60, 10-19.

Butt, B. (2010). Pastoral resource access and utilization: quantifying the spatial and temporal relationships between livestock mobility, density and biomass availability in southern Kenya. Land Degradation \& Development 21, 520-539.

Campbell, D. J., Gichohi, H., Mwangi, A., and Chege, L. (2000). Land use conflict in Kajiado District, Kenya. Land Use Policy 17, 337-348.

Carloni, A. S., and Crowley, E. L. (2005). Rapid guide for missions: analysing local institutions and livelihoods: guidelines (Vol. 1). Food \& Agriculture Organization of the United States, Rome.

Catley, A. (2013). Pathways to resilience in pastoralist areas: A synthesis of research in the Horn of Africa. Vol. 18, pp. 27. Boston: Feinstein International Center, Tufts.

Cervigni, R., and Morris, M. (2016). "Confronting drought in Africa's drylands: Opportunities for enhancing resilience," The World Bank.

Chambers, R., and Conway, G. (1992). "Sustainable rural livelihoods: practical concepts for the 21 st century," Institute of Development Studies (UK).

Chen, Y.-T., Hsu, Y.-C., and Wang, H.-J. (2018). A Stochastic Frontier Model with Endogenous Treatment Status and Mediator. Journal of Business \& Economic Statistics 0, 1-14.

Chesterman, N. S., Entwistle, J., Chambers, M. C., Liu, H.-C., Agrawal, A., and Brown, D. G. (2019). The effects of trainings in soil and water conservation on farming practices, livelihoods, and land-use intensity in the Ethiopian highlands. Land Use Policy 87, 112.

Christine, J., Willibald, L., Dominik, R., Michael, H., Awulachew, S. B., and Hagos, F. (2008). Impact of irrigation on livelihood and food security in the modern Hare River Irrigation Scheme in Southern Ethiopia.

Ciani, F., and Romano, D. (2014). "Testing for household resilience to food insecurity: Evidence from Nicaragua."

Cochrane, L., and Legault, D. D. (2020). The rush for land and agricultural investment in Ethiopia: What we know and what we are missing. Land 9, 167. https://doi.org/10.3390/land9050167.

Coppock, D. L., Bailey, D., Ibrahim, M., and Tezera, S. (2018). Diversified Investments of Wealthy Ethiopian Pastoralists Include Livestock and Urban Assets That Better Manage Risk. Rangeland Ecology \& Management 71, 138-148. 
Cotula, L. (2009). "Land grab or development opportunity?: agricultural investment and international land deals in Africa," Iied.

Coughlan, M. R., Nelson, D. R., Lonneman, M., and Block, A. E. (2017). Historical land use dynamics in the highly degraded landscape of the Calhoun Critical Zone Observatory. Land 6, 1-20.

Cox, S. J. B. (1985). No tragedy of the commons. Environmental Ethics 7, 49-61.

CSA (2001). Population growth and the environment in Ethiopia. In-depth studies from the 1994 population and housing census in Ethiopia. Italian Multi-Bi Research Project ETH/92/P01.

CSA (2007). "Population and Housing Census 2007 Report." Central Statistical Agency

CSA (2013a). Central Statistical Agency Population Projections for Ethiopia 2007-2037, Addis Ababa Ethiopia.

CSA (2013b). "Population Projection of Ethiopia for All Regions At Wereda Level from 2014 - 2017. Federal Democratic Republic of Ethiopia Central Statistical Agency. Addis Ababa

CSA (2014). Comprehensive Food Security and Vulnerability Analysis Ethiopia. UN World Food Programme and the Central Statistical Agency (CSA) of Ethiopia, Addis Abeba.

CSA (2017). Ethiopia Socio-economic Survey (ESS). Basic Information Document on Living Standards Measurement Study (LSMS), World Bank. Wave Three (2015/2016).

Daniel, A., Klaus, D., and Anthony, H. (2018). Does large farm establishment create benefits for neighboring smallholders? Evidence from Ethiopia. Lnad Governance 4.

Davies, J., Herrera, P., Ruiz-Mirazo, J., Mohamed-Katerere, J., Hannam, I., Nuesri, E., and Batello, C. (2016). "Improving governance of pastoral lands. Implementing the Voluntary Guidelines on the Responsible Governance of Tenure of Land, Fisheries and Forests in the Context of National Food Security. Governance of Tenure Technical Guide No. 6, Rome. FAO. http://www.fao.org/3/a-i5771e.pdf.

de Haan, C. (2016). "Prospects for Livestock-Based Livelihoods in Africa's Drylands," The World Bank.

De Haan, C., Dubern, E., Garancher, B., and Quintero, C. (2016). "Pastoralism Development in the Sahel: A Road to Stability?." World Bank.

De Schutter, O. (2011). How not to think of land-grabbing: three critiques of large-scale investments in farmland. The Journal of Peasant Studies 38, 249-279.

Debebe, A. (2016). Mobility and conflict: Persistent challenges in expanding access to education among pastoralists of south Omo, Ethiopia. Ethiopian Journal of Education and Sciences 11, 33-49.

Debela, D. D., Stellmacher, T., Azadi, H., Kelboro, G., Lebailly, P., and Ghorbani, M. (2020). The Impact of Industrial Investments on Land Use and Smallholder Farmers' Livelihoods in Ethiopia. Land Use Policy 99, 105091.

Deininger, K., and Byerlee, D. (2011). "Rising global interest in farmland: can it yield sustainable and equitable benefits?," World Bank Publications.

Deininger, K., and Xia, F. (2016). Quantifying Spillover Effects from Large Land-based Investment: The Case of Mozambique. World Development 87, 227-241.

Deininger, K. B., D (2010). The rise of large-scale farms in land-abundant developing countries: Does it have a future. In Conference Agriculture for Development-Revisited, University of California at Berkeley. October (pp. 1-2).

Dell'Angelo, J., D'Odorico, P., Rulli, M. C., and Marchand, P. (2017). The Tragedy of the Grabbed Commons: Coercion and Dispossession in the Global Land Rush. World Development 92, 1-12. 
Demeke, M., Guta, F., and Ferede, T. (2006). Agricultural development and food security in sub-Saharan Africa (SSA): Building a case for more public support. The case of Ethiopia. FAO, Rome.

Demeke, M., and Tefera, N. (2010). "Household Resilience to Food Insecurity in Ethiopia: Panel Data Evidence. Rome: Food and Agriculture Organisation (FAO-ESA)." Mimeo. Dercon, S.(2001). Assessing Vulnerability to Poverty. Oxford ....

Dercon, S., and Hoddinott, J. (2005). Livelihoods, growth, and links to market towns in 15 Ethiopian villages.

Devereux, S. (2006). "Vulnerable livelihoods in Somali region, Ethiopia," Institute of Development Studies Brighton.

Devereux, S., Baulch, B., Hussein, K., Shoham, J., and Wilcock, D. (2004). Improving the analysis of food insecurity. Food insecurity measurement, livelihoods approaches and policy: applications in FIVIMS. In "Improving the analysis of food insecurity. Food insecurity measurement, livelihoods approaches and policy: applications in FIVIMS". FIVIMS.

Devereux, S., and Sussex, I. (2000). "Food insecurity in Ethiopia," Institute for Development Studies.

DFID (1999). Sustainable livelihoods guidance sheets. London: DFID 445.

Dheressa, D. K. (2013). The Socio-Economic and Environmental Impacts of Large Scale (Agricultural) Land Acquisition on Local Livelihoods: A Case Study in Bako Tibe Woreda of Oromia Region, Ethiopia. MSc Thesis. Centre for Development and the Environment University of Oslo Blindern, Norway.

Di Falco, S., Laurent-Lucchetti, J., Veronesi, M., and Kohlin, G. (2019). Property Rights, Land Disputes and Water Scarcity: Empirical Evidence from Ethiopia. American Journal of Agricultural Economics 102, 54-71.

Dika, G., Tolossa, D., and Eyana, S. M. (2021). Multidimensional poverty of pastoralists and implications for policy in Boorana rangeland system, Southern Ethiopia. World Development Perspectives 21, 100293.

Dinku, A. M. (2018). Determinants of livelihood diversification strategies in Borena pastoralist communities of Oromia regional state, Ethiopia. Agriculture \& Food Security 7, 41.

Do, T. L., Nguyen, T. T., and Grote, U. (2019). Nonfarm employment and household food security: evidence from panel data for rural Cambodia. Food Security 11, 703-718.

Do Yun, S., and Waldorf, B. S. (2016). The day after the disaster: forced migration and income loss after hurricanes Katrina and Rita. Journal of Regional Science 56, 420-441.

Dong, S. (2016). Overview: Pastoralism in the world. building resilience of human-natural systems of pastoralism in the developing world, 1-37.

Dong, S., Wen, L., Liu, S., Zhang, X., Lassoie, J. P., Yi, S., Li, X., Li, J., and Li, Y. (2011). Vulnerability of worldwide pastoralism to global changes and interdisciplinary strategies for sustainable pastoralism. Ecology and society 16.

Douglas, I. (2006). The local drivers of land degradation in South-East Asia. Geographical Research 44, 123-134.

Dubovyk, O. (2017). The role of Remote Sensing in land degradation assessments: opportunities and challenges. European Journal of Remote Sensing 50, 601-613.

Dwivedi, R. (2002). Models and Methods in Development-Induced Displacement (Review Article). Development and Change 33, 709-732.

Dye, J. (2015). Food Security \& Large-Scale Land Acquisitions: The Cases of Tanzania and Ethiopia, University of Cincinnati.

EHNRI (1997). Kilo calories of different food groups. Ethiopian Health and Nutrition Research Institute/EHNRI/, . 
Elias, E. (2008). Pastoralists in Southern Ethiopia: Dispossession, Access to Resources and Dialogue with Policy Makers. DCG Report No. 53.

Elias, E., and Abdi, F. (2010). "Putting pastoralists on the policy agenda: Land alienation in Southern Ethiopia," IIED London.

Ellis, F. (2000). "Rural livelihoods and diversity in developing countries," Oxford university press.

ESC (2017). Ethiopian Sugar Corporation Factories Profile. http://ethiopiansugar.com/index.php/en/factories/omo-kuraz-sugar-factory-ii.

FAO (1996). Rome Declaration on World Food Security and World Food Summit Plan of Action.

FAO (2012). Pastoralism in Sub-Saharan Africa: Know its Advantages, Understand its Challenges, Act for its Sustainability: Food Sovereignity Brief No 5. Inter-Réseaux Développement Rural and SOS Faim, Belgium

FAO (2013). Comprehensive Africa Agriculture Development Programme (CAADP) East and Central Africa Regional CAADP Nutrition Program Development Workshop Nutrition Country Paper - Ethiopia DRAFT February 2013.

FAO (2016a). "Land Degradation Assessment in Drylnabds: Manual for Local Level Assessment of Land Degradation and Sustainable Land Management. Food And Agriculture Organization Of The United Nations Rome, 2016."

FAO (2016b). Rima-II. Resilience index measurement and analysis. Rome, Italy.

FAO (2018a). East Africa Resilience Strategy 2018-2022. Programme of work 2018-2019. Rome. 40 pp.

FAO (2018b). Pastoralism in Africa's drylands Reducing risks, addressing vulnerability and enhancing resilience. Food and Agriculture Organization of the United Nations (FAO), Rome

FAO (2018c). Protracted crises: Governance and political economy of agriculture-based livelihoods: Governance and policy series discussion brief 1, Rome, Italy

FAO (2021). Pastoralist Knowledge Hub: Background information. http://www.fao.org/pastoralist-knowledge-hub/background/en/ Accessed June 5, 2021.

Fareh, A. M. (2011). Opportunities and Challenges in Implementing Poverty Reduction Policies in Pastoral Communities: A Case Study from the Somali Regional State, Ethiopia.

FDRE (2013). Pastoral Community Development Project PCDP-3. Regional Pastoral Livelihood Resilience Project (RPLRP) Social Assessment Report.

FDRE (2014). Agricultural Growth Program-Livestock Market Development. Pastoral Livestock Trade and Growth in Ethiopia.

FDRE (2017). National Strategy on Prosopis Juliflora Management. Federal Democratic Republic of Ethiopia (FDRE) Minstry of Livestock \& Fisheries, Addis Ababa, Ethiopia. http://woodyweeds.org/wp-content/uploads/2017/03/Prosopis-Strategy-Ethiopia.pdf.

FDRE (2019). Lowland Livelihood Resilience Project (LLRP). Federal Democratic Republic of Ethiopia (FDRE). Ministry of Peace Final Social Assessment Report March 15, 2019 Addis Ababa, Ethiopia. Available at http://www.mofed.gov.et/documents/10182/13997/Final+LLRP+ESMF+0320191.pdf/.

Feleke, S., L. Kilmer, R., and H. Gladwin, C. (2005). Determinants of food security in Southern Ethiopia. Agricultural Economics 33, 351-363.

Fernandes, W. (2001). Development induced displacement and sustainable development. Social Change 31, 87-103.

Feyissa, T. K. (2015). Conflicts among Pastoralists in the Borana Area of Southern Ethiopia: The case of Borana and Garri, UiT Norges arktiske universitet. 
Fitawek, W., and Hendriks, S. L. (2021). Evaluating the Impact of Large-Scale Agricultural Investments on Household Food Security Using an Endogenous Switching Regression Model. Land 10, 323.

Folke, C. (2006). Resilience: The emergence of a perspective for social-ecological systems analyses. Global environmental change 16, 253-267.

Frankenberger, T. (2015). "Ethiopia Pastoralist Areas Resilience Improvement and Market Expansion (PRIME) Project Impact Evaluation Report of the Interim Monitoring." Technical report, Westat, Rockville, MD.

Frankenberger, T. (2016). Measuring Resilience: Evidence from Ethiopia, Kenya, Uganda, Niger and Burkina Faso. Global Health Practitioner Conference, Building Resilience in teh Horn of Africa. technical consertium of feed the future, TABGO, ILRI, TOPS.

Fre, Z., and Tesfagergis, B. (2013). Economic contribution of pastoral and agro pastoral production to food security and livelihoods systems in Africa: The case of Eastern Sudan, Eritrea and Western Ethiopia in the Horn of Africa. Ethiopian e-journal For Research and Innovation Foresight 5, 14-31.

FSIN (2015). Household Data Sources for Measuring and Understanding Resilience. FoosTechnical Series No. 3.

FSS (2002). "Poverty and Poverty Policy in Ethiopia. Food Security Strategy (FSS)." Proceeding of the workshop organized by Forum for social Studies., Addis Ababa, Ethiopia.

Garedew, E., Sandewall, M., Söderberg, U., and Campbell, B. M. (2009). Land-Use and LandCover Dynamics in the Central Rift Valley of Ethiopia. Environmental Management 44, 683-694.

Gebremeskel, E. N., Desta, S., and Kassa, G. K. (2019). Pastoral Development in Ethiopia:Trends and the Way Forward. Development Knowledge and Learning; Washington, DC: The World Bank. http://hdl.handle.net/10986/31818.

Gebreselassie, S., Kirui, O. K., and Mirzabaev, A. (2016). "Economics of Land Degradation and Improvement in Ethiopia. In: Nkonya E., Mirzabaev A., von Braun J. (eds) Economics of Land Degradation and Improvement - A Global Assessment for Sustainable Development. Springer, Cham. https://doi.org/10.1007/978-3-319-191683."

GEF (2019). Land Degradation. Investing in our planet. Global Environmental Facility (GEF). https://www.thegef.org/sites/default/files/publications/gef_land_degradation_bifold_a ugust 2019_0.pdf.

Gelbard, M. E., Deléchat, C., Fuli, M. E., Hussain, M. M., Jacoby, M. U., Glaser, M. D., Pani, M. M., Ramirez, M. G., and Xu, R. (2015). "Building resilience in sub-Saharan Africa's fragile states," International Monetary Fund.

Gmür, D. (2020). Not Affected the Same Way: Gendered Outcomes for Commons and Resilience Grabbing by Large-Scale Forest Investors in Tanzania. Land 9, 122.

Grandval, F. (2012). Pastoralism in sub-Saharan Africa: know its advantages; understand its challenges, act for its sustainability. Food Sovereignty Briefs.

Gujarati, D. N. (2009). "Basic econometrics," Tata McGraw-Hill Education.

Gyapong, A. Y. (2020). How and why large scale agricultural land investments do not create long-term employment benefits: A critique of the 'state' of labour regulations in Ghana. Land Use Policy 95, 104651.

Habibi, N. (2017). "Conflict in Ethiopia: The Impact of Precipitation and Its Transmission Mechanism." Households in Conflict Network.

Hailu, R. (2016). Population dynamism and agrarian transformation in Ethiopia. African Journal of Agricultural Research 11, 3863-3879. 
Haji, J., and Legesse, B. (2017). Impact of sedentarization program on the livelihood and food security of Ethiopian pastoralists. Journal of Arid Environments 136, 45-53.

Hak, S., McAndrew, J., and Neef, A. (2018). Impact of Government Policies and Corporate Land Grabs on Indigenous People's Access to Common Lands and Livelihood Resilience in Northeast Cambodia. Land 7, 122.

Halderman, J. M. (1985). Problems of pastoral development in Eastern Africa. Agricultural Administration 18, 199-216.

Halderman, M. (2004). "The political economy of pro-poor policy-making in Ethiopia. Propoor Livestock Policy Initiative." FAO PPLPI Working Paper 19. http://www. fao. org/ag/againfo/programmes/en

Haller, T., Käser, F., and Ngutu, M. (2020). Does Commons Grabbing Lead to Resilience Grabbing? The Anti-Politics Machine of Neo-Liberal Agrarian Development and Local Responses. Land 9, 220.

Hardin, G. (1968). The tragedy of the commons. science 162, 1243-1248.

Haslam, P. A., and Tanimoune, N. A. (2016). The determinants of social conflict in the Latin American mining sector: New evidence with quantitative data. World Development $\mathbf{7 8}$, 401-419.

Headey, D., Taffesse, A. S., and You, L. (2014). Diversification and development in pastoralist Ethiopia. World Development 56, 200-213.

Heckman, J., Tobias, J. L., and Vytlacil, E. (2003). Simple estimators for treatment parameters in a latent-variable framework. Review of Economics and Statistics 85, 748-755.

Heinrich, C., Maffioli, A., and Vázquez, G. (2010). "A Primer for Applying Propensity-Score Matching."

Hilhorst, T., and Zomers, A. (2011). How Can Large Scale Transnational Land Acquisition Contribute to Inclusive and Sustainable Growth. Tropical Institute KIT, University of Utrecht. 35pp.

Hoddinott, J. (1999). "Choosing outcome indicators of household food security," Citeseer.

Holling, C. S. (1973). Resilience and stability of ecological systems. Annual review of ecology and systematics 4, 1-23.

Homer-Dixon, T. F. (1994). Environmental scarcities and violent conflict: evidence from cases. International security 19, 5-40.

Homewood, K. M., Trench, P. C., and Brockington, D. (2012). Pastoralist livelihoods and wildlife revenues in East Africa: a case for coexistence? Pastoralism: Research, Policy and Practice 2, 19.

Hosseini, S., Barker, K., and Ramirez-Marquez, J. E. (2016). A review of definitions and measures of system resilience. Reliability Engineering \& System Safety 145, 47-61.

Hufe, P., and Heuermann, D. F. (2017). The local impacts of large-scale land acquisitions: a review of case study evidence from Sub-Saharan Africa. Journal of Contemporary African Studies 35, 168-189.

Hugo, G. (2006). Trends in land degradation in South America. Management of Natural and Environmental Resources for Sustainable Agricultural Development, 127.

Hules, M., and Singh, S. J. (2017). India's land grab deals in Ethiopia: Food security or global politics? Land Use Policy 60, 343-351.

Hundie, B. (2006). Property rights among Afar pastoralists of northeastern Ethiopia: forms, changes and conflicts. In "Survival of the Commons: Mounting Challenges and New Realities. Eleventh Conference of the International Association for the Study of Common Property, Bali, Indonesia".

Hundie, B. (2010). Conflicts between Afar pastoralists and their neighbors: Triggers and motivations. International Journal of Conflict and Violence (IJCV) 4, 134-148. 
Hussein, K. (2002). The relevance of livelihoods approaches to food insecurity measurement. ELDIS/IDS.

Ibrahim, J. (2016). Socio-Economic Effect of Tendaho Sugar cane Plantation on the Pastoral Livelihood of Afar National Regional State, St. Mary's University.

IFAD (2020). "Investing in rural people in Ethiopia. International Fund for Agricultural Development.

https://www.ifad.org/documents/38714170/39972426/Investing+in+rural+people+in+ Ethiopia.pdf/5bf10d3d-fef5-484b-b002-8f6ca9c515c2 ".

Iftikhar, S., and Mahmood, H. Z. (2017). Human capital development and food security nexus: An empirical appraisal from districts of Punjab province. Journal of Food and Drug Research 1.

ILRI (2017). "Ethiopia livestock sector analysis." Developed by the Ethiopia Ministry of Livestock and Fisheries and the International Livestock Research Institute

Livestock master plan team.

Ioras, F., Bandara, I., and Kemp, C. (2014). Introduction to climate change and land degradation. In "Climate change and restoration of degraded land" (B.-C. Arraiza, C. Santamarta, F. Ioras, R. García, I. Abrudan, H. Korjus and G. Borbála, eds.), pp. 15-52. Colegio de Ingenieros de Montes, Madrid.

IPPC (2019). Chapter 4: Land Degradation Final Government Distribution.IPCC SRCCL. https://www.ipcc.ch/site/assets/uploads/2019/08/2e.-Chapter-4_FINAL.pdf.

Jambo, Y., Alemu, A., and Tasew, W. (2021). Impact of small-scale irrigation on household food security: evidence from Ethiopia. Agriculture \& Food Security 10, 21.

Jolejole-Foreman, M. C., Baylis, K. R., and Lipper, L. (2012). Land Degradation's Implications on Agricultural Value of Production in Ethiopia: A look inside the bowl. In "International Association of Agricultural Economists (IAAE) Triennial Conference". International Association of Agricultural Economists., Foz do Iguacu, Brazil

Jones, L., Samman, E., and Vinck, P. (2018). Subjective measures of household resilience to climate variability and change. Ecology and Society 23.

Kameri-Mbote, P. (2013). Preface: Securing the land and resource rights of pastoral peoples in East Africa. Nomadic Peoples, 1-4.

Kapalanga, T. S. (2008). A Review of Land Degradation Assessment Methods. Land Restoration Training Programme Keldnaholt, 112 Reykjavík, Iceland, Final project 2008.

Kébé, M., and Muir, J. (2008). The sustainable livelihoods approach: new directions in West and Central African small-scale fisheries. Achieving poverty reduction through responsible fisheries: lessons from West and Central Africa, FAO Fisheries and Aquaculture Technical Paper, 5-22.

Kebede, T., Haji, J., Legesse, B., and Mammo, G. (2016). Econometric Analysis of Rural Households' Resilience to Food Insecurity in West Shoa, Ethiopia. Journal of Food Security 4, 58-67.

Keeley, J. (2014). "Large-scale land deals in Ethiopia: Scale, trends, features and outcomes to date," International Institute for Environment and Development (iied).

Keovilignavong, O., and Suhardiman, D. (2020). Linking land tenure security with food security: Unpacking farm households' perceptions and strategies in the rural uplands of Laos. Land Use Policy 90, 104260.

Kertész, Á. (2009). The global problem of land degradation and desertification. Hungarian Geographical Bulletin 58, 19-31.

Khandker, S., B. Koolwal, G., and Samad, H. (2009). "Handbook on impact evaluation: quantitative methods and practices," The World Bank. 
Kirui, O., and Mirzabaev, A. (2015). Drivers of land degradation and adoption of multiple sustainable land management practices in Eastern Africa. In "International Association of Agricultural Economists 2015 Conference", Milan, Italy.

Kisoza, L. (2014). Empirical Analysis of Resource-Use Conflicts Between Smallholder Farmers and Pastoralists in Semi-Arid Areas: A Case of Mkata Plains, Eastern Tanzania. Huria: Journal of the Open University of Tanzania 16, 104-116.

Koo, J., Thurlow, J., Eldidi, H., Ringler, C., and De Pinto, A. (2019). Building resilience to climate shocks in Ethiopia. Washington, DC: IFPRI.

Kosmas, C., Karamesouti, M., Kounalaki, K., Detsis, V., Vassiliou, P., and Salvati, L. (2016). Land degradation and long-term changes in agro-pastoral systems: An empirical analysis of ecological resilience in Asteroussia - Crete (Greece). CATENA 147, 196204.

Krantz, L. (2001). The sustainable livelihood approach to poverty reduction. SIDA. Division for Policy and Socio-Economic Analysis 44.

Kupzyk, K. A., and Beal, S. J. (2017). Advanced Issues in Propensity Scores: Longitudinal and Missing Data. The Journal of Early Adolescence 37, 59-84.

Lavers, T. (2012). Patterns of agrarian transformation in Ethiopia: State-mediated commercialisation and the 'land grab'. The Journal of Peasant Studies 39, 795-822.

Lavers, T. (2018). Responding to land-based conflict in Ethiopia: The land rights of ethnic minorities under federalism. African Affairs.

Lay, J., Nolte, K., and Sipangule, K. (2018). "Large-scale farms and smallholders: Evidence from Zambia. GIGA Working Papers." Kiel Institute for the World Economy.

Lay, J. N., K (2017). Determinants of foreign land acquisitions in low-and middle-income countries. Journal of Economic Geography, 18(1), 59-86.

Levine, S. (2014). Assessing resilience: why quantification misses the point. Humanitarian Policy Group (ODI) Working Paper, London Uk.

Liao, C., Barrett, C., and Kassam, K. A. (2015). Does diversification improve livelihoods? Pastoral households in Xinjiang, China. Development and Change 46, 1302-1330.

Lind, J., Sabates-Wheeler, R., Caravani, M., Kuol, L. D., and Nightingale, D. M. (2020). Newly evolving pastoral and post-pastoral rangelands of Eastern Africa. Pastoralism 10, 24.

Lind, J., Sabates-Wheeler, R., and Kohnstamm, S. (2016). Changes in the drylands of Eastern Africa: a review of evidence and data and their implications for efforts to strengthening resilience. Institute of Development Studies.

Lisansky, J., Andrews, M. S., and Lopez, R. A. (1988). The determinants of right-to-farm conflicts. Rural Sociology 53, 246.

Little, P. D. (2001). Income diversification among East African pastoralists. Pastoral Risk Management Project University of Kentucky.

Little, P. D., McPeak, J., Barrett, C. B., and Kristjanson, P. (2008). Challenging orthodoxies: understanding poverty in pastoral areas of East Africa. Development and Change 39, 587-611.

Little, P. D., and McPeak, J. G. (2014). Resilience and pastoralism in Africa south of the Sahara, with a particular focus on the horn of Africa and the Sahel, West Africa. In "2020 Conference Paper", Vol. 9.

Little., P., Behanke, R., McPeak, J., and Getachew, G. (2010). Future Scenarios for Pastoral Development in Ethiopia, 2010-2025.

Lode, K., and Kassa, G. (2001). Proceedings from a workshop on conflict resolution, organised by the Drylands Coordination Group (DCG), November 8-10, 2000, Nazareth, Ethiopia. Report-Drylands Coordination Group (Norway).

Lokshin, M., and Sajaia, Z. (2004). Maximum likelihood estimation of endogenous switching regression models. The Stata Journal 4, 282-289. 
Lucchetti, J. (2015). Property rights and land disputes: theory and evidences from the Highland of Ethiopia. In "Energy and Climate conference ", Toulouse (France).

Maddala, G. S. (1983). Limited-dependent and qualitative variables in econometrics.

Maliwichi, L., Oni, S., and Obadire, O. (2012). An investigation into the factors affecting food availability, choices and nutritional adequacy of smallholder farming households under irrigation and dryland farming in Vhembe district of Limpopo, province, South Africa. African Journal of Agricultural Research 7, 3653-3664.

Mango, N., Makate, C., Tamene, L., Mponela, P., and Ndengu, G. (2017). Awareness and adoption of land, soil and water conservation practices in the Chinyanja Triangle, Southern Africa. International Soil and Water Conservation Research 5, 122-129.

Martin, A., Blowers, A., and Boersema, J. (2006). Is environmental scarcity a cause of civil wars? Taylor \& Francis.

Maxwell, D., and Caldwell, R. (2008). The coping strategies index: Field methods manual. Cooperative for Assistance and Relief Everywhere, Inc.(CARE).

Maxwell, D., Vaitla, B., and Coates, J. (2014). How do indicators of household food insecurity measure up? An empirical comparison from Ethiopia. Food Policy 47, 107-116.

Maxwell, D., Watkins, B., Wheeler, R., and Collins, G. (2003). The coping strategies index: A tool for rapidly measuring food security and the impact of food aid programs in emergencies. Nairobi: CARE Eastern and Central Africa Regional Management Unit and the World Food Programme Vulnerability Assessment and Mapping Unit.

Mayanja, M., Rubaire-Akiiki, C., Greiner, T., and Morton, J. (2015). Characterising food insecurity in pastoral and agro-pastoral communities in Uganda using a consumption coping strategy index. Pastoralism 5, 11.

McDougal, T. L., and Almquist, L. (2014). The effects of agricultural cooperatives on land conflicts, violence, and community trust: Household-level evidence from rural Burundi. The Economics of Peace and Security Journal 9.

McPeak, J., and Little, P. (2003). Pastoral sedentarization and community resilience in response to drought: perspectives from Northern Kenya. Global Livestock Collaborative Support Project (GL-CRSP): Pastoral Risk Management Project, Research Brief, 03-02.

McPeak, J. G. (2001). Pastoralists' use of markets: Pastoral Risk Management Project. Global Livestock Collaborative Support Research Program. California, US. Research Brief, 0104.

McPeak, J. G., and Little, P. D. (2017). Applying the concept of resilience to pastoralist household data. Pastoralism 7, 14.

McPeak, J. G., and Little, P. D. (2018). Mobile peoples, contested borders: land use conflicts and resolution mechanisms among Borana and Guji Communities, Southern Ethiopia. World Development 103, 119-132.

McPeak, J. L., P. D. (2003). Land tenure and food security. A review of concepts, evidence, and methods 129.

Meaza, H., Frankl, A., Demissie, B., Poesen, J., Zenebe, A., Gebresamuel, G., Asfaha, T. G., Annys, S., Van Eetvelde, V., Jacob, M., Deckers, J., Raes, D., and Nyssen, J. (2019). Water balance components of the potential agricultural grabens along the Rift Valley in northern Ethiopia. Journal of Hydrology: Regional Studies 24, 100616.

Meaza, H., Frankl, A., Poesen, J., Zenebe, A., Deckers, J., Van Eetvelde, V., Demissie, B., Asfaha, T. G., and Nyssen, J. (2017). Natural resource opportunities and challenges for rural development in marginal grabens - The state of the art with implications for the Rift Valley system in Ethiopia. Journal of Arid Environments 147, 1-16.

Meaza, H., Frankl, A., Poesen, J., Zenebe, A., Van Eetvelde, V., Demissie, B., Asfaha, T. G., Deckers, J., Raes, D., and Nyssen, J. (2018). Water balance variability in the confined 
Aba'ala limestone graben at the western margin of the Danakil Depression, northern Ethiopia. Hydrological Sciences Journal 63, 957-977.

Mekonnen, T. (2017). Productivity and household welfare impact of technology adoption: Micro-level evidence from rural Ethiopia. United Nations University working paper (007).

Mekuyie, M., Jordaan, A., and Melka, Y. (2018a). Land-use and land-cover changes and their drivers in rangeland-dependent pastoral communities in the southern Afar Region of Ethiopia. African Journal of Range \& Forage Science 35, 33-43.

Mekuyie, M., Jordaan, A., and Melka, Y. (2018b). Understanding resilience of pastoralists to climate change and variability in the Southern Afar Region, Ethiopia. Climate Risk Management 20, 64-77.

Melketo, T., Martin, S., Michelle, B., Stefan, S., Klaus, M., and Marcos, L. (2021). Determinants of pastoral household resilience to food insecurity in Afar region, northeast Ethiopia. Journal of Arid Environments 188 (2021) 104454.

Menbere, A. (2013). Dynamics of pastoralist relations at change: an exploration into the causes of Afar-Karrayu conflict in the Awash Valley. Ethiopian Journal of the Social Sciences and Humanities 9, 1-28.

Mirzabaev, A., Nkonya, E., Goedecke, J., Johnson, T., and Anderson, W. (2016). Global drivers of land degradation and improvement. In "Economics of Land Degradation and Improvement-A Global Assessment for Sustainable Development", pp. 167-195. Springer, Cham.

Mkutu, K. (2001). "Pastoralism and conflict in the Horn of Africa," Saferworld. Organisation. Mohamed, A. (2016). Displacement and Environment in Africa: What is the relationship? .

Mohamud, A. Y. (2012). Study of conflict among pastoralists of Ethiopia: A review of cases and experiences. MSc thesis Haramaya University

Moreda, T. (2017). Large-scale land acquisitions, state authority and indigenous local communities: insights from Ethiopia. Third World Quarterly 38, 698-716.

Moreda, T. (2018). The right to food in the context of large-scale land investment in Ethiopia. Third World Quarterly, 1-22.

Mousseau, F., and Martin-Prével, A. (2016). "Miracle or Mirage? Manufacturing Hunger and Poverty in Ethiopia. The Oakland Institute."

Moyo, S. (2007). Land in the political economy of African development: Alternative strategies for reform. Africa Development 32.

Müller-Mahn, D., Rettberg, S., and Getachew, G. (2010). Pathways and dead ends of pastoral development among the Afar and Karrayu in Ethiopia. The European Journal of Development Research 22, 660-677.

Mulugeta, A. (2014). "' Development Facilitators", Land Acquisition and Governance in Pastoralist Areas of Ethiopia," University of Basel, Institute of Social Anthropology.

Mulugeta, A., and Hagmann, T. (2008). Governing violence in the pastoralist space: Karrayu and state notions of cattle raiding in the Ethiopian Awash Valley. Afrika Focus 21.

Mussa, M., Hashim, H., and Teha, M. (2016). Rangeland degradation: Extent, impacts, and alternative restoration techniques in the rangelands of Ethiopia. Tropical and Subtropical Agroecosystems 19.

Nachtergaele, F. O., and Licona-Manzur, C. (2008). The Land Degradation Assessment in Drylands (LADA) Project: reflections on indicators for land degradation assessment. In "The future of drylands", pp. 327-348. Springer.

Nana-Sinkam, S. (1995). "Land and environmental degradation and desertification in Africa: Issues and options for sustainable economic development with transformation. United Nations Food and Agriculture Organization, Addis Ababa." 
Nega, B. A., Birhanu Gebresillase, Samuel (2003). Current policy issues in Ethiopia. Ethiopian Policy Research Institute. Land reform 2003/3 Special edition pp. 103-154. Ethiopian Economic Policy Research Institute Addis Ababa, Ethiopia.

Nicol, A., and Otulana, M. (2014). Contested Margins, Complex Pathways: The Afar Triangle in the Horn of Africa Working Paper 094. www.future-agricultures.org.

Nigussie, Z., Tsunekawa, A., Haregeweyn, N., Adgo, E., Nohmi, M., Tsubo, M., Aklog, D., Meshesha, D. T., and Abele, S. (2017). Factors influencing small-scale farmers' adoption of sustainable land management technologies in north-western Ethiopia. Land Use Policy 67, 57-64.

Nixon, L. G. (2013). Implications of Government-Led Large-Scale Land and Water Acquisitions: On Local Communities Livelihoods In Ethiopia:- A Case of Omo-Kuraz Sugarcane Development Project At Lower Omo Valley. Master of Arts in Development Studies The Hague, The Netherlands.

Nkonya, E., Mirzabaev, A., and von Braun, J. (2016). Economics of land degradation and improvement: an introduction and overview. In "Economics of land degradation and improvement-a global assessment for sustainable development, Springer, Cham.", pp. 1-14. https://doi.org/10.1007/978-3-319-19168-3_1.

Nori, M., and Scoones, I. (2019). Pastoralism, Uncertainty and Resilience: Global Lessons from the Margins. Pastoralism 9, 10.

Nyssen, J., Frankl, A., Haile, M., Hurni, H., Descheemaeker, K., Crummey, D., Ritler, A., Portner, B., Nievergelt, B., and Moeyersons, J. (2014). Environmental conditions and human drivers for changes to north Ethiopian mountain landscapes over 145 years. Science of the total environment 485, 164-179.

Ochieng, C. (2011). "Toolkit and guidance for preventing and managing land and natural resources conflict: Conflict prevention in resource-rich economies."

Ola-Adams, B. A., and Okali, D. U. (2008). Impact of Land Use Conflict on Livelihood and Range Condition in the Awash Valley of Ethiopia. In "The Future of Drylands", pp. 457-469. Springer.

Onyango, O. D. (2017). Assessing the factors influencing food and livelihood security among pastoral communities in Turkana County, Kenya, University of Nairobi., University of Nairobi.

Osman, A., Olesambu, E., and Balfroid, C. (2018). Pastoralism in Africa's drylands: reducing risks, addressing vulnerability and enhancing resilience. FAO, Rome, Italy. .

Ostrom, E., Burger, J., Field, C. B., Norgaard, R. B., and Policansky, D. (1999). Revisiting the commons: local lessons, global challenges. science 284, 278-282.

Oyekale, T., and Oyekale, A. (2019). Endogenous-Switching Regression Modeling of Farmers' Exposure to Climate Hazards and Reforestation in Selected Villages in Africa, International Conference on Engineering for Sustainable World. Journal of Physics: Conference Series (JPCS) 1378, 1-14.

Pavanello, S. (2009). Pastoralists' vulnerability in the Horn of Africa: Exploring political marginalisation, donors' policies and cross-border issues-Literature review. Humanitarian Policy Group (HPG) Overseas Development Institute London, UK.

Percival, V., and Homer-Dixon, T. (1998). Environmental scarcity and violent conflict: the case of South Africa. Journal of Peace Research 35, 279-298.

PFE (2010). Proceeding Climate Change and pastoralism: The Emplication on Suatainable Pastoral Development in Ethiopia. of 5th National Conference on Pastoral Development in Ethiopia. August 25th -26th,2010. Addis Ababa. Ethiopia.

Pichler, M., and Brad, A. (2016). Political ecology and socio-ecological conflicts in Southeast Asia. ASEAS-Austrian Journal of South-East Asian Studies 9, 1-10. 
Pisano, U. (2012). Resilience and Sustainable Development: Theory of resilience, systems thinking. European Sustainable Development Network (ESDN) 26, 50.

Planel, S., and Labzaé, M. (2016). Report on the current drought in Awsa and the potential effects of the Tendaho sugar plantation on the oasis, Centre Français des Etudes Ethiopiennes.

Qasim, S., Shrestha, R., Shivakoti, G., and Tripathi, N. (2011). Socio-economic determinants of land degradation in Pishin sub-basin, Pakistan. International Journal of Sustainable Development \& World Ecology 18, 48-54.

Quandt, A. (2018). Measuring livelihood resilience: The Household Livelihood Resilience Approach (HLRA). World Development 107, 253-263.

Rahmato, D. (2011). "Land to investors: Large-scale land transfers in Ethiopia," African Books Collective.

Rahmato, D. (2014). The perils of development from above: land deals in Ethiopia. . African Identities 12, 26-44.

Rasch, S., Heckelei, T., Storm, H., Oomen, R., and Naumann, C. (2017). Multi-scale resilience of a communal rangeland system in South Africa. Ecological Economics 131, 129-138.

Rass, N. (2006). Policies and strategies to address the vulnerability of pastoralists in subSaharan Africa. Rome: FAO, Pro-poor Livestock Policy Initiative (PPLPI) Working Paper Series 37.

Reda, K. T. (2014). Formal and informal land tenure systems in Afar region, Ethiopia: Perceptions, attitudes and implications for land use disputes. African Journal on Conflict Resolution 14, 41-62.

Rettberg, S. (2010). "The impact of sugarcane plantations on pastoral livelihoods within the Afar Region of Ethiopia. In Altare, C (eds.) Sugar Cane and Indigenous People. Ethical Sugar, University of Bonn

$"$

Rodríguez, M. A., and Daza, N. A. (2012). Determinants of Civil Conflict in Colombia: How Robust are they? Defence and Peace Economics 23, 109-131.

Rosenbaum, P. R., and Rubin, D. B. (1983). The central role of the propensity score in observational studies for causal effects. Biometrika 70, 41-55.

Rufino, M. C., Thornton, P. K., Ng'ang'a, S. K., Mutie, I., Jones, P. G., van Wijk, M. T., and Herrero, M. (2013). Transitions in agro-pastoralist systems of East Africa: Impacts on food security and poverty. Agriculture, Ecosystems \& Environment 179, 215-230.

Safarzynska, K. (2018). The impact of resource uncertainty and intergroup conflict on harvesting in the common-pool resource experiment. Environmental and resource economics 71, 1001-1025.

Said, A. (1994). "Pastoralism and the state policies in Mid-Awash valley: the case of the Afar, Ethopia: Nordiska Afrikainstitutet. African Arid Lands Working Paper Series No. 1/94. http://www.diva-portal.org/smash/get/diva2:290195/FULLTEXT01.pdf."

Schipper, E. L. F., and Langston, L. (2015). A comparative overview of resilience measurement frameworks. Analyzing Indicators and Approaches; Overseas Development Institute: London, UK, 422.

Schlager, E., and Ostrom, E. (1992). Property-rights regimes and natural resources: a conceptual analysis. Land economics, 249-262.

Schmidt, M., and Pearson, O. (2016). Pastoral livelihoods under pressure: Ecological, political and socio-economic transitions in Afar (Ethiopia). Journal of Arid Environments 124, $22-30$.

Scoones, I. (1998). Sustainable rural livelihoods: a framework for analysis.

Scoones, I. (2020). Pastoralism and Development: Fifty Years of Dynamic Change. Institute of Development Studies (IDS) Bulletin 51A, Brighton. 
Semie, T. K., Silalertruksa, T., and Gheewala, S. H. (2019). The impact of sugarcane production on biodiversity related to land use change in Ethiopia. Global Ecology and Conservation 18, e00650.

Senda, T. S., Robinson, L. W., Gachene, C. K. K., Kironchi, G., and Doyo, J. (2020). An assessment of the implications of alternative scales of communal land tenure formalization in pastoral systems. Land Use Policy 94, 104535.

Serrat, O. (2017). The sustainable livelihoods approach. In "Knowledge solutions", pp. 21-26. Springer.

Shete, M., and Rutten, M. (2015). Impacts of large-scale farming on local communities' food security and income levels-Empirical evidence from Oromia Region, Ethiopia. Land Use Policy 47, 282-292.

Shiferaw , B., and Holden, S. T. (1998). Resource degradation and adoption of land conservation technologies in the Ethiopian Highlands: A case study in Andit Tid, North Shewa. Agricultural Economics 18, 233-247.

Sina, D., Chang-Richards, A. Y., Wilkinson, S., and Potangaroa, R. (2019). A conceptual framework for measuring livelihood resilience: Relocation experience from Aceh, Indonesia. World Development 117, 253-265.

Sirajea, I., and Bekeleb, A. (2013). Assessment of food insecurity and coping mechanisms among pastoral households of Afar national regional state: The case of Chifra district, Ethiopia. Ethiopian Journal of Agricultural Sciences 23, 145-156.

Slater, J., and Yeudall, F. (2015). Sustainable livelihoods for food and nutrition security in Canada: A conceptual framework for public health research, policy, and practice. Journal of hunger \& environmental nutrition 10, 1-21.

Smith, L. C., and Frankenberger, T. R. (2018). Does Resilience Capacity Reduce the Negative Impact of Shocks on Household Food Security? Evidence from the 2014 Floods in Northern Bangladesh. World Development 102, 358-376.

SNV (2012). "Improved Livelihoods for Pastoralists. SNV(Netherlands development Organization) Practice Brief, Issue 2."

Sombroek, W., and Sene, E. (1993). Land degradation in arid, semi-arid and dry sub-humid areas: rainfed and irrigated lands, rangelands and woodlands. In "Inter-Governmental Negotiating Committee for the Preparation of a Convention to Combat Desertification and Drought. Substantive Sess. 1, Nairobi (Kenya), 24 May-4 Jun 1993".

Sonneveld, B., Pande, S., Georgis, K., Keyzer, M., Seid Ali, A., and Takele, A. (2010). "Land Degradation and Overgrazing in the Afar Region, Ethiopia: A Spatial Analysis. In: Zdruli P., Pagliai M., Kapur S., Faz Cano A. (eds) Land Degradation and Desertification: Assessment, Mitigation and Remediation. Springer, Dordrecht. http://10.1007/978-90-481-8657-0_8."

Speranza, C. I., Wiesmann, U., and Rist, S. (2014). An indicator framework for assessing livelihood resilience in the context of social-ecological dynamics. Global Environmental Change 28, 109-119.

Stickler, M., Huntington, H., and Ewing, B. (2018). Measuring community perceptions of tenure security: Evidence from four African countries. In "Land governance in an an interconnected world ". The World Bank, Washington DC.

Storck, H., and Doppler, W. (1991). "Farming systems and farm management practices of smallholders in the Hararghe Highlands," Wissenschaftsverlag Vauk Kiel.

Sutton, P. C., Anderson, S. J., Costanza, R., and Kubiszewski, I. (2016). The ecological economics of land degradation: Impacts on ecosystem service values. Ecological Economics 129, 182-192.

Tache, B., and Oba, G. (2009). Policy-driven inter-ethnic conflicts in Southern Ethiopia. Review of African Political Economy 36, 409-426. 
Taddese, G. (2001). Land degradation: a challenge to Ethiopia. Environmental management 27, 815-824.

Tadesse, B., Beyene, F., Kassa, W., and Wentzell, R. (2015). The Dynamics of (Agro) Pastoral Conflicts in Eastern Ethiopia. Ethiopian Journal of the Social Sciences and Humanities 11, 29-60.

Tafere, K. (2013). Peace-making from within: the tradition of conflict resolution in Northern Afar, Ethiopia. Ethiopian Journal of the Social Sciences and Humanities 9, 57-78.

TANGO (2018). Methodological Guide: A Guide for Calculating Resilience Capacity: Resilience and resilience capacities measurement options. TANGO International. Tucson, USA

Tanner, T., Lewis, D., Wrathall, D., Bronen, R., Cradock-Henry, N., Huq, S., Lawless, C., Nawrotzki, R., Prasad, V., and Rahman, M. A. (2015). Livelihood resilience in the face of climate change. Nature Climate Change 5, 23-26.

Terminski, B. (2013). "Development-induced displacement and resettlement: Theoretical frameworks and current challenges," University of Geneva, Geneva, Switzerland.

The Oakland Institute (2016). Miracle or mirage? Manufacturing hunger and poverty in Ethiopia. www.oaklandinstitute.org

Tilahun, M. (2015). "The Economics of Land Degradation in Africa Benefits of Action Outweigh the Costs: A complementary report to the ELD Initiative, Bon, Germany," https://hdl.handle.net/20.500.11766/3470

Tilahun, M., Angassa, A., Abebe, A., and Mengistu, A. (2016). Perception and attitude of pastoralists on the use and conservation of rangeland resources in Afar Region, Ethiopia. Ecological Processes 5, 18.

Tsegaye, D., Moe, S. R., Vedeld, P., and Aynekulu, E. (2010). Land-use/cover dynamics in Northern Afar rangelands, Ethiopia. Agriculture, ecosystems \& environment 139, $174-$ 180.

Tsegaye, D., Vedeld, P., and Moe, S. R. (2013). Pastoralists and livelihoods: A case study from northern Afar, Ethiopia. Journal of Arid Environments 91, 138-146.

Uchehara, K. E. (2014). Understanding African Relationships: The Case of Eritrean-Ethiopian Border Dispute. International Journal of Social Inquiry 7.

UNCCD (1994). "Elaboration of an international convention to combat desertification in countries experiencing serious drought and/or desertification, particularly in Africa. United Nations Convention to Combat Desertification (UNCCD), UN Doc. A/AC. 241/27, 33 ILM 1328."

UNCED (1992). Rio declaration on environment and development. United Nations Department of Economic and Social Affairs. http://www.un.org/documents/ga/conf151/aconf15126.

UNDP (2003). Pastoralism and mobility in the drylands. Challenge paper series. Imperative, Global Drylands

New York: United Nations Development Program (UNDP).

UNDP (2018). Ethiopia National Human Development Report 2018, Industrialization with a Human Face. https://www.et.undp.org/content/ethiopia/en/home/library/ethiopianational-human-development-report-2018.html.

Vanclay, F. (2017). Project-induced displacement and resettlement: from impoverishment risks to an opportunity for development? Impact Assessment and Project Appraisal 35, 3-21.

Verbeek, M. (2008). "A guide to modern econometrics," John Wiley \& Sons.

Verschuur, J., Koks, E. E., Haque, A., and Hall, J. W. (2020). Prioritising resilience policies to reduce welfare losses from natural disasters: A case study for coastal Bangladesh. Global Environmental Change 65, 102179. 
Vidal, J. (2019). Is climate change responsible for the conflcits we are seeing around the world today? The relationship between a heating planet and violent clashes is complex and critical. https://ensia.com/features/climate-change-conflict-violence-extremismdraught-flood/.

Vlek, P. L. L., Q B Tamene, L (2010). "Assessment of land degradation, its possible causes and threat to food security in Sub-Saharan Africa."

Vu, Q. M., Le, Q. B., Frossard, E., and Vlek, P. L. (2014). Socio-economic and biophysical determinants of land degradation in Vietnam: An integrated causal analysis at the national level. Land Use Policy 36, 605-617.

Walpole, S. C. (1992). The Measurement of Land Degradation to Assess Losses in Agricultural Production. In "36th Annual Conference of the Australian Agricultural Economics Society". Australian Agricultural and Resource Economics Society, Canberra.

Wassie, S. B. (2020). Natural resource degradation tendencies in Ethiopia: a review. Environmental Systems Research 9, 33.

WASWA, B. (2012). Assessment of Land Degradation Patterns in Western Kenya: Implications for Restoration and Rehabilitation. PhD Thesis Bon University

Wayessa, G. O. (2020). Impacts of land leases in Oromia, Ethiopia: Changes in access to livelihood resources for local people. Land Use Policy 97, 104713.

WDI (2019). "Ethiopia - Poverty headcount ratio at national poverty line. World Development Indicators ".

Wehrmann, B. (2008). "Land conflicts: A practical guide to dealing with land disputes," GTZ Eschborn.

Weldegebriel, Z. B., and Amphune, B. E. (2017). Livelihood resilience in the face of recurring floods: an empirical evidence from Northwest Ethiopia. Geoenvironmental Disasters 4, 10.

Wendimu, M. A., Henningsen, A., and Gibbon, P. (2016). Sugarcane Outgrowers in Ethiopia:"Forced" to Remain Poor? World Development 83, 84-97.

Willemen, L., Nangendo, G., Belnap, J., Bolashvili, N., Denboba, M. A., Douterlungne, D., and Hahn, T. (2018). "Decision support to address land degradation and support restoration of degraded land. In L. Montanarella, R. Scholes, \& A. Brainich (Eds.), The IPBES assessment report on land degradation and restoration (pp. 591-648). Intergovernmental Science-Policy Platform on Biodiversity and Ecosystem Services.."

WISP (2007). Pastoralist's species and ecosystems knowledge as the basis for land managemen. World Initiative for Sustainable Pastoralism (WISP) POLICY BRIEF No. 5, Nairobi. .

World Bank (2019). Ethiopia economic overview and update. https://www.worldbank.org/en/country/ethiopia/overview

WWF (2005). "Sugar and the environment. Encouraging better management practices in sugar production and processing, World Wildlife Foundation (WWF)".

Yamane, T. (1973). "Statistics: An introductory analysis," Harper and Row, New York NY.

Yengoh, G. T., Steen, K., Armah, F. A., and Ness, B. (2016). Factors of vulnerability: How large-scale land acquisitions take advantage of local and national weaknesses in Sierra Leone. Land Use Policy 50, 328-340.

Young, A. (1994). "Land degradation in South Asia: its severity, causes and effects upon the people," Rep. No. 9251035954. FAO.

Zaehringer, J. G., Wambugu, G., Kiteme, B., and Eckert, S. (2018). How do large-scale agricultural investments affect land use and the environment on the western slopes of Mount Kenya? Empirical evidence based on small-scale farmers' perceptions and remote sensing. Journal of Environmental Management 213, 79-89.

Zoomers, E. B., and Otsuki, K. (2017). Addressing the impacts of large-scale land investments: Re-engaging with livelihood research. Geoforum 83, 164-171. 


\section{Summary}

Land is at the center of rural livelihoods in developing countries. Despite this, access to land is contested in developing countries, particularly in Africa. The situation in Ethiopia is not different. Since the 1970s, state-run large-scale land investments (LSLIs) in sugar plantations have encroached into pastoral rangelands in Ethiopia. As a result, pastoralists have lost access to dry season grazing areas. Since 2010, a new expansion plan for LSLIs has occupied the remaining productive rangelands exacerbating the long-standing problem. The conversion of rangelands to LSLIs in sugar plantations has implications for the livelihoods of the local population. The concerns are high in pastoral areas of Ethiopia where poverty and food insecurity are widespread. However, much of the research so far has focused on investigating the impacts of foreign-run LSLIs, although state-run investments cover the largest part of the agropastoral regions in Ethiopia. With this motivation, this thesis aims at investigating the impacts of LSLIs in sugar plantations on agropastoral livelihoods in four dimensions; food security, land degradation, land use conflict, and resilience. Chapter 1 provides an overview of the thesis.

Chapter two presents the impacts of LSLIs on household food security based on panel data. Food insecurity affects one-third of agropastoral households. The results show that proximity to LSLIs is associated with additional food intake. However, the positive effect of proximity to LSLIs on household food consumption should be regarded with care. According to the random effects regression, positive effects on food security are mainly due to household access to land, quality soil, irrigation, and forests. Moreover, the impact of proximity to LSLIs on food intake declines by household access to road and market. When using the household coping strategies index, food insecurity increases by household proximity to LSLIs. Hence, the food security impact of LSLIs varies by the indicator of food security. However, the food security of the study populations is generally low, and urgent actions need to be taken by the government of Ethiopia and other stakeholders to improve this situation.

Chapter three discusses the impact of LSLI-induced displacement on land degradation in agropastoral areas of Ethiopia by using cross-sectional survey data. The results show that $75 \%$ of the surveyed households have experienced moderate to severe land degradation and $55.8 \%$ lost land due to LSLIs. The results reveal that the displacement of households leads to a significant increase in land degradation. LSLIs aggravated land degradation directly by destroying common resources (clearing vegetation and grass) in favor of plantation production 
and dispossessing grazing land and exacerbating overgrazing. Drought and conflict exposure, the number of livestock, overgrazing, and sharecropping increase the intensity of land degradation. Market access, extension services, household income, and mobility, on the contrary, limit the occurrence of land degradation. Attention should be given to the rehabilitation of degraded lands and the prevention of people's displacement.

Chapter four identifies the determinants of land use conflict between agropastoralists and LSLIs. Based on household and community surveys, the study shows that land use conflict has been increasing since the establishment of LSLIs and has affected more than a quarter of the study population. The results show that dispossession of land by LSLIs, lack of trust for LSLIs, and scarcity of pasture land, both from a supply- (land degradation, drought, and invasive weeds) and a demand-side (herd size) perspective were the drivers of land conflict. The state appropriation of traditional pastures for industrial plantations exacerbates land conflicts. The Ethiopian government and stakeholders should resolve the conflict over land between LSLIs and local communities.

Chapter five explores the likely effect of LSLIs on household resilience in pastoral areas using panel data. About one-third of the study population has low resilience capacity, while more than half has low welfare resilience. The results show that proximity to LSLIs significantly reduces households' resilience capacity. Factors that enhance the resilience capacities of households include access to livestock markets, social safety nets, extension, mobility, and social and infrastructural services. Future resilience programs in agropastoral areas should mitigate the adverse effect of LSLIs by enhancing livelihood diversification and households' access to communal pastures. Providing resilience-enhancing interventions for pastoralists and particularly for women-headed households would improve their resilience capacities.

The overall findings of this thesis provide empirical evidence that LSLIs increase the vulnerability of local people to shocks, land conflicts, land degradation, and food insecurity in terms of coping strategies. Thus, I conclude that the following is needed: (i) balancing the tradeoff between maximizing export revenue from LSLIs and improving local livelihoods; (ii) ensuring land tenure security for communal lands to improve the livelihoods of pastoral people; (iii) resolving land conflicts between pastoralists and LSLIs through negotiations and traditional institutions (iv) enhancing the resilience capacity and food security of pastoral communities with more focus on women-headed households (v) promoting diverse livelihood strategies to specifically address the needs of different communities. 


\section{Samenvatting}

Land is een cruciaal onderdeel van de plattelandseconomie in ontwikkelingslanden. Met name op het Afrikaanse continent is de toegang tot land een bron van conflict. Zo ook in Ethiopië. Sinds de jaren '70 is door middel van door de staat gerunde, grootschalige investeringen (Large Scale Land Investments, LSLIs) in suikerplantages beslag gelegd op agropastorale gronden. Hierdoor hebben herders geen toegang meer tot de graasgebieden gedurende het droge seizoen. Door de uitbreiding van LSLIs sinds 2010 naar de nog resterende productieve gronden, is dit probleem verergerd. De LSLIs in suikerplantages hebben gevolgen voor het levensonderhoud van de lokale bevolking, met name voor herders onder wie armoede en voedselonzekerheid wijdverbreid zijn.

Tot dusver is veel onderzoek gedaan naar de invloed van buitenlandse LSLIs in suikerplantages terwijl voor de door de Ethiopische staat gerunde LSLIs in de agropastorale gebieden, die veruit in de meerderheid zijn, nauwelijks aandacht is geweest. Dit proefschrift heeft als doel in deze leemte te voorzien. De effecten van de door de staat gedane LSLIs in suikerplantages zullen op vier effecten voor de agropastorale bevolking worden onderzocht, namelijk; voedselzekerheid, landdegradatie, grondgebruiksconflicten en veerkracht.

Hoofdstuk 1 geeft een overzicht weer van dit proefschrift. Hoofdstuk 2 toont de effecten van LSLIs op de voedselzekerheid van huishoudens gebaseerd op paneldata. Voedselonzekerheid komt voor bij een derde van de agropastorale huishoudens. De onderzoeksresultaten tonen aan dat de nabijheid van LSLIs wordt geassocieerd met een hogere voedselconsumptie. Echter dit positieve effect van de nabijheid van LSLIs op huishoudelijke voedselconsumptie geeft niet het hele verhaal. De resultaten van een regressieanalyse met random effects tonen aan dat de positieve effecten op de voedselzekerheid voornamelijk toe te schrijven zijn aan de toegang tot land, bodemkwaliteit, irrigatie en bossen. Bovendien daalt het effect van de nabijheid van LSLIs op voedselinname met de afstand van het huishouden tot wegen en de markt. Wanneer in de regressiemodellen rekening wordt gehouden met aanpassingsstrategieën van huishoudens, dan neemt de voedselonzekerheid juist toe naarmate huishoudens zich dichterbij LSLIs bevinden.

Hoofdstuk 3 bespreekt het effect van de door LSLIs veroorzaakte landdegradatie in agropastorale gebieden. Hierbij wordt gebruik gemaakt van cross-sectie survey data. De resultaten laten zien dat 75\% van de ondervraagde huishoudens van mening is dat er sprake is van milde tot ernstige degradatie van land en dat $55.8 \%$ van de respondenten land heeft verloren door LSLIs. De resultaten tonen dat de verplichte verhuizing van huishoudens leidt tot een 
significante stijging van de landdegradatie. LSLIs hebben de landdegradatie verergerd door het vernietigen van gezamenlijke hulpbronnen (het verwijderen van vegetatie en gras) ten behoeve van de productie op plantages en door het onteigenen van graasgronden met als gevolg het verergeren van overbegrazing van de resterende gronden. Verder wordt landdegradatie bevorderd door droogte, conflicten en het bestaan van deelpacht waardoor de intensiteit van het grondgebruik toeneemt. Markttoegang, agrarische voorlichting, het huishoudelijk inkomen en mobiliteit, daarentegen, beperken landdegradatie.

Hoofdstuk 4 identificeert de determinanten van conflicten gerelateerd aan grondgebruik tussen herders en LSLIs. Het onderzoek op basis van enquêtes onder huishoudens en gemeenschappen laat zien dat grondgebruiksconflicten zijn toegenomen sinds de vestiging van LSLIs en dat dit meer dan een kwart van de bestudeerde huishoudens betreft. De resultaten tonen dat onteigening van land door LSLIs, gebrek aan vertrouwen in LSLIs en schaarste aan graasgronden, de drijfveren zijn voor conflicten over grond. De onteigening van traditionele graasgronden door de staat ten behoeve van industriële plantages verergert de conflicten over grond.

Hoofdstuk 5 onderzoekt het mogelijke effect van LSLIs op de veerkracht van huishoudens in pastorale gebieden door gebruik te maken van paneldata. Hiervoor zijn twee dimensies van veerkacht gemeten: veerkrachtcapaciteit, dat onder andere verwijst naar de middelen waar het huishouden over beschikt, en welvaartsveerkracht, dat verwijst naar de mogelijkheid om welvaart te behouden. Ongeveer een derde van de studiepopulatie heeft een lage veerkrachtcapaciteit, terwijl meer dan de helft een lage welvaartsveerkracht heeft. De resultaten geven aan dat de nabijheid van LSLIs de veerkrachtcapaciteit van huishoudens significant verlaagt. Factoren die de veerkrachtcapaciteit bevorderen, omvatten toegang tot veemarkten, sociale vangnetten, en diensten van agrarische, sociale en infrastructurele aard. Toekomstige programma's gericht op veerkracht voor agropastorale gebieden zouden het nadelige effect van LSLIs moeten verminderen door het stimuleren van diversificatie in levensonderhoud en het verbeteren van de toegang van huishoudens tot gemeenschappelijke graasgronden. Het bieden van veerkrachtverbeterende interventies voor herders en in het bijzonder voor vrouwen aan het hoofd van het huishouden, zal hun veerkrachtcapaciteit vergroten.

De algemene bevindingen van dit proefschrift bieden empirisch bewijs dat LSLIs de kwetsbaarheid van lokale mensen vergroten voor schokken, landconflicten, landdegradatie en voedselonzekerheid. Daarom concludeer ik dat het volgende nodig is: (i) een weloverwogen balans tussen de maximalisatie van exportinkomsten gegenereerd door LSLIs en de verbetering van het levensonderhoud van de agro-pastorale bevolking; (ii) het garanderen van toegang tot 
gemeenschappelijke gronden om het levensonderhoud van de agro-pastorale bevolking te verbeteren; (iii) het oplossen van grondconflicten tussen herders en LSLIs door middel van onderhandelingen en traditionele instituties; (iv) het vergroten van de veerkracht en voedselzekerheid van pastorale gemeenschappen met voldoende aandacht voor huishoudens geleid door een vrouw; (v) het bevorderen van de diversificatie van levensonderhoudstrategieën om specifiek in te spelen op de behoeften van verschillende gemeenschappen. 


\section{Biography}

Adugna Eneyew Bekele was born on 7 August 1980 in Gida Ayana, Oromia regional state, Ethiopia. With an MSc in Agriculture (Rural Development) from Haramaya University Ethiopia, the author has more than 15 years of teaching experience at Wolayta Soddo Agricultural Technical College, Arbaminch University, and Jimma University, where he currently works. His research focuses on sustainable livelihoods, food security, value chains, climate change, land policies, and impact evaluations. At Jimma University, he chaired the Department of Agricultural Economics and Extension and served as dean of the College of Agriculture and Veterinary Medicine (JUCAVM). He has been co-coordinating and participating in various projects, including women empowerment through postgraduate scholarships funded by RUFORUM, agribusiness (commercializing Ethiopian agriculture \& developing an executive MBA), integrated pest management (IPM) projects funded by NUFFIC, and the paradoxes of climate-smart coffee funded by Danida Fellowship Center. Moreover, the author has served as a consultant for the Food and Agriculture Organization of the United Nations (FAO), the German Development Agency (GIZ), the International Medical Corps (IMC), and other organizations. The author has received international fellowships, including the International Visitors Leadership Program (IVLP) on Food Security and Agriculture in the US. In November 2017, he started his Ph.D. studies at Wageningen University and Research funded by NUFFIC. 
Adugna Eneyew Bekele

Wageningen School of Social Sciences (WASS)

Completed Training and Supervision Plan

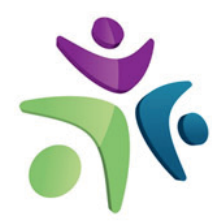

Wageningen School

of Social Sciences

Name of the learning activity
A) Project related competences
WASS PhD Introduction Course
Writing the PhD research Proposal
Intermediate Microeconomics (DEC 23306)
Advanced Econometrics (YSS-34306)
Environmental and Resource Economics
Module: Circular Economy
Social Costs and Benefits of biofuels (AEP-53306)
Research Methodology: from topic to proposal
'Proximity to large scale land investments and its
effect on household food security: Evidence from
pastoral areas in Ethiopia'

Department/I

nstitute

Year ECTS*

$\begin{array}{lcc}\text { WASS/ WUR } & 2018 & 1 \\ \text { WASS/ WUR } & 2018 & 6 \\ \text { DEC/WUR } & 2018 & 6 \\ \text { AEP / WUR } & 2018 & \\ \text { WIMEK/WU } & 2021 & 2\end{array}$

$\mathrm{R}$

AEP / WUR 2018

WASS/WUR $2018 \quad 4$

$10^{\text {th }}$ annual $\quad 2019 \quad 1$

research

Conference,

Jimma

University

'The resilience of agropastoral households affected by

IAAE $31^{\text {st }}$

2021

1

large scale land investments'

conference

virtual

'Large scale land investments and food security in

Joint IGC-IRC

2021

6

2

agro-pastoral areas of Ethiopia'

2021, Kenya,

virtual

\section{B) General research related competences}

Ethics for social science research

WASS/ WUR $2019 \quad 0.5$

Systematic approaches to reviewing literature

WASS/WUR $2020 \quad 4$

Introduction to $\mathrm{R}$ and $\mathrm{R}$ Studio

PE\&RC/

2021

0.9

WUR

Academic publication and presentation in social

WASS/ WUR

2018

4

sciences

Brain training

WGS/ WUR 2020

0.3 
Co-organizing the $11^{\text {th }}$ Annual Research Conference JUCAVM/Jim

\section{C) Career related competences}

Project and Time Management (PTM)

WGS/ WUR $2020 \quad 1.5$

Information Literacy for $\mathrm{PhD}$ including EndNote

WGS/ WUR

2018

0.6

Introduction

Msc. Supervision: 6 students

Jimma

$2018-2021 \quad 3$

University

Teaching: Rural livelihoods, food and nutrition

Jimma

2018-2021

1 security; Advanced quantitative methods in social University sciences

Total

*One credit according to ECTS is on average equivalent to 28 hours of study load 
The research described in this thesis was financially supported by the Netherlands Universities Foundation for International Cooperation (NUFFIC), NICHE-ETH-259. Financial support from Wageningen University is gratefully acknowledged. 




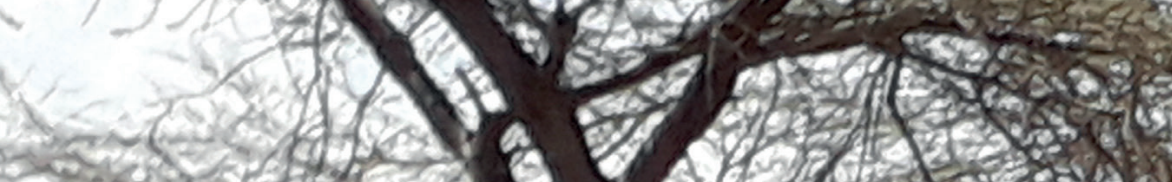

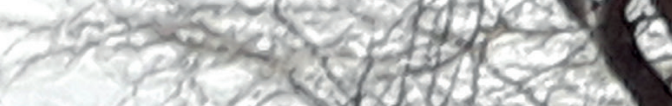

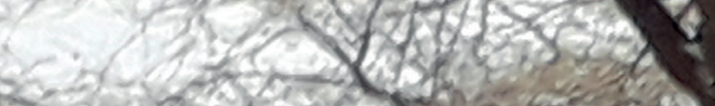

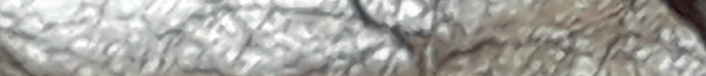

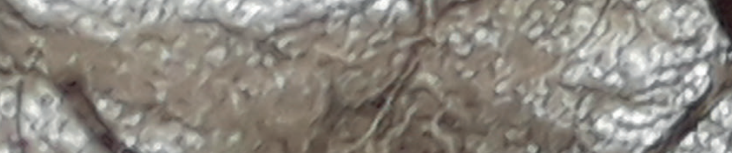

\section{(2) $2010 \operatorname{ses}$}

- 53 . 120.

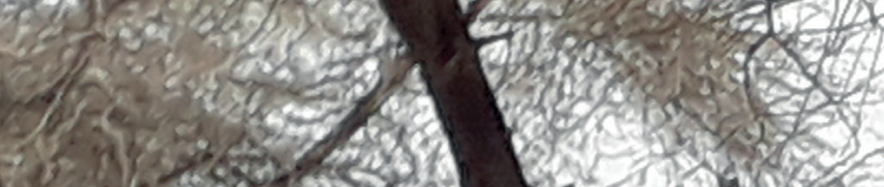



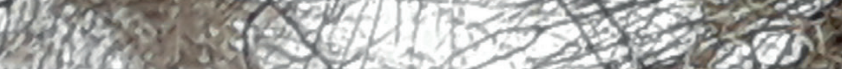
ㄱ.
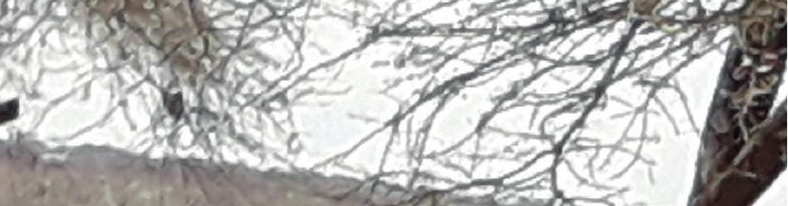

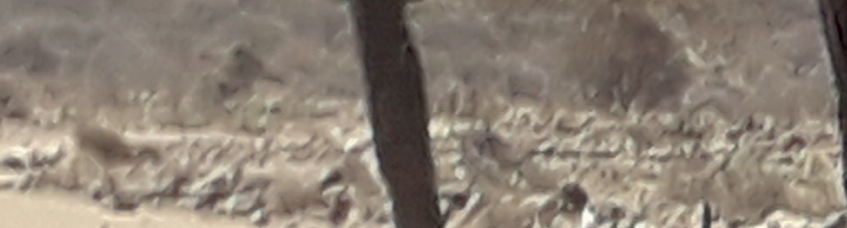



